\title{
Emergency Diesel Generator: Maintenance and Failure Unavailability, and Their Risk Impacts
}

Manuscript Completed: October 1994

Date Published: November 1994

Prepared by

P. Samanta, I. Kim, S. Uryasev, J. Penoyar, W. Vesely*

Brookhaven National Laboratory

Upton, NY 11973-5000

\section{Prepared for}

Division of Systems Research

Office of Nuclear Regulatory Research

U.S. Nuclear Regulatory Commission

Washington, DC 20555-0001

NRC FIN A3230

${ }^{*}$ Science Applications International Corporation, Columbus, $\mathrm{OH}$ 



\section{DISCLAIMER}

This report was prepared as an account of work sponsored by an agency of the United States Government. Neither the United States Government nor any agency thereof, nor any of their employees, make any warranty, express or implied, or assumes any legal liability or responsibility for the accuracy, completeness, or usefulness of any information, apparatus, product, or process disclosed, or represents that its use would not infringe privately owned rights. Reference herein to any specific commercial product, process, or service by trade name, trademark, manufacturer, or otherwise does not necessarily constitute or imply its endorsement, recommendation, or favoring by the United States Government or any agency thereof. The views and opinions of authors expressed herein do not necessarily state or reflect those of the United States Government or any agency thereof. 


\section{DISCLAIMER}

Portions of this document may be illegible in electronic image products. Images are produced from the best available original document. 


\begin{abstract}
Emergency Diesel Generators (EDGs) provide on-site emergency alternating current (ac) electric power for a nuclear plant in the event that all off-site power sources are lost. Existing regulations establish requirements for designing and testing of these on-site power sources to reduce to an acceptable level the probability of losing all ac power sources. Operating experience with EDGs has raised questions about their testing and maintenance to achieve the EDG reliability levels and the total EDG unavailability experienced (fraction of time EDG is out-of-service due to testing, maintenance, and failures). In this report, recent operating experience is used to assess EDG unavailability due to testing, maintenance, and failures during reactor power operation and during plant shutdown. Recent data show an improvement in EDG reliability, but an increase in EDG unavailability due to maintenance, a significant portion of which is due to routinely scheduled maintenances. Probabilistic safety assessments (PSAs) of selected nuclear power plants are used to assess the risk impact of EDG unavailability due to maintenance and failure during power operation, and during different stages of plant shutdown. The results of these risk analyses suggest qualitative insights for scheduling EDG maintenance that will have minimal impact on risk of operating nuclear power plants.
\end{abstract}





\section{CONTENTS}

$\underline{\text { Page }}$

ABSTRACT $\ldots \ldots \ldots \ldots \ldots \ldots \ldots \ldots \ldots \ldots \ldots \ldots \ldots \ldots \ldots \ldots$ iii

LIST OF FIGURES $\ldots \ldots \ldots \ldots \ldots \ldots \ldots \ldots \ldots \ldots \ldots \ldots \ldots$ ix

LIST OF TABLES $\ldots \ldots \ldots \ldots \ldots \ldots \ldots \ldots \ldots \ldots \ldots \ldots \ldots \ldots \ldots \ldots$

EXECUTIVE SUMMARY $\ldots \ldots \ldots \ldots \ldots \ldots \ldots \ldots \ldots \ldots$

ACKNOWLEDGMENT $\ldots \ldots \ldots \ldots \ldots \ldots \ldots \ldots \ldots \ldots \ldots \ldots \ldots$ xviii

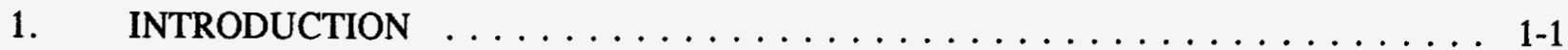

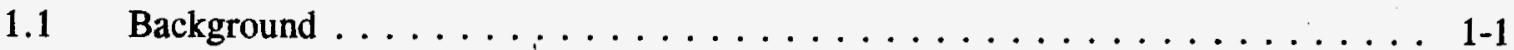

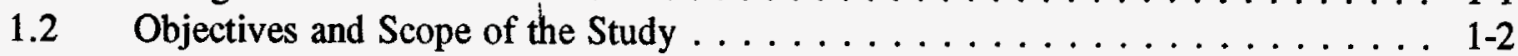

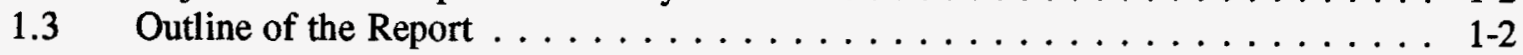

2. ANALYSIS OF EDG UNAVAILABILITY DUE TO MAINTENANCE

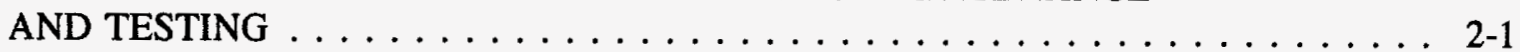

2.1 Definitions ........................... 2-1

2.2 Data Source: Industry-Wide EDG Outage Data . . . . . . . . . . . 2-2

2.3 Approach of the Analysis . . . . . . . . . . . . . . 2-2

2.3.1 Analysis of EDG Out-of-Service During Power Operation . . . . . . . 2-3

2.3.2 Analysis of EDG Out-of-Service During Plant Shutdown . . . . . . . . 2 2-4

2.4 EDG Unavailability Due to Maintenance and Testing During

Power Operation . . . . . . . . . . . . . . . . . . . . . 2 2-5

2.5 EDG Unavailability Due to Maintenance and Testing During

Plant Shutdown ... . . . . . . . . . . . . . . . . . . . 2-7

2.6 Assumptions and Limitations of the Study and Insights Gained . . . . . . . . 2-8

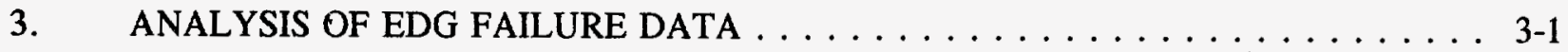

3.1 Definitions . . . . . . . . . . . . . . . . . . . 3-1

3.2 Empirical Bayes Approaches: Methodology $\ldots \ldots \ldots \ldots \ldots \ldots \ldots$. . . . . .

3.2.1 Estimation of the Mean and Variance of the Failure

Probability Distribution ................... 3-3

3.2.2 Estimates of Individual Failure Probabilities . . . . . . . . . . 3-5

3.2.3 Fitting the Failure Probability Distribution with a

Beta Distribution . . . . . . . . . . . . . . . 3-5

3.2.4 Fitting the Diesel Failure Probability Distribution with a

Lognormal Distribution . . . . . . . . . . . . . . 3-6 


\section{CONTENTS (Cont'd.)}

3.3 Analysis of Diesel Failure Data Using Empirical Bayes Approaches . . . . . . . . 3-7

3.3.1 Diesel Failure Probability Data Used $\ldots \ldots \ldots \ldots \ldots \ldots \ldots$. . . . . . . . . .

3.3.2 Limitations and Assumptions in the Analysis . . . . . . . . . . . 3-8

3.3.3 Specific Failure Probabilities Evaluated ... . . . . . . . . . . . 3-9

3.3.4 Mean and Variance of the Failure Probabilities Over the Population . . . . . . . . . . . . . . . . . . . 3-9

3.3.5 Diesel Failure Probabilities (Individual and Plant Sites) . . . . . . . . . 3-9

3.3.6 Histograms of the Individual and Plant Site Diesel Failure Probabilities . . . . . . . . . . . . . . . . . 3-9

3.3.7 Fitting a Beta Distribution to the Population of Failure Probabilities ....................... . . 3-10

3.3.8 Fitting a Lognormal Distribution to the Population of Failure Probabilities ................. . 3-10

3.3.9 Conversion of the Mean Failure to Load-Run Probabilities to a Failure Rate . . . . . . . . . . . . . . . . 3-11

3.3.10 Additional Statistical Analysis $\ldots \ldots \ldots \ldots \ldots \ldots$ 3-11

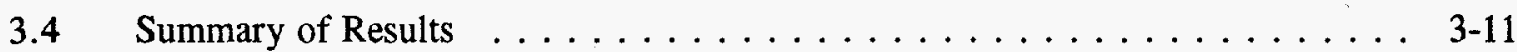

4. ASSESSMENT OF THE RISK IMPACT OF EDG UNAVAILABILITY $\ldots \ldots \ldots$

4.1 Risk Measures Used in the Calculation . . . . . . . . . . . . . . 4-1

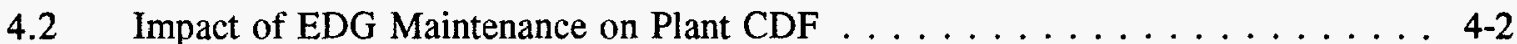

4.3 Sensitivity of Plant CDF to Increased EDG Unavailability . . . . . . . . . . . 4-3

4.4 Sensitivity of Plant CDF to EDG Failure Probability . . . . . . . . . . . . 4-3

4.5 Relative Effect of EDG Failure and Maintenance Unavailability on Plant CDF . . . . . . . . . . . . . . . . . . . . . . 4 4-4

4.6 Impact of Scheduling EDG Maintenances with Other Components . . . . . . . . 4-4

5. RISK IMPACT OF EDG MAINTENANCE DURING POWER OPERATION

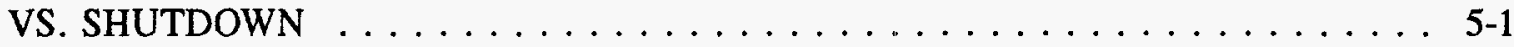

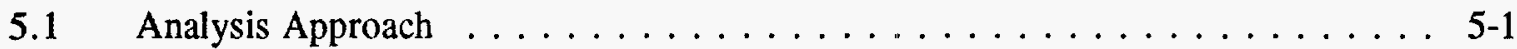

5.2 Limitations and Assumptions in the Analysis . . . . . . . . . . . . 5-3

5.3 Considerations for EDG Maintenance During Power Operation

Versus Shutdown . . . . . . . . . . . . . . . . . . . . 5 5-4

6. SUMMARY AND RECOMMENDATIONS $\ldots \ldots \ldots \ldots \ldots \ldots$ 
CONTENTS (Cont'd.)

Page REFERENCES $7-1$

APPENDIX A: List of Nuclear Units and EDG-Related Information A-1

APPENDIX B: EDG-Specific Unavailabilities in Nuclear Units During Power Operation and Shutdown Periods

APPENDIX C: EDG Failure Data $\ldots \ldots \ldots \ldots \ldots \ldots \ldots \ldots \ldots \ldots \ldots \ldots \ldots$

APPENDIX D: Estimated EDG Failure Probabilities $\ldots \ldots \ldots \ldots \ldots \ldots \ldots \ldots \ldots$

APPENDIX E: Box and Whisker Plots of Empirical Bayes Probabilities for

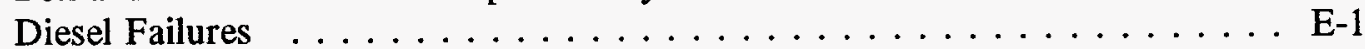

APPENDIX F: Distributions for Diesel Failure Probabilities $\ldots \ldots \ldots \ldots \ldots \ldots \ldots$ F-1

APPENDIX G: Comparison of Predicted and Actual EDG Failure Statistics, Regression Analyses

APPENDIX H: Sensitivity of Plant Core Damage Frequency and Station Blackout Frequency to EDG Maintenance Unavailability 



\section{LIST OF FIGURES}

Page

2.1 Empirical distribution of EDG unavailability due to preventive maintenance during power operatio

2.2 Empirical complementary cumulative distribution of EDG unavailability due to preventive maintenance during power operation

2.3 Empirical distribution of EDG unavailability due to corrective

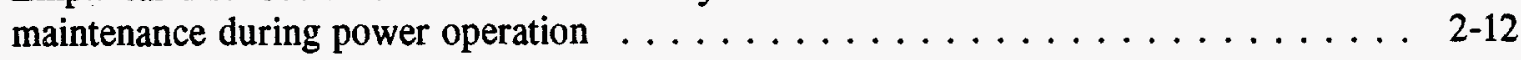

2.4 Empirical complementary cumulative distribution of EDG unavailability due to corrective maintenance during power operation

2.5 Empirical distribution of EDG unavailability due to preventive and corrective maintenance during power operation

2.6 Empirical complementary cumulative distribution of EDG unavailability due to corrective maintenance during power operation

2.7 Empirical distribution of EDG unavailability due to testing during power operation

2.8 Empirical complementary cumulative distribution of EDG unavailability due to testing during power operation

2.9 Empirical distribution of EDG unavailability due to $\mathrm{PM}, \mathrm{CM}$, and testing during power operation $\ldots \ldots \ldots \ldots \ldots \ldots \ldots \ldots$

2.10 Empirical complementary cumulative distribution of EDG unavailability due to $\mathrm{PM}, \mathrm{CM}$, and testing during power operation

2.11 Empirical distribution of annual frequency of PM acts during power operation . . . . 2-16

2.12 Empirical complementary cumulative distribution of annual frequency of PM acts during power operation

2.13 Empirical distribution of annual frequency of CM acts during power operation $\ldots \ldots$ 2-17

2.14 Empirical complementary cumulative distribution of annual frequency of $\mathrm{CM}$ acts during power operation 


\section{LIST OF FIGURES (Cont'd.)}

2.15 Empirical distribution of EDG unavailability due to preventive maintenance

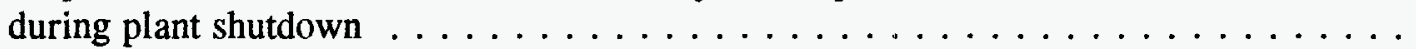

2.16 Empirical complementary cumulative distribution of EDG unavailability due to preventive maintenance during plant shutdown $\ldots \ldots \ldots \ldots \ldots$ 2-18

2.17 Empirical distribution of EDG unavailability due to corrective maintenance during plant shutdown

2.18 Empirical complementary cumulative distribution of EDG unavailability due to corrective maintenance during plant shutdown

2.19 Empirical distribution of EDG unavailability due to preventive and corrective maintenance during plant shutdown

2.20 Empirical complementary cumulative distribution of EDG unavailability due to corrective maintenance during plant shutdown

2.21 Empirical distribution of EDG unavailability due to testing during plant shutdown

2.22 Empirical complementary cumulative distribution of EDG unavailability due to testing during plant shutdown

2.23 Empirical distribution of EDG unavailability due to PM, CM, and testing during plant shutdown $\ldots \ldots \ldots \ldots \ldots \ldots \ldots \ldots$

2.24 Empirical complementary cumulative distribution of EDG unavailability due to PM, CM, and testing during plant shutdown

3.1 Histogram of simple estimates of failure to start probabilities for individual diesels (195 EDGs, 4 yrs. data)

3.2 Histogram of simple estimates of failure to load-run probabilities (195 EDGs, 4 yrs. data) . . . . . . . . . . . . . . . . . . . 3-13

4.1 Impact on plant core-damage frequency due to outage of a single EDG for maintenance 


\section{LIST OF FIGURES (Cont'd.)}

4.2 Sensitivity of plant core-damage frequency to increased EDG maintenance unavailability (during power operation) $\ldots \ldots \ldots \ldots \ldots \ldots \ldots \ldots$. . . . . . . . .

4.3 Sensitivity of plant core-damage frequency to EDG Failure Unavailability (during power operation) $\ldots \ldots \ldots \ldots \ldots \ldots \ldots \ldots \ldots \ldots \ldots \ldots$

4.4 Core-damage frequency levels in an example rolling-maintenance schedule $\ldots \ldots \ldots$. . . 4-7

5.1 Change in CDF (due to SBO Sequences) for taking an EDG out-of-service during different shutdown plant operating states

5.2 Increase in CDF for taking an EDG out-of-service during different shutdown plant operating states $\ldots \ldots \ldots \ldots \ldots \ldots \ldots \ldots \ldots \ldots$

5.3 Change in CDF for taking an EDG out-of-service during different modes of plant operation . . . . . . . . . . . . . . . . . . . 5-7

5.4 Increase in CDF for taking an EDG out-of-service during different shutdown plant operating states $\ldots \ldots \ldots \ldots \ldots \ldots \ldots \ldots \ldots \ldots \ldots \ldots \ldots$ 



\section{LIST OF TABLES}

Page

2.1 Mean, Median, and Standard Deviation of the EDG Unavailability Due to

Maintenance and Testing During Power Operation . . . . . . . . . . . . 2-23

2.2 Cumulative Distribution of the EDG Unavailability Due to Maintenance

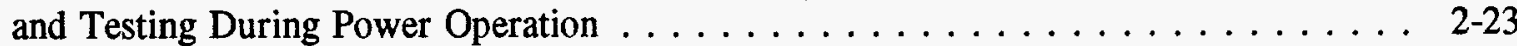

2.3 Mean and Standard Deviation of the Duration and Frequency of Maintenance

and Test Activities During Power Operation $\ldots \ldots \ldots \ldots \ldots \ldots \ldots$ 2-24

2.4 Mean, Median, and Standard Deviation of the EDG Unavailability Due to

Maintenance and Testing During Plant Shutdown . . . . . . . . . . . . . . 2-24

2.5 Cumulative Distribution of the EDG Unavailability Due to Maintenance and

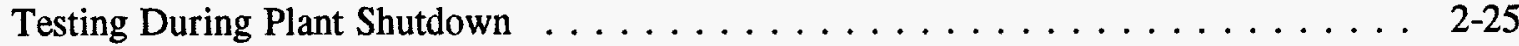

3.1 Mean, Variance, and Standard Deviation of Diesel Failure Probabilities Over

Individual Diesels and Over Plant Sites . . . . . . . . . . . . . . . . . 3-14

3.2 Beta Distribution Parameters $\ldots \ldots \ldots \ldots \ldots \ldots \ldots \ldots \ldots \ldots \ldots \ldots$

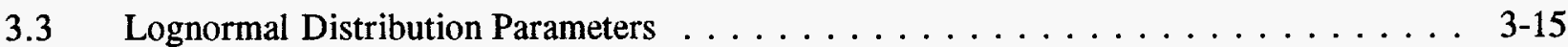

4.1 Risk Contributions of Maintenance During Power Operation $\ldots \ldots \ldots \ldots$. . . . . . 4-8

4.2 Average CDF Due to Increased Maintenance Unavailability . . . . . . . . . . 4-8

4.3 Average CDF Due to Different EDG Failure Unavailability . . . . . . . . . . . . . . . 4-9

4.4 Plant CDF for Different EDG Maintenance and Failure Unavailability . . . . . . . . . 4-9

4.5 Comparison of Increase in CDF Due to Increasing EDG Maintenance and

Failure Unavailability . . . . . . . . . . . . . . . . . . . . 4-10

4.6 Example Maintenance Schedule for Preventive Maintenance . . . . . . . . . . . . 4-11

5.1 Relative CDF Impact of EDG Out-of-Service for Maintenance $\ldots \ldots \ldots \ldots$

5.2 Relative CDF Impact of Taking EDG Out-of-Service for Maintenance $\ldots \ldots \ldots$ 


\section{LIST OF TABLES (Cont’d.)}

Page

5.3 Concern with Scheduled PM During Power Operation Versus Plant Shutdown . . . . 5-10

5.4 Scheduling EDG Maintenances $\ldots \ldots \ldots \ldots \ldots \ldots \ldots \ldots \ldots \ldots \ldots \ldots$ 


\section{EXECUTIVE SUMMARY}

Emergency Diesel Generators (EDGs) provide on-site alternating current (ac) electric power for a nuclear power plant in the event that all off-site power sources are lost. The loss of off-site ac power to essential and non-essential electrical buses, concurrent with a turbine trip and the unavailability of redundant on-site emergency ac power system, i.e., EDGs, is termed "Station Blackout." Probabilistic safety assessment (PSA) studies show that Station Blackout is an important contributor to the total risk from accidents at nuclear power plant. As a result, the Station Blackout (SBO) rule ${ }^{1}$ was issued to lower the risk from these sequences.

When the SBO rule was developed in the 1980s, EDG unavailability due to maintenance was estimated to be approximately 0.007 . This unavailability was significantly less than the probability that the EDG would fail to start and load-run on demand. Therefore, the station blackout rule (1988) did not explicitly address maintenance unavailability, but emphasized the importance of reliable EDGs.

In 1991, the NRC staff reviewed EDG performance during actual demands. They found that in 5 of 128 demands the EDG did not function because it was out of service for maintenance. ${ }^{2}$ This value of 5/128 represents an unavailability due to time out-of-service for maintenance of 0.04 versus 0.007 previously used in developing the SBO rule.

A question, therefore, arose about the significance of estimates of EDG unavailability due to maintenance. The analysis in this report was undertaken to address this question. Much of this work was previously summarized in a Commission paper, SECY-93-044. ${ }^{3}$ In addition, this report includes information on the risk impact of taking an EDG out of service during plant shutdown.

This report addresses the following topics:

a) EDG unavailability due to maintenance during power operation and shutdown, derived from a survey of EDG out-of-service data,

b) EDG unavailability due to failure to start and load-run on demand,

c) Sensitivity of core-damage frequency (CDF) associated with EDG maintenance unavailability compared to the failure to start and load-run on demand, and

d) Relative impact of core-damage frequency of EDG maintenance during power operation versus plant shutdown, and suggestions for consideration in scheduling EDG maintenances.

The findings of this study on each of these topics are discussed.

EDG unavailability due to testing and maintenance is estimated using EDG out-of-service data over two years (June 1990 to May 1992), provided by NRC regional offices. The estimate of EDG unavailability due to preventive maintenance (PM), corrective maintenance $(\mathrm{CM})$, and testing can be summarized as follows: 


\begin{tabular}{|l|l|l|}
\hline \multirow{3}{*}{$\begin{array}{l}\text { EDG unavailability due to } \\
\text { maintenance and testing }\end{array}$} & During Power Operation & During Shutdown \\
\cline { 2 - 3 } & $\begin{array}{l}\text { Mean: } 0.022 \\
\text { Standard Deviation: } 0.017\end{array}$ & $\begin{array}{l}\text { Mean: } 0.12 \\
\text { Standard Deviation: } 0.11\end{array}$ \\
\hline
\end{tabular}

For a plant with $70 \%$ capacity factor, this corresponds to taking EDGs out-of-service for maintenance about 5 days during the year when the reactor is at power, and 13 days when the reactor is shut down. This estimate is about a factor of three larger than the previous estimate used in the SBO rule. This analysis also shows that, during power operation, scheduled preventive maintenances constitute about $40 \%$ of the total EDG unavailability, and scheduled plus unscheduled maintenance may contribute as much as $60 \%$.

EDG unavailability due to failures was estimated using the number of failures to start and loadrun and the number of demands imposed on each EDG between 1988 and 1991 compiled by Nuclear Management and Resource Council (NUMARC), a nuclear industry organization. This database did not identify the plants nor the dates on which the failures were discovered. Also, the data were not verified by NRC or for this study. The mean, industry-averaged, rate of failure per demand to start and load-run is estimated to be 0.014 , slightly lower than a previous estimate of 0.020 based on data from 1981 to 1983 and 0.019 in 1984.

The impact of EDG unavailability on plant risk was assessed using PSA models for six plants. Sensitivity of CDF to changes in unavailability due to time out-of-service for maintenance during power operation and due to failure to start and load-run was analyzed to understand the relative impact of maintenance and failure unavailabilities. EDGs are among the most risk-important components in a nuclear power plant, and inoperability (i.e. unavailability of unity) of a single EDG results in about an order of magnitude increase in the plant CDF. During power operation, changes in CDF are more sensitive to EDG failure to start and load-run than to EDG maintenance unavailability.

To analyze the relative benefit of scheduling EDG maintenance during reactor power operation versus shutdown from a risk perspective, respective PSAs for these modes of operation were used to calculate and compare the CDF when an EDG is unavailable for maintenance. Two plants, a pressurized water reactor (PWR) and a boiling water reactor (BWR), were used in this analysis. Brookhaven National Laboratory (BNL) analyzed the risk impact in the PWR plant, and Sandia National Laboratories (SNL) analyzed the BWR plant. The results show that with respect to core-damage frequency, taking an EDG out of service during the early stages of shutdown is comparable with doing so during power operation. During the later stages of refueling when the decay heat is low and the water level is raised, the impact on CDF is substantially lower. Thus, from a risk perspective, it appears reasonable to schedule short preventive maintenances (e.g., less than 3 days) during power operation. For longer preventive maintenances, the likelihood of core-damage is reduced by scheduling long-duration maintenances during refueling when the decay heat is low and the water level is high.

In summary, EDGs play vital role in assuring the safety of light-water-cooled nuclear power plants and the maintenance of these equipment to assure reliable operation is important. This report presents approaches for analyzing EDG maintenance unavailability and its risk impact. 
1. 10CFR50.63, "Loss of all alternating current power," 1988.

2. T. C. Cintula, "Special Study Report; Performance of Emergency Diesel Generators in Restoring Power to their Associated Safety Busses -- a Review of Events Occurring at Power," AEOD/S9101, September 1991.

3. NRC Staff Paper SECY-93-044, "Resolution of Generic Safety Issue B-56, Diesel Generator Reliability," Enclosure 4, February 22, 1993. 


\section{ACKNOWLEDGEMENT}

The authors viould like to acknowledge Carl Johnson, Jr., of the U.S. Nuclear Regulatory Commission (USNRC), Technical Monitor of the project, for his many insightful comments, technical guidance during the project, and review of the document. Faust Rosa of the USNRC also gave many useful comments and suggestions, and coordinated the collection of data on emergency diesel generators from industry. Bevan Staple from Sandia National Laboratories provided EDG risk impact analyses for the Grand Gulf Nuclear Station, presented in Section 5.1 of this report. We also acknowledge the reviewers: James Higgins, Robert Hall and Ken Sullivan of Brookhaven National Laboratory, and many NRC staff.

The authors also would like to thank Donna Storan for her excellent work in helping load the EDG data into a Quattro spreadsheet and preparing this manuscript; Alan Paulus for his assistance in loading and analyzing the data; Patricia Ennis and Barbara Kowalski for their assistance in loading the raw data into a Quattro spreadsheet; and Ellie Karlund and Melissa Collichio for their assistance in preparing the manuscript. 


\section{INTRODUCTION}

\subsection{Background}

Emergency Diesel Generators (EDGs) provide onsite emergency ac power in the event that all offsite power sources are lost. The reliability of onsite ac sources, i.e., EDGs, is an important factor in assuring acceptable safety at light-water-cooled nuclear power plants.

The United States Nuclear Regulatory Commission (USNRC) Station Blackout (SBO) rule ${ }^{1}$ addressed the need for maintaining highly reliable ac electric power systems. When the SBO rule was developed in the 1980s, EDG unavailability due to time out-of-service for maintenance was estimated to be approximately 0.007 . This unavailability was significantly less than the probability that the EDG would fail to start and load-run on demand. Therefore, the SBO rule (1988) did not explicitly address maintenance unavailability, but emphasized the importance of reliable EDGs. Regulatory Guide $1.155,{ }^{2}$ developed in support of the SBO rule, noted that, "...in some cases outages due to maintenance can be a significant contribution to emergency diesel generator unavailability. This contribution can be kept low by having high quality test and maintenance procedures and by scheduling regular diesel generator maintenance at times when the reactor is shutdown."

Plant operational data and additional studies in recent years have provided information on EDG unavailability due to time out-of-service for maintenance and on EDG reliability.

a) Recently, the office of Analysis and Evaluation of Operational Data (AEOD) of USNRC analyzed EDG performance following actual demands. ${ }^{3}$ It was observed that in 5 out of 128 demands over $51 / 2$ years, EDGs were out of service for maintenance, corresponding to an unavailability of approximately 0.04 , substantially larger than the 0.007 used in developing the SBO rule. Also, probabilistic safety assessments (PSAs) use an estimate of EDG unavailability for maintenance in a similar range as that used in the SBO rule.

b) Some nuclear power plants carry out regular preventive maintenances (PMs) during power operation. This practice rather than PM during outage (shutdown periods), is partly necessitated by the longer fuel cycles, and partly due to the desire to shorten plant outages and to assure EDG reliability. The NRC Inspection Manual ${ }^{4}$ gives guidance on a voluntary entry into limiting conditions for operation (LCOs) to perform preventive maintenance.

c) Recent studies of risk during shutdown periods ${ }^{5,6}$ indicate that during some of these modes risk may be comparable with that during power operation. Accordingly, the risk of performing PMs during these periods also can be comparable, and it is not clear if there is an advantage to performing all PMs for EDGs during shutdown periods.

d) Since the issuance of the Station Blackout rule in 1988, the reliability of EDGs may have improved. 


\subsection{Objectives and Scope of the Study}

The following are the objectives of this study:

a) To estimate EDG unavailability due to maintenance and failures, based on recent industry-wide data,

b) To compare the risk sensitivity to EDG maintenance unavailability vs. EDG failure to start and load-run, and

c) To compare the relative risk impact of scheduling EDG maintenance during power operation versus shutdown periods, and identify approaches to EDG maintenance to assure acceptable level of safety.

The EDG unavailability due to testing and maintenance was assessed using plant-specific records. The USNRC Office of Nuclear Reactor Regulation (NRR) coordinated a collection of data on EDG unavailability through NRC's Regional Offices. ${ }^{7}$ This database, which we used, includes two years of data on time out-of-service for 212 EDGs at 97 plant units. The EDG unavailabilities are addressed for power operation and shutdown periods. EDG unavailabilities due to preventive maintenance, corrective maintenance, and testing are estimated separately. The distribution of the unavailabilities across the EDG population are analyzed, as well as plant-specific unavailabilities.

The EDG unavailability due to failures was assessed from data on EDG failure to start and loadrun on demand. These data covered 195 EDGs at 63 commercial plant ${ }^{13}$ covering four years, 1988 to 1991. The data did not identify plant sites.

The risk sensitivity of EDG unavailability during power operation was assessed from six plantspecific PSAs. The impact of EDG unavailabilities due to maintenance and failures was based on changes in the plant core-damage frequency (CDF). The relative effects of increasing/decreasing EDG maintenance and failures unavailabilities on the plant CDF were analyzed to understand their relative influence.

Using available low power and shutdown (LP\&SD) PSAs, the relative CDF impact of EDG maintenance during power operation and different shutdown states was assessed. This analysis was used to derive insights for scheduling EDG PMs, and to ascertain whether certain PMs should be allowed during power operation.

\subsection{Outline of the Report}

The report is organized as follows: Chapter 2 presents the analysis of EDG unavailability due to maintenance and testing using a recent survey of EDG out-of-service data. EDG test and maintenance unavailability are evaluated separately for power operation and shutdown periods. Similarly, Chapter 3 analyzes EDG failure data to estimate EDG failure unavailability. The risk impact of EDG unavailability is discussed in Chapter 4 , where the relative influence of maintenance and failure unavailabilities is studied. Chapter 5 compares the risk of EDG maintenance during power operation versus plant shutdown to define considerations for scheduling EDG maintenances. Analyses are given for a pressurized water reactor (PWR) and a boiling-water reactor (BWR), that were analyzed by Brookhaven National 
Laboratory (BNL) and Sandia National Laboratories (SNL), respectively. Chapter 6 summarizes the findings, and makes recommendations for future research.

Eight appendices provide detailed information on these analyses. Appendix A lists the nuclear units and the EDGs in operation in those units. Relevant information about EDGs also is presented. Appendix B presents the EDG-specific unavailabilities during power operation and shutdown periods, estimated from the recent EDG out-of-service time data, in operating nuclear units. Appendix C summarizes the EDG failure data analyzed to study EDG failure unavailability and associated distributions. Appendix D gives the estimated EDG failure probabilities using Empirical Bayes methods. Box and whisker plots of estimated EDG failure probabilities are provided in Appendix E. Lognormal and Beta distributions describing EDG failure probability, for use in PSA studies, are available in Appendix F. Finally, Appendix G compares the predicted and actual EDG failure statistics. Sensitivity of core-damage-frequency and SBO sequence frequency to maintenance unavailability for individual plants is discussed in Appendix $\mathrm{H}$. 


\section{ANALYSIS OF EDG UNAVAILABILITY DUE TO MAINTENANCE AND TESTING}

Emergency Diesel Generators (EDGs) are taken out of service for tests and maintenance. EDGs are tested regularly to detect any failures which need correction. Maintenance is performed to repair any failures or correct any degradations (called corrective maintenances), and also, planned maintenances may be carried out to assure that the EDGs operate reliably, i.e., to prevent failure of the equipment (called preventive maintenance). The unavailability of EDGs due to testing and maintenances can be the dominant part of the overall EDG unavailability. In this chapter, we present an analysis of such unavailability, based on the recent industry-wide EDG outage data.

The objectives of this analysis are to obtain:

a) estimates of EDG unavailability due to tests and maintenances for plants in the United States based on recent data, i.e., reflective of recent plant practices,

b) a breakdown of contribution to EDG unavailability due to preventive and corrective maintenances, and

c) a comparative assessment of EDG unavailability during power operation and shutdown periods of a plant.

Section 2.1 defines the basic concepts of EDG unavailability. Section 2.2 describes the source of EDG outage data and Section 2.3 discusses the approach we took to analyze it. Sections 2.4 and 2.5 present the unavailability of EDGs due to maintenance and testing during power operation and plant shutdown, respectively. The EDG unavailabilities are given, specifically, for preventive maintenance (PM), corrective maintenance (CM), and testing, and also the various combinations thereof, for power operation and also shutdown periods. Section 2.6 discusses the assumptions and limitations of the study, and the insights from the analysis of the data.

\subsection{Definitions}

The unavailability of a component is the probability that the component will fail to perform its required function. For an EDG, its unavailability is the probability that the EDG will fail to perform its function which is to start and assume electrical loads in some time-period, and then to continue running to supply power for a required time.

In general, the EDG unavailability can be expressed as the sum of two contributors, the probability of failure to start and the probability of failure to run for the required duration.

EDG unavailability $=$ Probability of failure to start + Probability of failure to run

The probability of failure to run is conditional on the probability that the EDG starts successfully.

The EDG probability of failure to start can be due to one of the following causes: a) undetected failure before the demand during the standby period or a failure caused by the demand, b) EDG unavailability due to maintenance, and c) EDG unavailability due to testing. The definition of EDG unavailability can thus be extended. 
EDG unavailability $=$ EDG unavailability due to maintenance + EDG unavailability due to testing + EDG unavailability due to failure to start + EDG unavailability due to failure to load-run +

The analytical expressions for estimating EDG unavailability due to testing and maintenance are provided in Section 2.3. Estimation of EDG unavailability due to failure to start and load-run is discussed in Section 3.2.

\subsection{Data Source: Industry-Wide EDG Outage Data}

We used industry-wide data on EDG outages due to maintenance and testing during power operation and plant shutdown, collected through the NRC's Regional Offices. ${ }^{7}$ These data include the following information on EDGs for two years, June 1, 1990 to May 31, 1992:

a) Plant name, unit

b) EDG ID/KW

c) EDGs per unit

d) Out-of-service (OOS) start date

e) Reactor status (at power or shutdown)

f) OOS duration (hrs)

g) Outage code $(\mathrm{P}$ - scheduled preventive maintenance, $\mathrm{C}$ - corrective maintenance, and $\mathrm{T}$ test)

h) Comments (optional; e.g., reasons for OOS)

The EDG outage data covers $235 \mathrm{EDGs}^{*}$ at 97 plant units for power operation, and 170 EDGs at 80 units for plant shutdown. However, the data on outages due to testing was provided by only about a half of the nuclear utilities.

Sometimes several different activities, e.g., CM and testing, were undertaken during an outage. In these cases, the outage time was partitioned into the time due to $\mathrm{CM}$ and the time due to testing, based on the typical duration of the specific type at the nuclear unit.

Appendix A gives a list of EDGs at various plant sites in the United States, together with other information relating to the configuration of EDGs, manufacturer and allowed outage times (AOTs) compiled from different sources, ${ }^{8,9}$ including plant safety analysis reports.

\subsection{Approach of the Analysis}

This section describes the way we analyzed the data on EDG outages because of PM, CM, or testing during power operation or plant shutdown. Essentially, the unavailability due to any of them, was

*Of the 235 EDGs, 23 EDGs are shared between two units at a site. Hence, the data actually covers 212 EDGs. However, for analyzing unavailability, these swing EDGs are counted separately because unavailability depends on the plant on-line or off-line hours at the specific unit. 
estimated by the fraction of time the EDG was unavailable because of this activity. ${ }^{*}$ EDG-specific estimates are based on individual EDG outage durations and time in power operation or shutdown. These estimates are combined to obtain an industry-wide distribution and average industry-wide estimates.

\subsubsection{Analysis of EDG Out-of-Service During Power Operation}

For a given period, e.g., 2 years in this analysis, let:

$$
\begin{aligned}
& \mathrm{t}_{\mathrm{p}}=\text { total time the plant unit was in power operation, } \\
& \mathrm{t}_{\mathrm{p}, \mathrm{PM}}=\text { total EDG OOS time due to PM during power operation, } \\
& \mathrm{t}_{\mathrm{p}, \mathrm{CM}}=\quad \text { total EDG OOS time due to CM during power operation, and } \\
& \mathrm{t}_{\mathrm{p}, \mathrm{T}}=\text { total EDG OOS time due to testing during power operation, }
\end{aligned}
$$

where $t_{p}$ can be assessed using the Gray Book, and the EDG OOS times from the plant data by summing the times for a particular OOS type.

Then, we can evaluate various EDG unavailabilities during plant operation as follows:

$$
\begin{aligned}
\mathrm{U}_{\mathrm{p}, \mathrm{PM}} & =\text { EDG unavailability due to preventive maintenance during power operation } \\
& =\mathrm{t}_{\mathrm{p}, \mathrm{PM}} / \mathrm{t}_{\mathrm{p}}, \\
\mathrm{U}_{\mathrm{p}, \mathrm{CM}} & =\text { EDG unavailability due to corrective maintenance during power operation } \\
& =t_{\mathrm{p}, \mathrm{CM}} / \mathrm{t}_{\mathrm{p}}, \\
\mathrm{U}_{\mathrm{p}, \mathrm{T}} & =\text { EDG unavailability due to testing during power operation } \\
& =\mathrm{t}_{\mathrm{p}, \mathrm{T}} / \mathrm{t}_{\mathrm{p}}, \\
\mathrm{U}_{\mathrm{p}, \mathrm{PM}+\mathrm{CM}} & =\mathrm{EDG} \text { unavailability due to maintenance during power operation } \\
& =\left(\mathrm{t}_{\mathrm{p}, \mathrm{PM}}+\mathrm{t}_{\mathrm{p}, \mathrm{CM}}\right) / \mathrm{t}_{\mathrm{p}}, \text { and }
\end{aligned}
$$

\footnotetext{
** In PSAs, maintenance unavailability is typically estimated by multiplying the frequency and mean duration of maintenance.for the component analyzed, because these parameters, instead of raw plant data on maintenance, are available generally. This is equivalent to dividing the mean duration of maintenance by the mean interval between maintenance, because the inverse of the frequency gives the mean interval. However, in this study, we obtain the EDG maintenance unavailability directly from the raw plant data by dividing the total time when maintenance was performed by the total time when the plant was in power operation (or shutdown). EDG test unavailability also was estimated similarly to the EDG maintenance unavailability.
} 
$\mathrm{U}_{\mathrm{P}, \mathrm{PM}+\mathrm{CM}+\mathrm{T}}=$ EDG unavailability due to maintenance and testing during power operation

$$
=\quad\left(t_{p, P M}+t_{p, C M}+t_{p, T}\right) / t_{p} .
$$

To evaluate the frequency of EDG maintenance and testing, for a given period, let:

$$
\begin{array}{ll}
\mathrm{n}_{\mathrm{p}, \mathrm{PM}}= & \text { number of PMs during power operation, } \\
\mathrm{n}_{\mathrm{p}, \mathrm{CM}}= & \text { number of CMs during power operation, and } \\
\mathrm{n}_{\mathrm{p}, \mathrm{T}}= & \text { number of tests during power operation }
\end{array}
$$

Then, we can assess the frequencies as follows:

$$
\begin{aligned}
\mathrm{f}_{\mathrm{P}, \mathrm{PM}} & =\quad \text { frequency of } \mathrm{PM} \text { during power operation } \\
& =\mathrm{n}_{\mathrm{P}, \mathrm{PM}} / \mathrm{t}_{\mathrm{p}}, \\
\mathrm{f}_{\mathrm{p}, \mathrm{CM}} & =\quad \text { frequency of CM during power operation } \\
& =\quad \mathrm{n}_{\mathrm{P}, \mathrm{CM}} / \mathrm{t}_{\mathrm{p}}, \text { and } \\
\mathrm{f}_{\mathrm{p}, \mathrm{T}} & =\text { frequency of tests during power operation } \\
& =\mathrm{n}_{\mathrm{P}, \mathrm{T}} / \mathrm{t}_{\mathrm{p}} .
\end{aligned}
$$

The average duration of each activity during power operation can be obtained using the following expression:

$$
\begin{aligned}
\mathrm{d}_{\mathrm{p}, \mathrm{PM}} & =\quad \text { average duration of a PM during power operation } \\
& =\quad \mathrm{t}_{\mathrm{p}, \mathrm{PM}} / \mathrm{n}_{\mathrm{P}, \mathrm{PM}}, \\
\mathrm{d}_{\mathrm{P}, \mathrm{CM}} & =\quad \text { average duration of a CM during power operation } \\
& =\quad \mathrm{p}_{\mathrm{P}, \mathrm{CM}} / \mathrm{n}_{\mathrm{P}, \mathrm{CM}}, \text { and } \\
\mathrm{d}_{\mathrm{p}, \mathrm{T}} & =\quad \text { average duration of a test during power operation } \\
& =\quad \mathrm{t}_{\mathrm{p}, \mathrm{T}} / \mathrm{n}_{\mathrm{P}, \mathrm{T}} .
\end{aligned}
$$

\subsubsection{Analysis of EDG Out-of-Service During Plant Shutdown}

The unavailabilities of EDGs due to maintenance or testing during plant shutdown were analyzed similarly to those during power operation. For a given period, e.g., 2 years in this analysis, let:

$\mathrm{t}_{\mathrm{s}}=$ total time the plant unit was in shutdown, 


$$
\begin{array}{ll}
\mathrm{t}_{\mathrm{B}, \mathrm{PM}}= & \text { total EDG OOS time due to PM during plant shutdown, } \\
\mathrm{t}_{\mathrm{B}, \mathrm{CM}}= & \text { total EDG OOS time due to CM during plant shutdown, and } \\
\mathrm{t}_{\mathrm{s}, \mathrm{T}}= & \text { total EDG OOS time due to testing during plant shutdown. }
\end{array}
$$

where $t_{8}$ can be obtained from the Gray Book, and the EDG OOS times from the plant data by summing the times for a particular OOS type.

Then, we can estimate EDG unavailabilities during plant shutdown as follows:

$$
\begin{aligned}
& \mathrm{U}_{\mathrm{s}, \mathrm{PM}}=\text { EDG unavailability due to PM during plant shutdown } \\
& =\quad t_{s, P M} / t_{s}, \\
& \mathrm{U}_{\mathrm{s}, \mathrm{CM}}=\quad \text { EDG unavailability due to CM during plant shutdown } \\
& =t_{s, C M} / t_{s}, \\
& \mathrm{U}_{\mathrm{s}, \mathrm{T}}=\quad \text { EDG unavailability due to testing during plant shutdown } \\
& =t_{s, T} / t_{s}, \\
& \mathrm{U}_{\mathrm{s}, \mathrm{PM}+\mathrm{CM}}=\quad \text { EDG unavailability due to maintenance during plant shutdown } \\
& =\left(t_{8, P M}+t_{8, C M}\right) / t_{s} \text {, and } \\
& \mathrm{U}_{\mathrm{s}, \mathrm{PM}+\mathrm{CM}+\mathrm{T}}=\quad \text { EDG unavailability due to maintenance and testing during plant shutdown } \\
& =\left(t_{s, P M}+t_{s, C M}+t_{s, r}\right) / t_{s} \text {. }
\end{aligned}
$$

The frequency of PM, CM, and testing, and the duration of each activity during plant shutdown can be assessed similarly, as we discussed earlier for power operation.

\subsection{EDG Unavailability Due to Maintenance and Testing During Power Operation}

The industry-wide EDG outage data were loaded into Quattro spreadsheets and analyzed using the expressions discussed in the previous sections. This section discusses the EDG unavailabilities due to maintenance and testing during power operation; the corresponding unavailabilities for plant shutdown are given in the following section.

The EDG unavailabilities for 235 EDGs at 97 plant units are analyzed specifically for PM, CM, or testing, and the various combinations thereof, and are presented in Appendix B. Here, the results are summarized. For each activity, an empirical distribution and a complementary cumulative distribution of unavailability are developed, along with the mean to develop insights on unavailability for the EDG population. 


\section{Preventive Maintenance}

Figure 2.1 shows the empirical distribution of EDG unavailability due to PM during power operation, i.e., $U_{p, P M}$, versus fraction of EDGs; this figure shows varied unavailability resulting from different $P M$ practices across utilities. The variability in $U_{\mathrm{p}, \mathrm{PM}}$ is also influenced by the diversity of EDG vendors and different vendor recommendations for PM practices. The $\mathrm{U}_{\mathrm{p}, \mathrm{PM}}$ generally spans from 0 to $4.5 \%$ with a mean of $.1 .3 \%$, however, one EDG had an exceptionally high unavailability, $9.87 \%$. The $\mathrm{U}_{\mathrm{p}, \mathrm{PM}}$ for specific EDGs is given in descending order in Table B.1 of Appendix B. Figure 2.2 shows the empirical complementary cumulative distribution of $U_{p . P M}$, which represents the fraction of EDGs that has PM unavailability greater than a certain value.

\section{Corrective Maintenance}

Figure 2.3 is the empirical distribution of EDG unavailability due to $C M$ during power operation, i.e., $U_{p, C M}$, versus fraction of EDGs, and shows that $U_{p, C M}$ was minimal for a large fraction of the EDG population. The empirical complementary cumulative distribution of $U_{p, C M}$, which indicates the fraction of EDGs that has CM unavailability greater than a certain value, is shown in Figure 2.4. For example, for about a half of the EDG population (109 EDGs), $\mathrm{U}_{\mathrm{p}, \mathrm{CM}}$ is less than $0.5 \%$. The mean is $0.9 \%$. However, significant CM was performed for a few EDGs, resulting in the CM unavailability greater than $2 \%$, even up to $6.5 \%$. The $U_{p, P M}$ for specific EDGs is shown in descending order in Table B.2 of Appendix B.

\section{Preventive and Corrective Maintenance}

Figure 2.5 shows the empirical distribution of EDG unavailability due to both PM and CM, i.e., $\mathrm{U}_{\mathrm{p}, \mathrm{PM}+\mathrm{CM}}$, versus fraction of EDGs. The mean of the distribution is $2 \%$. The empirical complementary cumulative distribution of $\mathrm{U}_{\mathrm{p}, \mathrm{PM}+\mathrm{CM}}$, which indicates the fraction of EDGs that has maintenance unavailability greater than a certain value, is shown in Figure 2.6 . For about $40 \%$ of the population (94 EDGs), the $\mathrm{U}_{\mathrm{p}, \mathrm{PM}+\mathrm{CM}}$ was greater than $2 \%$. The $\mathrm{U}_{\mathrm{p}, \mathrm{PM}+\mathrm{CM}}$ for specific EDGs is given in descending order in Table B.3 of Appendix B. One EDG was as high as $16.4 \%$.

\section{Testing}

Figures 2.7 and 2.8 show the distribution of EDG unavailability due to testing during power operation, i.e., $U_{p, T}$, based on 117 EDGs. Figure 2.7 shows the empirical distribution of $U_{p, T}$ versus fraction of EDGs. The unavailability is small; almost all the EDGs had $U_{p, T}$ less than $0.5 \%$. The $U_{p, T}$ for specific EDGs is given in the alphabetical order of plant names in Table B.4 of Appendix B, along with $U_{p, P M}$ and $U_{p, C M}$. Figure 2.8 shows the empirical complenentary cumulative distribution of $U_{p, r}$, which represents the fraction of EDGs that has test unavailability greater than a certain value.

\section{Preventive and Corrective Maintenance, and Testing}

Figures 2.9 and 2.10 show distribution of EDG unavailability due to the combination of PM, CM, and testing, i.e., $\mathrm{U}_{\mathrm{p}, \mathrm{PM}+\mathrm{CM}+\mathrm{T}}$. Figure 2.9 depicts the empirical distribution of $\mathrm{U}_{\mathrm{p}, \mathrm{PM}+\mathrm{CM}+\mathrm{T}}$ versus fraction of EDGs, showing that $U_{p, P M+C M+T}$ varies considerably from plant to plant, spanning 0 to $7 \%$ in general. Figure 2.10 shows the empirical complementary cumulative distribution of $U_{p, P M+C M+r}$, which represents the fraction of EDGs that has unavailability due to maintenance and testing greater than a certain value. 
Table 2.1 summarizes the mean, median, and standard deviation of the EDG unavailability due to maintenance and testing during power operation.

Table 2.2 gives the cumulative distribution of the EDG unavailability due to maintenance and testing during power operation for a selected set of values, i.e., $0.007,0.01,0.02,0.03$, and 0.04 . The value 0.007 was chosen because it was assumed in Regulatory Guide 1.155 to represent the industryaverage unavailability. This table indicates that only $13 \%$ of the EDGs had $U_{p, P M+C M+r}$ less than or equal to 0.007 . About a half of the EDGs had values greater than 0.02 . For about $10 \%$ of the EDGs, the unavailability was greater than 0.04 .

Table 2.3 gives mean and standard deviation of the duration and frequency of maintenance and test activities during power operation. We note from this table that the average durations of PM and CM are similar, but there is wider variability in the duration of CM compared to that of PM, because CM is an unplanned activity. The frequency, especially PM frequency, considerably differs among EDGs, reflecting diverse PM practices across nuclear utilities. Figures 2.11 through 2.14 show the empirical and cumulative distribution of PM and CM frequency.

\subsection{EDG Unavailability Due to Maintenance and Testing During Plant Shutdown}

There is an increasing concern over the risk during the shutdown stages of a nuclear power plant. This shutdown risk is significant, especially because many components undergo extensive maintenance and testing. As stated earlier, routine EDG maintenances are carried out during shutdown.

The unavailabilities of the EDGs during plant shutdown were evaluated similarly to those for power operation; namely, entering the data into Quattro spreadsheets and analyzing them using the software and the expressions discussed in Section 2.2. The EDG unavailabilities, analyzed for 170 EDGs at 80 plant units (the only units providing the EDG outage data for plant shutdown), are presented specifically for PM, CM, or testing, and also for the combination thereof.

\section{Preventive Maintenance}

Figure 2.15 shows the empirical distribution of EDG unavailability due to PM during plant shutdown, i.e., $U_{s, \mathrm{PM}}$, versus fraction of EDGs. The empirical complementary cumulative distribution of $\mathrm{U}_{\mathrm{s}, \mathrm{PM}}$, which represents the fraction of EDGs that has PM unavailability greater than a certain value, is shown in Figure 2.16. For about $31 \%$ of the EDGs, $U_{s, P M}$ was less than 0.025 . For the remainder, more PM was performed during plant shutdown; the PM unavailabilities vary significantly over the period studied, representing different PM practices across utilities. $\mathrm{U}_{8, \mathrm{PM}}$ generally spans from 0 to $37.5 \%$. Comparison of the $U_{\mathrm{p}, \mathrm{PM}}$ distribution (Figure 2.1) with the $\mathrm{U}_{\mathrm{s} . \mathrm{PM}}$ distribution (Figure 2.15) indicates that much more PM was done on EDGs during plant shutdown. The $\mathrm{U}_{\mathrm{s}, \mathrm{PM}}$ for specific EDGs is shown in Table B.5 of Appendix B.

\section{Corrective Maintenance}

Figure 2.17 depicts the empirical distribution of EDG unavailability due to CM during plant shutdown, i.e., $\mathrm{U}_{\mathrm{s}, \mathrm{CM}}$, versus fraction of EDGs. For about a half of the EDGs, $\mathrm{U}_{\mathrm{s}, \mathrm{CM}}$ was less than $2.5 \%$; for the remainder, more $C M$ was carried out during shutdown. The $\mathrm{U}_{\mathrm{s}, \mathrm{CM}}$ for specific EDGs are shown in Table B.6 of Appendix B. Figure 2.18 shows the empirical complementary cumulative distribution 
of $U_{s, C M}$, which indicates the fraction of EDGs that has CM unavailability greater than a certain value. As with PM, more CM was done on EDGs during shutdown than during power operation.

\section{Preventive and Corrective Maintenance}

Figure 2.19 shows the empirical distribution of EDG unavailability due to both PM and CM, i.e., $\mathrm{U}_{\mathrm{a}, \mathrm{PM}+\mathrm{CM}}$, versus fraction of EDGs. For about $27 \%$ of the EDGs, $\mathrm{U}_{\mathrm{B}, \mathrm{PM}+\mathrm{CM}}$ was less than $2.5 \%$; for the remainder, the maintenance unavailability varies considerably ranging between $2.5 \%$ and $47.5 \%$. The $\mathrm{U}_{8 \mathrm{PM}+\mathrm{CM}}$ for specific EDGs is given in Table B.7 of Appendix B. Figure 2.20 shows the empirical complementary cumulative distribution of $\mathrm{U}_{8, \mathrm{PM}+\mathrm{CM}}$, which indicates the fraction of EDGs that has maintenance unavailability greater than a certain value; about $22 \%$ had $\mathrm{U}_{\mathrm{s}, \mathrm{PM}+\mathrm{CM}}$ greater than 0.2 .

\section{Testing}

Figures 2.21 and 2.22 present the distribution of EDG unavailability due to testing during plant shutdown, i.e., $\mathrm{U}_{\mathrm{s}, \mathrm{T}}$, based on 75 EDGs (because data were given only for 75 diesels). Figure 2.21 shows the empirical distribution of $U_{8, T}$ versus fraction of EDGs. Comparison of the $U_{8, T}$ distribution (Figure 2.21) with the $\mathrm{U}_{\mathrm{p}, \mathrm{T}}$ distribution (Figure 2.7) indicates that a significant amount of testing was performed on some EDGs during plant shutdown. $U_{s, T}$ for specific EDGs is given in the alphabetical order of plant names in Table B.8 of Appendix B, along with $\mathrm{U}_{\mathrm{s}, \mathrm{PM}}$ and $\mathrm{U}_{\mathrm{B}, \mathrm{CM}}$. Figure 2.22 shows the empirical complementary cumulative distribution of $\mathrm{U}_{\mathrm{s}, \mathrm{T}}$, which represents the fraction of EDGs that has test unavailability greater than a certain value.

\section{Preventive and Corrective Maintenance, and Testing}

Figures 2.23 and 2.24 show distribution of EDG unavailability due to the combination of PM, $\mathrm{CM}$, and testing, i.e., $\mathrm{U}_{\mathrm{s}, \mathrm{PM}+\mathrm{CM}+\mathrm{T}}$. Figure 2.23 shows the empirical distribution of $\mathrm{U}_{\mathrm{s}, \mathrm{PM}+\mathrm{CM}+\mathrm{T}}$ versus fraction of EDGs during plant shutdown. This distribution follows a similar pattern to the $U_{8, P M+C M}$ distribution in Figure 2.19, showing a large variation in $\mathrm{U}_{s, \mathrm{PM}+\mathrm{CM}+\mathrm{T}}$ across about $70 \%$ of the EDGs. Figure 2.24 shows the empirical complementary cumulative distribution of $U_{8, P M+C M+T}$, which represents the fraction of EDGs that has unavailability due to maintenance and testing greater than a certain value.

Table 2.4 summarizes the mean, median, and standard deviation of the EDG unavailability due to maintenance and testing during plant shutdown.

Table 2.5 gives the cumulative distribution of the EDG unavailability due to maintenance and test activities during plant shutdown for a selected set of values, i.e., $0.1,0.2,0.3$, and 0.4 . This table indicates that about $22 \%$ of the EDGs had $\mathrm{U}_{\mathrm{s}, \mathrm{PM}+\mathrm{CM}}$ and $\mathrm{U}_{\mathrm{s}, \mathrm{PM}+\mathrm{CM}+\mathrm{T}}$ greater than 0.2 , i.e., a substantial amount of maintenance was performed on these EDGs during plant shutdown.

\subsection{Assumptions and Limitations of the Study and Insights Gained}

Our analysis of EDG unavailability was based on comprehensive EDG outage data covering almost the entire populations of EDGs in use at operating nuclear power plants, and the estimates are assumed to be reflective of recent practices there. Every effort was made to assure consistency and accuracy in the data; still, several assumptions apply: 
1) The EDG data used were submitted by individual resident inspectors, and were based on the same instructions provided to each inspector. No attempt was made to double check on the validity or accuracy of the data, unless an obvious error was detected during processing.

2) The data covered a period of 2 years including 212 EDGs at 97 plant units, approximately $92 \%$ of the EDGs in operation. For shutdown periods, data were available for 170 EDGs at 80 units. However, in general, there were sufficient data points to estimate the respective unavailabilities.

3) The database includes two types of maintenances: preventive and corrective maintenance. This distinction may vary from one plant to another, but its influence on our analysis is not judged to be significant. As mentioned earlier, in some cases, a combined outage time for different activities was reported. For our analysis, the time for each activity was estimated considering its typical duration at the nuclear unit.

4) The outage time due to testing estimated in this report is probably associated with large uncertainty for several reasons. About $40 \%$ of the units did not provide data for testing. In many cases, when data were given, it was a generic outage duration (e.g., 0.5 hrs. for each monthly surveillance test), as opposed to specific outage duration and identification of individual tests. In addition, it is not clear whether EDGs are unavailable over the entire period of testing.

5) For EDGs shared between multiple units, i.e., swing EDGs, multiple separate unavailabilities are obtained, each representing the value for a particular unit depending on its on-line hours. This resulted in a larger number of EDG unavailability data than the distinct EDGs in the database. A similar situation occurred in estimating EDG maintenance unavailabilities during the shutdown periods.

6) EDG maintenances were separated between power operation and shutdown. However, a plant shutdown state is comprised of a number of different stages, in terms of decay heat level, accident vulnerability, and plant configurations. EDG maintenance data were not further separated according to the stages of plant shutdown.

The insights gained from the analysis of EDG unavailabilities due to PM, CM, and testing can be summarized as follows:

(1) Preventive Maintenance Practices: Most plants ( $~ 95 \%)$ routinely carry out scheduled PM during power operation. There are significant differences in the number of PM during power operation representing diverse PM practices across nuclear utilities. On the average, during power operation, PM is performed every 2 months, a relatively high frequency, and for an average of 25 hours.

(2) Increasing PM During Power Operation: According to our data analysis, the industryaverage unavailability due to maintenance and testing during power operation $(\sim 0.02)$ is a factor of 3 greater than the 0.007 assumed in the SBO rule. ${ }^{2,10}$ Especially, the unavailability due to $\mathrm{PM}$ during power operation $(\sim 0.013)$ is about a factor of 2 greater than the value assumed in the rule. The reason for this high PM unavailability during power operation may reflect utility practices tending to move PM from shutdown to power operation. 
Monitoring of EDG-Unavailability Outlier: The data analysis indicates that the industryaverage EDG unavailability due to maintenance and testing during power operation $(\sim 0.02)$ is not as high as the value estimated in Reference 3 using actual demand data $(\sim 0.04)$. However, for a significant number of EDGs, the unavailability is quite high. For instance, for about $20 \%$ of the total EDGs examined, i.e., 47 , the unavailability is greater than 0.03 , and for about $10 \%$, i.e., 24 , it is greater than 0.04 . During plant shutdown, the EDG unavailability is about a factor of 6 higher than that during power operation; also, a significant portion of the EDGs has a very high unavailability during shutdown (4 EDGs had unavailability greater than 0.4). Monitoring of these outliers may be desirable during power operation and plant shutdown.

(4) Comparison of EDG Unavailability During Power Operation Versus Shutdown: EDG unavailability due to testing and maintenance during shutdown is considerably higher than that for power operation. The average unavailability due to maintenance (PM \& CM) during shutdown is approximately $0.12,6$ times higher than the corresponding value (0.02) for power operation. Both PM and CM unavailabilities during shutdown is higher by similar factors (6 to 8 ) than the corresponding values for power operation. This difference probably reflects the NRC Regulatory Guide 1.155 which suggests that regular EDG maintenances be scheduled during shutdown.

(5) Average EDG Maintenance Unavailability: The average maintenance unavailability was estimated to be 0.02 and 0.12 for power operation and shutdown periods, respectively. Assuming a plant is in power operation $70 \%$ of the time, an EDG is down for maintenance for about 5 days during power operations, and 13 days during shutdown, for a total of 18 days per year.

Comparison of EDG Maintenance Unavailability in United States With Operating Experience in Other Countries: The EDG maintenance unavailability estimated from the US operating experiences was compared to that reported by some other countries. Although the regulatory requirements, plant designs, and operating practices differ in those countries and should influence the unavailability, this comparison gives a perspective on the overall experience of EDG operation in the United States.

German estimates ${ }^{11}$ of EDG maintenance unavailabilities during power operation and shutdown are slightly smaller, but comparable; they are 0.016 (during power operation) and 0.11 (during shutdown). These estimates were obtained from the operating experience of 111 EDGs at 20 atomic power plants, covering approximately eight years of operation (1981 to 1987).

A study on Finnish and Swedish nuclear power plants ${ }^{12}$ reports a smaller contribution for EDG maintenance unavailability, 0.004 . This estimate is due to CM only, since the unavailability due to PM is separately controlled at less than 3 days per year, i.e., 0.008 . This study was based on 40 EDGs at 12 nuclear power plants from 1974 to 1981 . 

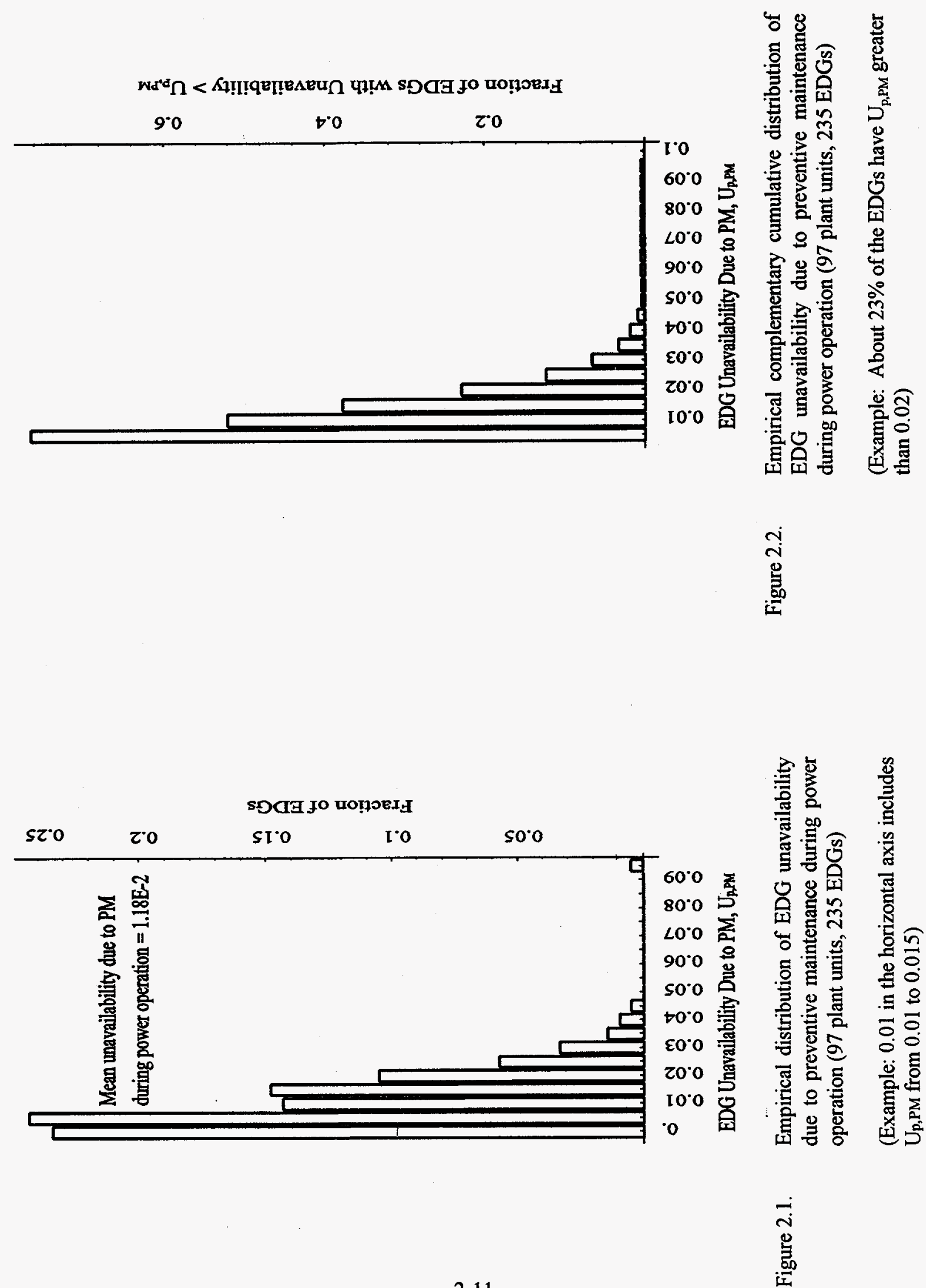


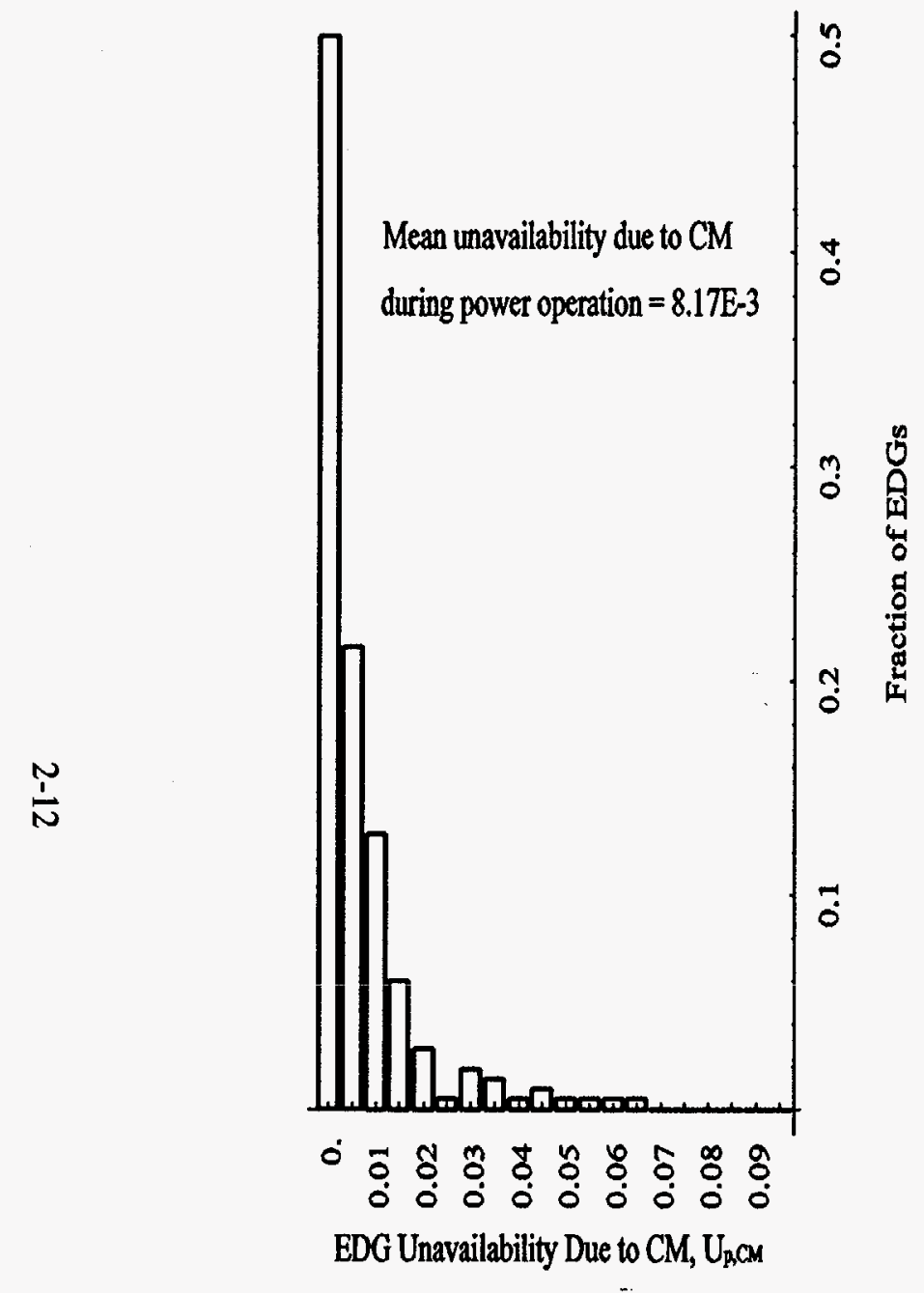

Figure 2.3. Empirical distribution of EDG unavailability due to corrective maintenance during power operation (97 plant units, 235 EDGs)

(Example: 0.01 in the horizontal axis includes $\mathrm{U}_{\mathrm{p}, \mathrm{CM}}$ from 0.01 to 0.015 )

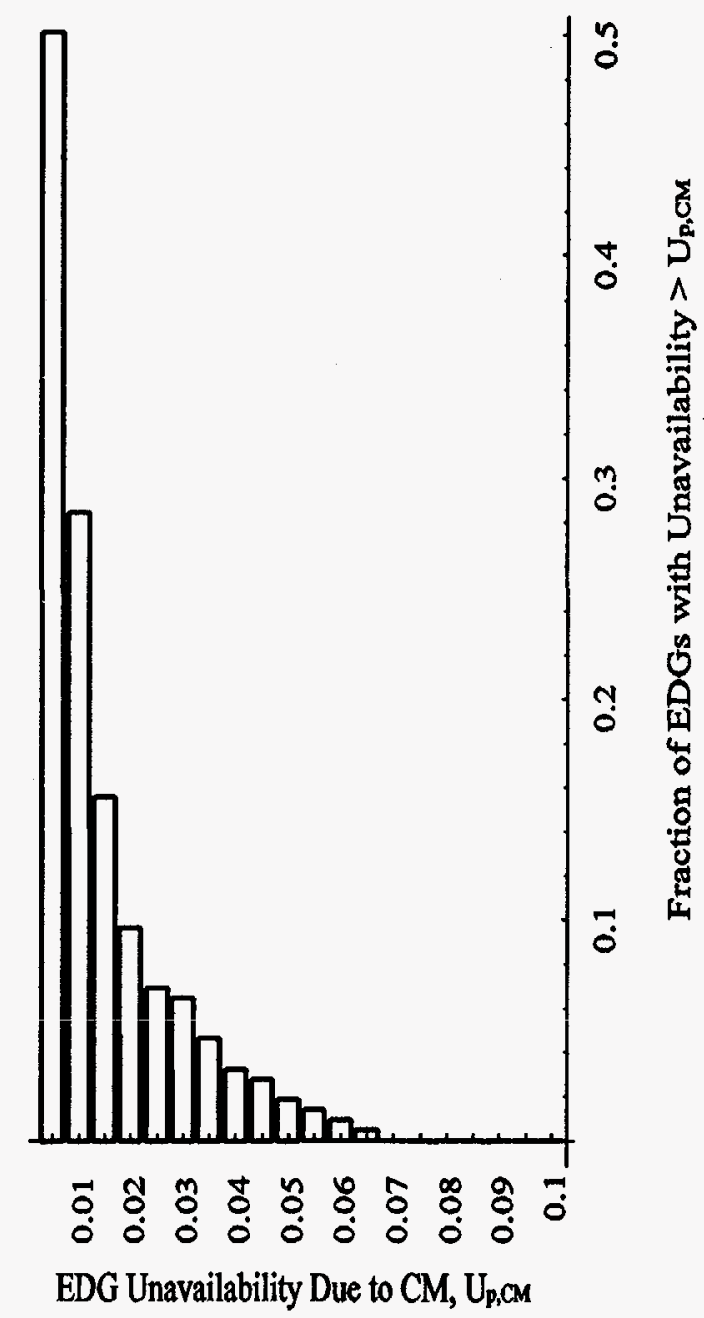

Figure 2.4. Empirical complementary cumulative distribution of EDG unavailability due to corrective maintenance during power operation (97 plant units, 235 EDGs)

(Example: About $28 \%$ of the EDGs have $\mathrm{U}_{\mathrm{p}, \mathrm{CM}}$ greater than 0.01) 

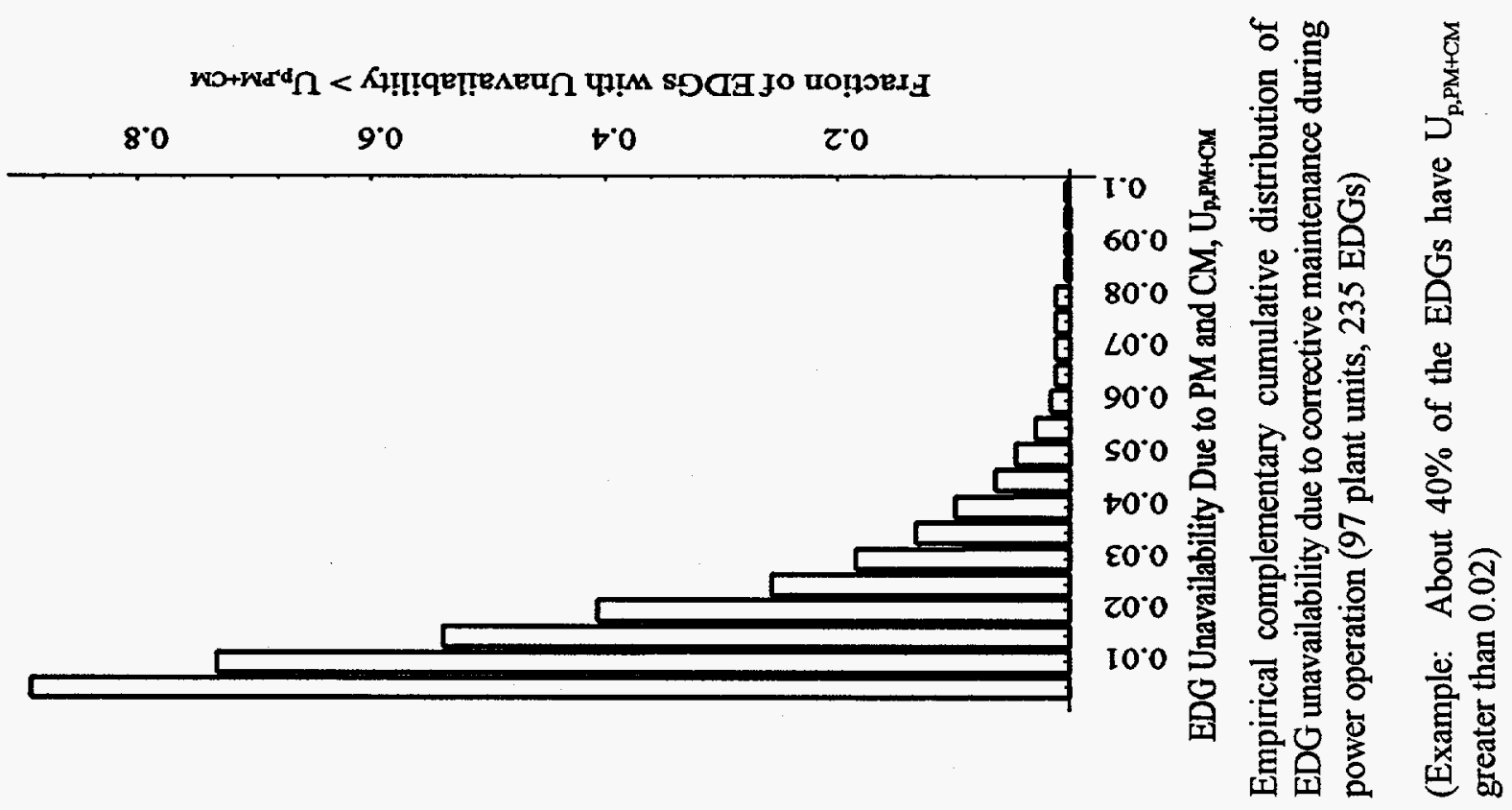

ن
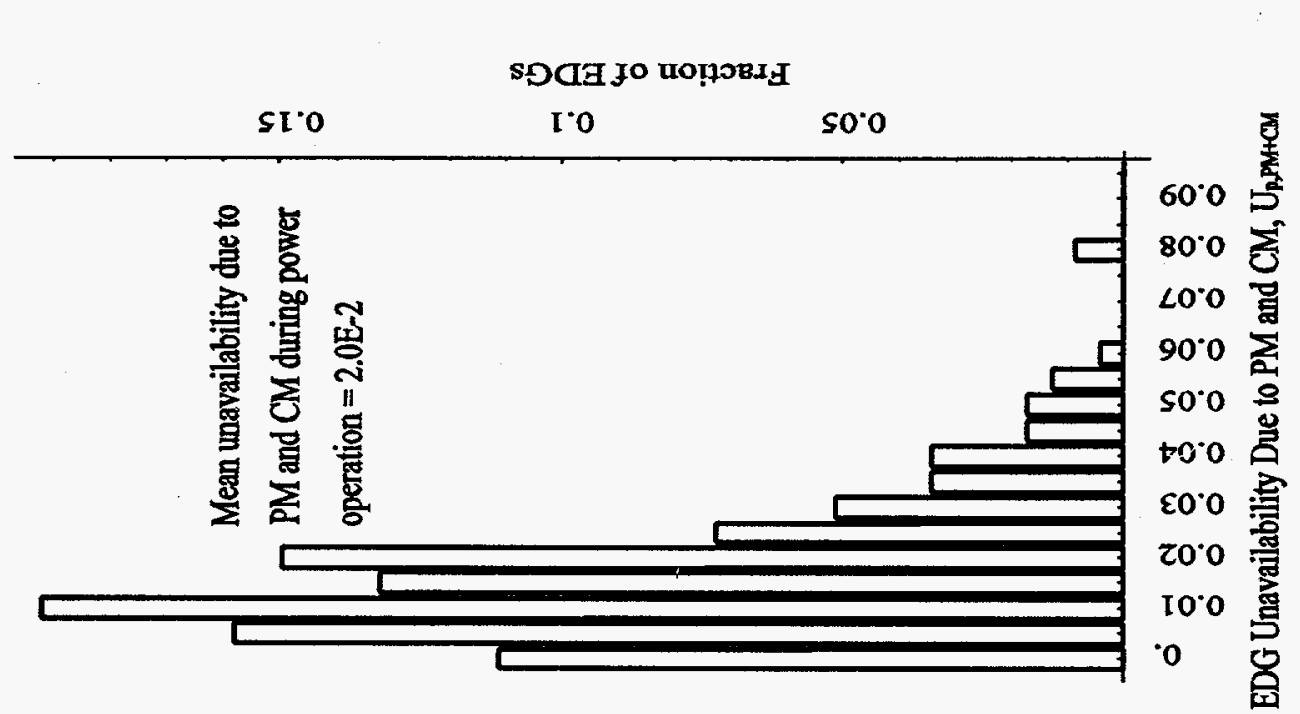

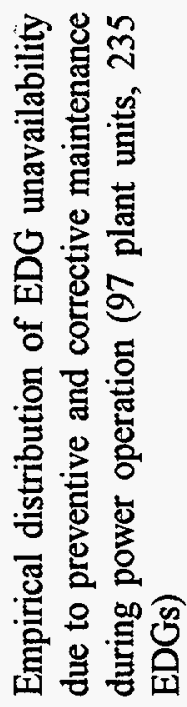

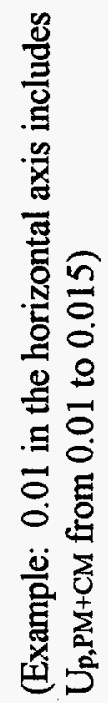

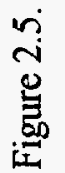




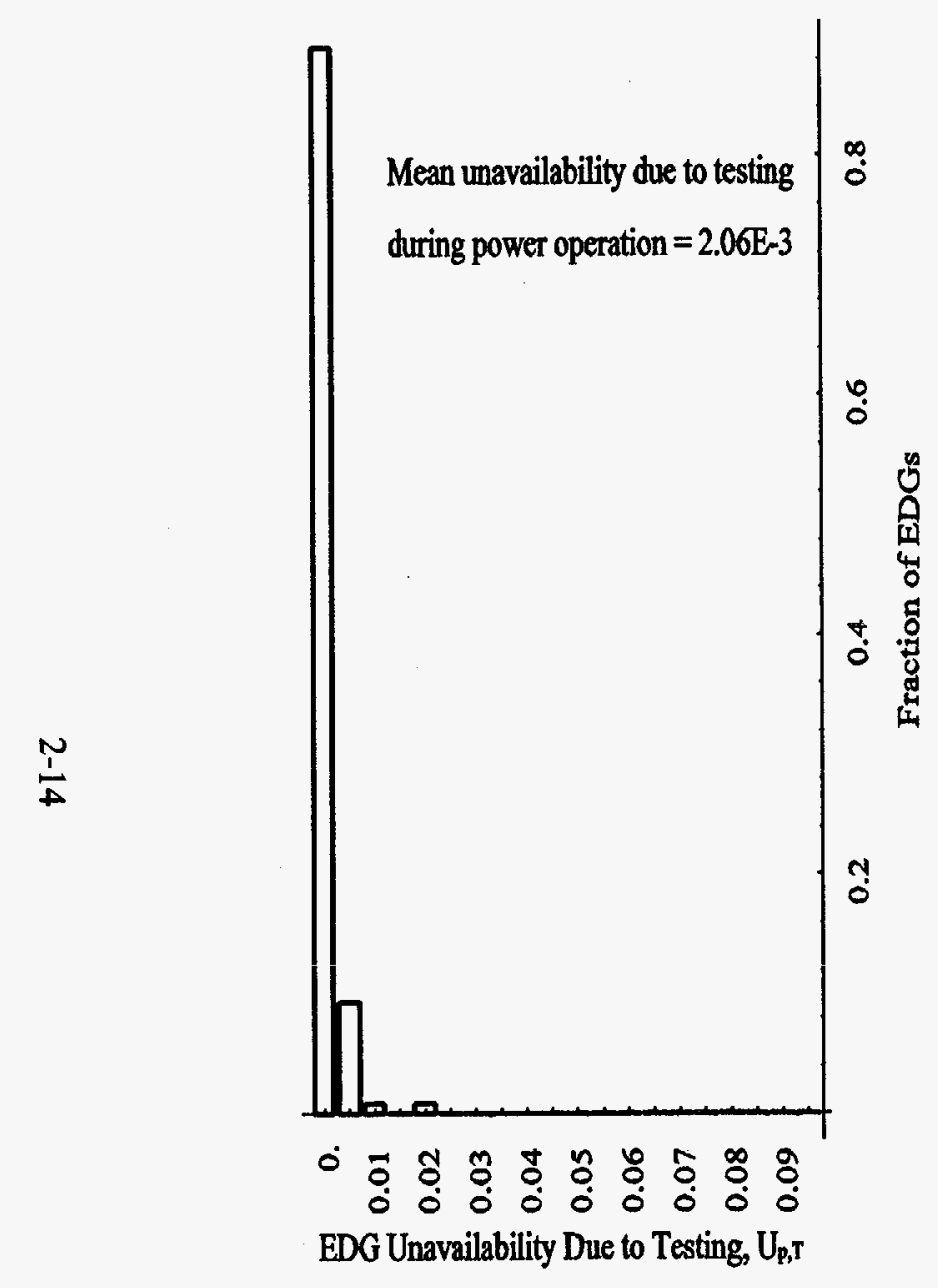

Figure 2.7. Empirical distribution of EDG unavailability due to testing during power operation ( 58 plant units, 117 EDGs)

(Example: 0.01 in the horizontal axis includes $\mathrm{U}_{\mathrm{p}, \mathrm{T}}$ from 0.01 to 0.015 )

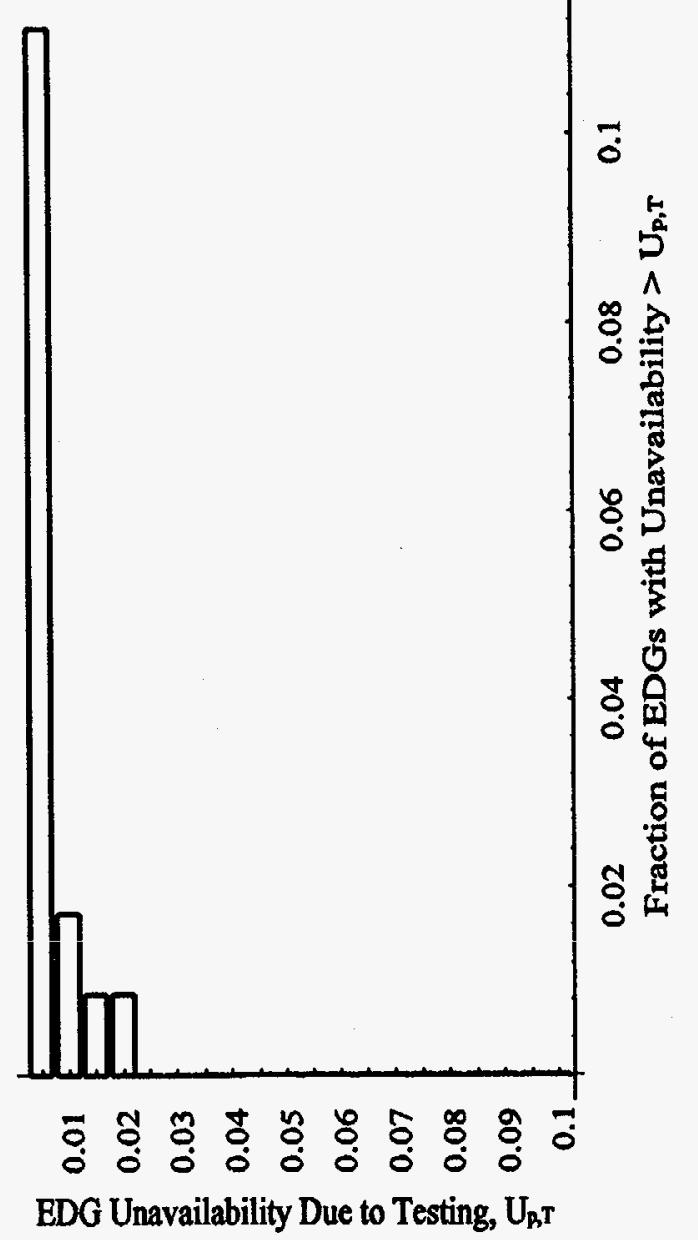

Figure 2.8. Empirical complementary cumulative distribution of EDG unavailability due to testing during power operation (58 plant units, 117 EDGs)

(Example: About $1.7 \%$ of the EDGs have $U_{p, T}$ greater than 0.01 


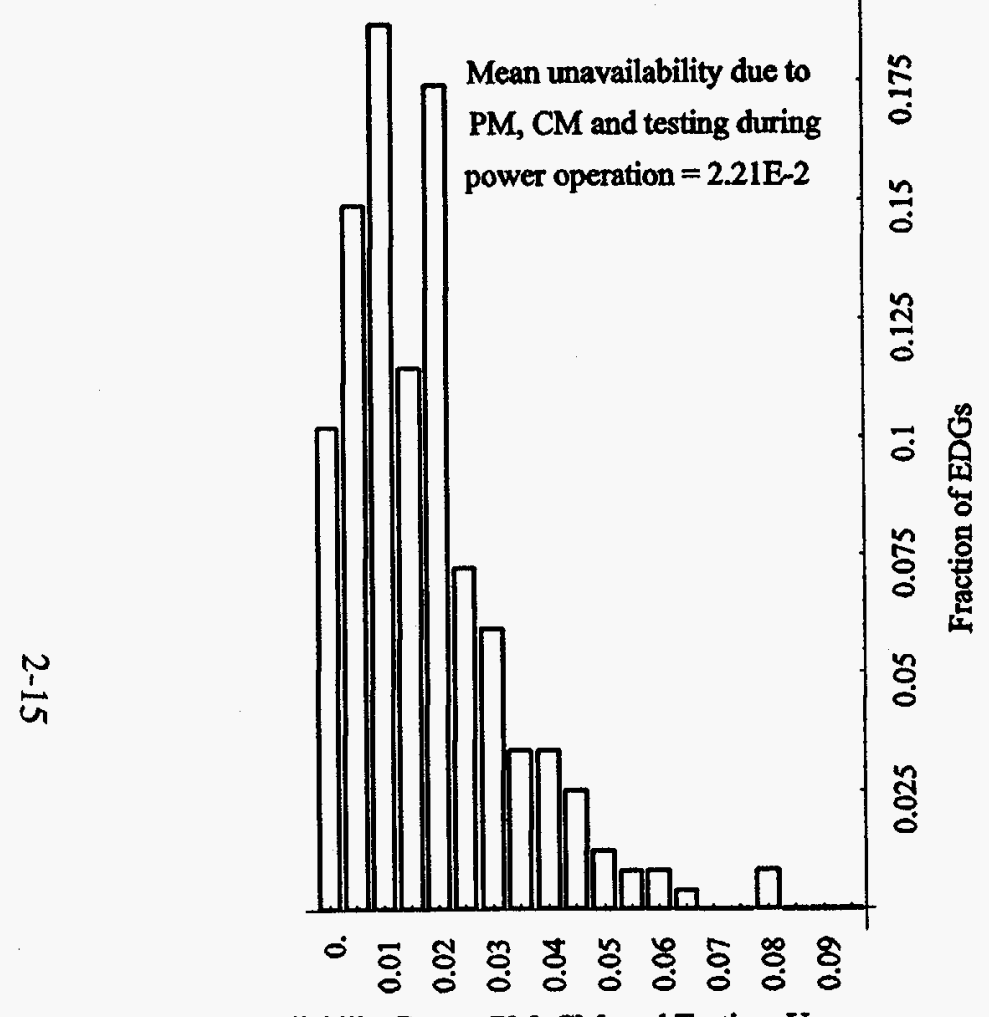

EDG Unavailability Due to PM, CM, and Testing, $\mathrm{U}_{\mathrm{p}, \mathrm{PM}+\mathrm{CM}+\mathrm{T}}$

Figure 2.9. Empirical distribution of EDG unavailability due to $\mathrm{PM}, \mathrm{CM}$, and testing during power operation (97 plant units, $235 \mathrm{EDGs}$ )

(Example: 0.01 in the horizontal axis includes $\mathrm{U}_{\mathrm{p}, \mathrm{PM}+\mathrm{CM}+\mathrm{T}}$ from 0.01 to 0.015 )

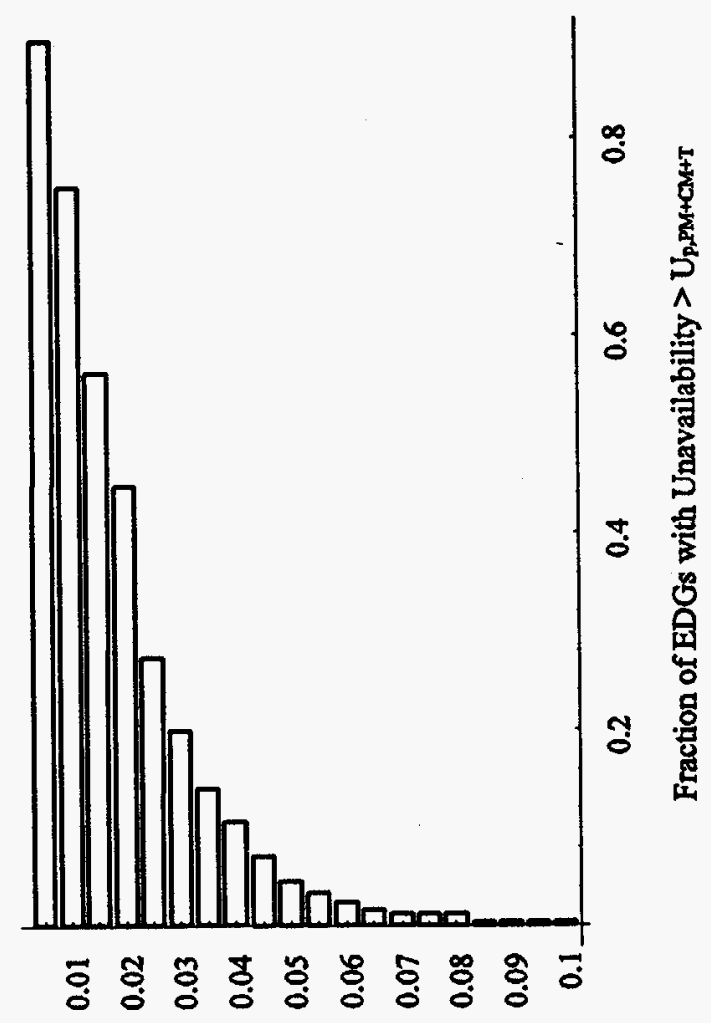

EDG Unavailability Due to PM, CM, Testing, $U_{P P M+C M+T}$

Figure 2.10. Empirical complementary cumulative distribution of EDG unavailability due to $\mathrm{PM}, \mathrm{CM}$, and testing during power operation ( 97 plant units, 235 EDGs)

(Example: About $44 \%$ of the EDGs have $\mathrm{U}_{\mathrm{p}, \mathrm{PM}+\mathrm{CM}+\mathrm{T}}$ greater than 0.02 ) 


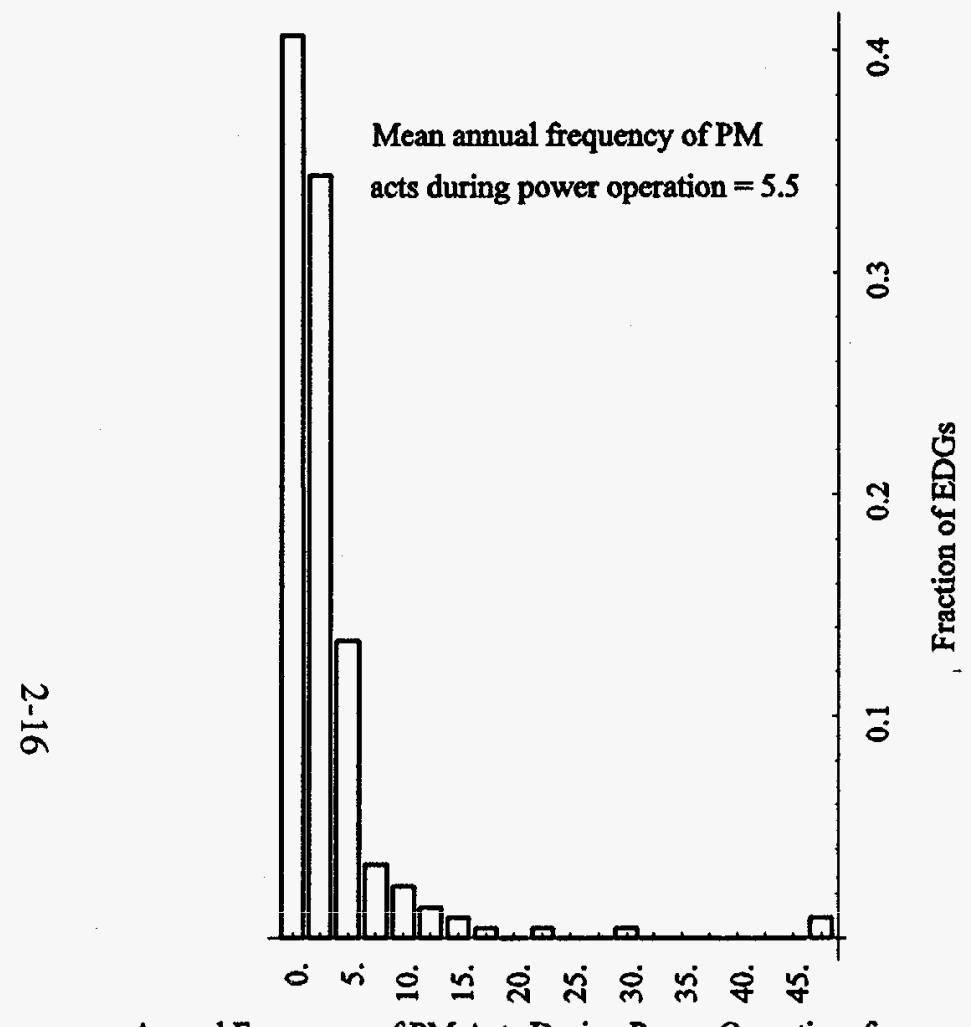

Annual Frequency of PM Acts During Power Operation, fp,PM

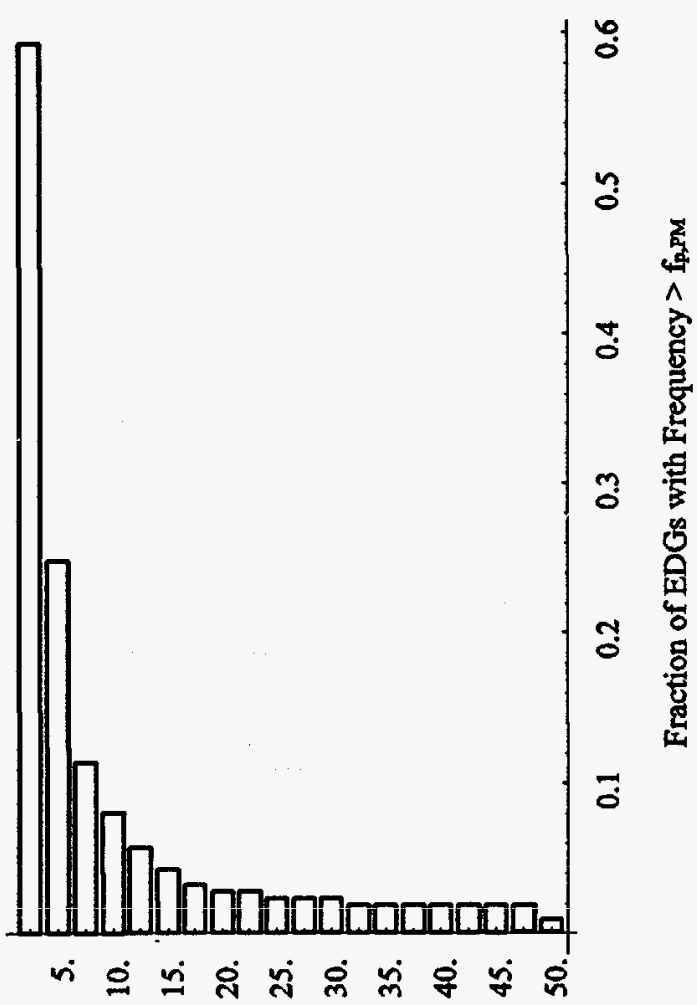

Annual Frequency of PM Acts During Power Operation, $f_{p}, \mathrm{PM}$
Figure 2.11. Empirical distribution of annual frequency of PM acts during power operation (97 plant units, 235 EDGs)

(Example: 5 in the horizontal axis includes annual frequency from 5 to 7.5 )
Figure 2.12. Empirical complememtary cumulative distribution of annual frequency of PM acts during power operation (97 plant units, 235 EDGs)

(Example: For about $8 \%$ of the EDGs, more than 10 PM acts were performed annually.) 


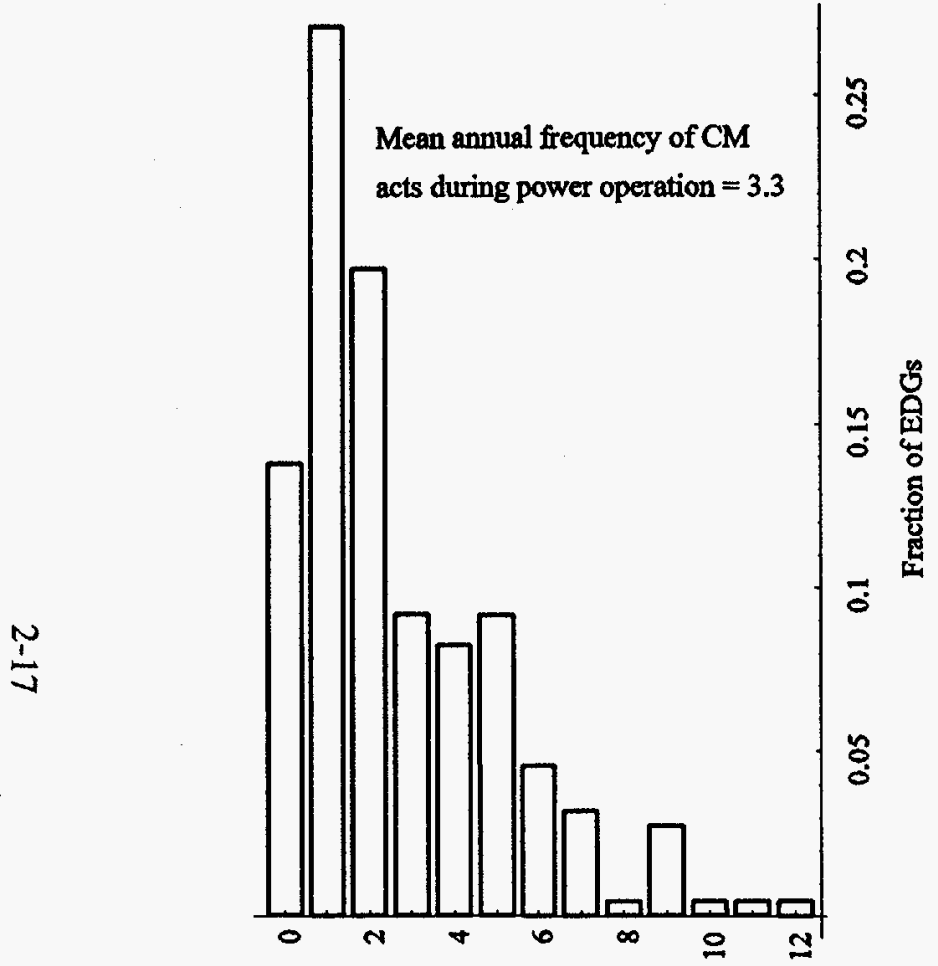

Annual Frequency of CM Acts During Power Operation, $\mathrm{f}_{\mathrm{p}, \mathrm{PM}}$

Figure 2.13. Empirical distribution of annual frequency of $\mathrm{CM}$ acts during power operation (97 plant units, 235 EDGs)

(Example: 2 in the horizontal axis includes annual frequency from 2 to 3 )

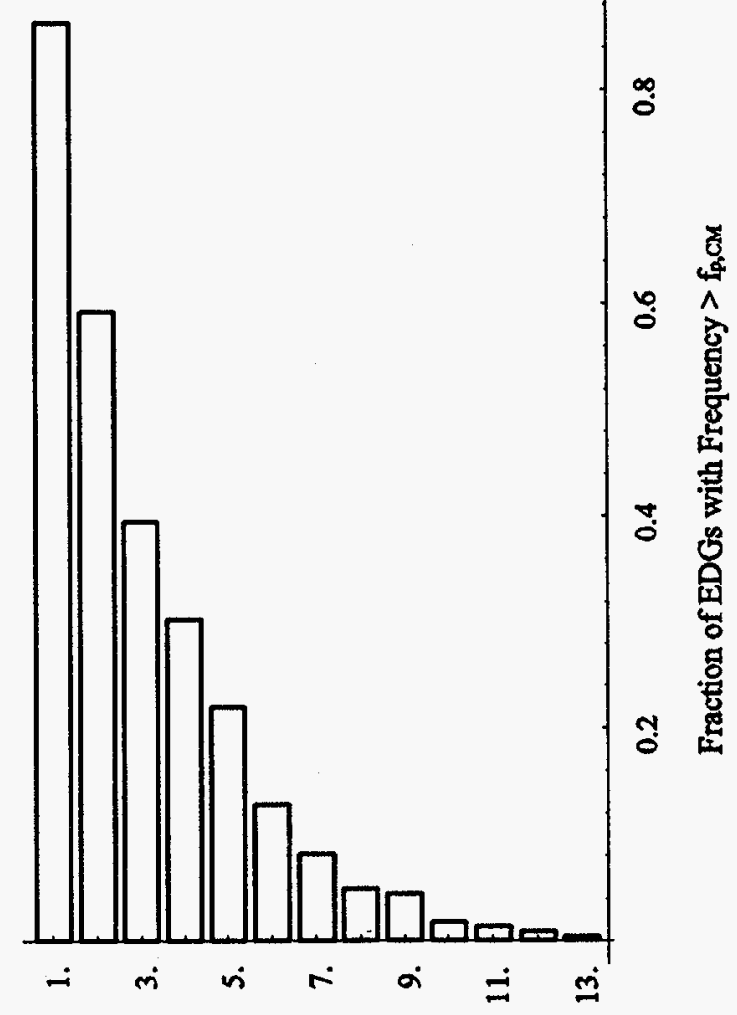

Annual Frequency of CM Acts During Power Operation, $f_{p}, c M$

Figure 2.14. Empirical complementary cumulative distribution of annual frequency of $\mathrm{CM}$ acts during power operation (97 plant units, 235 EDGs)

(Example: For about $30 \%$ of the EDGs, more than 4 $\mathrm{CM}$ acts were performed annually.) 


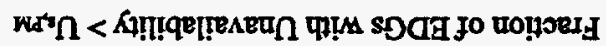
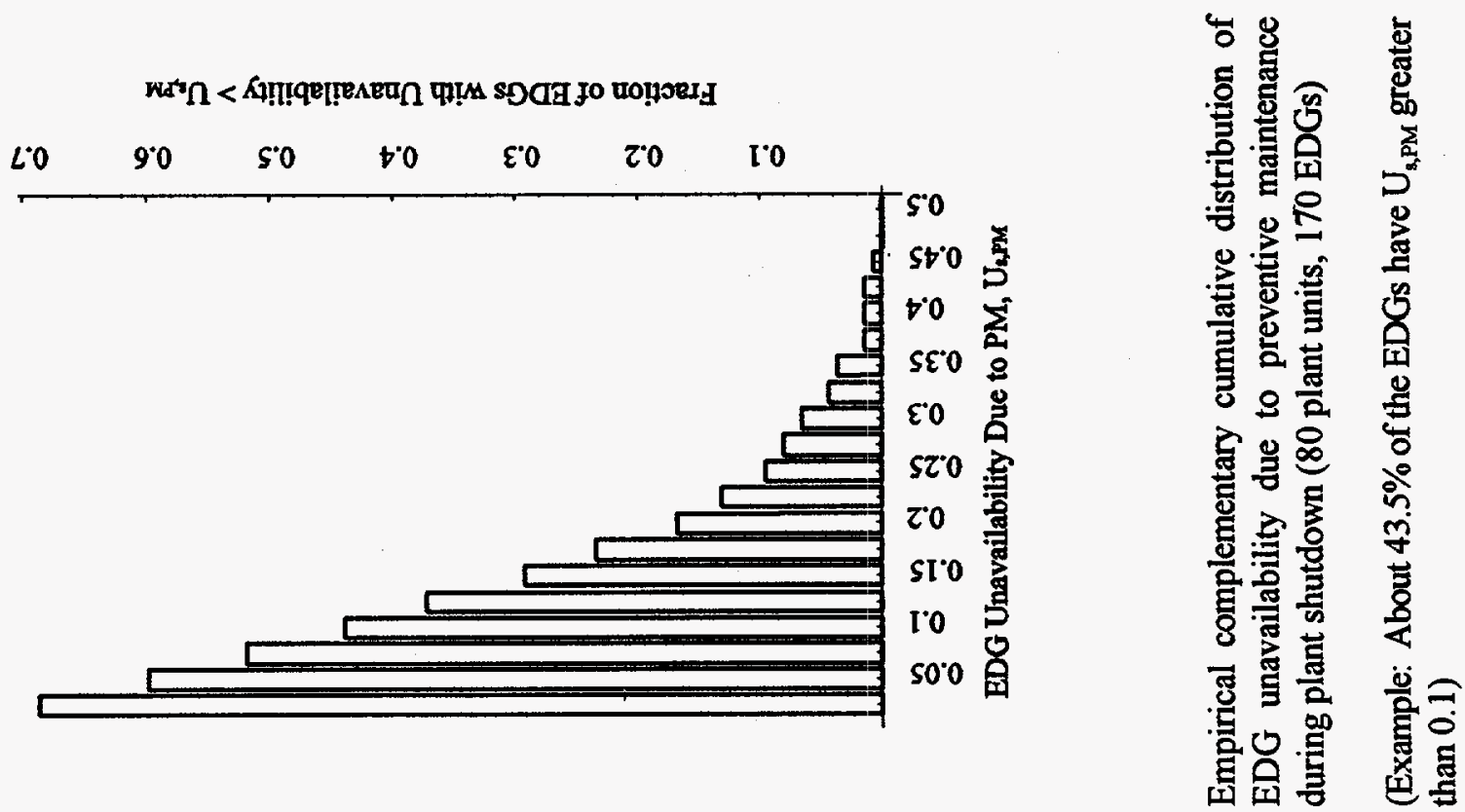

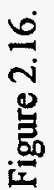

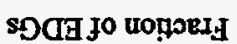
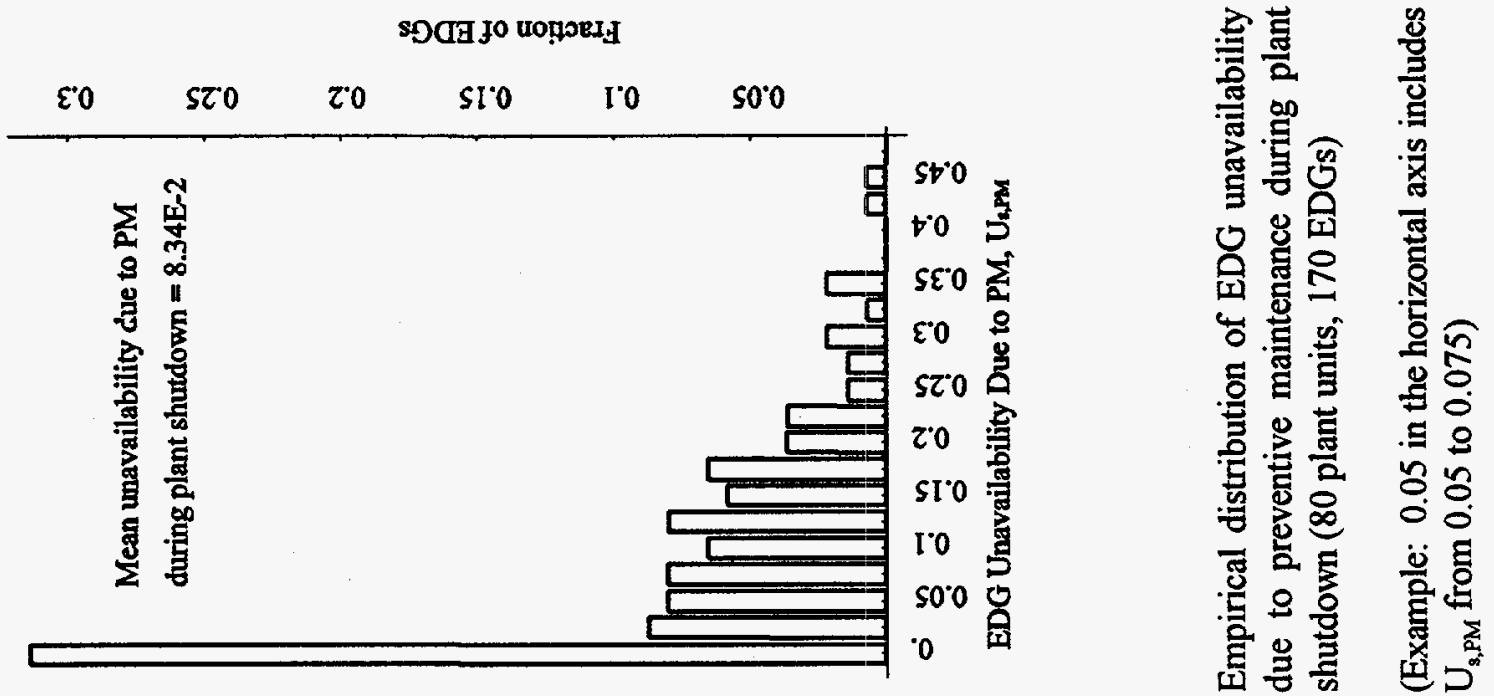

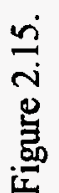




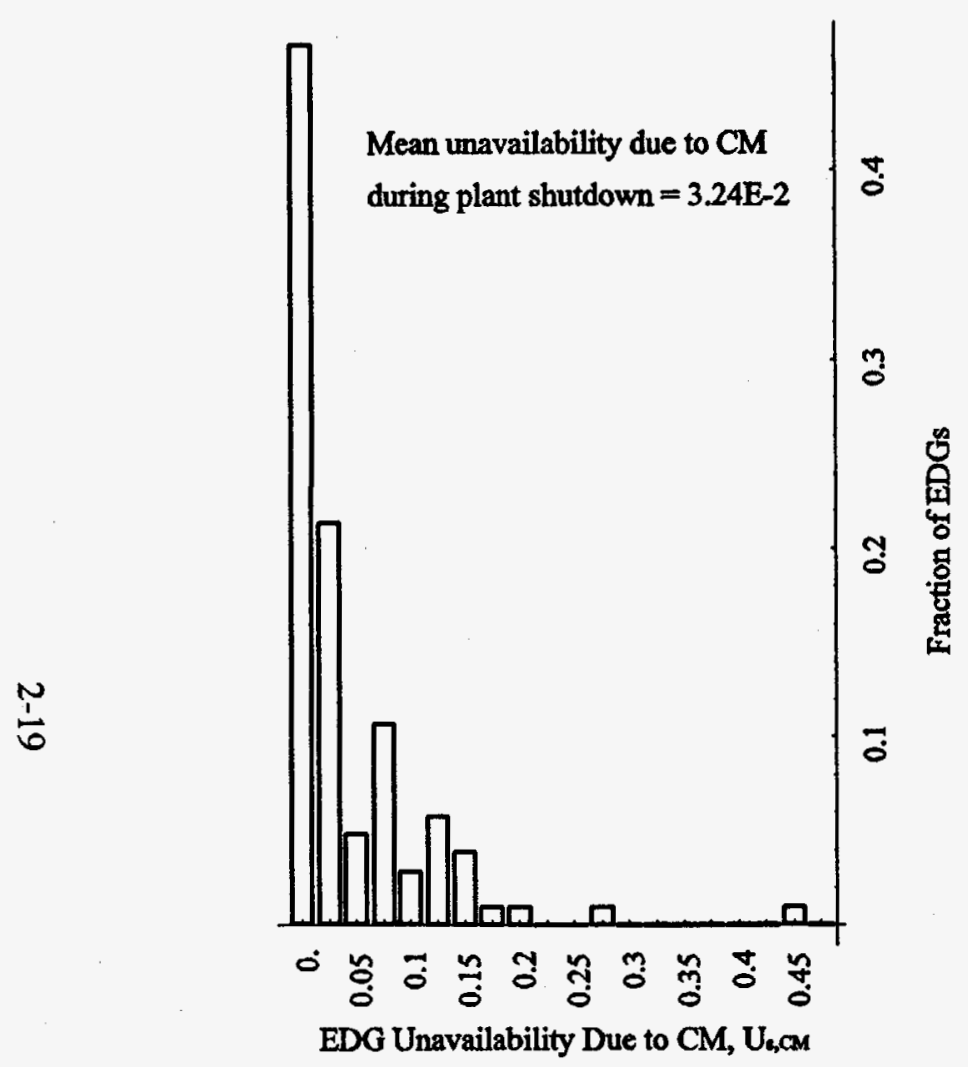

Figure 2.17. Empirical distribution of EDG unavailability due to corrective maintenance during plant shutdown (80 plant units, 170 EDGs)

(Example: 0.05 in the horizontal axis includes $\mathrm{U}_{\mathrm{s}, \mathrm{CM}}$ from 0.05 to 0.075 )

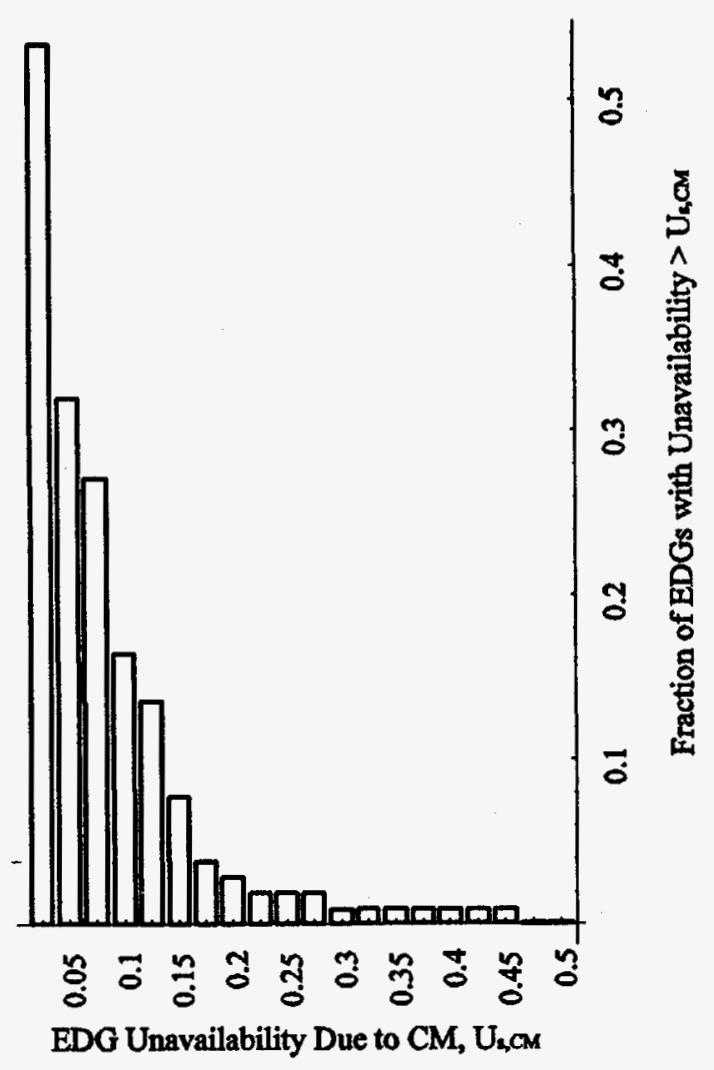

Figure 2.18. Empirical complementary cumulative distribution of EDG unavailability due to corrective maintenance during plant shutdown (80 plant units, 170 EDGs)

(Example: About $16.5 \%$ of the EDGs have $U_{\mathrm{s}, \mathrm{CM}}$ greater than 0.1) 
WD+Wd'

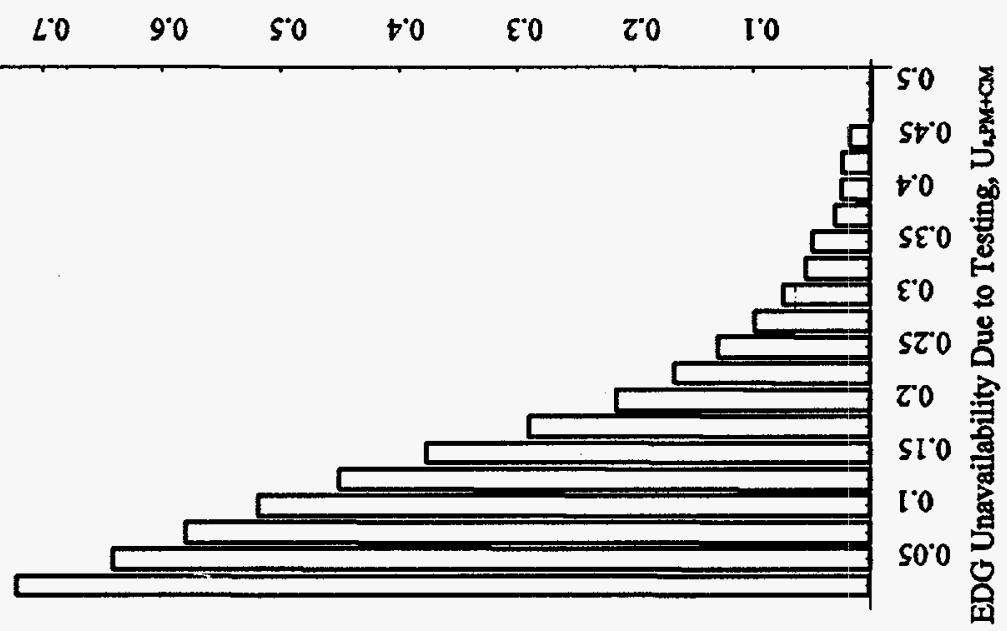

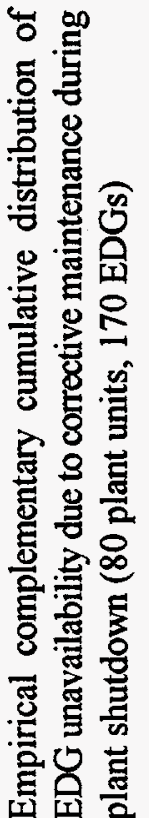

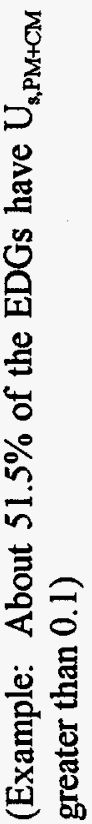

뭉

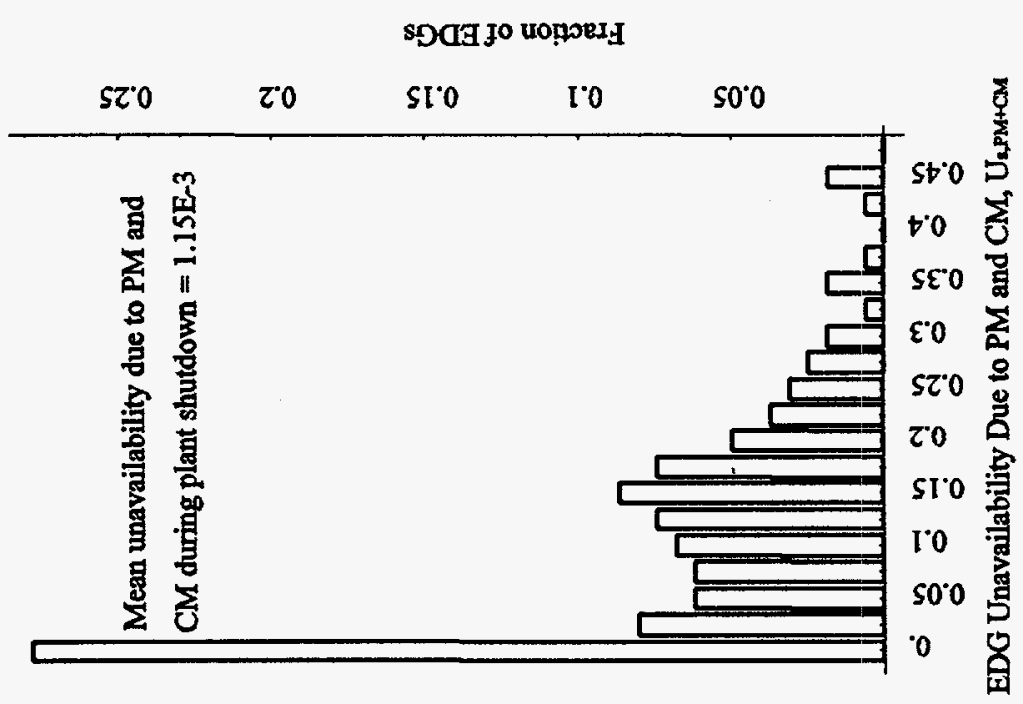

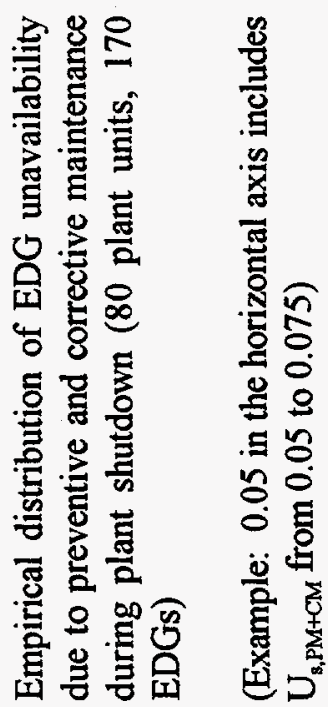




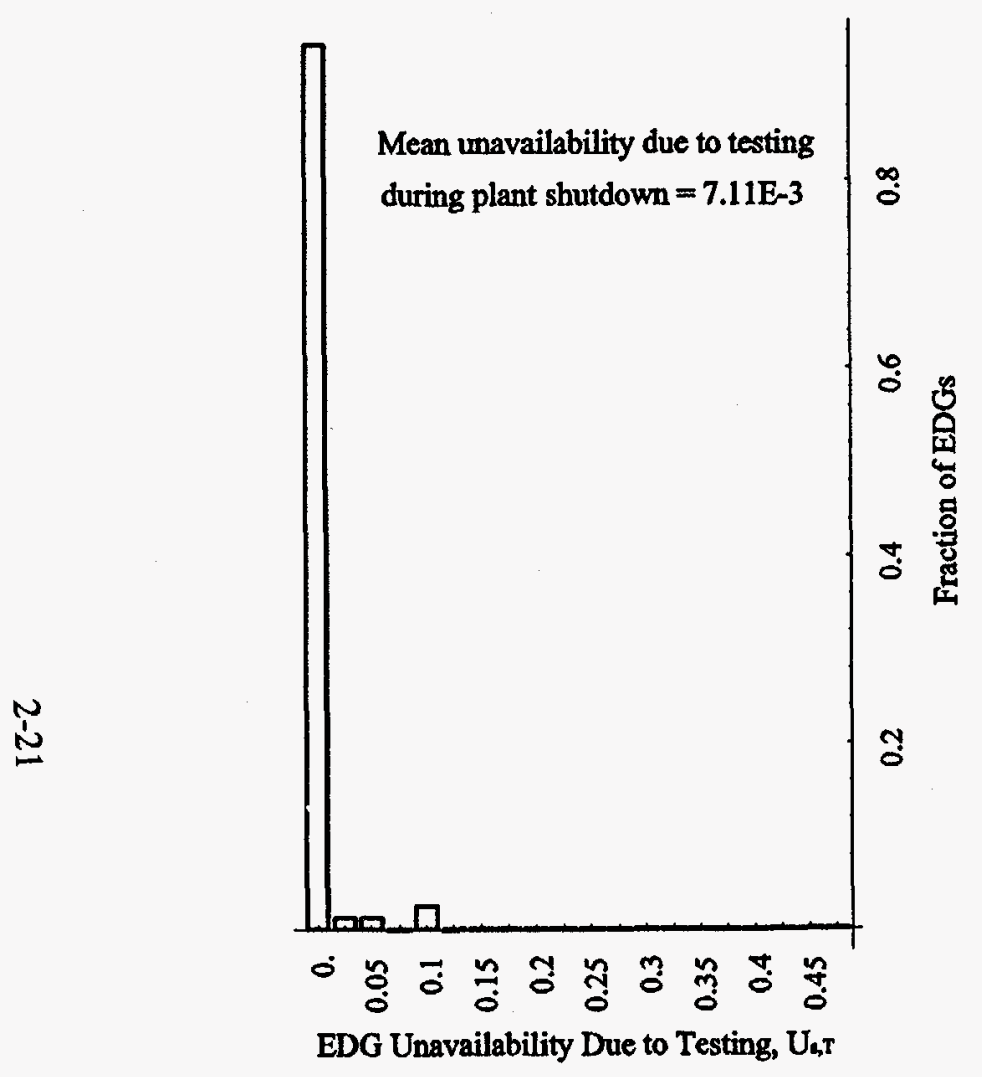

Figure 2.21. Empirical distribution of EDG unavailability due to testing during plant shutdown (43 plant units, 75 EDGs)

(Example: 0.05 in the horizontal axis includes $\mathrm{U}_{\mathrm{s}, \mathrm{T}}$ from 0.05 to 0.075 )

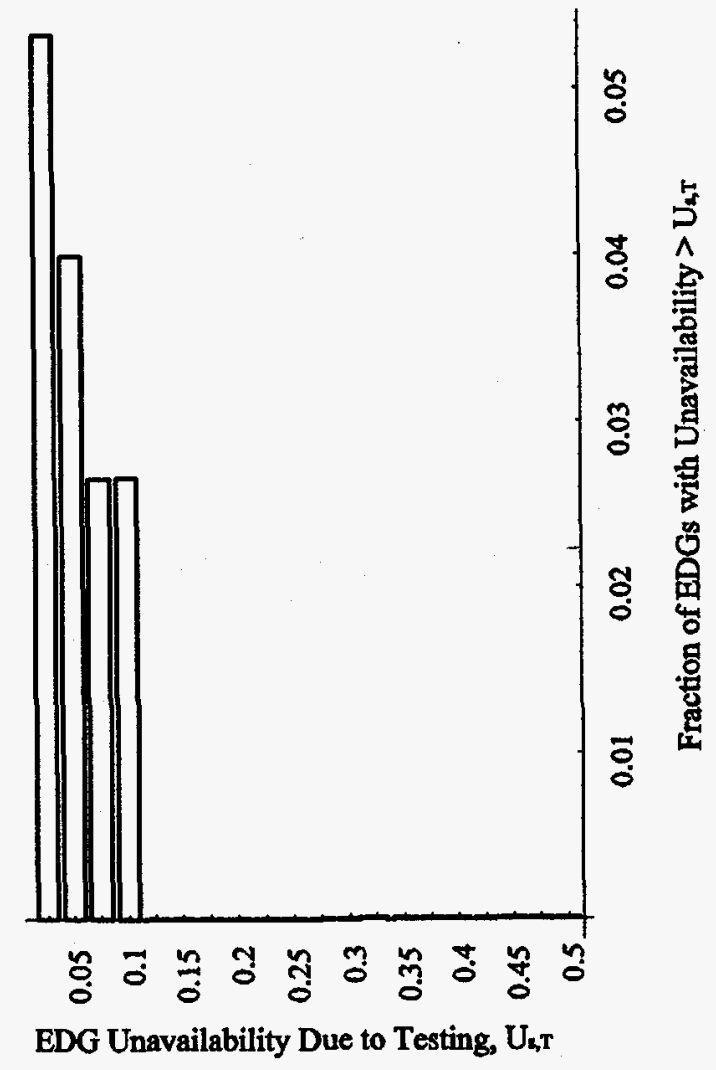

Figure 2.22. Empirical complementary cumulative distribution of EDG unavailability due to testing during plant shutdown (43 plant units, 75 EDGs)

(Example: About $4 \%$ of the EDGs have $U_{\mathrm{s}, \mathrm{T}}$ greater than 0.05) 


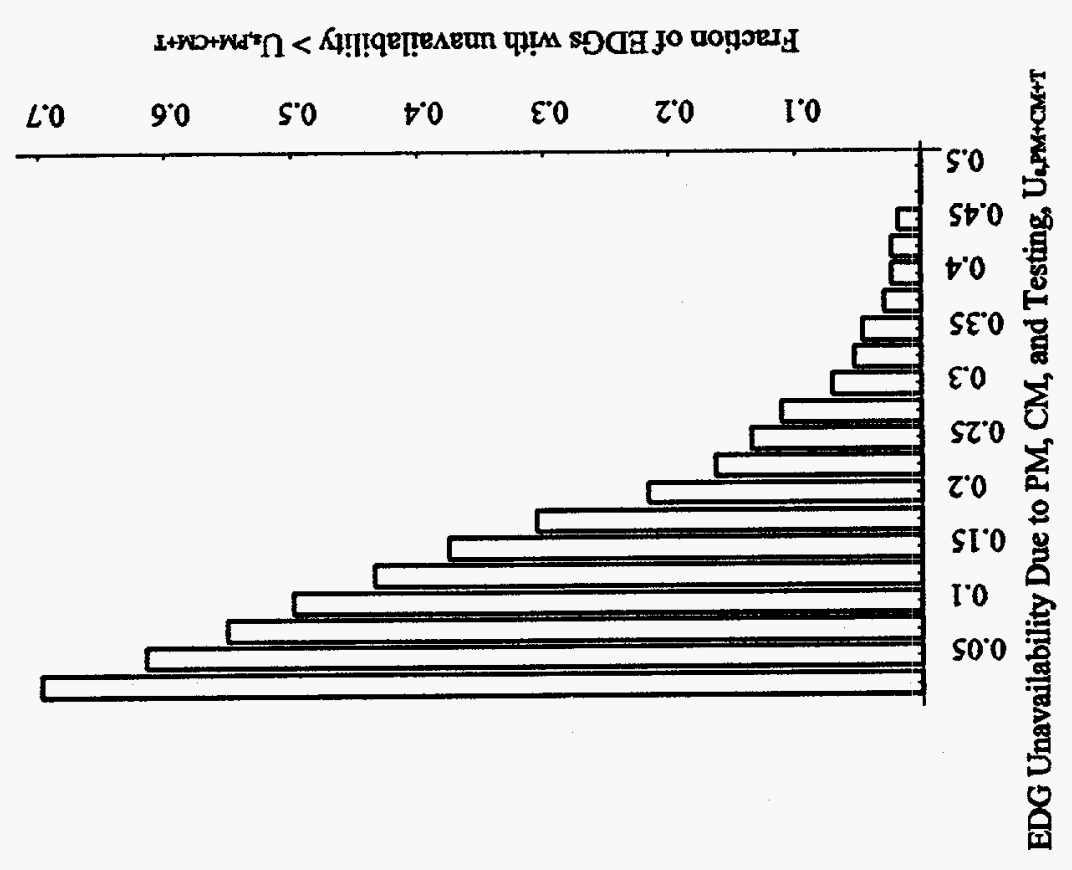

¿

동

象

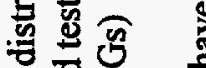

염

롱요

言㐫商

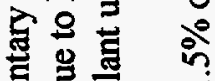

롱 줌 -

릉

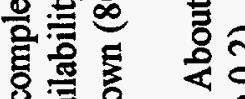

퓨 흠

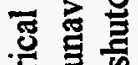

을응

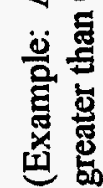

离

spat jo toppes

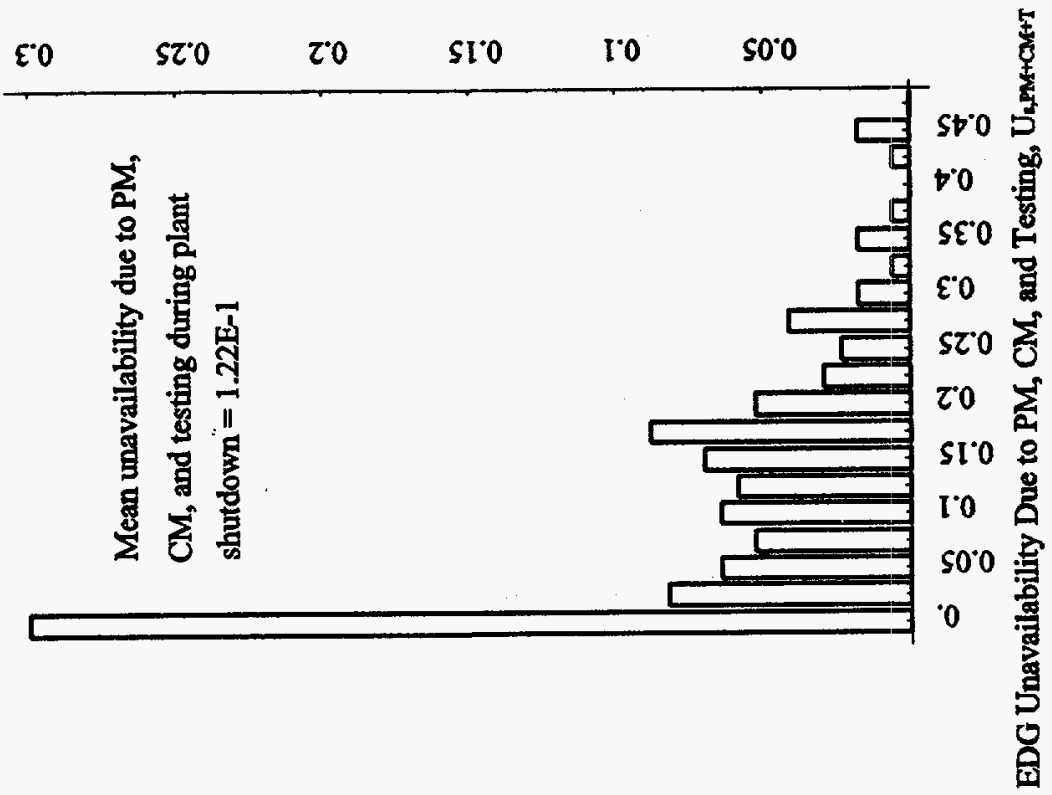

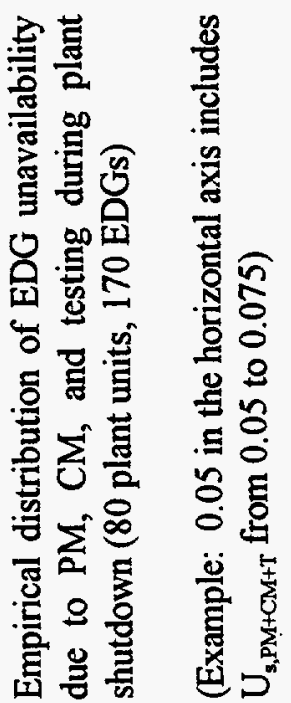

तु 
Table 2.1. Mean, Median, and Standard Deviation of the EDG Unavailability Due to Maintenance and Testing During Power Operation

\begin{tabular}{|c|c|c|c|}
\hline \multirow{2}{*}{ Activity } & \multicolumn{3}{|c|}{ EDG Unavailability During Power Operation } \\
\hline & Mean & Median & $\begin{array}{l}\text { Standard } \\
\text { Deviation }\end{array}$ \\
\hline PM & $1.18 \mathrm{E}-2$ & $1.13 \mathrm{E}-2$ & $1.14 \mathrm{E}-2$ \\
\hline $\mathrm{CM}$ & 8.17E-3 & $5.00 \mathrm{E}-3$ & $1.11 \mathrm{E}-2$ \\
\hline Test $^{1}$ & $2.06 \mathrm{E}-3$ & $1.01 \mathrm{E}-3$ & 2.97E-3 \\
\hline PM and $\mathrm{CM}$ & 2.0E-2 & $1.60 \mathrm{E}-2$ & $1.70 \mathrm{E}-2$ \\
\hline
\end{tabular}

${ }^{1}$ The values for test are based on only 117 EDGs at 58 units, about a half of the total EDG population analyzed in this study, for which test data were available.

Table 2.2. Cumulative Distribution of the EDG Unavailability Due to Maintenance and Testing During Power Operation

\begin{tabular}{|l|c|c|c|c|c|c|}
\hline \multirow{2}{*}{ Activity $^{*}$} & \multicolumn{6}{|c|}{ EDG Unavailability During Power Operation } \\
\cline { 2 - 8 } & $\leq 0.007$ & $\leq 0.01$ & $\leq 0.02$ & $\leq 0.03$ & $\leq 0.04$ & $>0.04$ \\
\hline \hline $\mathrm{PM}$ & $33.1 \%^{1}$ & $47.8 \%$ & $77.0 \%$ & $93.3 \%$ & $98.1 \%$ & $1.9 \%$ \\
\hline $\mathrm{CM}$ & $61.5 \%$ & $71.6 \%$ & $90.4 \%$ & $93.6 \%$ & $96.8 \%$ & $3.2 \%$ \\
\hline Test $^{2}$ & $93.2 \%$ & $98.3 \%$ & $99.1 \%$ & $100 \%$ & $100 \%$ & $0 \%$ \\
\hline $\mathrm{PM}$ and CM & $15.0 \%$ & $26.9 \%$ & $59.4 \%$ & $81.6 \%$ & $90.2 \%$ & $9.8 \%$ \\
\hline $\mathrm{PM}, \mathrm{CM}$ and Test & $13.2 \%$ & $25.1 \%$ & $55.3 \%$ & $80.0 \%$ & $89.4 \%$ & $10.6 \%$ \\
\hline
\end{tabular}

${ }^{1}$ This value indicates that $33.1 \%$ of the EDGs studied had EDG unavailability due to PM during power operation, i.e., $\mathrm{U}_{\mathrm{p}, \mathrm{PM}}$, smaller than or equal to 0.007 .

${ }^{2}$ The distribution of the unavailability due to testing, i.e., $\mathrm{U}_{\mathrm{p}, \mathrm{T}}$, is based on 117 EDGs. 
Table 2.3. Mean and Standard Deviation of the Duration and Frequency of Maintenance and Test Activities During Power Operation

\begin{tabular}{|c|c|c|c|c|c|}
\hline \multirow{2}{*}{ Activity } & \multicolumn{2}{|c|}{$\begin{array}{l}\text { Duration of Act } \\
\text { (hours) }\end{array}$} & \multicolumn{3}{|c|}{$\begin{array}{l}\text { Frequency of Act } \\
\text { (per year) }\end{array}$} \\
\hline & Mean & $\begin{array}{l}\text { Standard } \\
\text { Deviation }\end{array}$ & Meain & Median & $\begin{array}{l}\text { Standard } \\
\text { Deviation }\end{array}$ \\
\hline PM & 24.6 & 37.6 & 5.5 & 2.8 & 12.9 \\
\hline CM & 23.3 & 46.7 & 3.3 & 2.5 & 2.8 \\
\hline Test $^{1}$ & 2.2 & 6.9 & -- & -- & - \\
\hline $\mathbf{P M}$ and $\mathrm{CM}^{2}$ & -- & -- & 8.8 & 2.8 & 13.2 \\
\hline
\end{tabular}

${ }^{1}$ The values for test are based on only 117 EDGs for which the test data were available. These data on test duration are less reliable than the corresponding data on PM or CM, because some utilities did not include, in their EDG data, the periodic tests which are routinely performed as required by the plantspecific Technical Specifications.

Table 2.4. Mean, Median, and Standard Deviation of the EDG Unavailability Due to Maintenance and Testing During Plant Shutdown

\begin{tabular}{|c|c|c|c|}
\hline \multirow{2}{*}{ Activity } & \multicolumn{3}{|c|}{ EDG Unavailability During Plant Shutdown } \\
\hline & Mean & Median & $\begin{array}{l}\text { Standard } \\
\text { Deviation }\end{array}$ \\
\hline PM & 8.34E-2 & $8.05 E-2$ & $1.03 \mathrm{E}-1$ \\
\hline $\mathrm{CM}$ & 3.24E-2 & $2.90 \mathrm{E}-2$ & $6.86 \mathrm{E}-2$ \\
\hline Test $^{1}$ & $7.11 \mathrm{E}-3$ & $2.07 \mathrm{E}-3$ & $1.94 \mathrm{E}-2$ \\
\hline $\mathrm{PM}$ and $\mathrm{CM}$ & $1.15 \mathrm{E}-1$ & $1.02 \mathrm{E}-1$ & $1.11 \mathrm{E}-1$ \\
\hline
\end{tabular}

${ }^{1}$ The values for test are based on only 75 EDGs at 43 plant units, less than a half of the EDG population for which the industry provided the EDG outage data for plant shutdown. 
Table 2.5. Cumulative Distribution of the EDG Unavailability Due to Maintenance and Testing During Plant Shutdown

\begin{tabular}{|c|c|c|c|c|c|}
\hline \multirow{2}{*}{ Activity } & \multicolumn{5}{|c|}{ EDG Unavailability During Plant Shutdown } \\
\hline & $\leq 0.1$ & 50.2 & $\leq 0.3$ & $\leq 0.4$ & $>0.4$ \\
\hline PM & $56.2 \%^{1}$ & $83.2 \%$ & $93.4 \%$ & $98.5 \%$ & $1.5 \%$ \\
\hline CM & $83.5 \%$ & $97.1 \%$ & $99.0 \%$ & $99.0 \%$ & $1.0 \%$ \\
\hline Test $^{2}$ & $97.3 \%$ & $100 \%$ & $100 \%$ & $100 \%$ & $0 \%$ \\
\hline $\mathbf{P M}$ and $\mathrm{CM}$ & $48.1 \%$ & $78.4 \%$ & $92.6 \%$ & $97.5 \%$ & $2.5 \%$ \\
\hline PM, CM and Test & $50.0 \%$ & $78.2 \%$ & $92.9 \%$ & $97.6 \%$ & $2.4 \%$ \\
\hline
\end{tabular}

${ }^{1}$ This value indicates that $56.2 \%$ of 170 EDGs, for which data on EDG outage during plant shutdown were provided, had $U_{s, P M}$ smaller than or equal to 0.1 .

${ }^{2}$ The distribution of the unavailability due to testing, i.e., $\mathrm{U}_{\mathrm{p}, \mathrm{T}}$, is based on 75 EDGs. 


\section{ANALYSIS OF EDG FAILURE DATA}

This section presents an analysis of EDG failure probability using recent industry-wide data. In addition to EDG test and maintenance unavailability, EDG failure unavailability comprises the remainder of individual EDG unavailability. In essence, the primary motivation in test and maintenance is to reduce EDG failure unavailability. This section presents a method for, and the results of analyzing failure data from a population of EDGs to understand the failure behavior over a period.

The objectives of this analysis are as follows:

a) to obtain EDG failure distributions from the industry-wide data on start or load-run demands of EDGs,

b) to generate a smoothed distribution of EDG failure probability from the EDG failure data assuming similar performance over the entire population (using empirical Bayes methods),

c) to estimate the statistical characteristics of the failure probability distributions (such as mean, median, and variance) for PSA applications, and

d) to fit the failure probabilities to traditionally used distributions in PSA applications (lognormal and beta).

The empirical Bayes method used here to analyze the failure data gives individual and population estimates where each failure probability is treated as a sample value from an underlying population distribution. The mean estimate of the population, obtained using the Bayes method, is shown to be the same as that obtained as a simple estimate, i.e., by dividing the number of failures by the number of demands. However, the use of a simple estimate would give an unrealistic zero failure probability for many diesels where no failure is observed for the limited observation period. The individual estimates of failure probability obtained using empirical Bayes method take into account the failure data from other members of the population; the lack of data for a particular member of the population is not a serious concern. The population distribution then can be used directly to identify those diesels with higher or lower failure probability than that expected in the population.

The analysis of EDG failures uses industry-wide data over four years, 1988 to $1991 .^{13}$ The data covers 195 EDGs at 63 plant sites, i.e., about 84 percent of the EDGs, as opposed to $92 \%$ of the EDGs used in the analysis of maintenance unavailability. This data period partly overlaps with that for the maintenance data. The data include both actual and test demands, but do not discriminate between these two types of demands or failures.

\subsection{Definitions}

In this section we define EDG start and EDG load-run failures.

EDG start failures include any failure within the emergency generator system that prevents the generator from achieving specified frequency (or speed) and voltage. The EDG should be started in the ambient condition and accelerate to the required speed within the time specified in the Technical Specification of the plant. EDG load-run failures are counted when the EDG starts but does not pick up load and run successfully. This includes conditions where the diesel generator does not function properly 
and must be either manually tripped, or is automatically tripped, prior to the completion of the run-time. Failures that occur during the run-time are counted as a load-run failure. Tripping the diesel for an incipient condition that would not prevent successful operation of the diesel in an actual demand is not counted as a valid run test or failure to run.

EDG unavailability due to failure to start is the probability that the EDG fails to start as defined above due to undetected failures during the stand-by period or due to the demand on the EDG. EDG unavailability due to failure to load-run is the probability that the EDG will fail to load and successfully run for the required duration given a successful start. Method for estimating these failure probabilities or the associated EDG unavailabilities, based on the number of failures and the number of demands, is discussed below.

EDG unavailability due to failures or failure probability is simply the sum of these two probabilities: failure probability to start and failure probability to load-run, neglecting the intersection term which is small.

In PSA applications, EDG failure to load-run is expressed in per unit hour. This rate is converted into a probability depending on the number of hours the EDG is required to successfully run in response to a demand. Since the database did not provide the load-run durations, here the EDG failure probability to load-run is estimated and an approximate method for converting this probability to a per-hour rate is provided.

\subsection{Empirical Bayes Approaches: Methodology}

The diesel failure data consist of the number of demands $n_{i}$ and number of failures $f_{i}$ per year for each diesel in a given plant. The data are divided into numbers of start failures and numbers of load failures and the associated numbers of demands.

Our main objective was to determine the distribution of failure probabilities across the population of individual diesels and plants. Estimates of failure probabilities for individual diesels and for all diesels in a given plant are obtained as part of this analysis.

For data such as this, empirical Bayes approaches provide individual and population estimates with desirable statistical properties. ${ }^{14,15.16}$ Shultis et al. ${ }^{17}$ compared different empirical Bayes methods. The empirical Bayes estimates of failure probabilities have minimum mean square errors and outperform the simple failure probability estimates constructed from the number of failures divided by the number of demands. Also, uncertainty distributions are obtained, which can be used in uncertainty propagations in Probabilistic Safety Assessments (PSAs).

References 14, 15, and 16 give the general bases and optimal characteristics of empirical Bayes approaches. References 17, 18, and 19 describe algorithms and applications to failure and demand data. We summarize, below, the basic empirical Bayes methodology with the equations that are used to obtain the failure probability estimates.

Each diesel failure probability is treated as being a sample value from an underlying population distribution. The observed number of diesel failures in a given number of demands provides information on the individual probability, and also on the characteristics of the underlying failure probability distribution. The failures and demands observed for different diesels first are used to infer characteristics 
of the distribution of the underlying failure probabilities. For a given diesel, its observed failures and demands as well as those for the other diesels in the population then are used to obtain an optimal estimate of the diesel failure probability having minimal error.

The empirical Bayes estimate of the individual diesel failure probability is an optimally weighted average of the simple individual diesel failure probability and the population average. Let

$\bar{p}_{i}=$ the empirical Bayes estimate of the diesel failure probability for diesel $\mathbf{i}$

$\hat{p}_{i}=$ the simple failure probability estimate for the diesel defined as the number of diesel failures over the diesel demands

$\hat{\mu}=$ the average failure probability estimate for the total population

The empirical Bayes estimate $\bar{p}_{i}$ is then given by

$$
\bar{p}_{i}=\frac{1}{1+w_{i}} \hat{p}_{i}+\frac{w_{i}}{1+w_{i}} \hat{\mu}
$$

where $w_{i}$ is an optimal weight determined to minimize the mean square error associated with $\bar{p}_{i}$.

If all the diesels basically have the same failure probability within insignificant variations, then the estimate of individual probability with minimal error would simply be the average population estimate $\hat{\mu}$. If individual diesel failures show no pattern or relationship with one another, or if there is a large amount of data for the individual diesel, then the optimal failure probability for the individual diesel would be the simple estimate $\hat{\mathrm{p}}_{\mathrm{i}}$. In these special cases, the empirical Bayes estimate simplifies to these limiting estimates. For all other cases and for any given population, the empirical Bayes estimate used the optimal weighing of these two boundary estimates, where the weights are based on the amount of data for the diesel, and the pattern of failure behavior for the whole population.

The following is a summary of the steps used in applying the empirical Bayes approach.

\subsubsection{Estimation of the Mean and Variance of the Failure Probability Distribution}

The basic data consist of the observed demands $n_{i}$ and failures $f_{i}$ for each component $i$ in a given population. The component can be the individual diesel, or an aggregation of all the diesels in a station if we focus on the overall failure probability per plant. Each component has an underlying failure probability $p_{i}$ which is not observed. The objective is to estimate the failure probability for each component and the characteristics of the distribution of failure probabilities for the given population. In the Bayesian approach, a prior distribution is assigned to $p_{i}$ based on prior knowledge and judgment. In the empirical Bayes approach, the data $\left(n_{i}, f_{i}\right)$ are used to estimate the distribution characteristics of the failure probabilities $p_{i}$.

The basic characteristics used to describe the population are the mean and variance of the distribution of failure probabilities. We consider estimates which were used by Copas $^{19}$ to construct empirical Bayes method. These unbiased estimates do not depend upon any assumed shape for the population distribution; we simply give the equations for these estimates. The reader is referred to 
Reference 19 for the theoretical bases. Shultis et al. ${ }^{17}$ evaluated various empirical Bayes estimates and identified alternative estimates which had small bias and uncertainties when there were relatively few failures for each unit; we also give equations for these alternatives. Both sets of estimates gave similar results when applied to the diesel data.

Let $\mu$ be the mean of the distribution of failure probabilities $p_{i}$ for all the components in the population and let $\sigma^{2}$ be the variance of the distribution of failure probabilities across all units in the population. A component can be an individual diesel or an aggregate of all the diesels in a given station. Both Martz et al. ${ }^{18}$ and Shultis et al. ${ }^{17}$ identified the optimal estimate $\hat{\mu}$ of the mean of the population to be:

$$
\hat{\mu}=\frac{1}{\mathrm{~N}} \sum_{\mathrm{i}=1}^{\mathrm{N}} \hat{\mathrm{p}}_{\mathrm{i}},
$$

where $\hat{p}_{i}$ is the simple estimate of the failure probability for the $\mathrm{i}$-th component,

$$
\hat{p}_{i}=\frac{f_{i}}{n_{i}}
$$

here $f_{i}$ is the observed number of failures, and $n_{i}$ the number of demands for the $i$-th component. $N$ is the total number of components in the population. The optimal estimate of the mean of the failure probabilities in the population thus is simply the average of the individual estimates of failure probability $\hat{\mathrm{p}}_{\mathrm{i}}$.

Copas $^{19}$ used the unbiased estimate of the variance of the failure probabilities in the population:

$$
\hat{\sigma}^{2}=\frac{1}{\mathrm{~N}-\mathrm{k}}\left\{\sum_{\mathrm{i}=1}^{\mathrm{N}}\left(\hat{\mathrm{p}}_{\mathrm{i}}-\hat{\mu}\right)^{2}-\mathrm{k} \hat{\mu}(1-\hat{\mu})\right\},
$$

where

$$
k=\sum_{i=1}^{N} \frac{1}{n_{i}} .
$$

The first term in the estimate is basically the variance of the simple component estimates $\hat{\mathbf{p}}_{i}$ and the second term is a correction term. A potential problem is that this estimate can be negative; then, $\hat{\sigma}$ is set to zero with the interpretation that there are no significant differences among the underlying failure probabilities. 
Shultis et al. ${ }^{17}$ identified a modified variance estimate $\hat{\sigma}_{\mathrm{m}}{ }_{\mathrm{m}}$ which is similar to the unbiased estimate but which did not become negative, and is calculated using the formula.

$$
\hat{\sigma}_{m}^{2}=\frac{1}{N-1} \sum_{i=1}^{N}\left(\hat{p}_{i}-\hat{\mu}\right)^{2}
$$

This modified estimate is simply the variance of the simple failure probability estimates $\hat{p}_{\mathrm{i}}$, which Shultis et al. found to have near optimal statistical properties.

\subsubsection{Estimates of Individual Failure Probabilities}

As Copas $^{19}$ identified, the population mean and variance estimates, $\hat{\mu}$ and $\hat{\sigma}^{2}$, can be used to obtain the optimal estimate of the failure probability $p_{i}$ for each component. This estimate optimally combines both the individual component data $\left(n_{i}, f_{i}\right)$ and the population data. The optimal estimate is a form of James-Stein estimate which consists of a weighted average of the simple component estimate $\hat{p}$ with the population average estimate $\hat{\mu}$. The optimal estimate $\bar{p}_{i}$ of each component failure probability is calculated from the formula,

$$
\bar{p}_{i}=\frac{1}{1+w_{i}} \hat{p}_{i}+\frac{w_{i}}{1+w_{i}} \hat{\mu}
$$

where

$$
w_{i}=\frac{\hat{\mu}(1-\hat{\mu})-\hat{\sigma}^{2}}{n_{i} \hat{\sigma}^{2}} .
$$

The quantity $n_{i}$ is again the number of demands for component $i$. The estimate $\bar{p}_{i}$ is also called a shrunken estimate since the simple estimate $\hat{p}_{i}$ is shrunk toward the population mean. When $\hat{\sigma}^{2}$ is set to zero, then $w_{i}$ is infinity and the estimate $\bar{p}_{i}$ is equal to the population mean estimate $\hat{\mu}$. The alternative variance estimate $\hat{\sigma}_{\mathrm{m}}^{2}$ can be used in the above equations and, as determined by Shultis et al., will give a near optimal estimate.

\subsubsection{Fitting the Failure Probability Distribution with a Beta Distribution}

The estimates $\hat{\mu}$ and $\hat{\sigma}^{2}$ can be used to fit a given distribution to the failure probabilities. This distribution completely describes the variation and pattern in the failure probabilities. The distribution of failure probability can be used in PSAs in uncertainty propagations. We describe fitting a beta distribution, since it is a standard distribution used for failure probabilities; in the next section, we describe the alternative of fitting a lognormal distribution.

The beta distribution often is used in reliability applications because it simplifies Bayesian updating calculations. ${ }^{16}$ When the distribution of component failure probability is described by a beta distribution, then the density function $g(p)$ for the failure probability $p$ has the form 


$$
g(p)=\frac{p^{a-1}(1-p)^{b-1}}{B(a, b)}
$$

where $a$ and $b$ are the parameters of the beta distribution. $B(a, b)$ is the normalizing factor,

$$
\begin{gathered}
B(a, b)=\int_{0}^{1} p^{a-1}(1-p)^{b-1} d p \\
=\frac{\Gamma(a) \Gamma(b)}{\Gamma(a+b)}
\end{gathered}
$$

where $\Gamma(x)$ is the standard gamma function.

The values of the parameters $a$ and $b$ can be estimated from $\hat{\mu}$ and $\hat{\sigma}^{2}$ by determining the mean and variance of $g(p)$ and setting the expressions equal to $\hat{\mu}$ and $\hat{\sigma}^{2}$, respectively. Estimates for $a$ and $b$ then are determined in terms of $\hat{\mu}$ and $\hat{\sigma}^{2}$. These estimates are

$$
\hat{\mathbf{a}}=\frac{\hat{\mu}^{2}}{\hat{\sigma}^{2}}(1-\hat{\mu})-\hat{\mu}
$$

and

$$
\hat{\mathrm{b}}=\frac{\hat{\mu}}{\hat{\sigma}^{2}}(1-\hat{\mu})^{2}+\hat{\mu}-1
$$

These estimates of $\hat{a}$ and $\hat{b}$, which are moment estimates, were found to have optimal statistical properties by Shultis et al. ${ }^{12}$ The alternate estimate $\hat{\sigma}_{\mathrm{m}}{ }^{2}$ may be used in place of $\hat{\sigma}^{2}$ in the above equations. With $\hat{a}$ and $\hat{b}$ determined, and using the beta distribution, the complete distribution for the component failure probabilities is determined.

\subsubsection{Fitting the Diesel Failure Probability Distribution with a Lognormal Distribution}

The lognormal distribution is also used in PSAs to describe the failure probability distributions. Since the lognormal distribution can give probabilities greater than one, the probabilities are truncated at unity. The lognormal density function $h(p)$ for the failure probability $p$ is given by the formula 


$$
h(p)=\frac{1}{\zeta p \sqrt{2 \pi}} \exp \left[-\frac{1}{2}(\ln p-\alpha)^{2} / \zeta\right]^{2}
$$

where "exp" denotes the exponential function and "ln" denotes the natural logarithm. The two parameters of the lognormal distribution are $\alpha$ and $\zeta$.

If $\mu$ and $\sigma^{2}$ denote the mean and variance of the failure probability $\mathrm{p}$ then using the lognormal distribution, $\mu$ and $\sigma^{2}$ are related to $\alpha$ and $\zeta$ by the formulas:

$$
\mu=\exp \left(\alpha+\frac{1}{2} \xi^{2}\right)
$$

and

$$
\sigma^{2}=e^{2 \alpha} e^{\xi^{2}}\left(\mathrm{e}^{\xi^{2}}-1\right)
$$

These two equations may be used to solve for $\alpha$ and $\zeta$ in terms of $\mu$ and $\sigma^{2}$. Using the empirical Bayes estimates, the results are

$$
\hat{\zeta}=\sqrt{\ln \left(\frac{\hat{\sigma}^{2}}{\hat{\mu}^{2}}+1\right)}
$$

and

$$
\hat{\alpha}=\ln \hat{\mu}-\frac{1}{2} \hat{\zeta}^{2}
$$

In the above, the estimate $\hat{\zeta}$ is first calculated and then used in the formula for $\hat{\alpha}$. The estimates $\hat{\zeta}$ and $\alpha$ may then be used in the lognormal distribution formula to completely describe the failure probability distribution.

\subsection{Analysis of Diesel Failure Data Using Empirical Bayes Approaches}

The following sections apply empirical Bayes approaches to the diesel failure data to obtain estimates of individual failure probabilities. These approaches also are used to obtain estimates of the characteristics of the distribution of failure probabilities over the population of individual diesels. The diesel failure data are furthermore aggregated over all individual diesels in a given plant site to obtain estimates of diesel failure probabilities by plant site, and estimates of the characteristics of the distribution of diesel failure probabilities over plant sites. 


\subsubsection{Diesel Failure Data Used}

The diesel failure data set consists of the number of start failures, the number of starts, the number of load-runs failures, and the number of load-runs per year for each individual diesel in 63 plant sites for 1988 through 1991. These four parameters are summed over the four years to obtain the aggregated data which is used for the evaluations. The starts and load-runs include both surveillance tests and actual demands of the diesels during operation. For plant site evaluations, the individual diesel failures, starts, and load-runs are summed over all diesels to obtain the plant site aggregated data. Appendix $\mathrm{C}$ shows the diesel failure data used in this analysis. Table C. 1 gives the four year totals by each parameter for individual diesels and Table C. 2 gives the year totals by plant site.

\subsubsection{Limitations and Assumptions in the Analysis}

The characteristics of the data on diesel failures implied certain assumptions, and, to some extent, defined the types of analyses that can be performed. These items are discussed below:

a) The data covered $84 \%$ of the EDGs in use at operating nuclear power plants. This database was supplied by NUMARC, an industry organization. The data were accepted and used as is.

b) The database did not identify the plants nor the dates on which the failures were discovered, which precluded analyses of this data in conjunction with the test and maintenance data; i.e., for example, no analysis was performed to correlate EDGs with high maintenance unavailability to correspondingly lower failure unavailability, or vice versa.

c) The data did not distinguish between test demands and actual demands during operation. Accordingly, we could not determine whether the failure characteristics of actual demands differ from the test demands.

d) The data also do not distinguish between failures discovered during power operation from those during shutdown. However, the failure characteristics during power operation versus shutdown were not expected to differ significantly.

e) The EDG failure to load-run is estimated on failure per-demand basis, as opposed to failure rate (/hr.) basis. This is because the database used didn't provide the load-run durations. Typically, data on diesel load-runs are obtained from two types of surveillance tests and actual demands. Monthly surveillance tests are usually of 1 hour duration and a 24 hour test is run every 18 months. EDG run duration for actual demands varies. When the failure data include the type of load-run demands and/or the durations, then an estimate of EDG failure to load-run rate in per unit time can be obtained. An approximate approach for converting the load-run failure probabilities to a failure rate is presented.

f) The EDG load-run failure rate when estimated from this analysis and is used in PSA applications is converted to the EDG failure probability for a given scenario using the duration for which the diesel is required to run. In most of the loss-of-offsite power situations, the diesel is needed to run longer than 1 hour, but diesel failure to run estimates for different durations are not separately available. This assumption of estimating diesel failure to run on per-hour basis and assuming it to remain constant for the durations for which the diesel may be required is typical of PSAs performed for nuclear power plants. 
g) Common-cause failures of EDGs were not identified, nor could such information be extracted from this data base. It is assumed that the common-cause failures are included in individual EDG failures.

\subsubsection{Specific Failure Probabilities Evaluated}

For individual diesels and for plant sites, the following failure probabilities are of interest:

- probability of failure to start;

- probability of failure to load and run.

\subsubsection{Mean and Variance of the Failure Probabilities Over the Population}

Using the empirical Bayes approach, Table 3.1 gives the estimates of the mean, variance, and standard deviation of the failure probabilities over the population of individual diesels, and the population of plant sites. Alternative variance and standard deviation estimates are shown in parentheses. These alternative estimates (see Equ. 9) are generally conservative, since they do not involve the correction term used for the standard empirical Bayes estimates (Equ. 7). For comparison, the simple estimates of the means also are shown, calculated as the total number of failures over the population divided by the total number of starts or load-runs. The empirical Bayes means of the populations are similar to the simple means. The variances and standard deviations indicate a relatively large spread in failure probabilities among individual diesels and among plant sites.

\subsubsection{Diesel Failure Probabilities (Individual and Plant Sites)}

Figure 3.1 is a histogram of simple estimates of failure to start probabilities for individual diesels; Figure 3.2 shows the failure to load-run probabilities for individual diesels. These graphs summarize simple probabilities (ratios of amount of failures to amount of starts or load-runs) for 195 diesels over 4 years. For example, in Figure 3.1 we see that about $56 \%$ of diesels have failure probability to start [0.-0.0025].

Appendix D presents the simple and empirical Eayes estimates for individual diesels and for plant sites. Table D.1 gives the individual diesel failure probabilities: simple estimate of failure probability to start, simple estimate of failure probability to load-run, empirical Bayes probability to start, empirical Bayes probability to load-run. Table D.2 gives the corresponding failure probabilities for each plant site. The simple estimates are obtained by dividing the number of failures by the respective number of starts or load-runs (or their sum for the failure probability estimates). The empirical Bayes estimates are weighted averages of the simple estimates and population means, where the weights are chosen to minimize uncertainties in the estimations.

\subsubsection{Histograms of the Individual and Plant Site Diesel Failure Probabilities}

To provide a perspective on the shapes of the distributions, Figures D.1 through D. 8 in Appendix $\mathrm{D}$ display the histograms of the individual diesel failure probabilities and the plant site failure probabilities which were tabulated in the previous tables. The failure probabilities illustrated are the empirical Bayes estimates. (The simple failure probability estimates have many zero probability values because of observed zero failures, and their distribution plots are not particularly informative). The 30 bar 
histogram shows the grosser structure of the distribution, and the 60 bar histogram shows its finer structure. The histograms show clumpings of the failure probabilities, which indicate distinct subgroups of diesels with different failure behavior.

Box-whisker plots were used to represent diesel failure probabilities. These plots conveniently show the spread of the data and the outliers. Appendix E presents the box-whisker plots of empirical Bayes probabilities for diesel failures.

\subsubsection{Fitting a Beta Distribution to the Population of Failure Probabilities}

The population of individual diesel failure probabilities or plant site failure probabilities can be fitted to a parameter distribution for more concise description, and for application in PSAs. Table 3.2 gives the parameters for the beta distribution, which are obtained by equating the mean and variance of the beta distribution to those of the population.

Figures F.1 through F.4 in Appendix F illustrate the fits of the beta distribution to the populations of the failure to start and failure to load-run probabilities. A small number of histograms is used since the beta distribution is not intended to describe the detailed structure of the population. Since the beta distributions have the same mean and variance as the detailed failure probabilities, they describe the general variation of the failure probabilities. However, the plots indicate that the beta distributions tend to be more continuous and more spread out than the detailed histograms of the failure probabilities. The fits to the plant site failure probabilities are better because of the smoothing due to aggregating all diesels in a plant site.

These distributions can be used to calculate the statistical characteristics of the failure probabilities. For example, the 95 th percentile value $\mathrm{Z}$ is defined as the value such that with $95 \%$ probability all diesel probabilities are less than $Z$. In this case, 95 th percentile value for individual diesel failure to start beta distribution equals 0.010 , and 95 th percentile value for individual diesel failure to load-run beta distribution equals 0.0234 .

\subsubsection{Fitting a Lognormal Distribution to the Population of Failure Probabilities}

The population of individual diesel failure probabilities or plant site failure probabilities can also fit a lognormal distribution, which is commonly used in PSAs. Table 3.3 gives the lognormal distribution parameters which are obtained by equating the mean and variance of the lognormal distribution to those of the population of empirical Bayes failure probability estimates; if the failure probabilities surpass this value, they should be truncated at unity.

Figures F.5 through F.8 in Appendix F illustrate the lognormal fits for the failure to start and failure to load-run probabilities. Like the previous beta distribution fits, the lognormal fits tend to smooth out the population distribution providing the same mean and variance, but not reflecting the detailed structure. 
Lognormal distributions can be used for PSA applications. For example, the 95th percentile value for individual diesel failure to start lognormal distribution equals 0.010 , and the 95 th percentile value for individual diesel failure to load-run lognormal distribution equals 0.0228 .

\subsubsection{Conversion of the Mean Failure to Load-Run Probabilities to a Failure Rate}

For PSA applications, the mean failure to load-run probabilities can be roughly converted to a failure rate $(/ \mathrm{hr}$.) as follows. Consider the simple estimate for the population means. Here, the mean EDG load-run failure probability is obtained from a database for 195 EDGs which includes 182 load-run failures and 19,520 load-run demands. We assume that each of the 24 hour tests is scheduled at an interval of 18 months averaging 2.67 of this type of test for each EDG over 4 years. The remaining load-run demands consist of monthly surveillance tests and actual demands where the average duration is 1 hour. This implies 520 EDG test of 24 hours over 4 years and 19,000 load-run demands of 1 hour with a total run-time of 31,480 hours. Dividing the number of failures by the run-time we obtain EDG load-run failure rate as $5.8 \times 10^{-3} / \mathrm{hr}$.

\subsubsection{Additional Statistical Analysis}

The diesel failure probabilities obtained from Empirical Bayes analyses can be used to solve the reverse problem, i.e., predict failure statistics with known failure probabilities, assuming a binomial distribution of failures for each individual diesel, if failure probability and amount of trials is known. Appendix G compares the failure statistics for the diesels and predictions based on binomial distribution. Regression analysis is used to tune further parameters of empirical Bayes estimators to fit actual failure statistics and failure statistics predicted with binomial distributions. These results also are presented in Appendix G.

\subsection{Summary of Results}

In this chapter, we discussed our analysis of EDG failure probability using industry-wide failure data for 195 EDGs (about 84\% of the EDGs) over four years, 1988-1991. The empirical Bayes method was used to obtain estimates of the individual and plant site diesel failure probabilities and for the diesel population. The results also were fitted to standard lognormal and beta distributions for use in PSAs.

The EDG failure probability was separately estimated in terms of the probability of failure to start and failure to load-run. The overall EDG failure probability is simply the sum of the probabilities of failure to start and load-run, which is 0.014 . This value is lower than the generic estimate used in the PSAs. This estimate also is slightly smaller than the previous estimate 0.02 reported for $1981-83^{20}$ and 0.019 reported in $1984 .^{25}$ The 1984 estimate is based on the responses to NRC Generic Letter 84-15. The data collected there showed a failure probability of 0.019 for previous 20 starts and 0.023 for previous 100 starts.

Using the empirical Bayes methods, the individual failure probabilities for EDGs were obtained, which are slightly different than the simple estimates. Both the simple estimate and the empirical Bayes estimates for individual EDGs are presented in Appendix D. The empirical Bayes estimates provide a smooth distribution (Appendix F), and, as indicated in the box-whisker plots (Appendix E), the portion of the EDG population whose failure probability is significantly higher than the rest can be identified. 
The mean diesel failure probability estimated in this study is comparable to that reported for Swedish and Finnish plants ${ }^{21}(0.014$ for $1980-89)$, but higher than that for German plants ${ }^{11}(0.005$ for 1981-87).

The analysis presented in this chapter can be used to assess diesel performance over the industry and to delineate any overall trend in the failure data. 


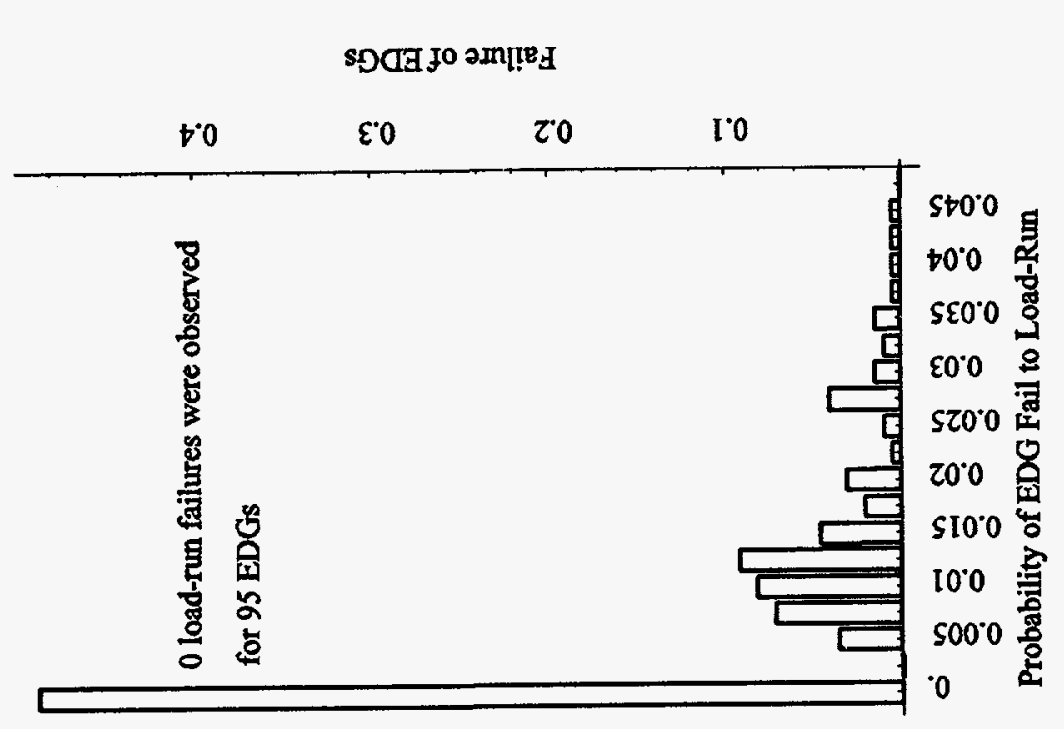

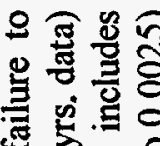

E.

出诸

记焉

四

跑饮

웡.

눙

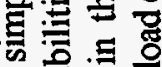

4 융ㅇ

혀을

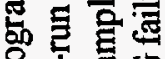

客密

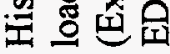

몸
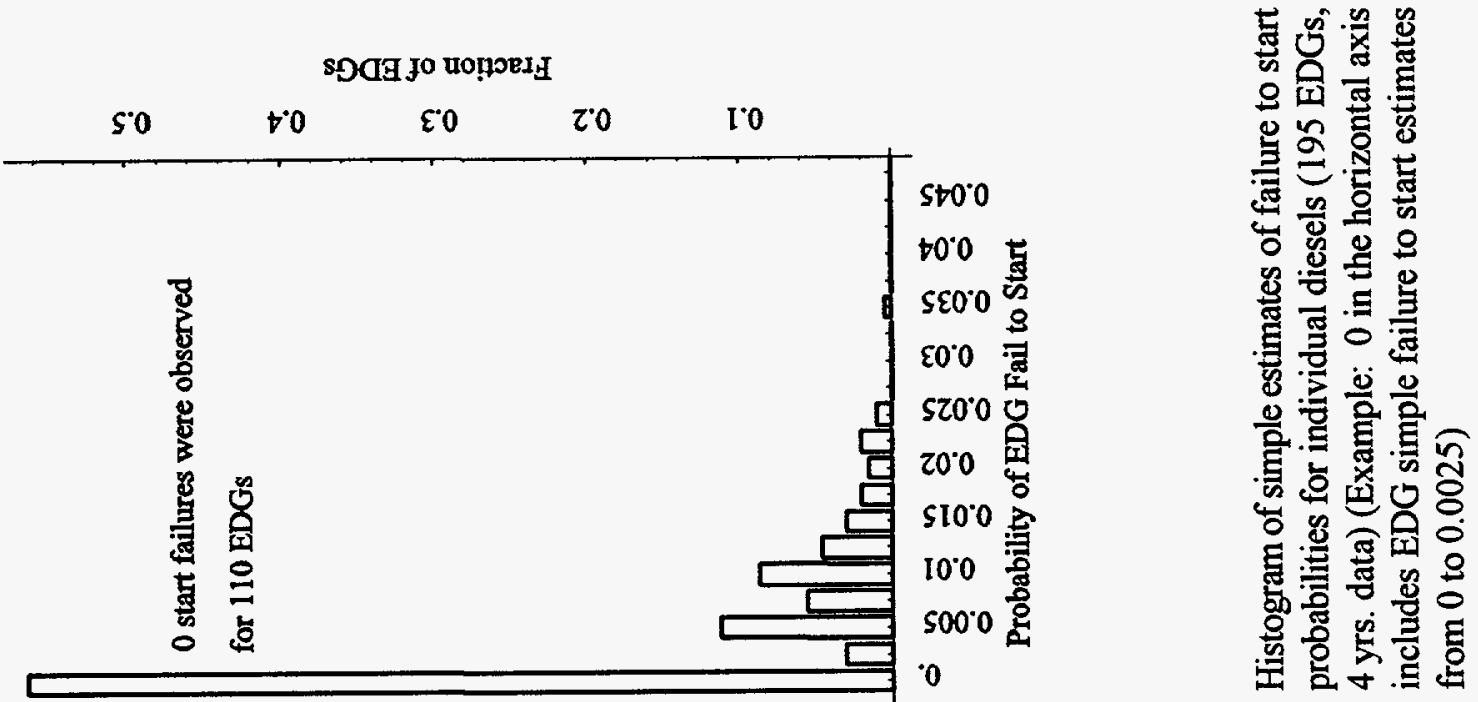

r 
Table 3.1 Mean, Variance, and Standard Deviation of Diesel Failure Probabilities Over Individual Diesels and Over Plant Sites

\section{Empirical Bayes Estimates}

\begin{tabular}{|c|c|c|c|}
\hline \multicolumn{4}{|c|}{ Individual Diesels. } \\
\hline & Mean & Variance $^{\dagger}$ & Standard Deviation $^{\dagger}$ \\
\hline Failure to start & $5.0 \mathrm{E}-03$ & 8.6E-06(5.0E-05) & $2.9 \mathrm{E}-03(7.0 \mathrm{E}-03)$ \\
\hline Failure to load-run & $9.6 \mathrm{E}-03$ & $5.1 E-05(1.6 E-04)$ & 7.1E-03(1.3E-02) \\
\hline
\end{tabular}

\section{Empirical Bayes Estimates}

\begin{tabular}{||l|c|c|c|}
\hline \multirow{2}{*}{} & \multicolumn{3}{|c|}{ Plant Sites } \\
\hline \hline & Mean & Variance $^{\dagger}$ & Standard Deviation $^{\dagger}$ \\
\hline Failure to start & $5.2 \mathrm{E}-03$ & $1.4 \mathrm{E}-05(3.0 \mathrm{E}-05)$ & $3.7 \mathrm{E}-03(5.5 \mathrm{E}-03)$ \\
\hline Failure to load-run & $9.5 \mathrm{E}-03$ & $2.9 \mathrm{E}-05(7.3 \mathrm{E}-05)$ & $5.4 \mathrm{E}-03(8.5 \mathrm{E}-03)$ \\
\hline
\end{tabular}

'Estimated using unbiased estimate, presented in Equ. 7; an alternate estimate, as discussed in Equ. 9, is presented in parenthesis.

Simple Estimates

\begin{tabular}{||l|c|}
\hline \multicolumn{2}{|c|}{ Simple Population Means } \\
\hline \hline Failure to start & $5.0 \mathrm{E}-03$ \\
\hline Failure to load-run & $9.3 \mathrm{E}-03$ \\
\hline
\end{tabular}


Table 3.2 Beta Distribution Parameters

\begin{tabular}{|l|c|c|}
\hline \hline & $\mathbf{a}$ & $\mathbf{b}$ \\
\hline & 2.89 & 575.7 \\
\hline Failure to start & 1.78 & 184.2 \\
\hline Failure to load & Individual Diesels & \\
\hline
\end{tabular}

\begin{tabular}{|l|c|c|}
\hline & Plant Sites & \\
\hline \hline & $\mathbf{a}$ & $\mathbf{b}$ \\
\hline Failure to start & 1.95 & 374.5 \\
\hline Failure to load & 3.09 & 320.7 \\
\hline
\end{tabular}

Table 3.3 Lognormal Distribution Parameters

\begin{tabular}{||l|c|c||}
\hline \hline & $\alpha$ & \multicolumn{1}{|c|}{ Individual Diesels } \\
\hline \hline Failure to start & -5.45 & 0.544 \\
\hline Failure to load & -4.87 & 0.664 \\
\hline
\end{tabular}

\begin{tabular}{||l|c|c||}
\hline & Plant Sites \\
\hline \hline & $\alpha$ & $\zeta$ \\
\hline Failure to start & -5.47 & 0.642 \\
\hline Failure to load & -4.79 & 0.527 \\
\hline
\end{tabular}




\section{ASSESSMENT OF THE RISK IMPACT OF EDG UNAVAILABILITY}

In the previous chapters, we assessed EDG unavailability due to testing and maintenance and from failure to start and load-run on demand. Here, we assess the risk impact of EDG maintenances and failures during power operation of nuclear power plants in terms of core-damage frequency (CDF). Assessment of the sensitivity of CDF contributions attributable to maintenance and failure provide a riskperspective of the relative effects of maintenances performed on, and failures experienced by, the EDGs.

The objectives of this analysis can be summarized as follows:

a) to assess the contribution of EDG unavailability due to maintenance on core-damage frequency of selected nuclear power plants,

b) to compare the risk sensitivity of EDG maintenance unavailability versus EDG failure to start and load-run during power operations, and

c) to evaluate the risk impact of scheduling EDG maintenances with other components, for example, in a rolling maintenance schedule.

The risk impact of EDG maintenance was evaluated using the PSAs for six nuclear power plants; two pressurized water reactor (PWR) plants - Surry Unit 1 and Sequoyah Unit 1; and four boiling water reactor (BWR) plants - Grand Gulf, Peach Bottom Unit 2, and Brunswick Units 1 and 2. These plants were chosen because their computerized PSA models are available. However, they represent four different EDG manufacturers, different EDG configurations, different TS requirements for allowed outage times (AOTs), different maintenance unavailabilities (presented in Appendix B, ranging from a high contributor to a low contributor), and varying risk (CDF) levels for performing EDG maintenance during power operation. Thus, the risk analyses for those plants are a good sample of the impact of EDG unavailability at the nuclear power plants in the United States.

\subsection{Risk Measures Used in the Calculation}

The effects of EDG maintenance and failure are calculated in terms of the impact on core-damage frequency of the plant. The overall impact depends on several factors, e.g., dominance of the loss-ofoffsite power accident sequences at plants where EDGs are needed, number of EDGs available, EDG unavailabilities due to maintenance and failure, and common-cause failure of EDGs. Since our focus is on assessing the impact of EDG unavailabilities due to maintenance and failure, the risk measures defined are related to observing the effect of variation of these contributions to the CDF.

In PSA models, the maintenance unavailability is due to the downtime of the EDG for the maintenance performed, and any increase/decrease in this unavailability correspondingly affects the CDF. Similarly, any increases in EDG failures are reflected in EDG failure rates which increase both EDG unavailability due to failure to start and load-run, and the common-cause failure of multiple EDGs, resulting in increases in $\mathrm{CDF}$, and vice versa.

The risk calculations we present can be summarized as follows:

a) Conditional CDF given that an EDG is unavailable: When an EDG is unavailable due to failure or maintenance, the plant CDF increases from its baseline value, calculated in the PSA. This 
measure defines this increased CDF. It is calculated by assigning the affected EDG an unavailability equal to 1 . This measure defines the CDF level for the duration for which the EDG is not available to perform its desired function.

b) Increased average CDF due to increased maintenance unavailability: When the average maintenance unavailability is increased, the average CDF calculated by a PSA increases. This measure defines the new average CDF due to the increased maintenance unavailability, but does not account for any improvement or decline in component failure rate due to the increased maintenance. The increased maintenance unavailability is applied to all the EDGs in the plant for this evaluation. This measure differs from the previous one where the conditional CDF is measured for the duration of the maintenance; here, the average CDF per year is calculated for the changed maintenance unavailability parameter for all the EDGs in the plant.

c) Increased average CDF due to increased EDG failure rate: When the EDG failure rate to start on demand (including failure to start and load-run) increases, the average CDF calculated by a PSA also increases. The increased failure rate contributes to increased unavailability of individual EDGs, and also to the increased common-cause failure contribution of the EDGs. The effect on the CDF is due to the change in individual EDG failure unavailability, and also in the common-cause failure term. The change in the latter is due to the change in the individual EDG failure rate and not in the common-cause parameter (e.g., $\beta$ ). In certain cases, the change in the common-cause contribution caused by the increased EDG failure rate has the dominant effect on the CDF.

d) Core-damage probability (CDP) contribution for a given duration: Another measure of the effect of the downtime associated with EDGs is the core-damage probability contribution associated with the downtime. The CDP contribution for a given downtime is the product of the CDF for the duration of the downtime and the downtime. This measure is similar to the measure defined in item (a) above, but it is associated with a given downtime. Usually, the CDP is calculated for a single EDG being unavailable for maintenance, and is evaluated to define the allowed time period, i.e., the allowed outage time (AOT), for the maintenance. When measured for an AOT period, this measure is sometimes called "single AOT risk."

In estimating the effect of changes in EDG maintenance and failure unavailabilities in these risk calculations, point estimates of CDF are calculated and are used to make the judgments. Calculation of mean values of $\mathrm{CDF}$ for each case would have been very time and resource-consuming. The relative results obtained using the point estimates are not expected to differ from those obtained using the mean values because the uncertainty in the results for different cases are expected to be more or less the same, and the effects on the point estimates are considered similar. Therefore, our conclusions are not affected using point estimates.

\subsection{Impact of EDG Maintenance on Plant CDF}

When an EDG is failed or taken down for maintenance, thus making it unavailable in case of an accident, the plant CDF is increased from its baseline or nominal value. Since EDGs are among the most critical or risk-important safety system components, the plant CDF is sensitive to their unavailability. Figure 4.1 shows the conditional CDF when individual EDGs are out of service for maintenance. The increase in CDF varies from plant to plant and also from one EDG to another, ranging from a factor of about 3 to about 12 . The risk impact of one EDG in a plant may vary from another, because it may 
serve a specific function (e.g., high pressure core spray diesel in Grand Gulf plant) or may be shared between two units (e.g., Surry plant).

In assessing the risk impact of EDG unavailability due to maintenance, not only the increased CDF level during maintenance, but also the duration of maintenance is important. The integrated risk impact over the duration is calculated as the product of the increased CDF for an EDG being unavailable for maintenance and the duration. Table 4.1 presents risk contributions of maintenance for individual EDGs in different plants, calculated for industry-average maintenance duration (calculated to be 7.3 days/year in Chapter 2) and for a single AOT period for the plant. These contributions depend on the CDF level when an EDG is taken out of service, rather than on the relative increase in the CDF level. The risk contributions over an AOT period also depend on the AOT. For an average maintenance duration per year, this contribution varies from 2.2E-7 to 5.3E-6 and over the similar range for an AOT duration. A core-damage probability of over 1.0E-6 for individual EDGs can be considered significant. Also, we note that the risk impacts of AOTs for EDGs are not consistent across plants. For example, the AOT for EDGs in the Surry plant is 7 days, even though both the CDF level and the CDP contribution of EDG maintenance are larger in Surry than other plants where the AOT is 3 days.

\subsection{Sensitivity of Plant CDF to Increased EDG Unavailability}

Figure 4.2 shows the effect of increasing the EDG maintenance unavailability on plant CDF for the six plants studied; it shows the increase in the average CDF for the changes in the average maintenance unavailability. Table 4.2 summarizes the average CDF for different estimates of maintenance unavailability: (1) the Station Blackout (SBO) Rule estimate of 0.007 , similar to the value used in PSAs, (2) estimate of 0.02 based on this study using plant-experience data over 2 years, and (3) the AEOD estimate of 0.04 . Appendix $\mathrm{H}$ presents plots of the sensitivity of CDF and SBO sequence frequency to maintenance unavailability for individual plants.

For a factor of 3 increase in average maintenance unavailability, the increase in average CDF is not significant. In this analysis, we assume that increased maintenance does not lower the EDG failure rate, i.e., any benefit of increased maintenance is not included, and only the downtime effect of EDGs is evaluated. For plants with maintenance unavailability of about 0.04 , the additional CDF contribution can be about $1 \times 10^{-5}$, which is significant.

\subsection{Sensitivity of Plant CDF to EDG Failure Probability}

Figure 4.3 shows the effect of changing EDG failure unavailability on the plant CDF, calculated using the plant PSA. The EDG failure unavailability was varied from approximately 0.014 to 0.16 , a range covering our estimated values for this parameter (including plant-specific variations) and the values typically used in the PSA studies. Similar to the effect of increasing maintenance unavailability, the plant CDF increases when the individual EDG failure unavailabilities increase. Table 4.3 summarizes the average CDF for different values of EDG failure unavailability: (1) PSA estimates ranging from 0.019 to 0.046 , (2) estimate of 0.014 based on this study for 4 years, and (3) estimates of 0.05 , the target value used in the SBO rule. 


\subsection{Relative Effect of EDG Failure and Maintenance Unavailability on Plant CDF}

The relative effect of EDG failure and maintenance unavailabilities was studied, based on their impact on plant CDF. As discussed below, the effect of EDG failure to start and load-run on plant CDF is greater than that for EDG maintenance; this is expected, since multiple EDGs can remain failed at the same time due to random failure or more likely, from common-cause failures. Multiple EDG unavailability due to maintenances is forbidden by the technical specification requirements of the plants. To compare the relative effects of EDG failure and maintenances, plant CDF is calculated for different EDG failure and maintenance unavailabilities. The CDFs for each of the cases are shown in Table 4.4. The different cases are defined using the unavailabilities estimated from the current experience data (as presented in this report) and in the SBO rule. Case A represents maintenance unavailability assumed in the SBO rule and the failure unavailability corresponding to current data (EDG-maintenance, $\mathrm{q}_{\mathrm{m}}=0.007$; EDG (FR, FS), $\left.\mathrm{q}_{\mathrm{f}}=0.014\right)$. Case $\mathrm{B}$ represents the unavailabilities assumed in the SBO rule $\left(\mathrm{q}_{\mathrm{m}}=\right.$ $\left.0.007, q_{f}=0.05\right)$. Case $C$ is representative of current industry-wide values where $q_{m}$ is estimated based on $92 \%$ of the EDG population and $\mathrm{q}_{\mathrm{f}}$ is based on $83 \%$ of the EDG population $\left(\mathrm{q}_{\mathrm{m}}=0.02, \mathrm{q}_{\mathrm{f}}=0.014\right)$. Case D represents current estimate of EDG maintenance unavailability and the EDG failure unavailability assumed in the SBO rule $\left(\mathrm{q}_{\mathrm{m}}=0.02, \mathrm{q}_{\mathrm{f}}=0.05\right)$. The case differences shown in Table 4.5 illustrate the change in $\mathrm{CDF}(\triangle \mathrm{CDF})$ associated with various assumptions.

The case differences represent the $\triangle \mathrm{CDF}$ for changes in maintenance unavailability when the failure to start and load-run contribution is assumed to remain constant, and similarly, the $\triangle \mathrm{CDF}$ for changes in failure to start and load-run contribution when the maintenance unavailability contribution is constant. Comparison of these $\triangle \mathrm{CDF}$ calculations show that the effect of change in EDG failure to start and load-run has a greater influence on the CDF than that for EDG maintenance unavailability. Increase in maintenance-related unavailability from 0.007 to 0.02 will be off-set by decrease in failure to start and load-run unavailability from 0.05 to 0.014 . In general, if increase in maintenance unavailability results in comparable (or slightly lower) decrease in failure unavailability, the plant CDF will remain at the same or at a slightly lower value.

\subsection{Impact of Scheduling EDG Maintenances with Other Components}

Another aspect relating to the risk impact of EDG maintenances is the scheduling of such maintenances. The risk is particularly sensitive to taking multiple equipment out of service simultaneously. In planning preventive maintenance schedules, care should be taken to avoid simultaneous maintenances of multiple equipment that can cause a large increase in the plant CDF. In particular, because the plant CDF is sensitive to taking an EDG out of service, taking additional equipment from service for maintenance may have a high risk impact. At the same time, maintaining the respective EDG support system during the same period may reduce the risk impact of scheduled maintenances. This is because a failure in the support system component fails the EDG and taking this component out for maintenance does not result in any additional risk impact. An example of the impact of EDG maintenance scheduling is presented below.

Figure 4.4 presents the plant CDF level over a 12 weeks where multiple equipment is taken out of service each week for scheduled maintenance. Table 4.6 show this schedule, called rolling maintenance schedule. This schedule is repeated every 12 weeks. Care is taken to avoid taking down redundant equipment during the same week, i.e., the maintenances of division-1 and division-2 batteries are performed during different weeks. Still, during certain weeks, multiple risk-significant equipment can be taken out of service simultaneously. For example, during the first and second week, batteries in 
one division, one EDG, and additional equipment are maintained. Simultaneous maintenances of these equipment can result in the peak risk significantly higher than the PSA baseline. This figure shows, conservatively, that the high risk level will remain for the entire week. Typically, maintenances are completed in much shorter times, whereby the high risk level may remain only for a portion of the week. The peak CDF level can be somewhat reduced by rearranging simultaneous maintenance of multiple equipment. 


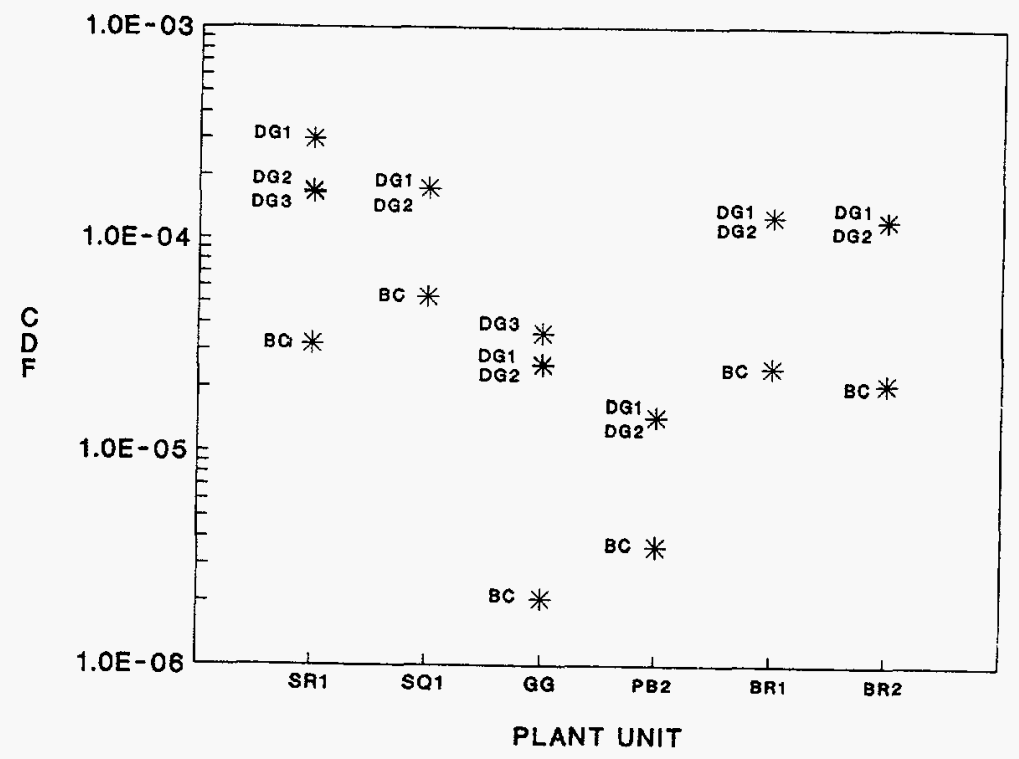

Figure 4.1 Impact on plant core-damage frequency due to outage of a single EDG for maintenance (SR1: Surry 1, SQ1: Sequoyah 1, GG: Grand Gulf, PB2: Peach Bottom 2, BR: Brunswick; $\mathrm{BC}$ : Base Case PRA core-damage frequency, DGi: core-damage frequency when $\mathrm{DGi}$ is out of service for maintenance, where $\mathrm{i}$ can be 1,2 , or 3 , representing DG1, DG2, or DG3)

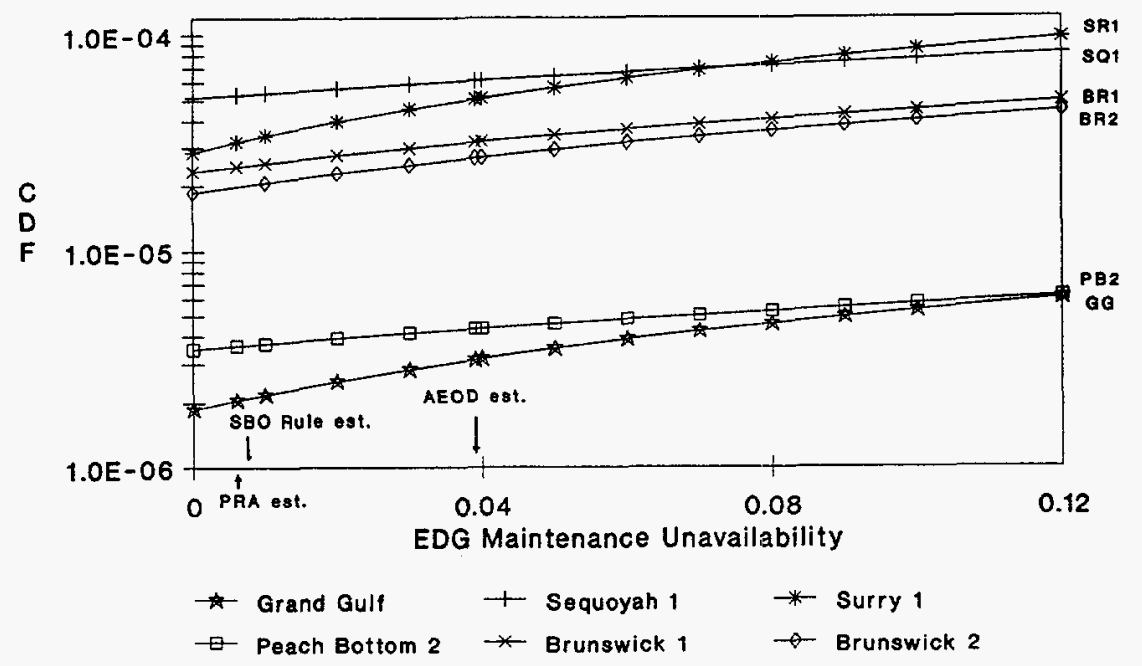

Figure 4.2 Sensitivity of plant core-damage frequency to increased EDG maintenance unavailability (during power operation) 


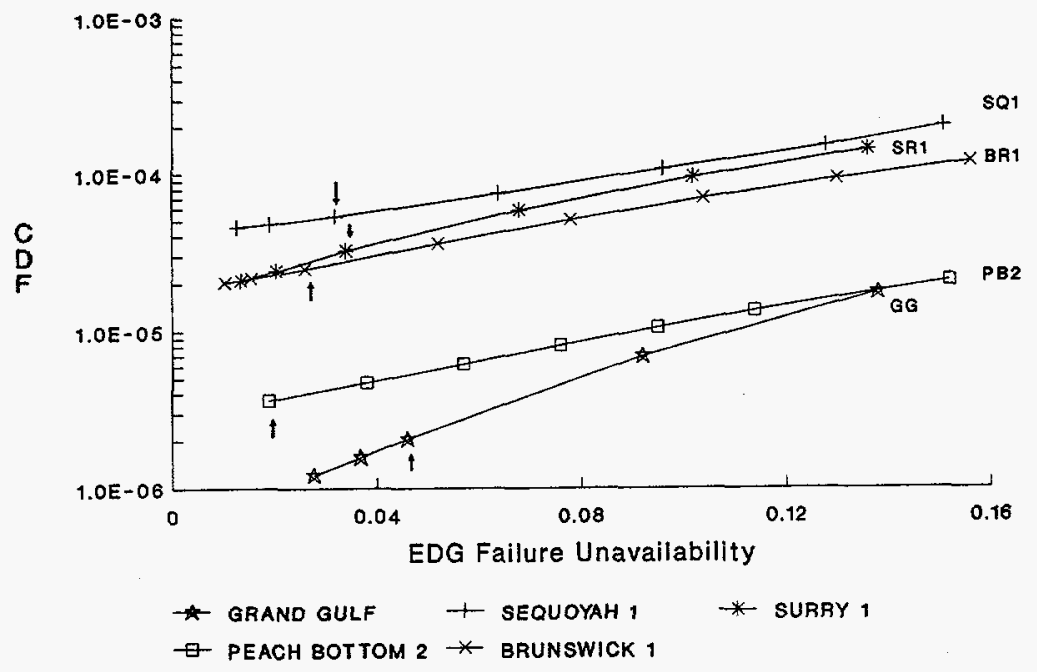

Figure 4.3 Sensitivity of plant core-damage frequency to EDG Failure Unavailability (during power operation) (Note: Arrows indicate the base-case EDG failure unavailabilities which were obtained by summing the EDG failure to start and failure to run unavailabilities used in PRAs. These combined failure unavailabilities were used for this sensitivity analysis, and thus the EDG failure to start and failure to run unavailabilities vary by the same proportion.)

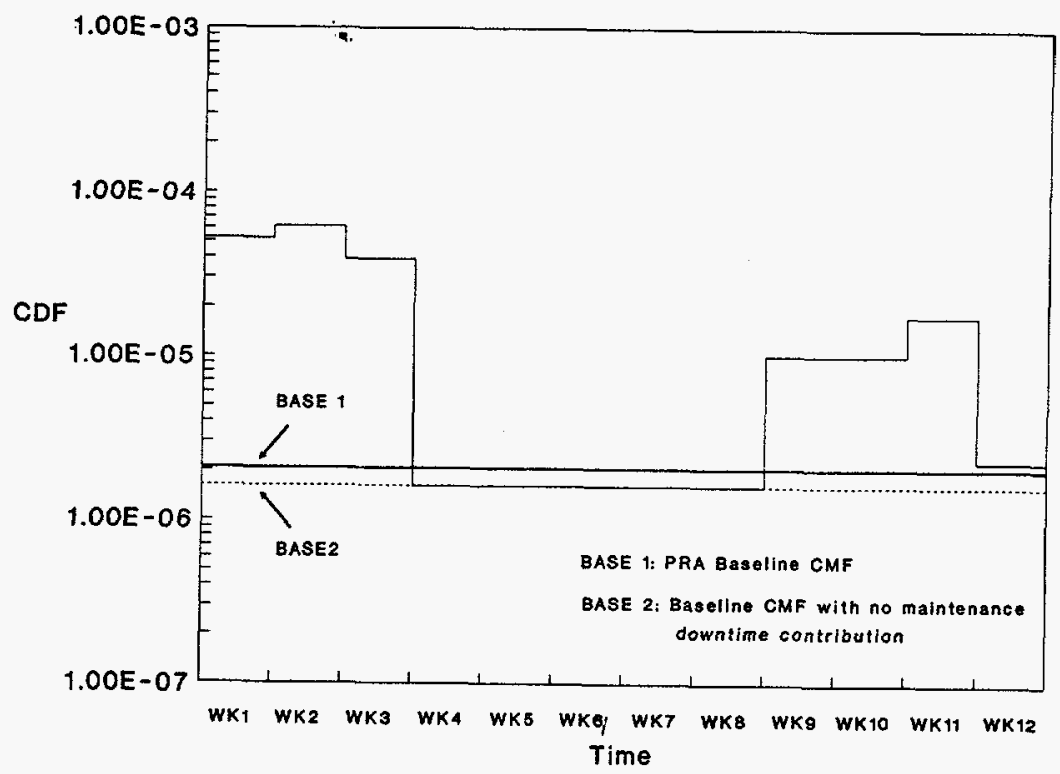

Figure 4.4 Core-damage frequency levels in an example rolling-maintenance schedule. (Note: multiple components are assumed to remain unavailable for the entire week: a bounding scenario) 
Table 4.1 Risk Contributions of Maintenance During Power Operation

\begin{tabular}{|c|c|c|c|c|}
\hline \multirow[b]{2}{*}{ Plant Unit } & \multirow[b]{2}{*}{ Baseline CDF } & \multicolumn{3}{|c|}{ Maintenance Risk Contribution } \\
\hline & & $\begin{array}{l}\text { CDF When single } \\
\text { EDG in Maint. } \\
(U \mathrm{yr})\end{array}$ & $\begin{array}{l}\text { Incr. CoP Cont. } \\
\text { for Industry Av. } \\
\text { Maint. } \\
\text { Duration }{ }^{2} \text { ? }\end{array}$ & Incr CDP Cont \\
\hline Surry 1 & $3.20 \mathrm{E}-5$ & $2.98 \mathrm{E}-4$ & $5.3 \mathrm{E}-6$ & $5.1 \mathrm{E}-6$ \\
\hline Grand Gulf & $2.06 \mathrm{E}-6$ & $2.58 \mathrm{E}-5$ & 4.7E-7 & $2.0 \mathrm{E}-7$ \\
\hline Sequoyah 1 & $5.30 \mathrm{E}-5$ & $1.73 \mathrm{E}-4$ & $2.4 \mathrm{E}-6$ & $1.0 \mathrm{E}-6$ \\
\hline Peach Bottom 2 & $3.62 E-6$ & $1.45 \mathrm{E}-5$ & $2.2 \mathrm{E}-7$ & 2.1E-7 \\
\hline Brunswick 1 & $2.47 \mathrm{E}-5$ & $1.28 \mathrm{E}-4$ & $2.1 E-6$ & $2.0 \mathrm{E}-6$ \\
\hline Brunswick 2 & $2.08 \mathrm{E}-5$ & $1.23 \mathrm{E}-4$ & $1.9 \mathrm{E}-6$ & $1.8 \mathrm{E}-6$ \\
\hline
\end{tabular}

${ }^{1}$ Increased contribution to core-damage probability (CDP) for a given duration is calculated as the product of the increased CDF for an EDG being unavailable for maintenance and the duration.

${ }^{2}$ Industry average maintenance duration during power operation is 7.3 days/year, assuming power operation for the entire year.

${ }^{3}$ The EDG AOT is 3 days for Grand Gulf and Sequoyah, and 7 days for the other plants.

Table 4.2 Average CDF Due to Increased Maintenance Unavailability

\begin{tabular}{|c|c|c|c|}
\hline \multirow[b]{2}{*}{ Plant Unit } & \multicolumn{3}{|c|}{ Average CDF for EDG Maintenance Unavailability $\left(\mathbf{q}_{\mathrm{m}}\right)$} \\
\hline & $\begin{array}{c}\mathbf{9}_{\mathrm{m}}=0.007 \\
\text { (SBO Rule Est) }\end{array}$ & (Plant-Experience Data) & (AEOD Estimate) \\
\hline Surry 1 & $3.2 \mathrm{E}-5$ & $3.98 \mathrm{E}-5$ & $5.11 \mathrm{E}-5$ \\
\hline Grand Gulf & $2.1 \mathrm{E}-6$ & $2.52 \mathrm{E}-6$ & $3.20 \mathrm{E}-6$ \\
\hline Sequoyah 1 & $5.3 E-5$ & $5.65 \mathrm{E}-5$ & $6.15 \mathrm{E}-5$ \\
\hline Peach Bottom 2 & $3.6 \mathrm{E}-6$ & $3.92 \mathrm{E}-6$ & 4.37E-6 \\
\hline Brunswick 1 & $2.5 \mathrm{E}-5$ & $2.78 \mathrm{E}-5$ & $3.20 \mathrm{E}-5$ \\
\hline Brunswick 2 & $2.0 \mathrm{E}-5$ & $2.29 \mathrm{E}-5$ & $2.72 \mathrm{E}-5$ \\
\hline
\end{tabular}


Table 4.3 Average CDF Due to Different EDG Failure Unavailability

\begin{tabular}{|c|c|c|c|c|}
\hline \multirow[t]{2}{*}{ Plant Unit } & \multirow{2}{*}{$\begin{array}{l}\text { EDG Failure } \\
\text { Gnavailability } \\
\text { q. (Respective } \\
\text { PSA V alue) }\end{array}$} & \multicolumn{3}{|c|}{$\begin{array}{l}\text { Average CDF for EDG Failure } \\
\text { Unavailability q }, 1 .\end{array}$} \\
\hline & & $\begin{array}{l}\text { gr (used in } \\
\text { PSA) }\end{array}$ & 0.014 & $q_{\mathrm{f}}=0.05$ \\
\hline Surry 1 & $3.4 \mathrm{E}-2$ & $3.2 \mathrm{E}-5$ & $2.14 \mathrm{E}-5$ & 4.37 E-5 \\
\hline Grand Gulf & $4.6 \mathrm{E}-2$ & $2.06 \mathrm{E}-6$ & $8.84 \mathrm{E}-7$ & $2.36 \mathrm{E}-6$ \\
\hline Sequoyah 1 & $4.2 \mathrm{E}-2$ & $5.30 \mathrm{E}-5$ & $4.47 \mathrm{E}-5$ & $5.65 \mathrm{E}-5$ \\
\hline Peach Bottom 2 & $1.9 \mathrm{E}-2$ & 3.62 E-6 & $3.42 \mathrm{E}-6$ & $5.61 \mathrm{E}-6$ \\
\hline Brunswick 1 & $3.6 \mathrm{E}-2$ & $2.47 \mathrm{E}-5$ & $2.13 \mathrm{E}-5$ & $3.48 \mathrm{E}-5$ \\
\hline
\end{tabular}

Table 4.4 Plant CDF for Different EDG Maintenance \& Failure Unavailability

\begin{tabular}{||l|c|c|c|c||}
\hline & Case A & Case B & Case C & Case D \\
\hline EDG-Maint, $\mathrm{q}_{\mathrm{m}}$ & 0.007 & 0.007 & 0.02 & 0.02 \\
\hline EDG(FS,FR), $\mathrm{q}_{\mathrm{f}}$ & 0.014 & 0.05 & 0.014 & 0.05 \\
\hline Plant Unit & & \multicolumn{4}{|c|}{ Core Damage Frequency (CDF) } \\
\hline Grand Gulf & $8.84 \mathrm{E}-07$ & $2.36 \mathrm{E}-06$ & $9.67 \mathrm{E}-07$ & $2.84 \mathrm{E}-06$ \\
\hline Surry 1 & $2.14 \mathrm{E}-05$ & $4.87 \mathrm{E}-05$ & $2.57 \mathrm{E}-05$ & $5.35 \mathrm{E}-05$ \\
\hline Sequohah 1 & $4.47 \mathrm{E}-05$ & $5.65 \mathrm{E}-05$ & $4.59 \mathrm{E}-05$ & $6.04 \mathrm{E}-05$ \\
\hline Peach Bottom 2 & $3.42 \mathrm{E}-06$ & $5.61 \mathrm{E}-06$ & $3.66 \mathrm{E}-06$ & $6.21 \mathrm{E}-06$ \\
\hline Brunswick 1 & $2.13 \mathrm{E}-05$ & $3.48 \mathrm{E}-05$ & $2.32 \mathrm{E}-05$ & $3.94 \mathrm{E}-05$ \\
\hline Avg Plant Value & $1.83 \mathrm{E}-05$ & $2.86 \mathrm{E}-05$ & $1.99 \mathrm{E}-05$ & $3.25 \mathrm{E}-05$ \\
\hline
\end{tabular}

EDG-Maint, $q_{m}$ : EDG maintenance unavailability

EDG(FS,FR), $q_{f}: \quad$ EDG failure unavailability (sum of EDG failure to start and failure to load-run and run unavailability) 
Table 4.5 Comparison of Increase in CDF Due to Increasing EDG Maintenance and Failure Unavailability

\begin{tabular}{||l||c|c||}
\hline & \multicolumn{3}{|c|}{$\Delta$ CDF DIFFERENCES BETWEEN CASES } \\
\hline Case C - Case A & $1.60 \mathrm{E}-06$ & $\Delta$ due to increased $\mathrm{q}_{\mathrm{m}}$ from 0.007 to 0.02 , constant $\mathrm{q}_{\mathrm{f}}=0.014$ \\
\hline Case D - Case B & $3.90 \mathrm{E}-06$ & $\Delta$ due to increased $\mathrm{q}_{\mathrm{m}}$ from 0.0007 to 0.02 , constant $\mathrm{q}_{\mathrm{f}}=0.05$ \\
\hline Case D - Case A & $1.42 \mathrm{E}-05$ & $\begin{array}{c}\Delta \text { due to increased } \mathrm{q}_{\mathrm{f}} \text { from } 0.014 \text { to } 0.05 \text {, and } \mathrm{q}_{\mathrm{m}} \text { from } 0.0007 \\
\text { to } 0.02\end{array}$ \\
\hline Case D - Case C & $1.24 \mathrm{E}-05$ & $\Delta$ due to increased $\mathrm{q}_{\mathrm{f}}$ from 0.014 to 0.05 , constant $\mathrm{q}_{\mathrm{m}}=0.02$ \\
\hline
\end{tabular}


Table 4.6 Example Schedule for Preventive Maintenance

\section{ROLLING MAINTENANCE}

Week 1 Div. 1

Battery \& DC Distribution (1)

Diesel Generator (1)

Low Pressure Core Spray

Diesel Generator Room Ventilation

(1)

Switchgear Heat Removal (1)*

Week 2 Div. 2

Batter \& DC Distribution (2)

Diesel Generator (2)

Residual Heat Removal (C)

DG Room Ventilation (2)

Switchgear Heat Removal (2)*

Week 3 Div. 3

Battery \& DC Distribution (3)

Diesel Generator (3)

High Pressure Core Spray

DG Room Ventilation (3)

Switchgear Heat Removal (3)*

Plant Service Water (C)

Week 4 Non-Div.

Control Rod (A)

Standby Liquid Control (B)

Week 5 Div. 1

Condensate Booster (C)*

Component Cooling (C)

Condensate (C)*

Standby Liquid Control (A)

Containment Building HVAC

Week 6 Div. 2

Component Cooling (B)

Residual Heat Removal (B)
Week $7 \quad$ Div. 3

Condensate Booster (A)

Condensate (A)*

Plant Service Air (A)

Week 8 Non-Div.

Fire Water (A)

Instrument Air

Plant Service Water (B)

Week 9 Div. 1

Component Cooling (A)

Condensate Booster (A)*

Condensate (A)*

RHR (A)

Shutdown Service Water

Week 10 Div. 2

Condensate Booster (B)*

Condensate (B)*

Control Rod Drive (B)

Shutdown Service Water (B)

Auxiliary Building HVAC (A)

Plant Service Water (A)

Week 11 Div. 3

Shutdown Service Water (3)

Auxiliary Building HVAC (B)

Week 12 Non-Div.

Fire Water (B)

Reactor Core Isolation Cooling

Supply Pool Makeup 


\section{RISK IMPACT OF EDG MAINTENANCE DURING POWER OPERATION VS. SHUTDOWN}

In this section, we compare the risk impact of EDG maintenance during power operation and shutdown periods. The findings are used to develop insights for scheduling EDG maintenance with minimal impact on risk.

NRC Regulatory Guide $1.155^{2}$ stated that "(EDG unavailability) contribution can be kept low...by scheduling regular diesel generator maintenance at times when the reactor is shutdown." This guidance is likely the cause of the average EDG unavailability during shutdown periods (due to scheduled maintenance) being substantially larger than that during power operation (as shown in Chapter 2). However, it is increasingly evident that scheduled preventive maintenance contributes to EDG reliability, and performing it during power operation can contribute to overall EDG availability. At the same time, probabilistic safety assessments (PSAs) of shutdown periods show that the risk impact of EDG maintenance during shutdown also can be substantial.

To understand the risk impact of EDG maintenance, and to identify periods when the impact of EDG maintenance is minimal, risk-based evaluations are undertaken. The impact of EDG maintenance is assessed both during power operation and shutdown, using their respective PSA models.

The objective of this phase of the analysis can thus be summarized as follows:

a) to assess the risk impact of EDG maintenance during power operation and during various stages of plant shutdown.

b) to identify periods in plant operation (power operation and shutdown) when the risk impacts of EDG maintenance are high and when they are low.

\subsection{Analysis Approach}

The basic approach is to assess the risk impact when the EDG is unavailable for maintenance in terms of the core-damage frequency (CDF). The conditional CDF, given that EDG is unavailable for maintenance, is calculated to identify the risk impact during shutdown vs. power operation.

Plant-specific PSA models are used to quantify the conditional CDF given that an EDG is in maintenance. The calculations were performed using the IRRAS computer models for two plants, the Grand Gulf Nuclear Power Station and the Surry Nuclear Power Station; both full-power and shutdown PSA models are available. BNL analyzed the impact of EDG maintenance for the Surry Nuclear Power Station, and SNL similarly analyzed the Grand Gulf Nuclear Power Station. ${ }^{22}$

For full-power operation, a single conditional CDF, given that an EDG is in maintenance, is calculated using the corresponding full power PSA. The shutdown periods are divided into several plant operating states (POSs), each represented by the respective PSA model which is used to calculate the CDF. The pressurized water reactor (PWR) low power and shutdown (LP\&SD) model, using the Surry plant as an example, defines 15 POSs, whereas the boiling water reactor (BWR) model, using the Grand Gulf plant as an example, defines 7 POSs. The impact of EDG maintenance differs from one POS to another. Accordingly, the effect of EDG maintenance on CDF is calculated for each POS using the respective PSA model. 
We compare the conditional CDF between power operation and shutdown periods, and among the shutdown POSs to identify the periods when the risk-impact of maintenance is minimal.

\section{Analysis for the Surry Plant}

The Surry Nuclear Power Station, in Surry, Virginia is a two-unit site, each a pressurized water reactor (PWR). Three EDGs are available; one EDG is dedicated to each unit, and the third can be connected to either unit (a swing EDG).

The Surry LP\&SD PSA was quite detailed in that it modelled 15 different POSs. Due to the extent of this effort, a detailed PSA has only been completed for the two most risk significant POSs, namely POSs 6 and 10 for midloop operations. For the other POSs a scoping PSA was done using conservative, screening type assumptions. Comparison of CDF numbers between these screening POSs and the full-power PSA numbers is not feasible. In this study the actual CDF numbers for Surry will not be used because of the conservative screening nature of the PSA.

The risk impact of EDG maintenance during power operation and shutdown periods was assessed using the corresponding PSA models for the Surry plant. The emergency power system, as modeled in the PSA, takes credit for the third EDG that can be cross-connected.

The risk impact of EDG maintenance (in term of conditional CDF) was evaluated for full power operation and also, for POSs 4 through 12, during a shutdown. These POSs were chosen because EDGs are maintained during them. Figure 5.1 shows the conditional CDF, given EDG in maintenance, for different POSs. The base-line CDF for each POS also is shown. The risk of EDG maintenance during early stages of cold shutdown (POS 4, 5), and midloop operations (POS 6, 10) are relatively high; it is low during POSs 8 and 12, i.e., during refueling, and when the reactor coolant system (RCS) is filled following refueling.

Figure 5.2 shows the increase in CDF ( $\triangle \mathrm{CDF}$ ) for each of the POSs when an EDG is maintained. The $\triangle C D F$ decreases as the time following shutdown increases, because of the diminishing decay heat and the increasing coolant inventory as the time in shutdown increases. Hence, from risk considerations, EDG maintenances should be scheduled towards the later part of the shutdown.

Table 5.1 compares the risk of EDG maintenance during full-power operation versus different shutdown POSs. Because the conditional CDFs calculated with fuli-power PSA and shutdown PSA are not directly comparable, the CDF accordingly is categorized as high $(\mathrm{H})$, medium $(\mathrm{M})$, and low $(\mathrm{L})$. The results show that the CDF impact of EDG maintenances during periods of shutdown can be comparable or higher than during power operation.

\section{Analysis for the Grand Gulf Plant ${ }^{22}$}

The Grand Gulf Nuclear Station is a General Electric boiling water reactor BWR-6, located at Port Gibson, Mississippi. The plant uses three emergency diesel generators; two (EDG 11 and 12) provide emergency power to Division 1 and 2 Engineered Safety Features (ESFs) following a loss of offsite power event. The third (EDG 13) is dedicated to the High Pressure Core Spray (HPCS) system. When the HPCS system is unavailable following a loss of offsite event, EDG 13 can be cross-tied to Division $2 \mathrm{AC}$ power supplies should EDG 12 fail to operate. 
The conditional CDF of an EDG out-of-service due to maintenance was assessed for full-power operation and during various stages of plant shutdown. The modeling of CDF in the low power and shutdown PSA for this plant was considered comparable to that for the full-power PSA model. Therefore, the conditional CDF of EDG maintenance during power operation versus plant shutdown is numerically compared to obtain insights into risk.

The risk impact of EDG maintenance was calculated for full-power operation and for each of the seven plant operating states (POSs) defined in the LP\&SD PSA (Figure 5.3) given EDG is in maintenance. Figure 5.4 shows the same results focussing on the shutdown POSs. As shown, the risk impact of EDG maintenance is the smallest during refueling (POSs 6 and 7). However, it is significantly higher when the plant is in cold shutdown, when the reactor-core isolation cooling (RCIC) system, i.e., the steam driven source of water, is assumed to be unavailable. The risk impact during low power and hot shutdown modes (POSs 2, 3, and 4) is comparable to that during full-power operation. Table 5.2 summarizes this information, giving both the conditional CDF and the increase in CDF ( $\triangle C D F)$ for EDG maintenance in each POS. Similar to the Surry plant, a PWR, the risk impact of EDG maintenance is substantially reduced during refueling, and is considerably higher during earlier periods of the shutdown outage.

\subsection{Limitations and Assumptions in the Analysis}

Our analysis is based on PSA models for power operation and shutdown and accordingly, the limitations and assumptions of PSA models apply. In addition, the following limitations and assumptions should be considered in deriving insights from the results presented below:

a) The shutdown PSA models are much simplified models compared to full power models, which were developed and refined over a long period, hence, the estimates from the shutdown models are expected have a much larger uncertainty. The Surry low power and shutdown model used in our analysis is a first phase model focussing on all 15 POSs. Thus, the CDF impacts of EDG maintenance for full power operation and shutdown periods are difficult to compare. The comparison of the impacts among the various shutdown POSs are more meaningful since they are modeled similarly. The Grand Gulf Shutdown model defines 6 shutdown POSs and is considered comparable to the full power model, and accordingly, quantitative comparison of the CDF impact of EDG maintenance is presented.

b) Similar to the analysis presented in the previous chapter, we used point estimates of CDFs to compare the risk impact of EDG maintenance during different periods of plant operation (power operation versus shutdown). The uncertainties in the CDF estimates for the different periods differ; hence, the point estimates are affected differently. Because of larger uncertainty in the CDF estimates of the shutdown periods, the mean value can be higher than the corresponding mean value for the power operation, when the point estimates of both are in a similar range. In general, this effect will further support the conclusions in this chapter. However, if there are significant conservatisms in the modeling that have resulted in high estimates of CDF for the shutdown periods, then the conclusions may be affected.

c) In this analysis, we consider scheduling PM for a single EDG. Typically, PMs can be scheduled for an EDG when the redundant EDGs are not failed or degraded. However, 
in certain situations, common degradation of EDGs may be evident where their reliability is lower and maintenances of all are desirable. Such situations are not studied here. Rohrer et al.$^{23}$ carried out a case study to decide on scheduling EDG inspections requiring disassembly of the generators for the Monticello Nuclear Generating Plant. Their results showed that, from a risk perspective, for short outages, e.g., less than one day, it is preferable to schedule the inspection of the EDGs during power operation. However, other considerations, weighted in favor of shutting the plant down and performing the EDG inspections.

\subsection{Considerations for EDG Maintenance During Power Operation Versus Shutdown}

In this section, we discuss the risks associated with scheduling EDG maintenances during various modes of plant operation. We present insights from our analyses which are used to define considerations for scheduling EDG maintenances. The risk concerns for the respective periods (power operation or shutdown), along with qualitative insights to address these concerns, are listed in Tables 5.3 and 5.4, and are discussed below.

The benefit of scheduling EDG PM during power operation is, primarily, to assure the reliable operation of the equipment, and, at the same time, reduce the burden of maintenance during shutdown. Such scheduling is partly necessitated by the longer fuel cycles, and also due to the desire to reduce the outage duration of a plant shutdown. However, there are several concerns (Table 5.3). Scheduling EDG PM for a short duration during power operation involves small risk, but repeated use of LCOs for EDG PM can significantly increase the risk due to increased EDG unavailability. It also can mask EDG failures being recorded. By scheduling EDG PMs just before Technical Specification Surveillance testing, failures may be corrected; the test may not detect all failures in the standby period so resulting in optimistic reliability data. Another concern is related to the disassembly of equipment to perform PM. If disassembly is performed during power operation, then the equipment cannot be returned to service at short notice if a need arises.

The primary motivation for scheduling all EDG PM during shutdown is to reduce the risk impact from the associated downtimes. However, the risk impact of EDG maintenance during the early stages of reactor shutdown is comparable with the risk impact during power operation. Thus, a low impact can be achieved by scheduling short-duration maintenance during power operation, and scheduling longduration maintenance during extended periods of reactor shutdown (e.g., refueling) when the decay heat is low and the water level is high. Also, we expect that carrying out certain maintenance at short intervals can improve the reliability of EDGs; this leads to consideration of a maintenance program spread between power operation and shutdown periods.

The insights obtained for EDG maintenance from the analysis of the two plants can be summarized as follows:

a) The risk impact of EDG maintenance during power operation and many stages of shutdown are comparable. However, all modes of shutdown are not the same. Considering the uncertainties, the risk impact of short duration PM is small for power operation and for much of the shutdown period. 
b) Clearly, long maintenance should be scheduled for specified shutdown periods, e.g., refueling POS when the coolant inventory is increased, the decay heat is minimal, and, as a consequence, risk is insensitive to EDG inoperability.

c) EDG maintenance should be avoided during certain shutdown periods. Through hot shutdown and the early stages of cold shutdown, the decay heat is high, the coolant inventory is limited, and only electric pumps are available to provide sources of cooling (steam is unavailable). The risk is sensitive to EDG unavailability. Also, a "running start" on EDG maintenance, i.e., maintenances started before initiating a scheduled shutdown, should be avoided as it may imply inoperable EDG during this initial period of plant shutdown.

d) For EDG maintenance that is neither short nor long, but intermediate in duration, the risk impact during power operation or in other periods, can be controlled by assuring the availability of redundant equipment, by controlling the allowed periods, and by controlling outage configurations of plant equipment that may adversely impact risk.

Table 5.4 presents the insights for scheduling EDG preventive maintenances. PMs are divided into three categories:

1. Scheduled PMs that need to be performed more frequently than 18 months,

2. Scheduled PMs that need to be performed at a frequency of 18 months or longer, and

3. Condition-directed PMs, based on test results, needed to correct degradations of equipment which may lead to failures.

In general, short duration PMs are recommended to be performed at power, while longer duration PMs are to be scheduled during the portion of a refueling shutdown when the risk impact is lower. For condition-directed PMs, somewhat longer PMs may be allowed during power operation since to shutdown the plant involves the additional risk of maneuvering to a safe shutdown state. 


\section{POS DEFINITIONS}

POS 1 - Low Power Operation and Reactor Shutdown

POS 2 - Cooldown with SGs to $345^{\circ} \mathrm{F}$

POS 3 - Cooldown with RHR to $200^{\circ} \mathrm{F}$

POS 4 - Cooldown with RHR to $140^{\circ} \mathrm{F}$

POS 5 - Draining the RCS to Midloop

POS 6 - Midloop Operation

POS 7 - Fill for Refueling

POS 8 - Refueling

POS 9 - Draining RCS to Midloop after Refueling

POS 10 - Midloop Operation after Refueling

POS 11 - Refill RCS Completely

POS 12 - RCS Heatup Solid and Draw Bubble

Relative CDF for SBO Sequences

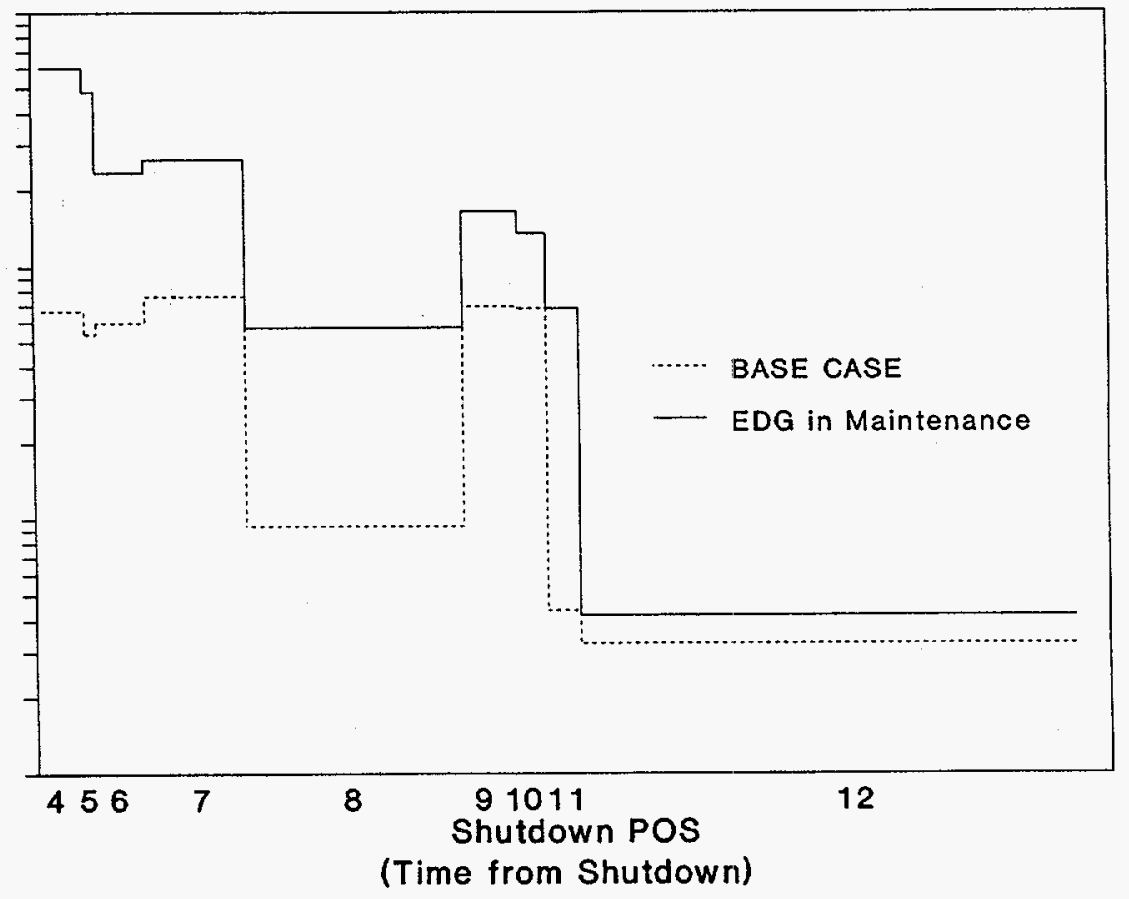

Figure 5.1 Change in CDF (due to SBO sequences) for taking an EDG out-of-service during different shutdown plant operating states (Surry 1, PWR) 
Increase in CDF due to SBO Sequence

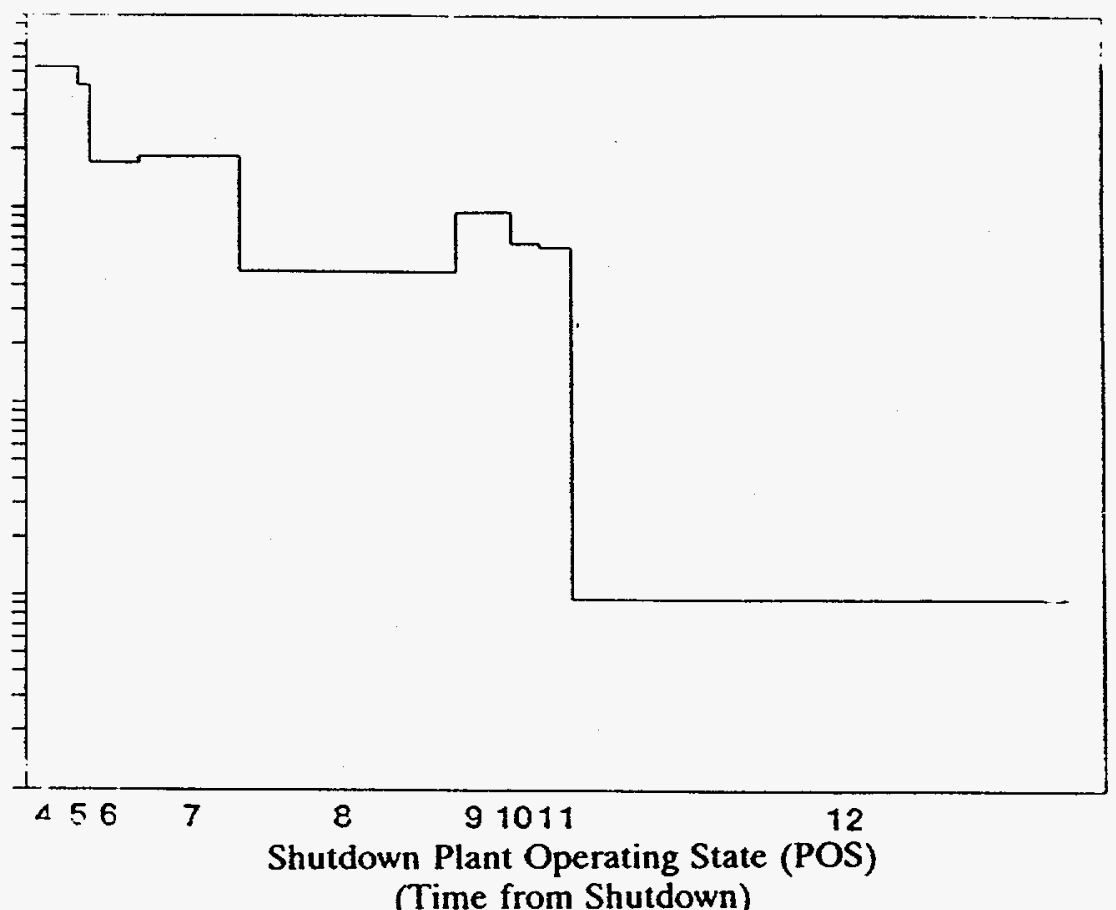

Figure 5.2 Increase in CDF for taking an EDG out-of-service during different shutdown plant operating states (Surry 1, PWR)

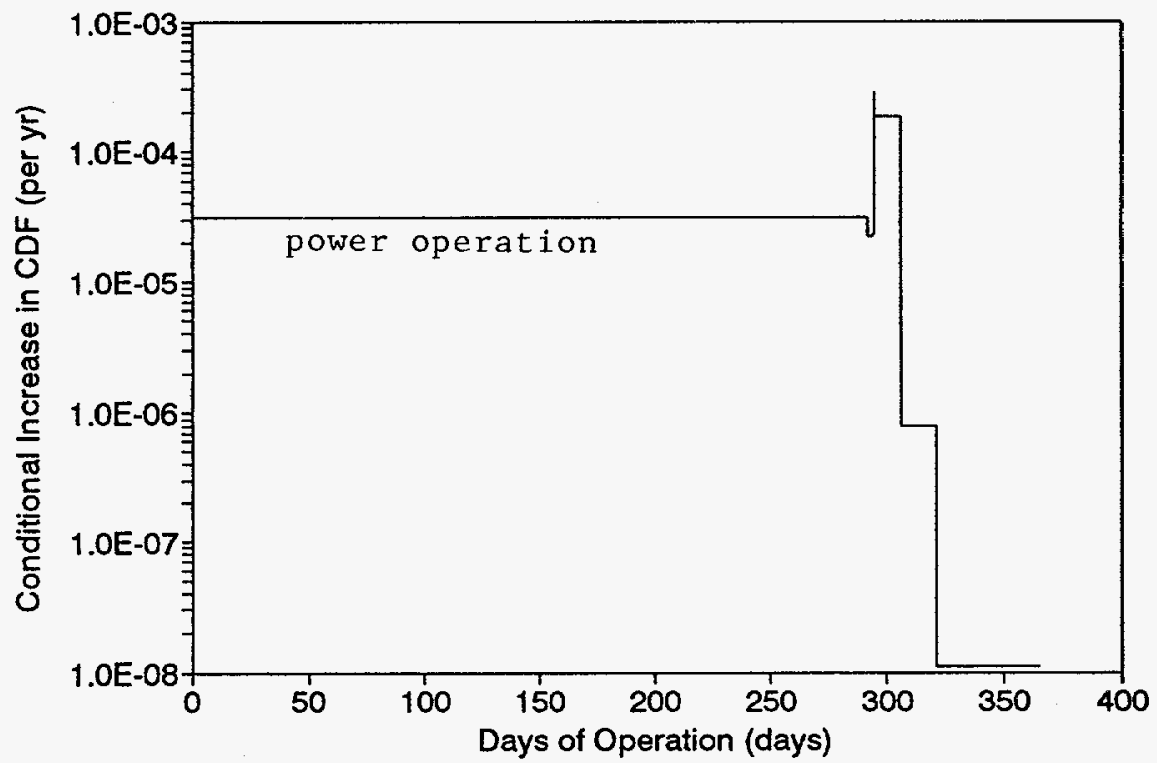

Figure 5.3 Change in CDF for taking an EDG out-of-service during different modes of plant operation (Grand Gulf, BWR), reproduced from Staple et al. ${ }^{22}$ 


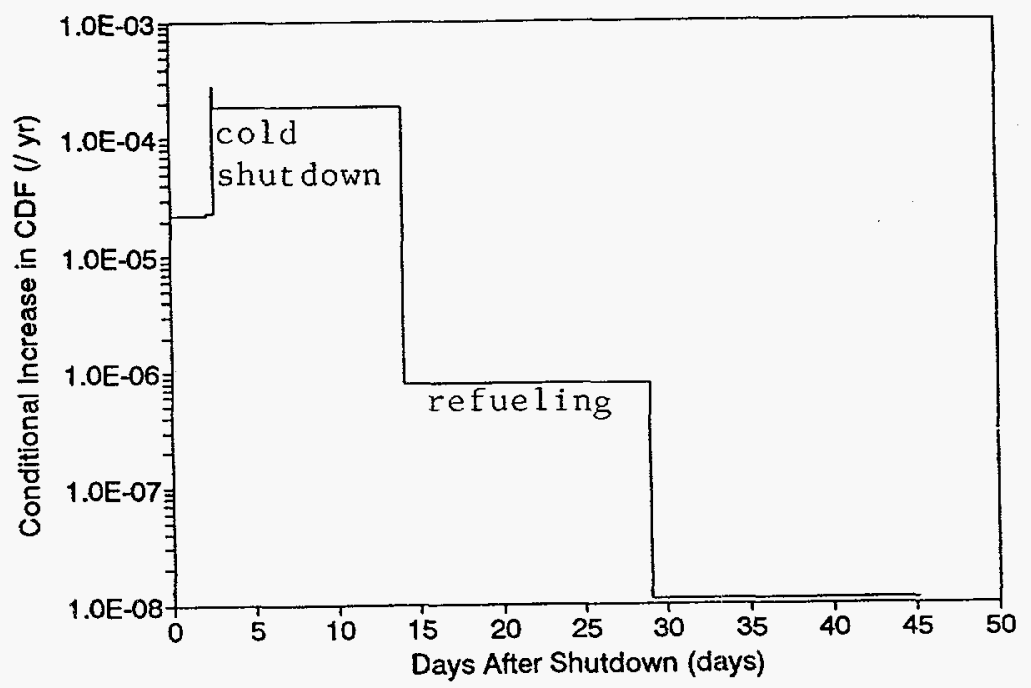

Figure 5.4 Increase in CDF for taking an EDG out-of-service during different shutdown plant operating states (Grand Gulf Nuclear Station, BWR), reproduced from Staple et al. ${ }^{22}$

Table 5.1 Relative CDF Impact of EDG Out-of-Service for Maintenance (Surry 1 Nuclear Plant, PWR)

\begin{tabular}{|l|c|c||}
\hline \multicolumn{1}{|c|}{ Plant Operational State } & $\begin{array}{c}\text { Average Duration } \\
\text { (hours) }\end{array}$ & $\begin{array}{c}\Delta \text { CDF 1,2 } \\
\text { (EDG in Maintenance) }\end{array}$ \\
\hline \hline \multicolumn{1}{|c|}{ POS O (Full Power) } & - & 3E-4 (M) \\
\hline POS 4 (Cooldown with RHR to 140 ${ }^{\circ}$ F) & 154 & $\mathrm{H}$ \\
\hline POS 5 (Draining the RCS to Midloop) & 46 & $\mathrm{H}$ \\
\hline POS 6 (Midloop Operation) & 183 & $\mathrm{H}$ \\
\hline POS 7 (Fill for Refueling) & 374 & $\mathrm{H}$ \\
\hline POS 8 (Refueling) & 810 & M to L \\
\hline $\begin{array}{l}\text { POS 9 (Draining RCS to Midloop after Refu- } \\
\text { eling) }\end{array}$ & 206 & $\mathrm{M}$ \\
\hline POS 10 (Midloop Operation after Refueling & 107 & $\mathrm{M}$ \\
\hline POS 11 (Refill RCS Completely) & 118 & $\mathrm{M}$ \\
\hline POS 12 (RCS Heatup Solid and Draw Bubble) & 1840 & $\mathrm{~L}$ \\
\hline
\end{tabular}

1: $\quad$ H: High, M: Medium, L: Low

2: $\triangle \mathrm{CDF}$ is the increase in CDF due to EDG being out of service for maintenance from the baseline CDF in the POS 
Table 5.2 Relative CDF Impact of Taking EDG Out-of-Service for Maintenance (Grand Gulf, BWR), from Staple et al. ${ }^{22}$

\begin{tabular}{||c|c|}
\hline Plant Operational State & $\Delta C D F$ (EDG in Maintenance) \\
\hline \hline POS 0 (Full Power) & $3.2 \mathrm{E}-5$ \\
\hline POS 1 (Power < 15\%) & $1.48 \mathrm{E}-5$ \\
\hline $\begin{array}{l}\text { POS } 2 \text { (Hot Shutdown, } \\
\text { P }>500 \text { psi) }\end{array}$ & $2.52 \mathrm{E}-5$ \\
\hline $\begin{array}{l}\text { POS } 3 \text { (Hot Shutdown, } \\
\text { P > 100 psi) }\end{array}$ & $2.52 \mathrm{E}-5$ \\
\hline $\begin{array}{l}\text { POS } 4 \text { (Hot Shutdown, } \\
\text { p < } 100 \text { psi, } \\
\text { RCIC unavailable) }\end{array}$ & $1.25 \mathrm{E}-4$ \\
\hline POS 5 (Cold Shutdown, p $=0$ ) & $1.85 \mathrm{E}-4$ \\
\hline POS 6 (Refueling, water level raised to steam lines) & $6.8 \mathrm{E}-7$ \\
\hline POS 7 (Refueling, upper pool filled) & $\epsilon$ \\
\hline
\end{tabular}

${ }^{*} \triangle \mathrm{CDF}$ is the increase in CDF due to EDG being out of service for maintenance from the baseline CDF in the POS. 
Table 5.3 Concern with Scheduled PM During Power Operation Versus Plant Shutdown

\begin{tabular}{|c|c|}
\hline \multicolumn{2}{|c|}{ PM DURING POWER OPERATION } \\
\hline Concerns & Insights \\
\hline $\begin{array}{l}\text { Repeated use of LCO to perform PM; in- } \\
\text { creased EDG unavailability }\end{array}$ & $\begin{array}{l}\text { Monitor EDG unavailability due to PM if PM } \\
\text { duration and frequency during power operation } \\
\text { is excessive or set limit for PM duration and } \\
\text { frequency during power operation }\end{array}$ \\
\hline $\begin{array}{l}\text { Unreliable EDG failure history; EDG failures } \\
\text { may be masked because of PMs prior to testing }\end{array}$ & Same as above \\
\hline $\begin{array}{l}\text { Uncertainty that PM can be completed and } \\
\text { component can be returned to service }\end{array}$ & Schedule during specified shutdown period \\
\hline \multicolumn{2}{|c|}{ PM DURING PLANT SHUTDOWN } \\
\hline Concerns & Insights \\
\hline $\begin{array}{l}\text { Risk impact during certain shutdown periods } \\
\text { significant }\end{array}$ & $\begin{array}{l}\text { Avoid EDG long duration PM during specified } \\
\text { shutdown activities (e.g., initial phases of shut- } \\
\text { down); guidance to perform PM during certain } \\
\text { low-risk shutdown periods }\end{array}$ \\
\hline $\begin{array}{l}\text { Outage duration can be lengthened, if the bur- } \\
\text { den of PM during shutdown period is increased }\end{array}$ & $\begin{array}{l}\text { Allow portion of PM activity spread during } \\
\text { power operation (avoid "running start" on } \\
\text { maintenance) }\end{array}$ \\
\hline Unreliable EDG during power operation & $\begin{array}{l}\text { Optimize PM program between power opera- } \\
\text { tion and shutdown; certain PM during power } \\
\text { operation may improve reliability of EDG }\end{array}$ \\
\hline
\end{tabular}


Table 5.4 Scheduling EDG Maintenances

\begin{tabular}{|c|c|c|c|c|}
\hline $\begin{array}{c}\text { Type of } \\
\text { Maintenance and } \\
\text { Frequency }\end{array}$ & $\begin{array}{c}\text { Maintenance } \\
\text { Duration }\end{array}$ & $\begin{array}{c}\text { Concern for Scheduling } \\
\text { Maintenance During Power } \\
\text { Operation }\end{array}$ & $\begin{array}{l}\text { Concern for Scheduling } \\
\text { Maintenance During } \\
\text { Shutdown }\end{array}$ & Insights $^{\dagger}$ \\
\hline $\begin{array}{l}\text { 1. Scheduled PMs } \\
\text { Fixed frequency } \\
\text { PMs that need to be } \\
\text { performed between } \\
\text { a refueling outage } \\
\text { (less than } 18 \\
\text { months) }\end{array}$ & $\begin{array}{l}\text { a) } \sim \text { AOT } \\
\text { b) Longer } \\
\text { than AOT }\end{array}$ & $\begin{array}{l}\text { - repeated use may impose } \\
\text { unacceptable risk } \\
\text { - repeated use prior to testing } \\
\text { masks EDG failure, unreli- } \\
\text { able EDG failure data } \\
\text { - risk impact may be unac- } \\
\text { ceptable }\end{array}$ & $\begin{array}{l}\text { - unreliable EDG during } \\
\text { power operation } \\
\text { - plant outage duration } \\
\text { can be lengthened } \\
\text { - unreliable EDG during } \\
\text { power operation }\end{array}$ & $\begin{array}{l}\text { - may schedule during power oper- } \\
\text { ation } \\
\text { - optimize PM during power oper- } \\
\text { ation and shutdown } \\
\text { - monitor EDG unavailability due } \\
\text { to PM (if PM duration or frequency } \\
\text { during power operation is exces- } \\
\text { sive, find and correct causes); or } \\
\text { set limit for PM duration and fre- } \\
\text { quency during power operation } \\
\text { - may be performed during power } \\
\text { operation with extended AOT in } \\
\text { order to assure EDG reliability dur- } \\
\text { ing this period. } \\
\text { - could involve exemption to AOT } \\
\text { - avoid "running start" on mainte- } \\
\text { nance }\end{array}$ \\
\hline
\end{tabular}


Table 5.4 Scheduling EDG Maintenances (Cont'd.)

\begin{tabular}{|c|c|c|c|c|}
\hline $\begin{array}{c}\text { Type of } \\
\text { Maintenance and } \\
\text { Frequency }\end{array}$ & $\begin{array}{c}\text { Maintenance } \\
\text { Duration }\end{array}$ & $\begin{array}{c}\text { Concern for Scheduling } \\
\text { Maintenance During Power } \\
\text { Operation }\end{array}$ & $\begin{array}{c}\text { Concern for Scheduling } \\
\text { Maintenance During } \\
\text { Shutdown }\end{array}$ & Insights $^{\dagger}$ \\
\hline $\begin{array}{l}\text { 2. Scheduled PMs } \\
\text { Fixed frequency } \\
\text { PMs that need to be } \\
\text { performed every } \\
11 \frac{1}{2} \text { to } 2 \text { yrs (or } \\
\text { longer) }\end{array}$ & $\begin{array}{l}\text { a) }<<\text { AOT } \\
\text { b) } \sim \text { AOT } \\
\text { c) Longer } \\
\text { than AOT }\end{array}$ & $\begin{array}{l}\text { - none } \\
\text { - uncertainty that PM can be } \\
\text { completed and the component } \\
\text { can be returned to service } \\
\text { within an AOT. } \\
\text { - repeated use of LCOs for } \\
\text { such maintenance imposes } \\
\text { unacceptable risk } \\
\text { - risk impact may be unac- } \\
\text { ceptable } \\
\text { - uncertainty that PM can be } \\
\text { completed and the component } \\
\text { can be returned to service }\end{array}$ & $\begin{array}{l}\text { - plant outage duration } \\
\text { can be lengthened } \\
\text { - risk impact during } \\
\text { certain shutdown periods } \\
\text { may be significant } \\
\text { - risk impact during } \\
\text { certain shutdown periods } \\
\text { significant }\end{array}$ & $\begin{array}{l}\text { - schedule during power operation } \\
\text { or shutdown } \\
\text { - optimize PM program between } \\
\text { power operation and shutdown } \\
\text { - schedule during shutdown } \\
\text { - define allowable states during } \\
\text { plant shutdown, e.g., avoid early } \\
\text { stages of shutdown. }\end{array}$ \\
\hline
\end{tabular}


Table 5.4 Scheduling EDG Maintenances (Cont'd.)

\begin{tabular}{|c|c|c|c|c|}
\hline $\begin{array}{c}\text { Type of } \\
\text { Maintenance and } \\
\text { Frequency }\end{array}$ & $\begin{array}{c}\text { Maintenance } \\
\text { Duration }\end{array}$ & $\begin{array}{l}\text { Concern for Scheduling } \\
\text { Maintenance During Power } \\
\text { Operation }\end{array}$ & $\begin{array}{l}\text { Concern for Scheduling } \\
\text { Maintenance During } \\
\text { Shutdown }\end{array}$ & Insights $^{\dagger}$ \\
\hline $\begin{array}{l}\text { 3. Condition - } \\
\text { Directed PMs } \\
\text { As needed to cor- } \\
\text { rect degradation of } \\
\text { equipment (choices } \\
\text { include scheduling } \\
\text { maintenance during } \\
\text { power operations, } \\
\text { waiting until the } \\
\text { next shutdown, or } \\
\text { immediately pro- } \\
\text { ceeding to shut- } \\
\text { down) }\end{array}$ & $\begin{array}{l}\text { a) <AOT } \\
\text { b) AOT } \\
\text { c) Longer } \\
\text { than AOT }\end{array}$ & $\begin{array}{l}\text { - repeated use increases risk } \\
\text { from EDG downtimes } \\
\text { - uncertainty that PM can be } \\
\text { completed and the component } \\
\text { may be returned to service } \\
\text { within an AOT } \\
\text { - uncertainty that PM can be } \\
\text { completed and the component } \\
\text { can be returned to service }\end{array}$ & $\begin{array}{l}\text { - unnecessary risk from } \\
\text { shutting down } \\
\text { - increased risk during } \\
\text { power operation } \\
\text { - larger relative risk to } \\
\text { perform maintenance } \\
\text { during critical phases of } \\
\text { shutdown } \\
\text { - increased risk of shut- } \\
\text { ting down with unreliable } \\
\text { EDG. } \\
\text { - long wait to perform } \\
\text { maintenance if a prefer- } \\
\text { able state in shutdown } \\
\text { mode is to be chosen }\end{array}$ & $\begin{array}{l}\text { - schedule during power operation } \\
\text { - control or monitor frequency to } \\
\text { avoid misuse } \\
\text { - schedule during power operation } \\
\text { - for scheduling during power } \\
\text { operation, test of redundant diesel } \\
\text { to assure availability, prior to start } \\
\text { of PM, may be desirable } \\
\text { - depends on a number of factors, } \\
\text { e.g., severity of degradation, time } \\
\text { to next scheduled outage, potential } \\
\text { for common cause failure } \\
\text { - may involve changes to TS if } \\
\text { scheduled during power operation, } \\
\text { e.g., increased AOT, additional test } \\
\text { requirements }\end{array}$ \\
\hline
\end{tabular}

${ }^{\dagger}$ Assumes that the assigned AOTs are appropriate based on risk considerations.

- AOT: Allowed Outage time, PM: Preventive Maintenance, EDG: Emergency Diesel Generator, TS: Technical Specification. 


\section{SUMMARY AND RECOMMENDATIONS}

This report presents an assessment of the unavailability of emergency diesel generators (EDGs) and its impact on the risk of operating nuclear power plants. Using recent operating-experience data from nuclear power plants in the United States, we estimated EDG unavailability due to maintenance, testing, and failures for both individual generators and populations. The unavailability of an EDG influences the plant risk, and this impact is measured in terms of the changes in the plant core-damage frequency (CDF), calculated using plant-specific probabilistic safety assessments (PSAs). The impact of EDG maintenance on plant CDF during shutdown periods also is evaluated, using the PSA models. The risk impacts of EDG maintenances during power operation versus shutdown are compared to obtain qualitative insights for scheduling routine EDG maintenances.

The results of this study and the insights gained are summarized below on each of the following four aspects:

a) EDG unavailability due to test and maintenances.

b) EDG unavailability due to failures.

c) Impact on core-damage frequency of EDG unavailability during power operation.

d) Comparison of the impact of core-damage frequency during power operation versus shutdown and the resultant considerations for scheduling routine EDG maintenances.

\section{EDG Unavailability Due to Maintenance and Tests}

The EDG unavailability due to scheduled preventive maintenance, unscheduled corrective maintenance, and test was evaluated for 212 EDGs at 97 plant units. EDG out-of-service data from a recent regional NRC survey covering two years (June 1990 to May 1992) were used. EDG unavailability contributions were analyzed separately for power operation and shutdown periods. The findings are summarized as follows:

- Scheduled preventive maintenance is routinely carried out in most plants during power operation.

- The estimates of EDG unavailability due to maintenance (corrective plus preventive) are the following:

\section{During Power \\ Operation}

EDG Unavailability

Due to Maintenance
Mean: 0.020

Standard deviation: 0.017
During Plant
Shutdown

Mean: 0.12

Standard deviation: 0.11

Since these estimates reflect recent plant practices from a very large population of EDGs in the United States, they can be used in PSAs as estimates for EDG unavailability due to maintenance.

- During power operation EDG unavailability due to maintenance is approximately 3-fold higher than the previous estimate of 0.007 . Scheduled maintenance contributes forty percent of the total 
EDG unavailability due to maintenance, testing, and failures; scheduled plus unscheduled maintenance may contribute as much as sixty percent of the total unavailability.

- Significant maintenance is performed during shutdown. About three quarters of EDG maintenances are being performed then.

- For a plant with a 70\% capacity factor, these estimates suggest that each EDG is out of service for 5 days over 8.4 months when the reactor is at power, and 13 days over 3.6 months when the reactor is shut down. For a plant in continued power operation for a year, each EDG is out of service for 7.2 days during that period.

- Scheduling of preventive-maintenance practices varies significantly from plant to plant. For some, EDG scheduled maintenance unavailabilities during power operation are over a factor of 2 larger than the industry average. Some plants with high EDG unavailabilities due to scheduled preventive maintenance also have high unavailabilities due to corrective maintenance. For about 10 percent of EDGs, scheduled preventive maintenances are performed, on the average, more than once a month. The mean frequency of scheduled maintenances is $5.5 /$ year.

- From the number of maintenances carried out on EDGs, we infer that significant EDG maintenances are needed to assure their needed reliability.

\section{EDG Unreliability for Failure to Start and Load-Run}

The EDG unreliability due to failure to start and load-run was analyzed using data from 195 EDGs at 63 plant sites. This database differs from the one used to estimate the test and maintenance unavailability. Compiled by Nuclear Management and Resource council (NUMARC), a nuclear industry organization, this database gives the number of failures to start and load-run and the number of demands imposed on each EDG between 1988 and 1991. It did not identify the plants nor the dates when the failures were discovered. Consequently, the data could not be used in conjunction with the EDG out-ofservice data for test and maintenance. For example, the frequency and duration of scheduled preventive maintenance could not be correlated to EDG reliability. However, the data were adequate to estimate individual EDG unreliability and the population distribution. The empirical Bayes method was used to assess EDG unreliability over the population of EDGs. Because failure dates were not included in the database, common-cause failures of EDGs, a dominant contributor to emergency ac system unavailability and the plant CDF, could not be identified and studied. The insights from the analyses are as follows:

- EDG unreliability, and, correspondingly, its contribution to unavailability due to failures, is 0.014 for 1988-1991, smaller than the previous estimate of 0.020 for 1981 to 1983 and 0.019 in 1984 . The probability of EDG failure during actual demands can be greater than that estimated from surveillance test data. This aspect was not studied because the database did not differentiate between these two types of demands.

- The reason for the apparent increase in the EDG reliability in recent years was not studied. However, the increase in EDG preventive maintenance noted as increased maintenance unavailability may be contributing to this improvement in reliability. 
- EDG failure data can be monitored or evaluated periodically (either on an EDG basis or an industry basis) to assess the reliability levels being achieved, to trend common-cause failures, and to identify outliers, i.e., those EDGs whose performances lie outside the average trend.

\section{Risk Impact of EDG Unavailability During Power Operation}

The risk impact of EDG unavailability was analyzed using six plant-specific PSAs. The sensitivity of plant CDF to changes in EDG unavailability due to maintenance-related activities and failure to start and load-run was studied using the unavailability estimates obtained in this report. The relative impact of maintenance and failure unavailabilities during power operation was assessed based on the sensitivity studies. As modeled in the PSA, the increased maintenance unavailability does not influence the EDG failure unavailability, i.e., the failure to start and load probabilities remain the same, and vice versa. The observations based on the risk impact analyses of EDG unavailability can be summarized as follows:

- Core-damage frequency is more sensitive to EDG failures to start and load-run than to maintenance unavailability.

- $\quad$ EDGs are among the most risk-significant components in a nuclear power plant, and taking individual EDGs out-of-service for maintenance results in about an order of magnitude increase in the plant CDF for the duration of the EDG outage. When taking an individual EDG out of service, the time for maintenance during power operation is limited by technical specification allowed outage time, usually 3 or 7 days.

- Plant CDF is relatively insensitive to increased EDG maintenance, although the CDF increase can be significant for those plants with high maintenance unavailability and when the maintenance is increased beyond current practice. Also, considering that effective maintenance is expected to result in reliable performance, EDG maintenance during power operation can be beneficial, provided that adequate care is taken to control the risk.

- Taking other components out of service in combination with an EDG may significantly increase plant CDF. Scheduling of EDG maintenance should avoid simultaneous outage of multiple risksignificant components.

- EDG maintenance practices that may not be contributing to EDG reliability, but contributing to increased risk, should be identified and eliminated. Guidance for preventive maintenance can be developed to balance the beneficial versus adverse risk impacts of maintenance during both power operation and plant shutdown.

\section{Consideration for EDG Maintenance During Power Operation Versus Shutdown}

The impact on plant core-damage frequency for taking an EDG out of service for maintenance during power operation and during plant shutdown was assessed for two plants, a pressurized water reactor (PWR), and a boiling water reactor (BWR). BNL analyzed a PWR, and SNL analyzed a BWR. For these plants, both full-power and shutdown PSA models were available. Conditional CDF given an out-of-service EDG was calculated and compared for different modes of plant operation, e.g., power operation, hot shutdown, and refueling. In general, the PSA models for modes other than power operation use conservative screening approaches and the level of detail may not be comparable to that 
of the power operation model. However, qualitative insights were derived on scheduling preventive maintenances. The results and insights are summarized below.

- The CDF impact of an EDG maintenance during early stages of plant shutdown, i.e., hot shutdown and early part of cold shutdown, is comparable with that for power operation.

- During refueling, when the water level is raised, the risk impact of taking an EDG out of service is substantially reduced. This period appears most favorable for scheduling EDG maintenances. Accordingly, preventive maintenances of long duration should be scheduled during such periods and the early stages of plant shutdown should be avoided.

- When the maintenance duration is relatively short, e.g., less than 1 or 2 days, the contribution to core-damage probability during power operation or during shutdown is relatively small. It is reasonable to schedule such maintenances during power operation. However, repeated maintenances involve increased risk.

\section{Recommendations for Future Research}

The analysis of EDG unavailability and its impact on plant risk provided valuable information on practices to assure reliable operation of this important equipment in nuclear power plants. However, many aspects about the relationship between test and maintenance practices and EDG reliability, and also, approaches to improve reliability were not studied. The database collected here can be supplemented using other databases, e.g., Nuclear Plant Reliability Data System (NPRDS), to study these additional aspects. Some of the recommended areas for further investigation are stated below:

- The relationship among different types of maintenance activities and EDG reliability needs to be understood better. For example, how does preventive maintenance affect EDG reliability? Does the frequency of such maintenances have an effect? Or is it the type and the duration involved that determine the influence of the preventive maintenance? Does the failure probability and the need for corrective maintenance decline with increased preventive maintenance?

- For failures of multiple EDGs, current TSs require immediate plant shutdown. Research on residual heat removal and standby service water system for a plant ${ }^{24}$ found that the risk of continued operation can be lower than shutting down the plant in case of multiple failures, and, when the repair duration is short, the best option can be to conduct it during power operation and make at least one train operable promptly. Specific strategies, considering the relative risk of continued power operation and shutting down, can be studied to define actions for multiple EDG failures.

- Scheduling preventive maintenances during various modes of plant operation (e.g., power operation, cold shutdown) should be analyzed further to better understand, from a riskperspective, the balance between beheficial and adverse aspects of maintenances. The need for EDG overhauls also should be considered.

- This study discussed monitoring of EDG unavailability due to maintenances and failures to identify unsatisfactory performances. Unsatisfactory performances include those outlier EDGs with high unavailability or low reliability or both. Specific approaches for monitoring EDG unavailability and their use in scheduling EDG maintenances should be considered. 


\section{REFERENCES}

1. U.S. Federal Register, Vol. 53, No. 119, Nuclear Regulatory Commission, 10 CFR Part 50, Station Blackout, June 21, 1988.

2. USNRC Regulatory Guide 1.155, Station Blackout, August 1988.

3. T.C. Cintula, "Special Study Report: Performance of Emergency Diesel Generators in Restoring Power to Their Associated Safety Buses -- A Review of Events Occurring at Power," AEOD/S9101, USNRC, September 1991.

4. USNRC Inspection Manual, Part 9900 - Technical Guidance, "Maintenance - Voluntary Entry into Limiting Conditions for Operation Action Statements to Perform Preventive Maintenances," April 18, 1991.

5. T.L. Chu, et al., "Evaluation of Potential Severe Accidents During Low Power and Shutdown Operations at Surry, Unit 1," NUREG/CR-6144, BNL-NUREG-52399, Vol. 2, Part 5, Appendix I, Brookhaven National Laboratory, June 1994.

6. D. W. Whitehead, et al., "BWR Low Power and Shutdown Accident Sequence Frequencies Project for Grand Gulf Nuclear Station," Draft Report, Sandia National Laboratory, June 1991.

7. Letter from Partlow, NRR to NRC Regional Offices, Request for Emergency Diesel Generator Unavailability Data Due to Planned Maintenance During' Power Operation and Shutdown, June 19, 1992.

8. P. Lobner, C. Donahoe, C. Cavalin, "Overview and Comparison of U.S. Commercial Nuclear Power Plants," NUREG/CR-5640, SAIC-891/1541, September 1990.

9. J. Higgins and M. Subudhi, "A Review of Emergency Diesel Generator Performance at Nuclear Power Plants," NUREG/CR-4410, Brookhaven National Laboratory, January 1985.

10. R. E. Battle and D. J. Campbell, "Reliability of Emergency AC Power System at Nuclear Power Plants," NUREG/CR-2989 (ORNL/TM-8545), July 1983.

11. M. Maqua, "Evaluation of Operational Experiences on the Reliability of Emergency Diesel Units in German Atomic Power Plants," The Federal Republic of Germany Ministry of Environment, Nature Conservation and Reactor Safety, Translation of German Report, NRC 2757, July 12, 1993.

12. U. Pulkkinen, T. Huovinen, L. Nowes, T. Mankamo, and J. Vanhala, "Reliability of Diesel Generators in the Finnish and Swedish Nuclear Power Plants," Technical Research Center of Finland, Research Note 1070, October 1989.

13. Letter from Alex Marion, NUMARC to H. Lewis, ACRS, Industry-Wide Data on Emergency Diesel Generator Performance, March 5, 1992.

14. J.S. Maritz and T. Lwin, Empirical Bayes Methods, Chapman and Hall, London, 1989. 
15. D. Collett, Modeling Binary Data, Chapman and Hall, London, 1991.

16. H. Martz and R. Waller, Bayesian Reliability Analysis, Krieger Publishing Co., Malabar, Florida, 1991.

17. J.K. Shultis, F.A. Tillman, N.D. Eckhoff, D. Ghosh, Bayesian Analysis of Component Failure Data, NUREG/CR-1110, November 1979.

18. H.F. Martz and M.G. Lian, Empirical Bayes Estimator of the Binomial Parameter, Biometrika, Vol. 61, 1974, pp. 517-523.

19. J.B. Copas, Empirical Bayes Methods and the Repeated Use of a Standard, Biometrika, Vol. 59, 1972, pp. 349-360.2.

20. R. E. Battle, "Emergency Diesel Generator Operational Experience, 1981-83, " NUREG/CR-4347 (ORNL/TM 9739), December 1985.

21. Reliability Data Book for Components in the Nordic Nuclear Power Plants, 3rd Edition, Swedish Nuclear Power Inspectorate, 1993.

22. B. D. Staple, G. Benavides, J. Yankle, J. Darby, "The Risk Impact of Diesel Generator Unavailabilities for BWRs During Low Power and Shutdown," Letter Report, Sandia National Laboratory, May 1993.

23. R. P. Rohrer, J. F. Quilliam, and D. P. Blanchard, "Risk Assessment of Diesel Generator Maintenance at Monticello," PSA'93 Probabilistic Safety Assessment International Topical Meeting, Clearwater Beach, Florida, January 26-29, 1993.

24. T. Mankamo, I. Kim, and P. Samanta, "Technical Specification Action Statements Requiring Shutdown: A Risk Prospective with Application to RHR/SSW Systems of a BWR," NUREG/CR5995, BNL-NUREG-52364, Brookhaven National Laboratory, November 1993.

25. J. Higgins, C. Czajkowski, and A. Tingle, "A Review of Issues Related to Improving Nuclear Power Plant Diesel Generator Reliability, "NUREG/CR-4557, BNL-NUREG-51969, Brookhaven National Laboratory, April 1986. 
APPENDIX A

LIST OF NUCLEAR UNITS AND EDG-RELATED INFORMATION 
Table A.1. Configurations of Emergency Electric Power Systems for PWR Plants

\begin{tabular}{|c|c|c|c|c|}
\hline Plant Name & Number of Units & $\begin{array}{c}\text { Dedicated } \\
\text { EDGs per Unit }\end{array}$ & EDGs Shared & Total EDGs \\
\hline Arkansas $1 \& 2$ & 2 & 2 & None & 4 \\
\hline Beaver Valley 1 \& 2 & 2 & 2 & None & 4 \\
\hline Braidwood 1 \& 2 & 2 & 2 & None & 4 \\
\hline Byron 1 \& 2 & 2 & 2 & None & 4 \\
\hline Callaway 1 & 1 & 2 & $N / A^{* 1}$ & 2 \\
\hline Calvert Cliffs $1 \& 2$ & 2 & 1 & 1 & 3 \\
\hline Catawba $1 \& 2$ & 2 & 2 & None & 4 \\
\hline Comanche Peak 1 & 1 & 2 & N/A & 2 \\
\hline Cook $1 \& 2$ & 2 & 2 & None & 4 \\
\hline Crystal River 3 & 1 & 2 & N/A & 2 \\
\hline Davis-Besse 1 & 1 & 2 & N/A & 2 \\
\hline Diablo Canyon $1 \& 2$ & 2 & 2 & 1 & 5 \\
\hline Farley 1 \& 2 & 2 & 1 & 3 & 5 \\
\hline Fort Calhoun 1 & 1 & 2 & N/A & 2 \\
\hline Ginna & 1 & 2 & $\mathrm{~N} / \mathrm{A}$ & 2 \\
\hline Haddam Neck & 1 & 2 & N/A & 2 \\
\hline Harris 1 & 1. & 2 & N/A & 2 \\
\hline Indian Point $2 \& 3$ & 2 & 3 & None & 6 \\
\hline Kewaunee & 1 & 2 & N/A & 2 \\
\hline Maine Yankee & 1 & 2 & $\mathrm{~N} / \mathrm{A}$ & 2 \\
\hline McGuire $1 \& 2$ & 2 & 2 & None & 4 \\
\hline Millstone 2 \& 3 & 2 & 2 & None & 4 \\
\hline North Anna $1 \& 2$ & 2 & 2 & None & 4 \\
\hline Oconee $1,2 \& 3$ & 3 & None & $2^{* 2}$ & 2 \\
\hline Palisades & 1 & 2 & N/A & 2 \\
\hline Palo Verde $1,2 \& 3$ & 3 & 2 & None & 6 \\
\hline Point Beach $1 \& 2$ & 2 & None & 2 & 2 \\
\hline
\end{tabular}


Table A.1. (Cont'd)

\begin{tabular}{||l|c|c|c|c||}
\hline \multicolumn{1}{|c|}{ Plant Name } & Number of Units & $\begin{array}{c}\text { Dedicated } \\
\text { EDGs per Unit }\end{array}$ & EDGs Shared & Total EDGs \\
\hline \hline Prairie Island 1 \& 2 & 2 & None & 2 & 2 \\
\hline Rancho Seco 1 & 1 & 2 & N/A & 2 \\
\hline Robinson 2 & 1 & 2 & N/A & 2 \\
\hline Salem 1 \& 2 & 2 & 3 & None & 6 \\
\hline San Onofre 1 & 1 & 2 & N/A & 2 \\
\hline San Onofre 2 \& 3 & 2 & 2 & None & 4 \\
\hline Seabrook 1 & 1 & 2 & N/A & 2 \\
\hline Sequoyah 1 \& 2 & 2 & 2 & None & 4 \\
\hline South Texas 1 \& 2 & 2 & 3 & None & 6 \\
\hline St Lucie 1 \& 2 & 2 & 2 & None & 4 \\
\hline Summer 1 & 1 & 2 & N/A & 2 \\
\hline Surry 1 \& 2 & 2 & 1 & 1 & 3 \\
\hline Three Mile Island 1 & 1 & 2 & N/A & 2 \\
\hline Trojan & 1 & None & N/A & 2 \\
\hline Turkey Point 3 \& 4 & 2 & 2 & None & 2 \\
\hline Vogtle 1 \& 2 & 1 & 2 & N/A & 2 \\
\hline Waterford 3 & 2 & 2 & 2 & 3 \\
\hline Wolfcreek 1 & 1 & 2 & 2 & 5 \\
\hline Yankee-Rowe 1 & 2 & 2 & 2 & 2 \\
\hline Zion 1 \& 2 & 2 & 2 & 2 & 2 \\
\hline
\end{tabular}

${ }^{*} 1$ Not applicable.

${ }^{* 2}$ Hydroelectric generators.

${ }^{*}$ Each generator has two engines. 
Table A.2. Configurations of Emergency Electric Power Systems for BWR Plants

\begin{tabular}{|c|c|c|c|c|c|}
\hline Plant Name & BWR Type & $\begin{array}{l}\text { Number } \\
\text { of Units }\end{array}$ & $\begin{array}{c}\text { Dedicated } \\
\text { EDGs per } \\
\text { Unit }\end{array}$ & $\begin{array}{l}\text { Shared } \\
\text { EDGs per } \\
\text { Plant }\end{array}$ & Total EDGs \\
\hline Big Rock Point 1 & 1 & 1 & 1 & $N / A^{* 1}$ & 1 \\
\hline Browns Ferry $1 \& 2$ & 4 & 2 & None & 4 & 4 \\
\hline Browns Ferry 3 & 4 & 1 & 4 & N/A & 4 \\
\hline Brunswick 1 \& 2 & 4 & 2 & 2 & None & 4 \\
\hline Clinton 1 & 6 & 1 & 3 & N/A & $3^{* 2}$ \\
\hline Cooper Station & 4 & 1 & 2 & $\mathrm{~N} / \mathrm{A}$ & 2 \\
\hline Dresden $2 \& 3$ & 3 & 2 & 1 & 1 & 3 \\
\hline Duane Arnold & 4 & 1 & 2 & N/A & 2 \\
\hline Fermi 2 & 4 & 1 & 4 & N/A & 4 \\
\hline Fitzpatrick & 4 & 1 & 4 & N/A & 4 \\
\hline Grand Gulf 1 & 6 & 1 & 3 & N/A & $3^{* 2}$ \\
\hline Hatch $1 \& 2$ & 4 & 2 & 2 & 1 & 5 \\
\hline Hope Creek 1 & 4 & 1 & 4 & N/A & 4 \\
\hline Lasalle 1 \& 2 & 5 & 2 & 2 & 1 & 5 \\
\hline Limerick $1 \& 2$ & 4 & 2 & 4 & None & 8 \\
\hline Millstone 1 & 3 & 1 & 2 & N/A & $2^{* 3}$ \\
\hline Monticello & 3 & 1 & 2 & N/A & 2 \\
\hline Nine Mile Point 1 & 2 & 1 & 2 & N/A & 2 \\
\hline Nine Mile Point 2 & 5 & 1 & 2 & N/A & 2 \\
\hline Oyster Creek 1 & 2 & 1 & 2 & N/A & 2 \\
\hline Peach Bottom $2 \& 3$ & 4 & 2 & None & 4 & 4 \\
\hline Perry 1 & 6 & 1 & 3 & N/A & $3^{* 2}$ \\
\hline Pilgrim 1 & 3 & 1 & 2 & N/A & 2 \\
\hline Quad Cities $1 \& 2$ & 3 & 2 & 1 & 1 & 3 \\
\hline River Bend 1 & 6 & 1 & 3 & N/A & $3^{* 2}$ \\
\hline Susquehanna $1 \& 2$ & 4 & 2 & None & 4 & $5^{* 4}$ \\
\hline
\end{tabular}


Table A.2. (Cont'd)

\begin{tabular}{|l|c|c|c|c|c|}
\hline Plant Name & BWR Type & $\begin{array}{c}\text { Number } \\
\text { of Units }\end{array}$ & $\begin{array}{c}\text { Dedicated } \\
\text { EDGs per } \\
\text { Unit }\end{array}$ & $\begin{array}{c}\text { Shared } \\
\text { EDGs per } \\
\text { Plant }\end{array}$ & Total EDGs \\
\hline \hline Vermont Yankee 1 & 4 & 1 & 2 & N/A & 2 \\
\hline Washington Nuclear 2 & 5 & 1 & 2 & N/A & 2 \\
\hline
\end{tabular}

${ }^{1}$ Not applicable.

${ }^{2}$ In these BWR/6 plants, one diesel generator is dedicated to the high pressure core spray (HPCS) system.

${ }^{3}$ One diesel generator and one gas turbine generator.

${ }^{4}$ Diesel generators A, B, C, and D on standby. Diesel generator E is available to replace any diesel which must be in maintenance. 
Table A.3. Diesel Generator Manufacturers and Allowed Outage Time

\begin{tabular}{|c|c|c|c|c|}
\hline $\begin{array}{c}\text { NRC Docket } \\
(50-)\end{array}$ & Plant Name & $\begin{array}{l}\text { Diesel Generator } \\
\text { Manufacturer }\end{array}$ & $\begin{array}{l}\text { DG AOT } \\
\text { (days) }\end{array}$ & $\begin{array}{c}\text { PM } \\
\text { Exemption }^{2}\end{array}$ \\
\hline 313 & Arkansas 1 & General Motors & 7 & \\
\hline 368 & Arkansas 2 & Fairbanks Morse & 3 & \\
\hline 334 & Beaver Valley 1 & General Motors & 3 & \\
\hline 412 & Beaver Valley 2 & Fairbanks Morse & 3 & \\
\hline 155 & Big Rock Point & Caterpillar & 3 & \\
\hline 456 & Braidwood 1 & Cooper Energy Services & 3 & \\
\hline 457 & Braidwood 2 & Cooper Energy Services & 3 & \\
\hline 259 & Browns Ferry 1 & General Motors & $7^{3}$ & \\
\hline 260 & Browns Ferry 2 & General Motors & 7 & \\
\hline 296 & Browns Ferry 3 & General Motors & 7 & \\
\hline 325 & Brunswick 1 & Nordberg & 7 & \\
\hline 324 & Brunswick 2 & Nordberg & 7 & \\
\hline 454 & Byron 1 & General Motors & 3 & \\
\hline 455 & Byron 2 & General Motors & 3 & \\
\hline 483 & Callaway & Fairbanks Morse & 3 & Yes \\
\hline 317 & Calvert Cliffs 1 & Fairbanks Morse & 3 & \\
\hline 318 & Calvert Cliffs 2 & Fairbanks Morse & 3 & \\
\hline 413 & Catawba 1 & TransAmerica DeLaval & 3 & Yes \\
\hline 414 & Catawba 2 & TransAmerica DeLaval & 3 & Yes \\
\hline 461 & Clinton 1 & General Motors & 3 & Yes \\
\hline 445 & Comanche Peak 1 & TransAmerica DeLaval & 3 & Yes \\
\hline 446 & Comanche Peak 2 & TransAmerica DeLaval & 3 & Yes \\
\hline 315 & Cook 1 & Worthington & 3 & Yes \\
\hline 316 & Cook 2 & Worthington & 3 & Yes \\
\hline 298 & Cooper Station & Cooper Energy Services & 7 & \\
\hline 302 & Crystal River 3 & Fairbanks Morse & 3 & \\
\hline 346 & Davis-Besse 1 & General Motors & 3 & \\
\hline
\end{tabular}


Table A.3. (Cont'd)

\begin{tabular}{|c|c|c|c|c|}
\hline $\begin{array}{c}\text { NRC Docket } \\
(50-)\end{array}$ & Plant Name & $\begin{array}{c}\text { Diesel Generator } \\
\text { Manufacturer }\end{array}$ & $\begin{array}{l}\text { DG AOT } \\
\text { (days) }\end{array}$ & $\begin{array}{c}\text { PM } \\
\text { Exemption }\end{array}$ \\
\hline 275 & Diablo Canyon 1 & Alco & 7 & Yes \\
\hline 323 & Diablo Canyon 2 & Alco & 7 & Yes \\
\hline 237 & Dresden 2 & General Motors & 7 & Yes \\
\hline 249 & Dresden 3 & General Motors & 7 & Yes \\
\hline 331 & Duane Arnold & Fairbanks Morse & 7 & \\
\hline 348 & Farley 1 & Fairbanks Morse & 8 & \\
\hline 364 & Farley 2 & Fairbanks Morse & 8 & \\
\hline 341 & Fermi 2 & Fairbanks Morse & 3 & \\
\hline 333 & Fitzpatrick & General Motors & 7 & \\
\hline 285 & Fort Calhoun 1 & General Motors & 7 & \\
\hline 244 & Ginna & Alco & 7 & \\
\hline 416 & Grand Gulf 1 & TransAmerica DeLaval & $3^{4}$ & \\
\hline 213 & Haddam Neck & General Motors & 3 & Yes \\
\hline 400 & Harris 1 & Unknown & 3 & \\
\hline 321 & Hatch 1 & Fairbanks Morse & 7 & \\
\hline 366 & Hatch 2 & Fairbanks Morse & 3 & \\
\hline 354 & Hope Creek 1 & Fairbanks Morse & 3 & Yes \\
\hline 247 & Indian Point 2 & Alco & 7 & \\
\hline 286 & Indian Point 3 & Alco & 3 & \\
\hline 305 & Kewaunee & General Motors & 7 & \\
\hline 373 & Lasalle 1 & General Motors & $3^{5}$ & Yes \\
\hline 374 & Lasalle 2 & General Motors & 3 & Yes \\
\hline 352 & Limerick 1 & Fairbanks Morse & $30^{6}$ & Yes \\
\hline 353 & Limerick 2 & Fairbanks Morse & 30 & Yes \\
\hline 309 & Maine Yankee & General Motors & 7 & \\
\hline 369 & McGuire 1 & Nordberg & 3 & Yes \\
\hline 370 & McGuire 2 & Nordberg & 3 & Yes \\
\hline
\end{tabular}


Table A.3. (Cont'd)

\begin{tabular}{|c|c|c|c|c|}
\hline $\begin{array}{l}\text { NRC Docket } \\
(50-)\end{array}$ & Plant Name & $\begin{array}{l}\text { Diesel Generator } \\
\text { Manufacturer }\end{array}$ & $\begin{array}{l}\text { DG AOT } \\
\text { (days) }\end{array}$ & $\stackrel{\text { PM }}{\text { Exemption }^{2}}$ \\
\hline 245 & Millstone 1 & Fairbanks Morse & 7 & \\
\hline 336 & Millstone 2 & Fairbanks Morse & 3 & \\
\hline 423 & Millstone 3 & Fairbanks Morse & 3 & Yes \\
\hline 263 & Monticello & General Motors & 7 & Yes \\
\hline 220 & Nine Mile Point 1 & General Motors & 7 & \\
\hline 410 & Nine Mile Point 2 & $\begin{array}{l}\text { Cooper Energy } \\
\text { Services/General Motors }\end{array}$ & 3 & Yes \\
\hline 338 & North Anna 1 & Fairbanks Morse & 3 & Yes \\
\hline 339 & North Anna 2 & Fairbanks Morse & 3 & Yes \\
\hline 219 & Oyster Creek 1 & General Motors & 7 & \\
\hline 255 & Palisades & Alco & 3 & \\
\hline 528 & Palo Verde 1 & Cooper Energy Services & 3 & Yes \\
\hline 529 & Palo Verde 2 & Cooper Energy Services & 3 & Yes \\
\hline 530 & Palo Verde 3 & Cooper Energy Services & 3 & Yes \\
\hline 277 & Peach Bottom 2 & Fairbanks Morse & 7 & \\
\hline 278 & Peach Bottom 3 & Fairbanks Morse & 7 & \\
\hline 440 & Perry 1 & General Motors & 3 & Yes \\
\hline 293 & Pilgrim 1 & Alco & 3 & \\
\hline 266 & Point Beach 1 & General Motors & 7 & \\
\hline 301 & Point Beach 2 & General Motors & 7 & \\
\hline 282 & Prairie Island 1 & General Motors & 3 & Yes \\
\hline 306 & Prairie Island 2 & General Motors & 3 & Yes \\
\hline 254 & Quad Cities 1 & General Motors & 7 & \\
\hline 265 & Quad Cities 2 & General Motors & 7 & \\
\hline 458 & River Bend 1 & General Motors & 3 & Yes \\
\hline 261 & Robinson 2 & Fairbanks Morse & 7 & \\
\hline 23 & Salem 1 & Alco & 3 & \\
\hline
\end{tabular}


Table A.3. (Cont'd)

\begin{tabular}{|c|c|c|c|c|}
\hline $\begin{array}{c}\text { NRC Docket } \\
(50-)\end{array}$ & Plant Name & $\begin{array}{c}\text { Diesel Generator } \\
\text { Manufacturer }\end{array}$ & $\begin{array}{c}\text { DG AOT } \\
\text { (days) }\end{array}$ & $\begin{array}{c}\text { PM } \\
\text { Exemption }^{2}\end{array}$ \\
\hline 311 & Salem 2 & Alco & 3 & \\
\hline 206 & San Onofre 1 & TransAmerica DeLaval & 3 & \\
\hline 361 & San Onofre 2 & General Motors & 3 & \\
\hline 362 & San Onofre 3 & General Motors & 3 & \\
\hline 443 & Seabrook 1 & Fairbanks Morse & 3 & \\
\hline 327 & Sequoyah 1 & General Motors & 3 & \\
\hline 328 & Sequoyah 2 & General Motors & 3 & \\
\hline 400 & Shearon Harris 1 & TransAmerica DeLaval & 3 & Yes \\
\hline 498 & South Texas 1 & Cooper Energy Services & 3 & Yes \\
\hline 499 & South Texas 2 & Cooper Energy Services & 3 & Yes \\
\hline 335 & St Lucie 1 & General Motors & 3 & Yes \\
\hline 389 & St Lucie 2 & General Motors & 3 & Yes \\
\hline 395 & Summer 1 & Fairbanks Morse & 3 & Yes \\
\hline 280 & Surry 1 & General Motors & 7 & Yes \\
\hline 281 & Surry 2 & General Motors & 7 & Yes \\
\hline 387 & Susquehanna 1 & Cooper Energy Services & 3 & \\
\hline 388 & Susquehanna 2 & Cooper Energy Services & 3 & \\
\hline 289 & Three Mile Island 1 & Fairbanks Morse & 7 & \\
\hline 344 & Trojan & General Motors & 3 & \\
\hline 250 & Turkey Point 3 & General Motors & 3 & Yes \\
\hline 251 & Turkey Point 4 & General Motors & 3 & Yes \\
\hline 271 & Vermont Yankee 1 & Fairbanks Morse & 7 & \\
\hline 424 & Vogtle 1 & TransAmerica DeLaval & 3 & Yes \\
\hline 425 & Vogtle 2 & TransAmerica DeLaval & 3 & Yes \\
\hline 397 & Washington Nuclear 2 & General Motors & 3 & \\
\hline 382 & Waterford 3 & Cooper Energy Services & 3 & Yes \\
\hline 482 & Wolf Creek 1 & Fairbanks Morse & 3 & Yes \\
\hline
\end{tabular}


Table A.3. (Cont'd)

\begin{tabular}{||l|l|l|c|c||}
\hline $\begin{array}{c}\text { NRC Docket } \\
(\mathbf{5 0 -})\end{array}$ & \multicolumn{1}{|c|}{ Plant Name } & \multicolumn{1}{|c|}{$\begin{array}{c}\text { Diesel Generator } \\
\text { Manufacturer }\end{array}$} & $\begin{array}{c}\text { DG AOT } \\
\text { (days) }\end{array}$ & $\begin{array}{c}\text { PM } \\
\text { Exemption }^{2}\end{array}$ \\
\hline \hline 029 & Yankee-Rowe 1 & General Motors & 3 & \\
\hline 295 & Zion 1 & Cooper Energy Services & 3 & \\
\hline 304 & Zion 2 & Cooper Energy Services & 3 & \\
\hline
\end{tabular}

${ }^{1}$ Allowed outage time during which the plant may stay at power with a diesel generator (DG) inoperable.

${ }^{2}$ For these plants, the inoperability of one DG does not require testing the other DG if the inoperability is for preplanned preventative maintenance (PM) or testing.

${ }^{3}$ During the AOT the DGs of all units are tested sequentially at one time. The unit technical specifications are tied together.

${ }^{4}$ Test is performed on division 3 DG when the associated high pressure core spray (HPCS) system is inoperable. Cross train check is to be made with one DG inoperable.

${ }^{5}$ Swing DG requires same actions as for regular DGs.

${ }^{6}$ With two DGs inoperable, the surveillance interval is $1 / 8$ hours. Restore one DG to operable within 8 hours, two DGs to operable within 72 hours. 
APPENDIX B

EDG-SPECIFIC UNAVAILABILITIES IN NUCLEAR UNITS DURING POWER OPERATION AND SHUTDOWN PERIODS 
Table B.1. EDG Unavailability Due to Preventive Maintenance, $\mathrm{U}_{\mathrm{p}, \mathrm{PM}}$, During Power Operation in Descending Order

\begin{tabular}{|c|c|c|c|c|c|c|}
\hline Plant Name & $\begin{array}{c}\text { Docket } \\
\text { No }\end{array}$ & EDG ID & $\begin{array}{c}\text { Outage } \\
\text { Code }\end{array}$ & $\begin{array}{l}\text { Total EDG } \\
\text { OOS Hours }\end{array}$ & $\begin{array}{l}\text { Plant On-Line } \\
\text { Hours }\end{array}$ & $\begin{array}{c}\text { Unavail. due } \\
\text { to } \mathrm{PM}\end{array}$ \\
\hline FITZPATRICK & 333 & 12EDG & $\mathbf{P}$ & 238.38 & 2414.3 & $9.87 e-02$ \\
\hline LIMERICK 2 & 353 & D24 & $\mathbf{P}$ & 659.73 & 14521.3 & $4.54 \mathrm{e}-02$ \\
\hline LIMERICK 1 & 352 & D11 & $\mathbf{P}$ & 495.10 & 12050.7 & $4.11 \mathrm{e}-02$ \\
\hline FARLEY 1 & 348 & $1 B$ & $\mathbf{P}$ & 638.41 & 15578.1 & $4.10 e-02$ \\
\hline PILGRIM 1 & 293 & A & $\mathbf{P}$ & 288.00 & 7623.4 & $3.78 \mathrm{e}-02$ \\
\hline LIMERICK 1 & 352 & D12 & $\mathbf{P}$ & 447.84 & 12050.7 & $3.72 e-02$ \\
\hline FARLEY 2 & 364 & $2 \mathrm{~A}$ & $\mathbf{P}$ & 489.21 & 13486.7 & $3.63 e-02$ \\
\hline FARLEY 1 & 348 & $1 \mathrm{~A}$ & $\mathbf{P}$ & 533.46 & 15578.1 & $3.42 \mathrm{e}-02$ \\
\hline DRESDEN 2 & 237 & $\mathrm{DG} 2 / 3$ & $\mathbf{P}$ & 352.30 & 10327.1 & $3.41 \mathrm{e}-02$ \\
\hline DRESDEN 3 & 249 & $\mathrm{DG} 2 / 3$ & $\mathbf{P}$ & 352.30 & 10786.8 & $3.27 \mathrm{e}-02$ \\
\hline SUMMER & 395 & A & $\mathbf{P}$ & 495.60 & 15571.0 & $3.18 \mathrm{e}-02$ \\
\hline QUAD CITIES 1 & 254 & $\mathrm{U} 1 / 2$ & $\mathbf{P}$ & 374.40 & 11988.5 & $3.12 \mathrm{e}-02$ \\
\hline PILGRIM 1 & 293 & B & $\mathbf{P}$ & 237.00 & 7623.4 & $3.11 \mathrm{e}-02$ \\
\hline INDIAN POINT 2 & 247 & 22EDG & $\mathbf{P}$ & 384.67 & 12475.4 & $3.08 \mathrm{e}-02$ \\
\hline FARLEY 2 & 364 & $2 \mathrm{~B}$ & $\mathbf{P}$ & 401.85 & 13486.7 & $2.98 \mathrm{e}-02$ \\
\hline POINT BEACH 1 & 266 & G-01 & $\mathbf{P}$ & 439.30 & 14872.0 & $2.95 \mathrm{e}-02$ \\
\hline РЕACH ВOTTOM 3 & 278 & E4 & $\mathbf{P}$ & 372.60 & 12804.4 & $2.91 \mathrm{e}-02$ \\
\hline РEACH BOTTOM 2 & 277 & E4 & $\mathbf{P}$ & 372.60 & 13241.0 & $2.81 \mathrm{e}-02$ \\
\hline SURRY 2 & 281 & EDG3 & $\mathbf{P}$ & 388.36 & 13942.1 & $2.79 \mathrm{e}-02$ \\
\hline CALVERT CLIFFS 1 & 317 & 12EDG & $\mathbf{P}$ & 132.62 & 4855.1 & $2.73 e-02$ \\
\hline BROWNS FERRY 2 & 260 & A & $\mathbf{P}$ & 207.50 & 7685.6 & $2.70 \mathrm{e}-02$ \\
\hline POINT BEACH 2 & 301 & G-01 & $\mathbf{P}$ & 398.35 & 15296.6 & $2.60 \mathrm{e}-02$ \\
\hline INDIAN POINT 2 & 247 & 21EDG & $\mathbf{P}$ & 324.67 & 12475.4 & $2.60 \mathrm{e}-02$ \\
\hline SOUTH TEXAS 2 & 499 & EDG21 & $\mathbf{P}$ & 329.50 & 12739.0 & $2.59 \mathrm{e}-02$ \\
\hline CALVERT CLIFFS 1 & 317 & 11EDG & $\mathbf{P}$ & 262.00 & 10168.6 & $2.58 \mathrm{e}-02$ \\
\hline FITZPATRICK & 333 & 21EDG & $\mathbf{P}$ & 114.66 & 4536.7 & $2.53 \mathrm{e}-02$ \\
\hline WOLF CREEK 1 & 482 & B & $\mathbf{P}$ & 344.25 & 13858.9 & $2.48 \mathrm{e}-02$ \\
\hline LASALLE 2 & 374 & 0 & $\mathbf{P}$ & 345.32 & 13968.2 & $2.47 \mathrm{e}-02$ \\
\hline ZION 2 & 304 & $\mathrm{C}$ & $\mathbf{P}$ & 228.59 & 9256.5 & $2.47 e-02$ \\
\hline POINT BEACH 1 & 266 & G-02 & $\mathbf{P}$ & 354.80 & 14872.0 & $2.39 \mathrm{e}-02$ \\
\hline
\end{tabular}


Table B.1. (Cont'd)

\begin{tabular}{|c|c|c|c|c|c|c|}
\hline Plant Name & $\begin{array}{c}\text { Docket } \\
\text { No }\end{array}$ & EDG ID & $\begin{array}{c}\text { Outage } \\
\text { Code }\end{array}$ & $\begin{array}{l}\text { Total EDG } \\
\text { OOS Hours }\end{array}$ & $\begin{array}{c}\text { Plant On-Line } \\
\text { Hours }\end{array}$ & $\begin{array}{c}\text { Unavail. due } \\
\text { to } \mathbf{P M} \\
\end{array}$ \\
\hline PEACH BOTTOM 3 & 278 & E2 & $\mathbf{P}$ & 301.20 & 12804.4 & $2.35 e-02$ \\
\hline POINT BEACH 2 & 301 & G-02 & $\mathbf{P}$ & 354.80 & 15296.6 & $2.32 e-02$ \\
\hline FORT CALHOUN & 285 & DG-1 & $\mathbf{P}$ & 315.40 & 13599.8 & $2.32 \mathrm{e}-02$ \\
\hline SOUTH TEXAS 2 & 499 & EDG22 & $\mathbf{P}$ & 291.30 & 12739.0 & $2.29 \mathrm{e}-02$ \\
\hline РEACH ВОТTOM 2 & 277 & E2 & $\mathbf{P}$ & 301.20 & 13241.0 & $2.27 e-02$ \\
\hline SOUTH TEXAS 1 & 498 & EDG11 & $\mathbf{P}$ & 286.90 & 12622.2 & $2.27 e-02$ \\
\hline SOUTH TEXAS 1 & 498 & EDG12 & $\mathbf{P}$ & 286.50 & 12622.2 & $2.27 e-02$ \\
\hline SEQUOYAH 2 & 328 & $\mathrm{AA}$ & $\mathbf{P}$ & 312.73 & 13813.2 & $2.26 \mathrm{e}-02$ \\
\hline PRAIRIE ISLAND 2 & 306 & D2 & $\mathbf{P}$ & 354.40 & 16125.8 & $2.20 \mathrm{e}-02$ \\
\hline PRAIRIE ISLAND 1 & 282 & D2 & $\mathbf{P}$ & 366.80 & 16703.9 & $2.20 \mathrm{e}-02$ \\
\hline WOLF CREEK 1 & 482 & $\mathrm{~A}$ & $\mathbf{P}$ & 303.60 & 13858.9 & $2.19 \mathrm{e}-02$ \\
\hline MILLSTONE 3 & 423 & $3 \mathrm{~A}$ & $\mathbf{P}$ & 196.77 & 9220.0 & $2.13 e-02$ \\
\hline RIVER BEND & 458 & II & $\mathbf{P}$ & 254.00 & 11921.3 & $2.13 e-02$ \\
\hline PEACH BOTTOM 3 & 278 & E1 & $\mathbf{P}$ & 270.20 & 12804.4 & $2.11 \mathrm{e}-02$ \\
\hline BROWNS FERRY 2 & 260 & B & $\mathbf{P}$ & 161.50 & 7685.6 & $2.10 \mathrm{e}-02$ \\
\hline FORT CALHOUN & 285 & DG-2 & $\mathbf{P}$ & 283.10 & 13599.8 & $2.08 \mathrm{e}-02$ \\
\hline PEACH BOTTOM 2 & 277 & E1 & $\mathbf{P}$ & 270.20 & 13241.0 & $2.04 e-02$ \\
\hline SEQUOYAH 2 & 328 & BB & $\mathbf{P}$ & 281.20 & 13813.2 & $2.04 \mathrm{e}-02$ \\
\hline CLINTON 1 & 461 & $1 \mathrm{E} 22001$ & $\mathbf{P}$ & 217.19 & 10873.3 & $2.00 e-02$ \\
\hline SOUTH TEXAS 2 & 499 & EDG23 & $\mathbf{P}$ & 252.05 & 12739.0 & $1.98 \mathrm{e}-02$ \\
\hline INDIAN POINT 2 & 247 & 23EDG & $\mathbf{P}$ & 233.66 & 12475.4 & $1.87 e-02$ \\
\hline SEABROOK 1 & 443 & B & $\mathbf{P}$ & 246.38 & 13175.6 & $1.87 e-02$ \\
\hline FARLEY 1 & 348 & $1 \mathrm{C}$ & $\mathbf{P}$ & 285.17 & 15578.1 & $1.83 \mathrm{e}-02$ \\
\hline РЕACH ВOTTOM 3 & 278 & E3 & $\mathbf{P}$ & 233.50 & 12804.4 & $1.82 \mathrm{e}-02$ \\
\hline LASALLE 2 & 374 & 2B & $\mathbf{P}$ & 250.32 & 13968.2 & $1.79 e-02$ \\
\hline SALEM 2 & 311 & 2B & $\mathbf{P}$ & 185.25 & 10379.5 & $1.78 \mathrm{e}-02$ \\
\hline FARLEY 2 & 364 & $1 \mathrm{C}$ & $\mathbf{P}$ & 239.87 & 13486.7 & $1.78 \mathrm{e}-02$ \\
\hline MILLSTONE 3 & 423 & 3B & $\mathbf{P}$ & 162.73 & 9220.0 & $1.76 \mathrm{e}-02$ \\
\hline PEACH ВOTTOM 2 & 277 & E3 & $\mathbf{P}$ & 233.50 & 13241.0 & $1.76 e-02$ \\
\hline SEQUOYAH 1 & 327 & $\mathrm{AA}$ & $\mathbf{P}$ & 245.72 & 14144.2 & $1.74 e-02$ \\
\hline LIMERICK 2 & 353 & $\mathrm{D} 23$ & $\mathbf{P}$ & 249.40 & 14521.3 & $1.72 \mathrm{e}-02$ \\
\hline
\end{tabular}


Table B.1. (Cont'd)

\begin{tabular}{|c|c|c|c|c|c|c|}
\hline Plant Name & $\begin{array}{c}\text { Docket } \\
\text { No }\end{array}$ & EDG ID & $\begin{array}{c}\text { Outage } \\
\text { Code }\end{array}$ & $\begin{array}{l}\text { Total EDG } \\
\text { OOS Hours } \\
\end{array}$ & $\begin{array}{l}\text { Plant Ou-Line } \\
\text { Hours } \\
\end{array}$ & $\begin{array}{c}\text { Unavail. due } \\
\text { to } \mathbf{P M}\end{array}$ \\
\hline LIMERICK 2 & 353 & D21 & $\mathbf{P}$ & 248.00 & 14521.3 & $1.71 \mathrm{e}-02$ \\
\hline MCGUIRE 1 & 369 & IA & $\mathbf{P}$ & 215.10 & 12717.6 & $1.69 \mathrm{e}-02$ \\
\hline LASALLE 1 & 373 & 0 & $\mathbf{P}$ & 244.57 & 14462.1 & $1.69 \mathrm{e}-02$ \\
\hline RIVER BEND & 458 & 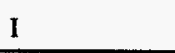 & $\mathbf{P}$ & 201.00 & 11921.3 & $1.69 \mathrm{e}-02$ \\
\hline BROWNS FERRY 2 & 260 & $\mathrm{C}$ & $\mathbf{P}$ & 129.17 & 7685.6 & $1.68 \mathrm{e}-02$ \\
\hline SEQUOYAH 1 & 327 & BB & $\mathbf{P}$ & 233.38 & 14144.2 & $1.65 \mathrm{e}-02$ \\
\hline RIVER BEND & 458 & III & $\mathbf{P}$ & 195.00 & P1921.3 & $1.64 \mathrm{e}-02$ \\
\hline PALO VERDE 3 & 530 & 3MDGAH0I & $\mathbf{P}$ & 236.55 & 14774.1 & $1.60 \mathrm{e}-02$ \\
\hline SALEM 1 & 272 & $1 \mathrm{~B}$ & $\mathbf{P}$ & 195.22 & 12295.6 & $1.59 \mathrm{e}-02$ \\
\hline DIABLO CANYON 1 & 275 & DEG1-3 & $\mathbf{P}$ & 243.72 & 15494.8 & $1.57 \mathrm{e}-02$ \\
\hline ST LUCIE 2 & 389 & 2B & $\mathbf{P}$ & 229.00 & 14571.0 & $1.57 \mathrm{e}-02$ \\
\hline SALEM 2 & 311 & $2 \mathrm{~A}$ & $\mathbf{P}$ & 162.83 & 10379.5 & $1.57 \mathrm{e}-02$ \\
\hline LIMERICK 1 & 352 & D14 & $\mathrm{P}$ & 188.40 & 12050.7 & $1.56 \mathrm{e}-02$ \\
\hline SALEM 1 & 272 & $1 \mathrm{~A}$ & $\mathbf{P}$ & 191.70 & 12295.6 & $1.56 \mathrm{e}-02$ \\
\hline BROWNS FERRY 2 & 260 & $\mathrm{D}$ & $\mathbf{P}$ & 119.00 & 7685.6 & $1.55 \mathrm{e}-02$ \\
\hline DIABLO CANYON 2 & 323 & DEGI-3 & $\mathbf{P}$ & 243.72 & 16072.3 & $1.52 \mathrm{e}-02$ \\
\hline PALO VERDE 3 & 530 & 3MDGBH01 & $\mathbf{P}$ & 222.45 & 14774.1 & $1.51 \mathrm{e}-02$ \\
\hline SUMMER & 395 & B & $\mathbf{P}$ & 233.60 & 15571.0 & $1.50 \mathrm{e}-02$ \\
\hline LIMERICK 2 & 353 & D22 & $\mathbf{P}$ & 216.97 & 14521.3 & $1.49 \mathrm{e}-02$ \\
\hline THREE MILE ISLAND 1 & 289 & EDG-1A & $\mathbf{P}$ & 242.08 & 16320.6 & $1.48 \mathrm{e}-02$ \\
\hline PERRY 1 & 440 & A & $\mathrm{P}$ & 176.38 & 12148.3 & $1.45 \mathrm{e}-02$ \\
\hline THREE MILE ISLAND 1 & 289 & EDG-1B & $\mathbf{P}$ & 235.59 & 16320.6 & $1.44 \mathrm{e}-02$ \\
\hline LASALLE 1 & 373 & $1 \mathrm{~B}$ & $\mathbf{P}$ & 207.72 & 14462.1 & $1.44 \mathrm{e}-02$ \\
\hline PERRY 1 & 440 & B & $\mathbf{P}$ & 174.16 & 12148.3 & $1.43 \mathrm{e}-02$ \\
\hline SOUTH TEXAS 1 & 498 & EDG 13 & $\mathbf{P}$ & 178.85 & 12622.2 & $1.42 \mathrm{e}-02$ \\
\hline MCGUIRE 1 & 369 & $1 \mathrm{~B}$ & $\mathbf{P}$ & 175.40 & 12717.6 & $1.38 \mathrm{e}-02$ \\
\hline MAINE YANKEE & 309 & DG-1A & $\mathbf{P}$ & 174.70 & 13046.6 & $1.34 \mathrm{e}-02$ \\
\hline FARLEY 2 & 364 & $2 \mathrm{C}$ & $\mathbf{P}$ & 176.39 & 13486.7 & $1.31 \mathrm{e}-02$ \\
\hline COMANCHE PEAK 1 & 445 & $1-02$ & $\mathbf{P}$ & 165.60 & 12670.2 & $1.31 \mathrm{e}-02$ \\
\hline SURRY 1 & 280 & EDG3 & $\mathbf{P}$ & 181.57 & 13970.0 & $1.30 \mathrm{e}-02$ \\
\hline NORTH ANNA 1 & 338 & $1 \mathrm{H}$ & $\mathbf{P}$ & 178.55 & 13776.7 & $1.30 e-02$ \\
\hline
\end{tabular}


Table B.1. (Cont'd)

\begin{tabular}{|c|c|c|c|c|c|c|}
\hline Plant Name & $\begin{array}{l}\text { Docket } \\
\text { No }\end{array}$ & EDG ID & $\begin{array}{c}\text { Outage } \\
\text { Code }\end{array}$ & $\begin{array}{l}\text { Total EDG } \\
\text { OOS Hours }\end{array}$ & $\begin{array}{l}\text { Plant On-Line } \\
\text { Hours }\end{array}$ & $\begin{array}{l}\text { Unavail. due } \\
\text { to } \mathbf{P M}\end{array}$ \\
\hline CLINTON 1 & 461 & $1 \mathrm{DG} 01 \mathrm{KA}$ & $\mathbf{P}$ & 140.65 & 10873.3 & $1.29 \mathrm{e}-02$ \\
\hline BRAIDWOOD 1 & 456 & $1 \mathrm{~B}$ & $\mathbf{P}$ & 167.35 & 12957.2 & $1.29 \mathrm{e}-02$ \\
\hline LIMERICK 1 & 352 & D13 & $\mathbf{P}$ & 154.01 & 12050.7 & $1.28 \mathrm{e}-02$ \\
\hline DIABLO CANYON 1 & 275 & DEGI-1 & $\mathbf{P}$ & 195.51 & 15494.8 & $1.26 \mathrm{e}-02$ \\
\hline MAINE YANKEE & 309 & DG-1B & $\mathbf{P}$ & 164.00 & 13046.6 & $1.26 \mathrm{e}-02$ \\
\hline LASALLE 1 & 373 & $1 \mathrm{~A}$ & $\mathbf{P}$ & 176.54 & 14462.1 & $1.22 \mathrm{e}-02$ \\
\hline CLINTON 1 & 461 & $1 \mathrm{DG} 01 \mathrm{~KB}$ & $\mathbf{P}$ & 132.56 & 10873.3 & $1.22 \mathrm{e}-02$ \\
\hline NORTH ANNA 1 & 338 & $1 \mathbf{J}$ & $\mathbf{P}$ & 167.56 & 13776.7 & $1.22 \mathrm{e}-02$ \\
\hline SALEM 2 & 311 & $2 \mathrm{C}$ & $\mathbf{P}$ & 125.97 & 10379.5 & $1.21 \mathrm{e}-02$ \\
\hline DIABLO CANYON 1 & 275 & DEG1-2 & $\mathbf{P}$ & 187.36 & 15494.8 & $1.21 \mathrm{e}-02$ \\
\hline ST LUCIE 1 & 335 & $1 \mathrm{~A}$ & $\mathbf{P}$ & 176.00 & 14938.7 & $1.18 \mathrm{e}-02$ \\
\hline SAN ONOFRE 2 & 361 & DG3 & $\mathbf{P}$ & 100.91 & 8764.7 & $1.15 \mathrm{e}-02$ \\
\hline GRAND GULF & 416 & DG11 & $\mathbf{P}$ & 153.00 & 13546.6 & $1.13 \mathrm{e}-02$ \\
\hline ST LUCIE 2 & 389 & $2 \mathrm{~A}$ & $\mathbf{P}$ & 158.70 & 14571.0 & $1.09 \mathrm{e}-02$ \\
\hline SAN ONOFRE 3 & 362 & DG3 & $\mathbf{P}$ & 125.59 & 11759.4 & $1.07 \mathrm{e}-02$ \\
\hline GRAND GULF & 416 & DG12 & $\mathbf{P}$ & 143.00 & 13546.6 & $1.06 \mathrm{e}-02$ \\
\hline PALISADES & 255 & DG1-1 & $\mathbf{P}$ & 115.56 & 10989.6 & $1.05 \mathrm{e}-02$ \\
\hline NORTH ANNA 2 & 339 & $2 \mathrm{H}$ & $\mathbf{p}$ & 139.59 & 14043.4 & $9.94 \mathrm{e}-03$ \\
\hline DIABLO CANYON 2 & 323 & DEG2-2 & $\mathbf{P}$ & 156.15 & 16072.3 & $9.72 \mathrm{e}-03$ \\
\hline ROBINSON 2 & 261 & $\mathrm{~A}$ & $\mathbf{P}$ & 109.69 & 11467.5 & $9.57 \mathrm{e}-03$ \\
\hline FERMI 2 & 341 & EDG 14 & $\mathbf{P}$ & 128.50 & 13751.4 & $9.34 \mathrm{e}-03$ \\
\hline ROBINSON 2 & 261 & B & $\mathbf{P}$ & 105.38 & 11467.5 & $9.19 \mathrm{e}-03$ \\
\hline CALLAWAY & 483 & $\mathrm{~A}$ & $\mathrm{P}$ & 129.75 & 14434.2 & $8.99 e-03$ \\
\hline PALO VERDE 2 & 529 & 2MDGBH01 & $\mathrm{P}$ & 124.95 & 13927.6 & $8.97 \mathrm{e}-03$ \\
\hline BRAIDWOOD 2 & 457 & $2 \mathrm{~A}$ & $\mathbf{P}$ & 132.60 & 14928.9 & $8.88 \mathrm{e}-03$ \\
\hline FERMI 2. & 341 & EDG11 & $\mathbf{P}$ & 121.50 & 13751.4 & $8.84 \mathrm{e}-03$ \\
\hline VERMONT YANKEE & 271 & EDGB & $\mathbf{P}$ & 129.20 & 14725.0 & $8.77 e-03$ \\
\hline PALISADES & 255 & DG1-2 & $\mathbf{P}$ & 95.28 & 10989.6 & $8.67 e-03$ \\
\hline CALLAWAY & 483 & B & $\mathbf{P}$ & 122.50 & 14434.2 & $8.49 \mathrm{e}-03$ \\
\hline DAVIS-BESSE & 346 & EDG2 & $\mathbf{P}$ & 124.70 & 14829.2 & $8.41 \mathrm{e}-03$ \\
\hline CRYSTAL RIVER 3 & 302 & $1 \mathrm{~A}$ & $P$ & 115.86 & 13782.0 & $8.41 \mathrm{e}-03$ \\
\hline
\end{tabular}


Table B.1. (Cont'd)

\begin{tabular}{|c|c|c|c|c|c|c|}
\hline Plant Name & $\begin{array}{c}\text { Docket } \\
\text { No }\end{array}$ & EDG ID & $\begin{array}{c}\text { Outage } \\
\text { Code }\end{array}$ & $\begin{array}{l}\text { Total EDG } \\
\text { OOS Hours }\end{array}$ & $\begin{array}{l}\text { Plant On-Line } \\
\text { Hours }\end{array}$ & $\begin{array}{l}\text { Unavail. due } \\
\text { to PM }\end{array}$ \\
\hline ST LUCIE 1 & 335 & $1 \mathrm{~B}$ & $\mathbf{P}$ & 124.80 & 14938.7 & $8.35 e-03$ \\
\hline MCGUIRE 2 & 370 & $2 \mathrm{~B}$ & $\mathbf{P}$ & 103.20 & 12440.7 & $8.30 e-03$ \\
\hline CATAWBA 1 & 413 & IB & $\mathbf{P}$ & 51.20 & 6173.1 & $8.29 \mathrm{e}-03$ \\
\hline PERRY 1 & 440 & c & $\mathbf{P}$ & 100.52 & 12148.3 & $8.27 e-03$ \\
\hline LASALLE 2 & 374 & $2 \mathrm{~A}$ & $\mathbf{P}$ & 115.28 & 13968.2 & $8.25 e-03$ \\
\hline BRUNSWICK 1 & 325 & EDG1 & $\mathbf{P}$ & 89.00 & 10878.0 & $8.18 \mathrm{e}-03$ \\
\hline PALO VERDE 1 & 528 & 1MDGAH01 & $\mathbf{P}$ & 105.90 & 12983.2 & $8.16 \mathrm{e}-03$ \\
\hline PALO VERDE 1 & 528 & 1MDGBH01 & $\mathbf{P}$ & 99.95 & 12983.2 & $7.70 e-03$ \\
\hline SUSQUEHANNA 1 & 387 & $\mathrm{~A}$ & $\mathbf{P}$ & 94.64 & 12659.7 & $7.48 \mathrm{e}-03$ \\
\hline DAVIS-BESSE & 346 & EDG1 & $\mathbf{P}$ & 108.20 & 14829.2 & $7.30 \mathrm{e}-03$ \\
\hline SUSQUEHANNA 1 & 387 & $\mathrm{C}$ & $\mathbf{P}$ & 92.30 & 12659.7 & $7.29 \mathrm{e}-03$ \\
\hline НАТСН 1 & 321 & B & $\mathbf{P}$ & 105.49 & 14537.8 & $7.26 \mathrm{e}-03$ \\
\hline FARLEY 1 & 348 & $2 \mathrm{C}$ & $\mathbf{P}$ & 111.89 & 15578.1 & $7.18 \mathrm{e}-03$ \\
\hline PALO VERDE 2 & 529 & 2MDGAH01 & $\mathbf{P}$ & 99.95 & 13927.6 & $7.18 \mathrm{e}-03$ \\
\hline NORTH ANNA 2 & 339 & 2J & $\mathbf{P}$ & 99.67 & 14043.4 & $7.10 \mathrm{e}-03$ \\
\hline SAN ONOFRE 3 & 362 & $\mathrm{DG} 2$ & $\mathbf{P}$ & 83.33 & 11759.4 & $7.09 e-03$ \\
\hline DRESDEN 3 & 249 & DG3 & $\mathbf{P}$ & 75.90 & 10786.8 & $7.04 \mathrm{e}-03$ \\
\hline HOPE CREEK 1 & 354 & A & $\mathbf{P}$ & 105.70 & 15238.4 & $6.94 \mathrm{e}-03$ \\
\hline SUSQUEHANNA 2 & 388 & A & $\mathbf{P}$ & 94.64 & 13779.7 & $6.87 \mathrm{e}-03$ \\
\hline CATAWBA 2 & 414 & $2 \mathrm{~B}$ & $\mathbf{P}$ & 19.30 & 2813.0 & $6.86 \mathrm{e}-03$ \\
\hline BIG ROCK POINT & 155 & A & $\mathbf{P}$ & 74.00 & 10899.2 & $6.79 e-03$ \\
\hline BRAIDWOOD 1 & 456 & $1 \mathrm{~A}$ & $\mathrm{P}$ & 87.80 & 12957.2 & $6.78 \mathrm{e}-03$ \\
\hline CRYSTAL RIVER 3 & 302 & $1 \mathrm{~B}$ & $\mathbf{P}$ & 91.50 & 13782.0 & $6.64 \mathrm{e}-03$ \\
\hline PRAIRIE ISLAND 2 & 306 & D1 & $\mathbf{P}$ & 104.60 & 16125.8 & $6.49 \mathrm{e}-03$ \\
\hline PRAIRIE ISLAND 1 & 282 & D1 & $\mathbf{P}$ & 104.60 & 16703.9 & $6.26 \mathrm{e}-03$ \\
\hline ZION 2 & 304 & $2 \mathrm{~A}$ & $\mathbf{P}$ & 57.52 & 9256.5 & $6.21 \mathrm{e}-03$ \\
\hline SUSQUEHANNA 1 & 387 & E & $\mathbf{P}$ & 76.03 & 12659.7 & $6.01 \mathrm{e}-03$ \\
\hline MCGUIRE 2 & 370 & $2 \mathrm{~A}$ & $\mathbf{P}$ & 74.00 & 12440.7 & $5.95 \mathrm{e}-03$ \\
\hline DIABLO CANYON 2 & 323 & DEG2-1 & $\mathbf{P}$ & 94.44 & 16072.3 & $5.88 \mathrm{e}-03$ \\
\hline SUSQUEHANNA 2 & 388 & D & $\mathbf{P}$ & 80.38 & 13779.7 & $5.83 \mathrm{e}-03$ \\
\hline CATAWBA 1 & 413 & $1 \mathrm{~A}$ & $\mathbf{P}$ & 34.40 & 6173.1 & $5.57 \mathrm{e}-03$ \\
\hline
\end{tabular}


Table B.1. (Cont'd)

\begin{tabular}{|c|c|c|c|c|c|c|}
\hline Plant Name & $\begin{array}{c}\text { Docket } \\
\text { No } \\
\end{array}$ & EDG ID & $\begin{array}{l}\text { Outage } \\
\text { Code }\end{array}$ & $\begin{array}{l}\text { Total EDG } \\
\text { OOS Hours }\end{array}$ & $\begin{array}{c}\text { Plaut On-Line } \\
\text { Hours } \\
\end{array}$ & $\begin{array}{c}\text { Unavail. due } \\
\text { to } \mathbf{P M} \\
\end{array}$ \\
\hline SUSQUEHANNA 2 & 388 & $\mathrm{C}$ & $\mathbf{P}$ & 72.35 & 13779.7 & $5.25 \mathrm{e}-03$ \\
\hline ROBINSON 2 & 261 & $\mathrm{D} / \mathrm{S}$ & $\mathbf{P}$ & 60.00 & 11467.5 & $5.23 \mathrm{e}-03$ \\
\hline HADDAM NECK & 213 & EG-2B & $\mathbf{P}$ & 56.97 & 11062.5 & $5.15 \mathrm{e}-03$ \\
\hline SUSQUEHANNA 2 & 388 & $E$ & $\mathbf{P}$ & 70.50 & 13779.7 & $5.12 \mathrm{e}-03$ \\
\hline OYSTER CREEK & 219 & EDG-1 & $\mathbf{P}$ & 69.50 & 13588.2 & $5.11 \mathrm{e}-03$ \\
\hline SAN ONOFRE 2 & 361 & DG2 & $\mathbf{P}$ & 44.25 & 8764.7 & $5.05 \mathrm{e}-03$ \\
\hline BRAIDWOOD 2 & 457 & 2B & $\mathbf{P}$ & 73.20 & 14928.9 & $4.90 \mathrm{e}-03$ \\
\hline OYSTER CREEK & 219 & EDG-2 & $\mathbf{P}$ & 66.00 & 13588.2 & $4.86 \mathrm{e}-03$ \\
\hline SUSQUEHANNA 1 & 387 & $\mathrm{D}$ & $\mathbf{P}$ & 60.43 & 12659.7 & $4.77 \mathrm{e}-03$ \\
\hline COMANCHE PEAK 1 & 445 & $1-01$ & $\mathbf{P}$ & 59.50 & 12670.2 & $4.70 \mathrm{e}-03$ \\
\hline HATCH 2 & 366 & B & $\mathbf{P}$ & 70.89 & 15276.0 & $4.64 \mathrm{e}-03$ \\
\hline ZION 2 & 304 & $2 \mathrm{~B}$ & $\mathrm{P}$ & 36.40 & 9256.5 & $3.93 \mathrm{e}-03$ \\
\hline SALEM 1 & 272 & IC & $\mathbf{P}$ & 47.98 & 12295.6 & $3.90 \mathrm{e}-03$ \\
\hline FERMI 2 & 341 & EDG12 & $\mathbf{P}$ & 53.00 & 13751.4 & $3.85 \mathrm{e}-03$ \\
\hline WATERFORD 3 & 382 & B & $\mathbf{P}$ & 57.89 & 15066.1 & $3.84 \mathrm{e}-03$ \\
\hline DRESDEN 2 & 237 & DG2 & $\mathbf{P}$ & 37.80 & 10327.1 & $3.66 \mathrm{e}-03$ \\
\hline HADDAM NECK & 213 & EG-2A & $\mathbf{P}$ & 37.76 & 11062.5 & $3.41 \mathrm{e}-03$ \\
\hline BYRON 1 & 454 & $1 \mathrm{~B}$ & $\mathbf{P}$ & 53.15 & 15689.6 & $3.39 \mathrm{e}-03$ \\
\hline BEAVER VALLEY 1 & 334 & EDG 1-1 & $\mathbf{P}$ & 43.70 & 13174.8 & $3.32 e-03$ \\
\hline HOPE CREEK 1 & 354 & $\mathrm{c}$ & $\mathbf{P}$ & 48.10 & 15238.4 & $3.16 \mathrm{e}-03$ \\
\hline GRAND GULF & 416 & DG13 & $\mathbf{P}$ & 42.00 & 13546.6 & $3.10 \mathrm{e}-03$ \\
\hline GINNA & 244 & EDGA & $P$ & 39.02 & 15053.9 & $2.59 e-03$ \\
\hline FERMI 2 & 341 & EDG13 & $\mathbf{P}$ & 35.50 & 13751.4 & $2.58 \mathrm{e}-03$ \\
\hline GINNA & 244 & EDGB & $\mathbf{P}$ & 38.78 & 15053.9 & $2.58 \mathrm{e}-03$ \\
\hline BYRON 1 & 454 & $1 \mathrm{~A}$ & $\mathrm{P}$ & 37.20 & 15689.6 & $2.37 \mathrm{e}-03$ \\
\hline BEAVER VALLEY 2 & 412 & EDG2-1 & $\mathbf{P}$ & 31.00 & 14038.4 & $2.21 \mathrm{e}-03$ \\
\hline BEAVER VALLEY 1 & 334 & EDG1-2 & $\mathbf{P}$ & 27.06 & 13174.8 & $2.05 \mathrm{e}-03$ \\
\hline SURRY 1 & 280 & EDG1 & $\mathbf{P}$ & 27.85 & 13970.0 & $1.99 \mathrm{e}-03$ \\
\hline SUSQUEHANNA 1 & 387 & B & $\mathbf{P}$ & 25.17 & 12659.7 & $1.99 \mathrm{e}-03$ \\
\hline HARRIS 1 & 400 & IA-SA & $\mathbf{P}$ & 29.24 & 15067.4 & $1.94 \mathrm{e}-03$ \\
\hline HOPE CREEK 1 & 354 & B & $\mathbf{P}$ & 28.87 & 15238.4 & $1.89 e-03$ \\
\hline
\end{tabular}


Table B.1. (Cont'd)

\begin{tabular}{|c|c|c|c|c|c|c|}
\hline Plant Name & $\begin{array}{l}\text { Docket } \\
\text { No }\end{array}$ & EDG ID & $\begin{array}{c}\text { Outage } \\
\text { Code }\end{array}$ & $\begin{array}{l}\text { Total EDG } \\
\text { OOS Hours }\end{array}$ & $\begin{array}{l}\text { Plant On-Liue } \\
\text { Hours }\end{array}$ & $\begin{array}{l}\text { Unavail, due } \\
\text { to } P M\end{array}$ \\
\hline ZION 1 & 295 & C & $\mathbf{P}$ & 18.42 & 9880.1 & $1.86 \mathrm{e}-03$ \\
\hline SUSQUEHANNA 2 & 388 & B & $\mathbf{P}$ & 25.17 & 13779.7 & $1.83 e-03$ \\
\hline SURRY 2 & 281 & EDG2 & $\mathbf{P}$ & 24.00 & 13942.1 & $1.72 \mathrm{e}-03$ \\
\hline BEAVER VALLEY 2 & 412 & EDG2-2 & $\mathbf{P}$ & 22.80 & 14038.4 & $1.62 \mathrm{e}-03$ \\
\hline QUAD CITIES 2 & 265 & U2 & $\mathbf{P}$ & 20.90 & 13053.6 & $1.60 \mathrm{e}-03$ \\
\hline BYRON 2 & 455 & $2 \mathrm{~B}$ & $\mathbf{P}$ & 20.40 & 13700.5 & $1.49 \mathrm{e}-03$ \\
\hline BYRON 2 & 455 & $2 A$ & $\mathbf{P}$ & 19.90 & 13700.5 & $1.45 \mathrm{e}-03$ \\
\hline DUANE ARNOLD & 331 & A & $\mathbf{P}$ & 15.40 & 11760.5 & $1.31 \mathrm{e}-03$ \\
\hline QUAD CITIES 1 & 254 & U1 & $\mathbf{P}$ & 14.10 & 11988.5 & $1.18 \mathrm{e}-03$ \\
\hline KEWAUNEE & 305 & DGA & $\mathbf{P}$ & 15.49 & 15034.3 & $1.03 \mathrm{e}-03$ \\
\hline DUANE ARNOLD & 331 & B & $\mathbf{P}$ & 12.10 & 11760.5 & $1.03 \mathrm{e}-03$ \\
\hline WATERFORD 3 & 382 & $A$ & $\mathbf{P}$ & 11.85 & 15066.1 & $7.87 \mathrm{e}-04$ \\
\hline WASHINGTON NUCLEAR 2 & 397 & DIVII & $\mathbf{P}$ & 7.00 & 9355.3 & $7.48 \mathrm{e}-04$ \\
\hline VERMONT YANKEE & 271 & EDGA & $\mathbf{P}$ & 9.80 & 14725.0 & $6.66 \mathrm{e}-04$ \\
\hline HARRIS 1 & 400 & 1B-SB & $\mathbf{P}$ & 9.70 & 15067.4 & $6.44 e-04$ \\
\hline QUAD CITIES 2 & 265 & $\mathrm{U} 1 / 2$ & $\mathbf{P}$ & 4.10 & 13053.6 & $3.14 \mathrm{e}-04$ \\
\hline НАТCH 1 & 321 & $\mathrm{C}$ & $\mathbf{P}$ & 4.11 & 14537.8 & $2.83 e-04$ \\
\hline KEWAUNEE & 305 & DGB & $\mathbf{P}$ & 3.76 & 15034.3 & $2.50 \mathrm{e}-04$ \\
\hline COOPER STATION & 298 & DG-2 & $\mathbf{P}$ & 0.90 & 6760.9 & $1.33 \mathrm{e}-04$ \\
\hline НАTCH 1 & 321 & A & $\mathbf{P}$ & 1.50 & 14537.8 & $1.03 \mathrm{e}-04$ \\
\hline НАТСН 2 & 366 & A & $\mathbf{P}$ & 0.50 & 15276.0 & $3.27 \mathrm{e}-05$ \\
\hline BRUNSWICK 1 & 325 & EDG2 & $\mathbf{P}$ & 0.30 & 10878.0 & $2.76 \mathrm{e}-05$ \\
\hline BRUNSWICK 2 & 324 & EDG4 & $\mathbf{P}$ & 0.25 & 11332.3 & $2.21 \mathrm{e}-05$ \\
\hline & & & & & AVERAGE* & $1.18 \mathrm{e}-02$ \\
\hline
\end{tabular}

*The average is obtained considering 235 EDGs used in this study. EDGs reporting zero 00S hours due to PM are not included in the table. 
Table B.2. EDG Unavailability Due to Corrective Maintenance, $\mathrm{U}_{\mathrm{p}, \mathrm{CM}}$, During Power Operation in Descending Order

\begin{tabular}{|c|c|c|c|c|c|c|}
\hline Plant Name & $\begin{array}{c}\text { Docket } \\
\text { No }\end{array}$ & EDG ID & $\begin{array}{l}\text { Outage } \\
\text { Code }\end{array}$ & $\begin{array}{l}\text { Total EDG } \\
\text { OOS Hours }\end{array}$ & $\begin{array}{l}\text { Plant On- } \\
\text { Line Hours }\end{array}$ & $\begin{array}{c}\text { Unavail. due } \\
\text { to } \mathrm{CM}\end{array}$ \\
\hline PERRY 1 & 440 & B & $\mathrm{C}$ & 816.14 & 12148.3 & $6.72 \mathrm{e}-02$ \\
\hline FITZPATRICK & 333 & 12EDG & c & 156.84 & 2414.3 & $6.50 \mathrm{e}-02$ \\
\hline ZION 2 & 304 & C & C & 514.84 & 9256.5 & $5.56 \mathrm{e}-02$ \\
\hline SUSQUEHANNA 1 & 387 & A & C & 654.63 & 12659.7 & $5.17 \mathrm{e}-02$ \\
\hline SUSQUEHANNA 2 & 388 & A & C & 654.63 & 13779.7 & $4.75 e-02$ \\
\hline ZION 1 & 295 & C & c & 448.00 & 9880.1 & $4.53 e-02$ \\
\hline MILLSTONE 1 & 245 & $1 \mathrm{~A}$ & $\mathrm{C}$ & 390.31 & 9104.9 & $4.29 \mathrm{e}-02$ \\
\hline ROBINSON 2 & 261 & $D / S$ & c & 429.00 & 11467.5 & $3.74 \mathrm{e}-02$ \\
\hline CATAWBA 2 & 414 & $2 \mathrm{~A}$ & $\mathrm{C}$ & 102.85 & 2813.0 & $3.66 \mathrm{e}-02$ \\
\hline SALEM 1 & 272 & $1 \mathrm{~A}$ & C & 435.73 & 12295.6 & $3.54 \mathrm{e}-02$ \\
\hline SEABROOK 1 & 443 & B & C & 441.80 & 13175.6 & $3.35 \mathrm{e}-02$ \\
\hline PILGRIM 1 & 293 & B & C & 253.00 & 7623.4 & $3.32 e-02$ \\
\hline VOGTLE 1 & 424 & DG1A & C & 321.55 & 9883.7 & $3.25 \mathrm{e}-02$ \\
\hline CALVERT CLIFFS 1 & 317 & 12EDG & C & 151.66 & 4855.1 & $3.12 \mathrm{e}-02$ \\
\hline SALEM 2 & 311 & $2 \mathrm{~B}$ & $\mathrm{C}$ & 260.36 & 10379.5 & $2.51 \mathrm{e}-02$ \\
\hline SUSQUEHANNA 1 & 387 & B & C & 306.50 & 12659.7 & $2.42 e-02$ \\
\hline VOGTLE 2 & 425 & DG2A & $\mathrm{C}$ & 271.93 & 11954.1 & $2.27 e-02$ \\
\hline FARLEY 2 & 364 & $2 \mathrm{~B}$ & C & 300.65 & 13486.7 & $2.23 \mathrm{e}-02$ \\
\hline SUSQUEHANNA 2 & 388 & B & $\mathrm{C}$ & 306.50 & 13779.7 & $2.22 \mathrm{e}-02$ \\
\hline FARLEY 2 & 364 & $2 \mathrm{~A}$ & c & 292.60 & 13486.7 & $2.17 e-02$ \\
\hline PALO VERDE 3 & 530 & 3MDGBH01 & $\mathrm{C}$ & 301.45 & 14774.1 & $2.04 \mathrm{e}-02$ \\
\hline DAVIS-BESSE & 346 & EDG2 & $\mathrm{C}$ & 288.70 & 14829.2 & $1.95 \mathrm{e}-02$ \\
\hline VOGTLE 1 & 424 & DG1B & c & 189.65 & 9883.7 & $1.92 \mathrm{e}-02$ \\
\hline SAN ONOFRE 1 & 206 & DG2 & C & 188.99 & 10028.0 & $1.88 \mathrm{e}-02$ \\
\hline CALVERT CLIFFS I & 317 & 11EDG & C & 185.58 & 10168.6 & $1.83 \mathrm{e}-02$ \\
\hline BEAVER VALLEY 2 & 412 & EDG2-1 & C & 252.20 & 14038.4 & $1.80 \mathrm{e}-02$ \\
\hline BRUNSWICK 1 & 325 & EDG1 & $\mathrm{C}$ & 193.80 & 10878.0 & $1.78 \mathrm{e}-02$ \\
\hline PALO VERDE 3 & 530 & 3MDGAH01 & c & 262.35 & 14774.1 & $1.78 \mathrm{e}-02$ \\
\hline SALEM 2 & 311 & $2 \mathrm{~A}$ & $\mathrm{C}$ & 183.08 & 10379.5 & $1.76 \mathrm{e}-02$ \\
\hline CATAWBA 1 & 413 & $1 \mathrm{~A}$ & $\mathrm{C}$ & 104.40 & 6173.1 & $1.69 \mathrm{e}-02$ \\
\hline
\end{tabular}


Table B.2. (Cont'd)

\begin{tabular}{|c|c|c|c|c|c|c|}
\hline Plant Name & $\begin{array}{c}\text { Docket } \\
\text { No }\end{array}$ & EDG ID & $\begin{array}{c}\text { Outage } \\
\text { Code }\end{array}$ & $\begin{array}{l}\text { Total EDG } \\
\text { oos Hours }\end{array}$ & $\begin{array}{l}\text { Plant On- } \\
\text { Line Hours }\end{array}$ & $\begin{array}{l}\text { Unavail. due } \\
\text { to } \mathrm{CM}\end{array}$ \\
\hline MAINE YANKEE & 309 & DG-1A & $\mathrm{c}$ & 208.30 & 13046.6 & $1.60 \mathrm{e}-02$ \\
\hline PEACH BOTTOM 3 & 278 & E4 & $\mathrm{c}$ & 202.40 & 12804.4 & $1.58 \mathrm{e}-02$ \\
\hline PEACH BOTTOM 2 & 277 & E4 & $\mathrm{c}$ & 202.40 & 13241.0 & $1.53 e-02$ \\
\hline ZION 2 & 304 & $2 \mathrm{~B}$ & $\mathrm{c}$ & 141.16 & 9256.5 & $1.52 e-02$ \\
\hline FARLEY 1 & 348 & $1 \mathrm{~A}$ & $\mathrm{c}$ & 225.43 & 15578.1 & $1.45 \mathrm{e}-02$ \\
\hline FORT CALHOUN & 285 & DG-1 & $\mathrm{c}$ & 195.60 & 13599.8 & $1.44 \mathrm{e}-02$ \\
\hline ARKANSAS 1 & 313 & $\mathrm{~B}$ & $\mathrm{c}$ & 82.95 & 5812.5 & $1.43 \mathrm{e}-02$ \\
\hline HARRIS 1 & 400 & 1A-SA & c & 210.44 & 15067.4 & $1.40 \mathrm{e}-02$ \\
\hline SAN ONOFRE 2 & 361 & DG3 & $\mathrm{c}$ & 119.31 & 8764.7 & $1.36 \mathrm{e}-02$ \\
\hline ZION 2 & 304 & $2 \mathrm{~A}$ & c & 125.39 & 9256.5 & $1.35 e-02$ \\
\hline PALO VERDE 2 & 529 & 2MDGAH01 & $\mathrm{C}$ & 188.15 & 13927.6 & $1.35 \mathrm{e}-02$ \\
\hline CATAWBA 2 & 414 & $2 \mathrm{~B}$ & $\mathrm{C}$ & 37.80 & 2813.0 & $1.34 \mathrm{e}-02$ \\
\hline MONTICELLO & 263 & 11 & $\mathrm{c}$ & 197.37 & 15180.9 & $1.30 \mathrm{e}-02$ \\
\hline QUAD CITIES 1 & 254 & $\mathrm{U} 1 / 2$ & $\mathrm{c}$ & 152.20 & 11988.5 & $1.27 e-02$ \\
\hline DRESDEN 2 & 237 & $\mathrm{DG} 2$ & $\mathrm{C}$ & 128.60 & 10327.1 & $1.25 \mathrm{e}-02$ \\
\hline VOGTLE 2 & 425 & $\mathrm{DG} 2 \mathrm{~B}$ & $\mathrm{c}$ & 146.61 & 11954.1 & $1.23 \mathrm{e}-02$ \\
\hline PALO VERDE 1 & 528 & 1MDGBH01 & $\mathrm{c}$ & 158.25 & 12983.2 & $1.22 \mathrm{e}-02$ \\
\hline COOK 2 & 316 & $2 A B$ & c & 131.47 & 10977.1 & $1.20 \mathrm{e}-02$ \\
\hline SOUTH TEXAS 2 & 499 & EDG21 & $\mathrm{c}$ & 151.50 & 12739.0 & $1.19 \mathrm{e}-02$ \\
\hline PALO VERDE 1 & 528 & 1MDGAH01 & $\mathrm{c}$ & 154.40 & 12983.2 & $1.19 e-02$ \\
\hline SAN ONOFRE 1 & 206 & DG1 & $\mathrm{c}$ & 118.96 & 10028.0 & $1.19 \mathrm{e}-02$ \\
\hline COOK 1 & 315 & $1 \mathrm{AB}$ & $\mathrm{C}$ & 164.68 & 14558.7 & $1.13 \mathrm{e}-02$ \\
\hline ARKANSAS 1 & 313 & $\mathrm{~A}$ & $\mathrm{c}$ & 65.24 & 5812.5 & $1.12 \mathrm{e}-02$ \\
\hline PALISADES & 255 & DG 1-1 & $\mathrm{c}$ & 120.03 & 10989.6 & $1.09 \mathrm{e}-02$ \\
\hline SOUTH TEXAS 1 & 498 & EDG12 & $\mathrm{c}$ & 135.50 & 12622.2 & $1.07 e-02$ \\
\hline CALLAWAY & 483 & B & $\mathrm{c}$ & 153.15 & 14434.2 & $1.06 \mathrm{e}-02$ \\
\hline SOUTH TEXAS 1 & 498 & EDG11 & c & 133.60 & 12622.2 & $1.06 \mathrm{e}-02$ \\
\hline QUAD CITIES 2 & 265 & $\mathrm{u} 1 / 2$ & $\mathrm{C}$ & 135.60 & 13053.6 & $1.04 \mathrm{e}-02$ \\
\hline COOK 2 & 316 & $2 \mathrm{CD}$ & $\mathrm{c}$ & 113.13 & 10977.1 & $1.03 e-02$ \\
\hline DIABLO CANYON 1 & 275 & DEG1-2 & $\mathrm{c}$ & 159.32 & 15494.8 & $1.03 \mathrm{e}-02$ \\
\hline OYSTER CREEK & 219 & EDG-2 & c & 138.00 & 13588.2 & $1.02 \mathrm{e}-02$ \\
\hline
\end{tabular}


Table B.2. (Cont'd)

\begin{tabular}{|c|c|c|c|c|c|c|}
\hline Plant Name & $\begin{array}{c}\text { Docket } \\
\text { No } \\
\end{array}$ & EDG ID & $\begin{array}{c}\text { Outage } \\
\text { Code }\end{array}$ & $\begin{array}{l}\text { Total EDG } \\
\text { OOS Hours }\end{array}$ & $\begin{array}{c}\text { Plant On- } \\
\text { Line Hours }\end{array}$ & $\begin{array}{c}\text { Unavail. due } \\
\text { to } \mathrm{CM} \\
\end{array}$ \\
\hline VERMONT YANKEE & 271 & EDGA & $\mathrm{C}$ & 147.80 & 14725.0 & $1.00 \mathrm{e}-02$ \\
\hline WOLF CREEK 1 & 482 & $\mathrm{~A}$ & $\mathrm{C}$ & 136.50 & 13858.9 & $9.85 \mathrm{e}-03$ \\
\hline CALLAWAY & 483 & $\mathrm{~A}$ & $\mathbf{c}$ & 140.35 & 14434.2 & $9.72 e-03$ \\
\hline RIVER BEND & 458 & III & $\mathrm{C}$ & 113.00 & 11921.3 & $9.48 \mathrm{e}-03$ \\
\hline BRAIDWOOD 2 & 457 & $2 \mathrm{~A}$ & $\mathbf{c}$ & 140.30 & 14928.9 & $9.40 \mathrm{e}-03$ \\
\hline KEWAUNEE & 305 & DGA & $\mathrm{C}$ & 137.80 & 15034.3 & $9.17 \mathrm{e}-03$ \\
\hline RIVER BEND & 458 & $\mathbf{I}$ & $\mathrm{c}$ & 108.00 & 11921.3 & $9.06 \mathrm{e}-03$ \\
\hline PALISADES & 255 & DG1-2 & $\mathrm{c}$ & 96.86 & 10989.6 & $8.81 \mathrm{e}-03$ \\
\hline PERRY 1 & 440 & $\mathrm{~A}$ & c & 105.15 & 12148.3 & $8.66 \mathrm{e}-03$ \\
\hline ZION 1 & 295 & $1 \mathrm{~B}$ & c & 84.99 & 9880.1 & $8.60 \mathrm{e}-03$ \\
\hline SOUTH TEXAS 2 & 499 & EDG23 & $\mathrm{c}$ & 107.45 & 12739.0 & $8.43 \mathrm{e}-03$ \\
\hline SURRY 1 & 280 & EDG3 & $\mathrm{C}$ & 115.78 & 13970.0 & $8.29 \mathrm{e}-03$ \\
\hline SAN ONOFRE 3 & 362 & DG2 & $\mathrm{c}$ & 91.78 & 11759.4 & $7.80 \mathrm{e}-03$ \\
\hline COOK 1 & 315 & $1 \mathrm{CD}$ & $\mathrm{c}$ & 110.11 & 14558.7 & $7.56 \mathrm{e}-03$ \\
\hline SOUTH TEXAS 2 & 499 & EDG22 & $\mathrm{c}$ & 96.20 & 12739.0 & $7.55 \mathrm{e}-03$ \\
\hline FITZPATRICK & 333 & $21 \mathrm{EDG}$ & $\mathrm{C}$ & 34.25 & 4536.7 & $7.55 \mathrm{e}-03$ \\
\hline WATERFORD 3 & 382 & $\mathrm{~A}$ & $\mathrm{c}$ & 111.51 & 15066.1 & $7.40 \mathrm{e}-03$ \\
\hline CRYSTAL RIVER 3 & 302 & $1 \mathrm{~A}$ & C & 101.92 & 13782.0 & $7.40 e-03$ \\
\hline DUANE ARNOLD & 331 & $\mathrm{~A}$ & $\mathrm{C}$ & 86.20 & 11760.5 & $7.33 e-03$ \\
\hline BROWNS FERRY 2 & 260 & $\mathrm{D}$ & $\mathrm{C}$ & 56.25 & 7685.6 & $7.32 \mathrm{e}-03$ \\
\hline BRUNSWICK 1 & 325 & EDG2 & $\mathrm{c}$ & 78.90 & 10878.0 & $7.25 \mathrm{e}-03$ \\
\hline SUSQUEHANNA 1 & 387 & $\mathrm{D}$ & c & 89.11 & 12659.7 & $7.04 e-03$ \\
\hline ZION 1 & 295 & $1 \mathrm{~A}$ & $\mathrm{c}$ & 69.20 & 9880.1 & $7.00 \mathrm{e}-03$ \\
\hline PALO VERDE 2 & 529 & 2MDGBH01 & $\mathrm{C}$ & 95.35 & 13927.6 & $6.85 \mathrm{e}-03$ \\
\hline LASALLE 2 & 374 & 0 & $\mathrm{C}$ & 89.00 & 13968.2 & $6.37 \mathrm{e}-03$ \\
\hline LASALLE 1 & 373 & 0 & $\mathrm{C}$ & 91.19 & 14462.1 & $6.31 \mathrm{e}-03$ \\
\hline QUAD CITIES 1 & 254 & $\mathrm{u} 1$ & $\mathrm{C}$ & 74.55 & 11988.5 & $6.22 \mathrm{e}-03$ \\
\hline SURRY 2 & 281 & EDG2 & $\mathrm{c}$ & 86.49 & 13942.1 & $6.20 \mathrm{e}-03$ \\
\hline FORT CALHOUN & 285 & DG-2 & $\mathrm{C}$ & 83.90 & 13599.8 & $6.17 e-03$ \\
\hline FARLEY 1 & 348 & $2 \mathrm{C}$ & $\mathrm{c}$ & 95.39 & 15578.1 & $6.12 \mathrm{e}-03$ \\
\hline CRYSTAL RIVER 3 & 302 & $1 \mathrm{~B}$ & $\mathrm{c}$ & 84.16 & 13782.0 & $6.11 \mathrm{e}-03$ \\
\hline
\end{tabular}


Table B.2. (Cont'd)

\begin{tabular}{|c|c|c|c|c|c|c|}
\hline Plant Name & $\begin{array}{c}\text { Docket } \\
\text { No }\end{array}$ & EDG ID & $\begin{array}{c}\text { Outage } \\
\text { Code }\end{array}$ & $\begin{array}{l}\text { Total EDG } \\
\text { OOS Hours }\end{array}$ & $\begin{array}{l}\text { Plaut On- } \\
\text { Line Hours }\end{array}$ & $\begin{array}{l}\text { Unavail. due } \\
\text { to } \mathrm{CM}\end{array}$ \\
\hline CATAWBA 1 & 413 & $1 \mathrm{~B}$ & c & 37.10 & 6173.1 & $6.01 \mathrm{e}-03$ \\
\hline FARLEY 1 & 348 & $1 B$ & c & 93.55 & 15578.1 & $6.01 \mathrm{e}-03$ \\
\hline SEQUOYAH 2 & 328 & AA & c & 82.93 & 13813.2 & $6.00 e-03$ \\
\hline SOUTH TEXAS 1 & 498 & EDG13 & c & 74.65 & 12622.2 & $5.91 \mathrm{e}-03$ \\
\hline MAINE YANKEE & 309 & DG-1B & c & 77.00 & 13046.6 & $5.90 \mathrm{e}-03$ \\
\hline BEAVER VALLEY 2 & 412 & EDG2-2 & C & 81.70 & 14038.4 & $5.82 \mathrm{e}-03$ \\
\hline BEAVER VALLEY 1 & 334 & EDG 1-2 & c & 76.01 & 13174.8 & $5.77 \mathrm{e}-03$ \\
\hline WATERFORD 3 & 382 & B & c & 86.85 & 15066.1 & $5.76 \mathrm{e}-03$ \\
\hline SEABROOK 1 & 443 & A & c & 75.16 & 13175.6 & $5.70 \mathrm{e}-03$ \\
\hline SALEM 1 & 272 & $1 \mathrm{~B}$ & c & 69.02 & 12295.6 & $5.61 \mathrm{e}-03$ \\
\hline SAN ONOFRE 2 & 361 & DG2 & c & 47.92 & 8764.7 & $5.47 \mathrm{e}-03$ \\
\hline MCGUIRE 2 & 370 & $2 \mathrm{~A}$ & c & 67.40 & 12440.7 & $5.42 \mathrm{e}-03$ \\
\hline COMANCHE PEAK 1 & 445 & $1-01$ & c & 67.70 & 12670.2 & $5.34 \mathrm{e}-03$ \\
\hline HADDAM NECK & 213 & EG-2A & c & 55.75 & 11062.5 & $5.04 \mathrm{e}-03$ \\
\hline MILLSTONE 3 & 423 & 3B & c & 46.38 & 9220.0 & $5.03 e-03$ \\
\hline BRUNSWICK 2 & 324 & EDG3 & c & 57.00 & 11332.3 & $5.03 \mathrm{e}-03$ \\
\hline MCGUIRE 1 & 369 & $1 \mathrm{~A}$ & $\mathrm{c}$ & 63.60 & 12717.6 & $5.00 \mathrm{e}-03$ \\
\hline BRAIDWOOD 1 & 456 & $1 \mathrm{~A}$ & $\mathrm{c}$ & 64.70 & 12957.2 & $4.99 \mathrm{e}-03$ \\
\hline РЕACH ВOTTOM 3 & 278 & E3 & $\mathrm{c}$ & 62.30 & 12804.4 & $4.87 e-03$ \\
\hline HАТCH 1 & 321 & A & c & 69.40 & 14537.8 & $4.77 e_{-03}^{-03}$ \\
\hline РЕACH ВОТTОМ 2 & 277 & E3 & $\mathrm{c}$ & 62.30 & 13241.0 & $4.71 \mathrm{e}-03$ \\
\hline LIMERICK 1 & 352 & D13 & c & 56.09 & 12050.7 & $4.65 e-03$ \\
\hline ST LUCIE 1 & 335 & IB & c & 68.20 & 14938.7 & $4.57 \mathrm{e}-03$ \\
\hline BROWNS FERRY 2 & 260 & B & c & 34.25 & 7685.6 & $4.46 \mathrm{e}-03$ \\
\hline HOPE CREEK 1 & 354 & B & c & 66.80 & 15238.4 & $4.38 \mathrm{e}-03$ \\
\hline MCGUIRE 2 & 370 & $2 \mathrm{~B}$ & $\mathrm{c}$ & 54.20 & 12440.7 & $4.36 \mathrm{e}-03$ \\
\hline SUSQUEHANNA 2 & 388 & D & c & 59.96 & 13779.7 & $4.35 \mathrm{e}-03$ \\
\hline QUAD CITIES 2 & 265 & $\mathrm{U} 2$ & $\mathrm{C}$ & 56.70 & 13053.6 & $4.34 \mathrm{e}-03$ \\
\hline COOPER STATION & 298 & DG-1 & $\mathrm{c}$ & 61.50 & 14304.2 & $4.30 \mathrm{e}-03$ \\
\hline WOLF CREEK 1 & 482 & B & c & 58.55 & 13858.9 & $4.22 \mathrm{e}-03$ \\
\hline FERMI 2 & 341 & EDG13 & $\mathrm{c}$ & 57.00 & 13751.4 & $4.15 \mathrm{e}-03$ \\
\hline
\end{tabular}


Table B.2. (Cont'd)

\begin{tabular}{|c|c|c|c|c|c|c|}
\hline Plant Name & $\begin{array}{l}\text { Docket } \\
\text { No }\end{array}$ & EDG ID & $\begin{array}{l}\text { Outage } \\
\text { Code }\end{array}$ & $\begin{array}{l}\text { Total EDG } \\
\text { oOS Hours }\end{array}$ & $\begin{array}{l}\text { Plant On- } \\
\text { Line Hours }\end{array}$ & $\begin{array}{l}\text { Unavail. due } \\
\text { to } \mathrm{CM}\end{array}$ \\
\hline ARKANSAS 2 & 368 & B & c & 58.75 & 14344.4 & $4.10 \mathrm{e}-03$ \\
\hline НАТСН 2 & 366 & A & c & 60.90 & 15276.0 & $3.99 \mathrm{e}-03$ \\
\hline FARLEY 2 & 364 & $1 \mathrm{C}$ & c & 53.47 & 13486.7 & $3.96 \mathrm{e}-03$ \\
\hline COOPER STATION & 298 & DG-2 & c & 26.60 & 6760.9 & $3.93 \mathrm{e}-03$ \\
\hline HOPE CREEK 1 & 354 & A & c & 59.95 & 15238.4 & $3.93 \mathrm{e}-03$ \\
\hline MILLSTONE 3 & 423 & $3 \mathrm{~A}$ & $\mathrm{c}$ & 36.07 & 9220.0 & $3.91 \mathrm{e}-03$ \\
\hline BEAVER VALLEY 1 & 334 & EDG 1-1 & c & 51.50 & 13174.8 & $3.91 \mathrm{e}-03$ \\
\hline CLINTON 1 & 461 & 1DG01KA & c & 41.35 & 10873.3 & $3.80 \mathrm{e}-03$ \\
\hline SUMMER & 395 & B & c & 57.55 & 15571.0 & $3.70 e-03$ \\
\hline HATCH 1 & 321 & B & $\mathrm{c}$ & 52.31 & 14537.8 & $3.60 \mathrm{e}-03$ \\
\hline HATCH 2 & 366 & B & $\mathrm{C}$ & 54.71 & 15276.0 & $3.58 \mathrm{e}-03$ \\
\hline WASHINGTON NUCLEAR 2 & 397 & DIVI & c & 33.50 & 9355.3 & $3.58 \mathrm{e}-03$ \\
\hline PERRY 1 & 440 & $\mathrm{C}$ & $\mathrm{c}$ & 43.08 & 12148.3 & $3.55 \mathrm{e}-03$ \\
\hline HARRIS 1 & 400 & 1B-SB & $\mathrm{c}$ & 52.60 & 15067.4 & $3.49 \mathrm{e}-03$ \\
\hline FARLEY 1 & 348 & $1 \mathrm{C}$ & $\mathrm{c}$ & 53.47 & 15578.1 & $3.43 \mathrm{e}-03$ \\
\hline MONTICELLO & 263 & 12 & c & 51.10 & 15180.9 & $3.37 e-03$ \\
\hline SALEM 1 & 272 & $1 \mathrm{C}$ & $\mathrm{c}$ & 39.17 & 12295.6 & $3.19 \mathrm{e}-03$ \\
\hline LIMERICK 1 & 352 & D11 & c & 37.77 & 12050.7 & $3.13 \mathrm{e}-03$ \\
\hline SURRY 1 & 280 & EDG1 & $\mathrm{c}$ & 43.69 & 13970.0 & $3.13 \mathrm{e}-03$ \\
\hline SURRY 2 & 281 & EDG3 & $\mathrm{c}$ & 42.95 & 13942.1 & $3.08 \mathrm{e}-03$ \\
\hline COMANCHE PEAK 1 & 445 & $1-02$ & c & 37.50 & 12670.2 & $2.96 \mathrm{e}-03$ \\
\hline VERMONT YANKEE & 271 & EDGB & c & 43.30 & 14725.0 & $2.94 e-03$ \\
\hline DRESDEN 2 & 237 & DG2/3 & c & 30.10 & 10327.1 & $2.91 \mathrm{e}-03$ \\
\hline BROWNS FERRY 2 & 260 & c & c & 22.35 & 7685.6 & $2.91 \mathrm{e}-03$ \\
\hline LIMERICK 2 & 353 & D23 & c & 42.00 & 14521.3 & $2.89 \mathrm{e}-03$ \\
\hline SEQUOYAH 1 & 327 & AA & c & 40.69 & 14144.2 & $2.88 \mathrm{e}-03$ \\
\hline DRESDEN 3 & 249 & $\mathrm{DG} 2 / 3$ & $\mathrm{c}$ & 30.10 & 10786.8 & $2.79 \mathrm{e}-03$ \\
\hline SUMMER & 395 & $\mathrm{~A}$ & c & 43.00 & 15571.0 & $2.76 \mathrm{e}-03$ \\
\hline FERMI 2 & 341 & EDG11 & $\mathrm{c}$ & 37.50 & 13751.4 & $2.73 e-03$ \\
\hline ROBINSON 2 & 261 & B & c & 30.56 & 11467.5 & $2.66 \mathrm{e}-03$ \\
\hline ROBINSON 2 & 261 & A & c & 29.74 & 11467.5 & $2.59 \mathrm{e}-03$ \\
\hline
\end{tabular}


Table B.2. (Cont'd)

\begin{tabular}{|c|c|c|c|c|c|c|}
\hline Plant Name & $\begin{array}{c}\text { Docket } \\
\text { No }\end{array}$ & EDG ID & $\begin{array}{c}\text { Outage } \\
\text { Code }\end{array}$ & $\begin{array}{l}\text { Total EDG } \\
\text { OOS Hours }\end{array}$ & $\begin{array}{c}\text { Plant On- } \\
\text { Line Hours }\end{array}$ & $\begin{array}{l}\text { Unavail, due } \\
\text { to } \mathrm{CM}\end{array}$ \\
\hline WASHINGTON NUCLEAR 2 & 397 & DIVIII & $\mathrm{C}$ & 24.00 & 9355.3 & $2.57 e-03$ \\
\hline INDIAN POINT 2 & 247 & 21EDG & c & 32.00 & 12475.4 & $2.57 e-03$ \\
\hline THREE MILE ISLAND 1 & 289 & EDG-1A & c & 40.77 & 16320.6 & $2.50 \mathrm{e}-03$ \\
\hline SUSQUEHANNA 1 & 387 & E & $\mathrm{C}$ & 31.53 & 12659.7 & $2.49 \mathrm{e}-03$ \\
\hline BYRON 2 & 455 & $2 \mathrm{~A}$ & C & 33.80 & 13700.5 & $2.47 e-03$ \\
\hline WASHINGTON NUCLEAR 2 & 397 & DIVII & $\mathrm{C}$ & 23.00 & 9355.3 & $2.46 e-03$ \\
\hline PRAIRIE ISLAND 2 & 306 & D1 & C & 39.30 & 16125.8 & $2.44 \mathrm{e}-03$ \\
\hline GRAND GULF & 416 & DG12 & c & 33.00 & 13546.6 & $2.44 e-03$ \\
\hline OYSTER CREEK & 219 & EDG-1 & $\mathrm{C}$ & 33.00 & 13588.2 & $2.43 e-03$ \\
\hline INDIAN POINT 2 & 247 & 23EDG & $\mathrm{c}$ & 30.00 & 12475.4 & $2.40 e-03$ \\
\hline CLINTON 1 & 461 & 1DG01KB & $\mathrm{c}$ & 26.04 & 10873.3 & $2.39 e-03$ \\
\hline NORTH ANNA 1 & 338 & $1 \mathrm{~J}$ & $\mathrm{C}$ & 32.49 & 13776.7 & $2.36 \mathrm{e}-03$ \\
\hline PRAIRIE ISLAND 1 & 282 & D1 & $\mathrm{c}$ & 39.30 & 16703.9 & $2.35 \mathrm{e}-03$ \\
\hline DRESDEN 3 & 249 & DG3 & $\mathrm{c}$ & 25.10 & 10786.8 & $2.33 e-03$ \\
\hline LIMERICK 2 & 353 & D21 & $\mathrm{C}$ & 33.25 & 14521.3 & $2.29 \mathrm{e}-03$ \\
\hline SUSQUEHANNA 2 & 388 & E & $\mathrm{C}$ & 31.53 & 13779.7 & $2.29 e-03$ \\
\hline BYRON 2 & 455 & $2 \mathrm{~B}$ & $\mathrm{C}$ & 29.60 & 13700.5 & $2.16 \mathrm{e}-03$ \\
\hline SALEM 2 & 311 & $2 \mathrm{C}$ & $\mathrm{C}$ & 22.27 & 10379.5 & $2.15 \mathrm{e}-03$ \\
\hline LASALLE 2 & 374 & $2 \mathrm{~A}$ & $\mathrm{c}$ & 29.75 & 13968.2 & $2.13 \mathrm{e}-03$ \\
\hline BROWNS FERRY 2 & 260 & $\mathrm{~A}$ & $\mathrm{c}$ & 16.00 & 7685.6 & $2.08 \mathrm{e}-03$ \\
\hline MCGUIRE 1 & 369 & $1 \mathrm{~B}$ & $\mathrm{C}$ & 25.90 & 12717.6 & $2.04 \mathrm{e}-03$ \\
\hline DAVIS-BESSE & 346 & EDGI & $\mathrm{C}$ & 29.50 & 14829.2 & $1.99 \mathrm{e}-03$ \\
\hline LASALLE 1 & 373 & $1 \mathrm{~A}$ & $\mathrm{C}$ & 27.67 & 14462.1 & $1.91 \mathrm{e}-03$ \\
\hline ARKANSAS 2 & 368 & $\mathrm{~A}$ & $\mathrm{C}$ & 27.02 & 14344.4 & $1.88 \mathrm{e}-03$ \\
\hline НАТСH 2 & 366 & C & c & 27.70 & 15276.0 & $1.81 \mathrm{e}-03$ \\
\hline BIG ROCK POINT & 155 & $\mathrm{~A}$ & $\mathrm{c}$ & 18.90 & 10899.2 & $1.73 \mathrm{e}-03$ \\
\hline SUSQUEHANNA 2 & 388 & $\mathrm{C}$ & $\mathrm{c}$ & 23.20 & 13779.7 & $1.68 \mathrm{e}-03$ \\
\hline GINNA & 244 & EDGA & $\mathrm{C}$ & 24.54 & 15053.9 & $1.63 \mathrm{e}-03$ \\
\hline LASALLE 1 & 373 & $1 \mathrm{~B}$ & C & 22.00 & 14462.1 & $1.52 \mathrm{e}-03$ \\
\hline NORTH ANNA 1 & 338 & $1 \mathrm{H}$ & C & 20.85 & 13776.7 & $1.51 \mathrm{e}-03$ \\
\hline RIVER BEND & 458 & II & c & 18.00 & 11921.3 & $1.51 \mathrm{e}-03$ \\
\hline
\end{tabular}


Table B.2. (Cont'd)

\begin{tabular}{|c|c|c|c|c|c|c|}
\hline Plant Name & $\begin{array}{c}\text { Docket } \\
\text { No }\end{array}$ & EDG ID & $\begin{array}{c}\text { Outage } \\
\text { Code }\end{array}$ & $\begin{array}{l}\text { Total EDG } \\
\text { OOS Hours }\end{array}$ & $\begin{array}{l}\text { Plant On- } \\
\text { Line Hours }\end{array}$ & $\begin{array}{c}\text { Unavail, due } \\
\text { to } \mathrm{CM}\end{array}$ \\
\hline GINNA & 244 & EDGB & $\mathrm{c}$ & 20.94 & 15053.9 & $1.39 \mathrm{e}-03$ \\
\hline DUANE ARNOLD & 331 & B & $\mathrm{c}$ & 16.20 & 11760.5 & $1.38 \mathrm{e}-03$ \\
\hline GRAND GULF & 416 & DG11 & C & 18.00 & 13546.6 & $1.33 \mathrm{e}-03$ \\
\hline LIMERICK 2 & 353 & D22 & $\mathrm{c}$ & 18.92 & 14521.3 & $1.30 \mathrm{e}-03$ \\
\hline HATCH 1 & 321 & $\mathrm{c}$ & $\mathbf{c}$ & 17.89 & 14537.8 & $1.23 \mathrm{e}-03$ \\
\hline HOPE CREEK 1 & 354 & $\mathrm{C}$ & $\mathrm{C}$ & 18.20 & 15238.4 & $1.19 \mathrm{e}-03$ \\
\hline BRAIDWOOD 1 & 456 & 1B & $\mathbf{c}$ & 15.25 & 12957.2 & $1.18 \mathrm{e}-03$ \\
\hline FARLEY 2 & 364 & $2 \mathrm{C}$ & $\mathrm{c}$ & 14.98 & 13486.7 & $1.11 \mathrm{e}-03$ \\
\hline SEQUOYAH 1 & 327 & $\mathrm{BB}$ & $\mathrm{c}$ & 14.90 & 14144.2 & $1.05 e-03$ \\
\hline CLINTON 1 & 461 & 1E22001 & $\mathrm{c}$ & 11.31 & 10873.3 & $1.04 \mathrm{e}-03$ \\
\hline SEQUOYAH 2 & 328 & $\mathrm{BB}$ & $\mathrm{c}$ & 13.74 & 13813.2 & $9.95 \mathrm{e}-04$ \\
\hline HADDAM NECK & 213 & EG-2B & c & 11.00 & 11062.5 & $9.94 \mathrm{e}-04$ \\
\hline ST LUCIE 2 & 389 & $2 \mathrm{~B}$ & $\mathrm{c}$ & 13.10 & 14571.0 & $8.99 \mathrm{e}-04$ \\
\hline PEACH BOTTOM 3 & 278 & E2 & $\mathrm{C}$ & 11.50 & 12804.4 & $8.98 \mathrm{e}-04$ \\
\hline PEACH BOTTOM 2 & 277 & E2 & $\mathrm{c}$ & 11.50 & 13241.0 & $8.69 e-04$ \\
\hline POINT BEACH 2 & 301 & G-02 & $\mathrm{c}$ & 11.80 & 15296.6 & $7.71 \mathrm{e}-04$ \\
\hline SUSQUEHANNA 1 & 387 & $\mathrm{c}$ & c & 8.58 & 12659.7 & $6.78 \mathrm{e}-04$ \\
\hline PRAIRIE ISLAND 2 & 306 & $\mathrm{D} 2$ & $\mathrm{c}$ & 10.00 & 16125.8 & $6.20 \mathrm{e}-04$ \\
\hline PRAIRIE ISLAND 1 & 282 & $\mathrm{D} 2$ & c & 10.00 & 16703.9 & $5.99 \mathrm{e}-04$ \\
\hline INDIAN POINT 2 & 247 & 22EDG & $\mathrm{c}$ & 7.22 & 12475.4 & $5.79 \mathrm{e}-04$ \\
\hline NORTH ANNA 2 & 339 & $2 \mathrm{~J}$ & $\mathrm{c}$ & 7.26 & 14043.4 & $5.17 \mathrm{e}-04$ \\
\hline DIABLO CANYON 2 & 323 & DEG2-1 & $\mathrm{c}$ & 7.98 & 16072.3 & $4.97 \mathrm{e}-04$ \\
\hline THREE MILE ISLAND 1 & 289 & EDG-1 B & $\mathrm{c}$ & 7.54 & 16320.6 & $4.62 e-04$ \\
\hline FERMI 2 & 341 & EDG 14 & $\mathrm{C}$ & 5.00 & 13751.4 & $3.64 \mathrm{e}-04$ \\
\hline BRUNSWICK 2 & 324 & EDG4 & $\mathrm{c}$ & 3.98 & 11332.3 & $3.51 e-04$ \\
\hline KEWAUNEE & 305 & DGB & $\mathrm{c}$ & 4.92 & 15034.3 & $3.27 \mathrm{e}-04$ \\
\hline BYRON 1 & 454 & $1 \mathrm{~B}$ & c & 4.40 & 15689.6 & $2.80 \mathrm{e}-04$ \\
\hline LASALLE 2 & 374 & $2 \mathrm{~B}$ & $\mathrm{c}$ & 3.01 & 13968.2 & $2.15 \mathrm{e}-04$ \\
\hline SAN ONOFRE 3 & 362 & DG3 & $\mathrm{C}$ & 1.57 & 11759.4 & $1.34 \mathrm{e}-04$ \\
\hline BYRON 1 & 454 & $1 \mathrm{~A}$ & $\mathrm{c}$ & 0.90 & 15689.6 & $5.74 \mathrm{e}-05$ \\
\hline LIMERICK 2 & 353 & D24 & c & 0.40 & 14521.3 & $2.75 e-05$ \\
\hline
\end{tabular}


Table B.2. (Cont'd)

\begin{tabular}{||l|c|l|r|r|r|r|}
\hline \multicolumn{1}{|c|}{ Plant Name } & $\begin{array}{c}\text { Docket } \\
\text { No }\end{array}$ & \multicolumn{1}{|c|}{ EDG ID } & $\begin{array}{c}\text { Outage } \\
\text { Code }\end{array}$ & $\begin{array}{c}\text { Total EDG } \\
\text { OOS Hours }\end{array}$ & $\begin{array}{c}\text { Plant On- } \\
\text { Line Hours }\end{array}$ & $\begin{array}{c}\text { Unavail. due } \\
\text { to CM }\end{array}$ \\
\hline \hline LIMERICK 1 & 352 & D12 & C & 0.09 & 12050.7 & $7.47 \mathrm{e}-06$ \\
\hline ST LUCIE 2 & 389 & $2 \mathrm{~A}$ & $\mathrm{C}$ & 0.10 & 14571.0 & $6.86 \mathrm{e}-06$ \\
\hline & & & & & & \\
\hline & & & & & AVERAGE* & $8.17 \mathrm{e}-03$ \\
\hline
\end{tabular}

*The average is obtained considering 235 EDGs used in this study. EDGs reporting zero 00S hours are not included in this table. 
Table B.3. EDG Unavailability Due to Preventive and Corrective Maintenance, $\mathrm{U}_{\mathrm{p}, \mathrm{PM}+\mathrm{CM}}$, During Power Operation in Descending Order

\begin{tabular}{|c|c|c|c|c|c|}
\hline Plant Name & $\begin{array}{l}\text { Docket } \\
\text { No }\end{array}$ & EDG ID & $\begin{array}{l}\text { Total EDG } \\
\text { OOS Hours }\end{array}$ & $\begin{array}{l}\text { Plant On-Line } \\
\text { Hours }\end{array}$ & $\begin{array}{l}\text { Unavail. due to } \\
\qquad \mathbf{P M}+\mathbf{C M}\end{array}$ \\
\hline FITZPATRICK & 333 & 12EDG & 395.22 & 2414.3 & $1.64 \mathrm{e}-01$ \\
\hline PERRY 1 & 440 & B & 990.30 & 12148.3 & $8.15 \mathrm{e}-02$ \\
\hline ZION 2 & 304 & C & 743.43 & 9256.5 & $8.03 e-02$ \\
\hline PILGRIM 1 & 293 & B & 490.00 & 7623.4 & $6.43 e-02$ \\
\hline SUSQUEHANNA 1 & 387 & A & 749.27 & 12659.7 & $5.92 e-02$ \\
\hline CALVERT CLIFFS 1 & 317 & 12EDG & 284.28 & 4855.1 & $5.86 \mathrm{e}-02$ \\
\hline FARLEY 2 & 364 & $2 \mathrm{~A}$ & 781.81 & 13486.7 & $5.80 \mathrm{e}-02$ \\
\hline SUSQUEHANNA 2 & 388 & $\mathbf{A}$ & 749.27 & 13779.7 & $5.44 \mathrm{e}-02$ \\
\hline SEABROOK 1 & 443 & B & 688.18 & 13175.6 & $5.22 \mathrm{e}-02$ \\
\hline FARLEY 2 & 364 & 2B & 702.50 & 13486.7 & $5.21 \mathrm{e}-02$ \\
\hline SALEM 1 & 272 & $1 \mathrm{~A}$ & 6.27 .43 & 12295.6 & $5.10 \mathrm{e}-02$ \\
\hline FARLEY 1 & 348 & $1 \mathrm{~A}$ & 758.89 & 15578.1 & $4.87 e-02$ \\
\hline ZION 1 & 295 & C & 466.42 & 9880.1 & $4.72 \mathrm{e}-02$ \\
\hline FARLEY 1 & 348 & $1 \mathrm{~B}$ & 731.96 & 15578.1 & $4.70 \mathrm{e}-02$ \\
\hline LIMERICK 2 & 353 & D24 & 660.13 & 14521.3 & $4.55 \mathrm{e}-02$ \\
\hline PEACH BOTTOM 3 & 278 & E4 & 575.00 & 12804.4 & $4.49 \mathrm{e}-02$ \\
\hline LIMERICK 1 & 352 & D11 & 532.87 & 12050.7 & $4.42 \mathrm{e}-02$ \\
\hline CALVERT CLIFFS 1 & 317 & 11EDG & 447.58 & 10168.6 & $4.40 \mathrm{e}-02$ \\
\hline QUAD CITIES 1 & 254 & $\mathrm{U} 1 / 2$ & 526.60 & 11988.5 & $4.39 \mathrm{e}-02$ \\
\hline PEACH BOTTOM 2 & 277 & E4 & 575.00 & 13241.0 & $4.34 \mathrm{e}-02$ \\
\hline SALEM 2 & 311 & 2B & 445.61 & 10379.5 & $4.29 \mathrm{e}-02$ \\
\hline MILLSTONE 1 & 245 & $1 \mathrm{~A}$ & 390.31 & 9104.9 & $4.29 \mathrm{e}-02$ \\
\hline ROBINSON 2 & 261 & $D / S$ & 489.00 & 11467.5 & $4.26 \mathrm{e}-02$ \\
\hline PILGRIM 1 & 293 & $\mathbf{A}$ & 288.00 & 7623.4 & $3.78 \mathrm{e}-02$ \\
\hline SOUTH TEXAS 2 & 499 & EDG21 & 481.00 & 12739.0 & $3.78 \mathrm{e}-02$ \\
\hline FORT CALHOUN & 285 & DG-1 & 511.00 & 13599.8 & $3.76 \mathrm{e}-02$ \\
\hline LIMERICK 1 & 352 & D12 & 447.93 & 12050.7 & $3.72 \mathrm{e}-02$ \\
\hline DRESDEN 2 & 237 & $\mathrm{DG} 2 / 3$ & 382.40 & 10327.1 & $3.70 \mathrm{e}-02$ \\
\hline CATAWBA 2 & 414 & $2 \mathrm{~A}$ & 102.85 & 2813.0 & $3.66 \mathrm{e}-02$ \\
\hline PALO VERDE 3 & 530 & 3MDGBHOI & 523.90 & $14774 . \dot{1}$ & $3.55 \mathrm{e}-02$ \\
\hline
\end{tabular}


Table B.3. (Cont'd)

\begin{tabular}{|c|c|c|c|c|c|}
\hline Plant Name & $\begin{array}{c}\text { Docket } \\
\text { No }\end{array}$ & EDG ID & $\begin{array}{l}\text { Total EDG } \\
\text { oOS Hours }\end{array}$ & $\begin{array}{l}\text { Plant On-Line } \\
\text { Hours }\end{array}$ & $\begin{array}{c}\text { Unavail. due to } \\
\mathbf{P M}+\mathbf{C M}\end{array}$ \\
\hline DRESDEN 3 & 249 & DG2/3 & 382.40 & 10786.8 & $3.55 \mathrm{e}-02$ \\
\hline SUMMER & 395 & A & 538.60 & 15571.0 & $3.46 \mathrm{e}-02$ \\
\hline PALO VERDE 3 & 530 & 3MDGAH01 & 498.90 & 14774.1 & $3.38 \mathrm{e}-02$ \\
\hline SOUTH TEXAS 1 & 498 & EDG12 & 422.00 & 12622.2 & $3.34 \mathrm{e}-02$ \\
\hline SALEM 2 & 311 & $2 \mathrm{~A}$ & 345.91 & 10379.5 & $3.33 \mathrm{e}-02$ \\
\hline SOUTH TEXAS 1 & 498 & EDG11 & 420.50 & 12622.2 & $3.33 \mathrm{e}-02$ \\
\hline FITZPATRICK & 333 & 21EDG & 148.91 & 4536.7 & $3.28 \mathrm{e}-02$ \\
\hline VOGTLE 1 & 424 & DG1A & 321.55 & 9883.7 & $3.25 \mathrm{e}-02$ \\
\hline WOLF CREEK 1 & 482 & A & 440.10 & 13858.9 & $3.18 \mathrm{e}-02$ \\
\hline INDIAN POINT 2 & 247 & 22EDG & 391.89 & 12475.4 & $3.14 \mathrm{e}-02$ \\
\hline LASALLE 2 & 374 & 0 & 434.32 & 13968.2 & $3.11 \mathrm{e}-02$ \\
\hline SURRY 2 & 281 & EDG3 & 431.31 & 13942.1 & $3.09 \mathrm{e}-02$ \\
\hline SOUTH TEXAS 2 & 499 & EDG22 & 387.50 & 12739.0 & $3.04 e-02$ \\
\hline POINT BEACH 1 & 266 & G-01 & 439.30 & 14872.0 & $2.95 \mathrm{e}-02$ \\
\hline MAINE YANKEE & 309 & DG-1A & 383.00 & 13046.6 & $2.94 \mathrm{e}-02$ \\
\hline BROWNS FERRY 2 & 260 & $\mathbf{A}$ & 223.50 & 7685.6 & $2.91 \mathrm{e}-02$ \\
\hline WOLF CREEK 1 & 482 & B & 402.80 & 13858.9 & $2.91 \mathrm{e}-02$ \\
\hline SEQUOYAH 2 & 328 & AA & 395.66 & 13813.2 & $2.86 e-02$ \\
\hline INDIAN POINT 2 & 247 & 21EDG & 356.67 & 12475.4 & $2.86 \mathrm{e}-02$ \\
\hline SOUTH TEXAS 2 & 499 & EDG23 & 359.50 & 12739.0 & $2.82 \mathrm{e}-02$ \\
\hline DAVIS-BESSE & 346 & EDG2 & 413.40 & 14829.2 & $2.79 \mathrm{e}-02$ \\
\hline FORT CALHOUN & 285 & DG-2 & 367.00 & 13599.8 & $2.70 \mathrm{e}-02$ \\
\hline SUSQUEHANNA 1 & 387 & B & 331.67 & 12659.7 & $2.62 \mathrm{e}-02$ \\
\hline POINT BEACH 2 & 301 & G-01 & 398.35 & 15296.6 & $2.60 \mathrm{e}-02$ \\
\hline BRUNSWICK 1 & 325 & EDG1 & 282.80 & 10878.0 & $2.60 e-02$ \\
\hline RIVER BEND & 458 & 1 & 309.00 & 11921.3 & $2.59 \mathrm{e}-02$ \\
\hline RIVER BEND & 458 & III & 308.00 & 11921.3 & $2.58 \mathrm{e}-02$ \\
\hline BROWNS FERRY 2 & 260 & B & 195.75 & 7685.6 & $2.55 \mathrm{e}-02$ \\
\hline MILLSTONE 3 & 423 & $3 \mathrm{~A}$ & 232.84 & 9220.0 & $2.53 \mathrm{e}-02$ \\
\hline SAN ONOFRE 2 & 361 & DG3 & 220.22 & 8764.7 & $2.51 \mathrm{e}-02$ \\
\hline РEACH ВОТTOM 3 & 278 & E2 & 312.70 & 12804.4 & $2.44 e-02$ \\
\hline
\end{tabular}


Table B.3. (Cont'd)

\begin{tabular}{|c|c|c|c|c|c|}
\hline Plant Name & $\begin{array}{c}\text { Docket } \\
\text { No }\end{array}$ & EDG ID & $\begin{array}{l}\text { Total EDG } \\
\text { OOS Hours }\end{array}$ & $\begin{array}{c}\text { Plant On-Line } \\
\text { Hours }\end{array}$ & $\begin{array}{l}\text { Unavail. due to } \\
\text { PM + CM }\end{array}$ \\
\hline SUSQUEHANNA 2 & 388 & B & 331.67 & 13779.7 & $2.41 \mathrm{e}-02$ \\
\hline POINT BEACH 2 & 301 & G-02 & 366.60 & 15296.6 & $2.40 \mathrm{e}-02$ \\
\hline POINT BEACH 1 & 266 & G-02 & 354.80 & 14872.0 & $2.39 \mathrm{e}-02$ \\
\hline PEACH BOTTOM 2 & 277 & E2 & 312.70 & 13241.0 & $2.36 \mathrm{e}-02$ \\
\hline LASALLE 1 & 373 & 0 & 335.76 & 14462.1 & $2.32 \mathrm{e}-02$ \\
\hline PERRY 1 & 440 & A & 281.53 & 12148.3 & $2.32 \mathrm{e}-02$ \\
\hline PEACH BOTTOM 3 & 278 & E3 & 295.80 & 12804.4 & $2.31 \mathrm{e}-02$ \\
\hline RIVER BEND & 458 & II & 272.00 & 11921.3 & $2.28 \mathrm{e}-02$ \\
\hline BROWNS FERRY 2 & 260 & D & 175.25 & 7685.6 & $2.28 \mathrm{e}-02$ \\
\hline VOGTLE 2 & 425 & $\mathrm{DG} 2 \mathrm{~A}$ & 271.93 & 11954.1 & $2.27 e-02$ \\
\hline MILLSTONE 3 & 423 & 3B & 209.11 & 9220.0 & $2.27 \mathrm{e}-02$ \\
\hline PRAIRIE ISLAND 2 & 306 & $\mathrm{D} 2$ & 364.40 & 16125.8 & $2.26 \mathrm{e}-02$ \\
\hline PRAIRIE ISLAND 1 & 282 & D2 & 376.80 & 16703.9 & $2.26 \mathrm{e}-02$ \\
\hline CATAWBA 1 & 413 & $1 \mathrm{~A}$ & 138.80 & 6173.1 & $2.25 \mathrm{e}-02$ \\
\hline DIABLO CANYON 1 & 275 & DEG1-2 & 346.68 & 15494.8 & $2.24 \mathrm{e}-02$ \\
\hline PEACH BOTTOM 2 & 277 & E3 & 295.80 & 13241.0 & $2.23 \mathrm{e}-02$ \\
\hline MCGUIRE 1 & 369 & $1 \mathrm{~A}$ & 278.70 & 12717.6 & $2.19 \mathrm{e}-02$ \\
\hline FARLEY 2 & 364 & $1 \mathrm{C}$ & 293.34 & 13486.7 & $2.18 \mathrm{e}-02$ \\
\hline FARLEY 1 & 348 & $1 \mathrm{C}$ & 338.64 & 15578.1 & $2.17 e-02$ \\
\hline SALEM 1 & 272 & $1 \mathrm{~B}$ & 264.24 & 12295.6 & $2.15 \mathrm{e}-02$ \\
\hline PALISADES & 255 & DG1-1 & 235.59 & 10989.6 & $2.14 \mathrm{e}-02$ \\
\hline SEQUOYAH 2 & 328 & $\mathrm{BB}$ & 294.94 & 13813.2 & $2.14 \mathrm{e}-02$ \\
\hline SURRY 1 & 280 & EDG3 & 297.35 & 13970.0 & $2.13 \mathrm{e}-02$ \\
\hline INDIAN POINT 2 & 247 & 23EDG & 263.66 & 12475.4 & $2.11 \mathrm{e}-02$ \\
\hline PEACH ВOTTOM 3 & 278 & E1 & 270.20 & 12804.4 & $2.11 \mathrm{e}-02$ \\
\hline CLINTON 1 & 461 & $1 \mathrm{E} 22001$ & 228.50 & 10873.3 & $2.10 \mathrm{e}-02$ \\
\hline PALO VERDE 2 & 529 & 2MDGAH01 & 288.10 & 13927.6 & $2.07 e-02$ \\
\hline PEACH BOTTOM 2 & 277 & E1 i & 270.20 & 13241.0 & $2.04 \mathrm{e}-02$ \\
\hline CATAWBA 2 & 414 & 2B & 57.10 & 2813.0 & $2.03 \mathrm{e}-02$ \\
\hline SEQUOYAH 1 & 327 & AA & 286.41 & 14144.2 & $2.02 \mathrm{e}-02$ \\
\hline BEAVER VALLEY 2 & 412 & EDG2-1 & 283.20 & 14038.4 & $2.02 \mathrm{e}-02$ \\
\hline
\end{tabular}


Table B.3. (Cont'd)

\begin{tabular}{|c|c|c|c|c|c|}
\hline Plant Name & $\begin{array}{c}\text { Docket } \\
\text { No }\end{array}$ & EDG ID & $\begin{array}{l}\text { Total EDG } \\
\text { OOS Hours }\end{array}$ & $\begin{array}{c}\text { Plant On-Line } \\
\text { Hours } \\
\end{array}$ & $\begin{array}{c}\text { Unavail. dne to } \\
\mathbf{P M}+\mathbf{C M}\end{array}$ \\
\hline SOUTH TEXAS 1 & 498 & EDG13 & 253.50 & 12622.2 & $2.01 \mathrm{e}-02$ \\
\hline LIMERICK 2 & 353 & D23 & 291.40 & 14521.3 & $2.01 \mathrm{e}-02$ \\
\hline PALO VERDE 1 & 528 & 1MDGAH01 & 260.30 & 12983.2 & $2.00 \mathrm{e}-02$ \\
\hline PALO VERDE 1 & 528 & 1MDGBH01 & 258.20 & 12983.2 & $1.99 \mathrm{e}-02$ \\
\hline ZION 2 & 304 & $2 \mathrm{~A}$ & 182.91 & 9256.5 & $1.98 \mathrm{e}-02$ \\
\hline BROWNS FERRY 2 & 260 & c & 151.52 & 7685.6 & $1.97 \mathrm{e}-02$ \\
\hline LIMERICK 2 & 353 & $\mathrm{D} 21$ & 281.25 & 14521.3 & $1.94 \mathrm{e}-02$ \\
\hline VOGTLE 1 & 424 & DG1B & 189.65 & 9883.7 & $1.92 \mathrm{e}-02$ \\
\hline ZION 2 & 304 & $2 \mathrm{~B}$ & 177.56 & 9256.5 & $1.92 \mathrm{e}-02$ \\
\hline CALLAWAY & 483 & B & 275.65 & 14434.2 & $1.91 \mathrm{e}-02$ \\
\hline SAN ONOFRE 1 & 206 & DG2 & 188.99 & 10028.0 & $1.88 \mathrm{e}-02$ \\
\hline CALLAWAY & 483 & $\mathrm{~A}$ & 270.10 & 14434.2 & $1.87 e-02$ \\
\hline SUMMER & 395 & B & 291.15 & 15571.0 & $1.87 e-02$ \\
\hline MAINE YANKEE & 309 & DG-1B & 241.00 & 13046.6 & $1.85 \mathrm{e}-02$ \\
\hline BRAIDWOOD 2 & 457 & $2 \mathrm{~A}$ & 272.90 & 14928.9 & $1.83 \mathrm{e}-02$ \\
\hline LASALLE 2 & 374 & $2 \mathrm{~B}$ & 253.33 & 13968.2 & $1.81 \mathrm{e}-02$ \\
\hline SEQUOYAH 1 & 327 & BB & 248.28 & 14144.2 & $1.76 \mathrm{e}-02$ \\
\hline PALISADES & 255 & DG1-2 & 192.14 & 10989.6 & $1.75 \mathrm{e}-02$ \\
\hline LIMERICK 1 & 352 & D13 & 210.10 & 12050.7 & $1.74 \mathrm{e}-02$ \\
\hline THREE MILE ISLAND 1 & 289 & EDG-1A & 282.85 & 16320.6 & $1.73 \mathrm{e}-02$ \\
\hline CLINTON 1 & 461 & 1DG01KA & 182.00 & 10873.3 & $1.67 \mathrm{e}-02$ \\
\hline ST LUCIE 2 & 389 & 2B & 242.10 & 14571.0 & $1.66 \mathrm{e}-02$ \\
\hline LIMERICK 2 & 353 & $\mathrm{D} 22$ & 235.89 & 14521.3 & $1.62 \mathrm{e}-02$ \\
\hline DRESDEN 2 & 237 & DG2 & 166.40 & 10327.1 & $1.61 \mathrm{e}-02$ \\
\hline COMANCHE PEAK 1 & 445 & $1-02$ & 203.10 & 12670.2 & $1.60 \mathrm{e}-02$ \\
\hline HARRIS 1 & 400 & 1A-SA & 239.68 & 15067.4 & $1.59 \mathrm{e}-02$ \\
\hline LASALLE 1 & 373 & 1B & 229.72 & 14462.1 & $1.59 \mathrm{e}-02$ \\
\hline MCGUIRE 1 & 369 & $1 \mathrm{~B}$ & 201.30 & 12717.6 & $1.58 \mathrm{e}-02$ \\
\hline PALO VERDE 2 & 529 & 2MDGBH01 & 220.30 & 13927.6 & $1.58 \mathrm{e}-02$ \\
\hline CRYSTAL RIVER 3 & 302 & $1 \mathrm{~A}$ & 217.78 & 13782.0 & $1.58 \mathrm{e}-02$ \\
\hline DIABLO CANYON 1 & 275 & DEG1-3 & 243.72 & 15494.8 & $1.57 \mathrm{e}-02$ \\
\hline
\end{tabular}


Table B.3. (Cont'd)

\begin{tabular}{|c|c|c|c|c|c|}
\hline Plant Name & $\begin{array}{l}\text { Docket } \\
\text { No }\end{array}$ & EDG ID & $\begin{array}{l}\text { Total EDG } \\
\text { OOS Hours }\end{array}$ & $\begin{array}{c}\text { Plant On-Line } \\
\text { Hours }\end{array}$ & $\begin{array}{c}\text { Unavail. due to } \\
\text { PM + CM }\end{array}$ \\
\hline LIMERICK 1 & 352 & D14 & 188.40 & 12050.7 & $1.56 \mathrm{e}-02$ \\
\hline DIABLO CANYON 2 & 323 & DEG1-3 & 243.72 & 16072.3 & $1.52 \mathrm{e}-02$ \\
\hline OYSTER CREEK & 219 & EDG-2 & 204.00 & 13588.2 & $1.50 \mathrm{e}-02$ \\
\hline THREE MILE ISLAND 1 & 289 & EDG-1 B & 243.13 & 16320.6 & $1.49 \mathrm{e}-02$ \\
\hline SAN ONOFRE 3 & 362 & DG2 & 175.11 & 11759.4 & $1.49 \mathrm{e}-02$ \\
\hline CLINTON 1 & 461 & $1 \mathrm{DG} 01 \mathrm{~KB}$ & 158.60 & 10873.3 & $1.46 \mathrm{e}-02$ \\
\hline NORTH ANNA 1 & 338 & $1 \mathrm{~J}$ & 200.05 & 13776.7 & $1.45 \mathrm{e}-02$ \\
\hline NORTH ANNA 1 & 338 & $1 \mathrm{H}$ & 199.40 & 13776.7 & $1.45 \mathrm{e}-02$ \\
\hline CATAWBA 1 & 413 & 1B & 88.30 & 6173.1 & $1.43 \mathrm{e}-02$ \\
\hline SALEM 2 & 311 & $2 \mathrm{C}$ & 148.24 & 10379.5 & $1.43 \mathrm{e}-02$ \\
\hline ARKANSAS 1 & 313 & $\mathrm{~B}^{\prime}$ & 82.95 & 5812.5 & $1.43 \mathrm{e}-02$ \\
\hline FARLEY 2 & 364 & $2 \mathrm{C}$ & 191.37 & 13486.7 & $1.42 \mathrm{e}-02$ \\
\hline LASALLE 1 & 373 & $1 \mathrm{~A}$ & 2.04 .21 & 14462.1 & $1.41 \mathrm{e}-02$ \\
\hline BRAIDWOOD 1 & 456 & $1 \mathrm{~B}$ & 182.60 & 12957.2 & $1.41 \mathrm{e}-02$ \\
\hline FARLEY 1 & 348 & $2 \mathrm{C}$ & 2.07 .28 & 15578.1 & $1.33 \mathrm{e}-02$ \\
\hline MONTICELLO & 263 & 11 & 197.37 & 15180.9 & $1.30 \mathrm{e}-02$ \\
\hline GRAND GULF & 416 & DG12 & 176.00 & 13546.6 & $1.30 \mathrm{e}-02$ \\
\hline ST LUCIE 1 & 335 & $1 \mathrm{~B}$ & 193.00 & 14938.7 & $1.29 \mathrm{e}-02$ \\
\hline CRYSTAL RIVER 3 & 302 & $1 \mathrm{~B}$ & 175.66 & 13782.0 & $1.27 \mathrm{e}-02$ \\
\hline MCGUIRE 2 & 370 & 2B & 157.40 & 12440.7 & $1.27 \mathrm{e}-02$ \\
\hline GRAND GULF & 416 & DG11 & 171.00 & 13546.6 & $1.26 \mathrm{e}-02$ \\
\hline DIABLO CANYON 1 & 275 & DEG1-1 & 195.51 & 15494.8 & $1.26 \mathrm{e}-02$ \\
\hline VOGTLE 2 & 425 & DG2B & 146.61 & 11954.1 & $1.23 \mathrm{e}-02$ \\
\hline ROBINSON 2 & 261 & $\mathrm{~A}$ & 1.39 .43 & 11467.5 & $1.22 \mathrm{e}-02$ \\
\hline COOK 2 & 316 & $2 \mathrm{AB}$ & 1.31 .47 & 10977.1 & $1.20 \mathrm{e}-02$ \\
\hline SAN ONOFRE 1 & 206 & DG1 & 1.18 .96 & 10028.0 & $1.19 \mathrm{e}-02$ \\
\hline ROBINSON 2 & 261 & B & 1.35 .94 & 11467.5 & $1.19 \mathrm{e}-02$ \\
\hline PERRY 1 & 440 & $\mathrm{C}$ & 1.43 .60 & 12148.3 & $1.18 \mathrm{e}-02$ \\
\hline SUSQUEHANNA 1 & 387 & $\mathrm{D}$ & 1149.54 & 12659.7 & $1.18 \mathrm{e}-02$ \\
\hline ST LUCIE 1 & 335 & $1 \mathrm{~A}$ & 1176.00 & 14938.7 & $1.18 \mathrm{e}-02$ \\
\hline BRAIDWOOD 1 & 456 & $1 \mathrm{~A}$ & 152.50 & 12957.2 & $1.18 \mathrm{e}-02$ \\
\hline
\end{tabular}


Table B.3. (Cont'd)

\begin{tabular}{|c|c|c|c|c|c|}
\hline Plant Name & $\begin{array}{c}\text { Docket } \\
\text { No }\end{array}$ & EDG ID & $\begin{array}{l}\text { Total EDG } \\
\text { OOS Hours }\end{array}$ & $\begin{array}{l}\text { Plant On-Line } \\
\text { Hours }\end{array}$ & $\begin{array}{l}\text { Unavail. due to } \\
\text { PM + CM }\end{array}$ \\
\hline VERMONT YANKEE & 271 & EDGB & 172.50 & 14725.0 & $1.17 \mathrm{e}-02$ \\
\hline FERMI 2 & 341 & EDG11 & 159.00 & 13751.4 & $1.16 \mathrm{e}-02$ \\
\hline MCGUIRE 2 & 370 & $2 \mathrm{~A}$ & 141.40 & 12440.7 & $1.14 \mathrm{e}-02$ \\
\hline COOK 1 & 315 & $1 \mathrm{AB}$ & 164.68 & 14558.7 & $1.13 \mathrm{e}-02$ \\
\hline ARKANSAS 1 & 313 & $A^{\prime}$ & 65.24 & 5812.5 & $1.12 \mathrm{e}-02$ \\
\hline ST LUCIE 2 & 389 & $2 \mathrm{~A}$ & 158.80 & 14571.0 & $1.09 \mathrm{e}-02$ \\
\hline HOPE CREEK 1 & 354 & A & 165.65 & 15238.4 & $1.09 \mathrm{e}-02$ \\
\hline HATCH 1 & 321 & $\mathrm{~B}$ & 157.80 & 14537.8 & $1.09 \mathrm{e}-02$ \\
\hline SAN ONOFRE 3 & 362 & DG3 & 127.16 & 11759.4 & $1.08 \mathrm{e}-02$ \\
\hline VERMONT YANKEE & 271 & EDGA & 157.60 & 14725.0 & $1.07 \mathrm{e}-02$ \\
\hline QUAD CITIES 2 & 265 & $\mathrm{U} 1 / 2$ & 139.70 & 13053.6 & $1.07 \mathrm{e}-02$ \\
\hline SAN ONOFRE 2 & 361 & $\mathrm{DG} 2$ & 92.17 & 8764.7 & $1.05 \mathrm{e}-02$ \\
\hline LASALLE 2 & 374 & $2 \mathrm{~A}$ & 145.03 & 13968.2 & $1.04 \mathrm{e}-02$ \\
\hline COOK 2 & 316 & $2 \mathrm{CD}$ & 113.13 & 10977.1 & $1.03 \mathrm{e}-02$ \\
\hline KEWAUNEE & 305 & DGA & 153.29 & 15034.3 & $1.02 \mathrm{e}-02$ \\
\hline SUSQUEHANNA 2 & 388 & $\mathrm{D}$ & 140.34 & 13779.7 & $1.02 \mathrm{e}-02$ \\
\hline COMANCHE PEAK 1 & 445 & $1-01$ & 127.20 & 12670.2 & $1.00 \mathrm{e}-02$ \\
\hline NORTH ANNA 2 & 339 & $2 \mathrm{H}$ & 139.59 & 14043.4 & $9.94 \mathrm{e}-03$ \\
\hline DIABLO CANYON 2 & 323 & DEG2-2 & 156.15 & 16072.3 & $9.72 e-03$ \\
\hline FERMI 2 & 341 & EDG14 & 133.50 & 13751.4 & $9.71 \mathrm{e}-03$ \\
\hline WATERFORD 3 & 382 & B & 144.74 & 15066.1 & $9.61 \mathrm{e}-03$ \\
\hline DRESDEN 3 & 249 & DG3 & 101.00 & 10786.8 & $9.36 \mathrm{e}-03$ \\
\hline DAVIS-BESSE & 346 & EDG1 & 137.70 & 14829.2 & $9.29 \mathrm{e}-03$ \\
\hline PRAIRIE ISLAND 2 & 306 & DI & 143.90 & 16125.8 & $8.92 \mathrm{e}-03$ \\
\hline DUANE ARNOLD & 331 & $\mathrm{~A}$ & 101.60 & 11760.5 & $8.64 \mathrm{e}-03$ \\
\hline PRAIRIE ISLAND 1 & 282 & D1 & 143.90 & 16703.9 & $8.61 \mathrm{e}-03$ \\
\hline ZION 1 & 295 & $1 \mathrm{~B}$ & 84.99 & 9880.1 & $8.60 \mathrm{e}-03$ \\
\hline BIG ROCK POINT & 155 & $\mathrm{~A}$ & 92.90 & 10899.2 & $8.52 \mathrm{e}-03$ \\
\hline SUSQUEHANNA 1 & 387 & $\mathrm{E}$ & 107.56 & 12659.7 & $8.50 \mathrm{e}-03$ \\
\hline HADDAM NECK & 213 & EG-2A & 93.51 & 11062.5 & $8.45 \mathrm{e}-03$ \\
\hline НАТСН 2 & 366 & B & 125.60 & 15276.0 & $8.22 \mathrm{e}-03$ \\
\hline
\end{tabular}


Table B.3. (Cont'd)

\begin{tabular}{|c|c|c|c|c|c|}
\hline Plant Name & $\begin{array}{c}\text { Docket } \\
\text { No }\end{array}$ & EDG ID & $\begin{array}{l}\text { Total EDG } \\
\text { OOS Hours }\end{array}$ & $\begin{array}{c}\text { Plant On-Line } \\
\text { Hours } \\
\end{array}$ & $\begin{array}{l}\text { Unavail, due to } \\
\text { PM + CM }\end{array}$ \\
\hline WATERFORD 3 & 382 & A & 123.36 & 15066.1 & $8.19 \mathrm{e}-03$ \\
\hline SUSQUEHANNA 1 & 387 & $\mathrm{c}$ & 100.88 & 12659.7 & $7.97 e-03$ \\
\hline SURRY 2 & 281 & EDG2 & 110.49 & 13942.1 & $7.92 \mathrm{e}-03$ \\
\hline BEAVER VALLEY 1 & 334 & EDG1-2 & 103.07 & 13174.8 & $7.82 \mathrm{e}-03$ \\
\hline NORTH ANNA 2 & 339 & $2 \mathrm{~J}$ & 106.93 & 14043.4 & $7.61 \mathrm{e}-03$ \\
\hline COOK 1 & 315 & $1 \mathrm{CD}$ & 110.11 & 14558.7 & $7.56 \mathrm{e}-03$ \\
\hline OYSTER CREEK & 219 & EDG-1 & 102.50 & 13588.2 & $7.54 \mathrm{e}-03$ \\
\hline BEAVER VALLEY 2 & 412 & EDG2-2 & 104.50 & 14038.4 & $7.44 \mathrm{e}-03$ \\
\hline SUSQUEHANNA 2 & 388 & E & 102.03 & 13779.7 & $7.40 \mathrm{e}-03$ \\
\hline QUAD CITIES 1 & 254 & u1 & 88.65 & 11988.5 & $7.39 \mathrm{e}-03$ \\
\hline BRUNSWICK 1 & 325 & EDG2 & 79.20 & 10878.0 & $7.28 \mathrm{e}-03$ \\
\hline BEAVER VALLEY 1 & 334 & EDG1-1 & 95.20 & 13174.8 & $7.23 \mathrm{e}-03$ \\
\hline SALEM 1 & 272 & $1 \mathrm{C}$ & 87.15 & 12295.6 & $7.09 \mathrm{e}-03$ \\
\hline ZION 1 & 295 & $1 \mathrm{~A}$ & 69.20 & 9880.1 & $7.00 \mathrm{e}-03$ \\
\hline SUSQUEHANNA 2 & 388 & $\mathrm{c}$ & 95.55 & 13779.7 & $6.93 \mathrm{e}-03$ \\
\hline FERMI 2 & 341 & EDG13 & 92.50 & 13751.4 & $6.73 \mathrm{e}-03$ \\
\hline DIABLO CANYON 2 & 323 & DEG2-1 & 102.42 & 16072.3 & $6.37 \mathrm{e}-03$ \\
\hline HOPE CREEK 1 & 354 & $\mathbf{B}$ & 95.67 & 15238.4 & $6.28 \mathrm{e}-03$ \\
\hline HADDAM NECK & 213 & EG-2B & 67.97 & 11062.5 & $6.14 \mathrm{e}-03$ \\
\hline QUAD CITIES 2 & 265 & $\mathrm{U} 2$ & 77.60 & 13053.6 & $5.94 \mathrm{e}-03$ \\
\hline SEABROOK 1 & 443 & A & 75.16 & 13175.6 & $5.70 \mathrm{e}-03$ \\
\hline SURRY 1 & 280 & EDG1 & 71.54 & 13970.0 & $5.12 \mathrm{e}-03$ \\
\hline BRUNSWICK 2 & 324 & EDG3 & 57.00 & 11332.3 & $5.03 \mathrm{e}-03$ \\
\hline BRAIDWOOD 2 & 457 & 2B & 73.20 & 14928.9 & $4.90 \mathrm{e}-03$ \\
\hline HATCH 1 & 321 & $\mathrm{~A}$ & 70.90 & 14537.8 & $4.88 \mathrm{e}-03$ \\
\hline HOPE CREEK 1 & 354 & c & 66.30 & 15238.4 & $4.35 \mathrm{e}-03$ \\
\hline COOPER STATION & 298 & DG-1 & 61.50 & 14304.2 & $4.30 \mathrm{e}-03$ \\
\hline GINNA & 244 & EDGA & 63.56 & 15053.9 & $4.22 \mathrm{e}-03$ \\
\hline HARRIS 1 & 400 & $1 \mathrm{~B}-\mathrm{SB}$ & 62.30 & 15067.4 & $4.13 \mathrm{e}-03$ \\
\hline ARKANSAS 2 & 368 & B & 58.75 & 14344.4 & $4.10 \mathrm{e}-03$ \\
\hline COOPER STATION & 298 & DG-2 & 27.50 & 6760.9 & $4.07 \mathrm{e}-03$ \\
\hline
\end{tabular}


Table B.3. (Cont'd)

\begin{tabular}{|c|c|c|c|c|c|}
\hline Plant Name & $\begin{array}{c}\text { Docket } \\
\text { No }\end{array}$ & EDG ID & $\begin{array}{l}\text { Total EDG } \\
\text { OOS Hours }\end{array}$ & $\begin{array}{l}\text { Plant On-Line } \\
\text { Hours }\end{array}$ & $\begin{array}{l}\text { Unavail. due to } \\
\qquad \mathbf{P M}+\mathbf{C M}\end{array}$ \\
\hline НАТСH 2 & 366 & A & 61.40 & 15276.0 & $4.02 \mathrm{e}-03$ \\
\hline GINNA & 244 & EDGB & 59.72 & 15053.9 & $3.97 \mathrm{e}-03$ \\
\hline BYRON 2 & 455 & $2 A$ & 53.70 & 13700.5 & $3.92 \mathrm{e}-03$ \\
\hline FERMI 2 & 341 & EDG12 & 53.00 & 13751.4 & $3.85 \mathrm{e}-03$ \\
\hline BYRON 1 & 454 & 1B & 57.55 & 15689.6 & $3.67 \mathrm{e}-03$ \\
\hline BYRON 2 & 455 & 2B & 50.00 & 13700.5 & $3.65 e-03$ \\
\hline WASHINGTON NUCLEAR 2 & 397 & DTVI & 33.50 & 9355.3 & $3.58 \mathrm{e}-03$ \\
\hline MONTICELLO & 263 & 12 & 51.10 & 15180.9 & $3.37 \mathrm{e}-03$ \\
\hline WASHINGTON NUCLEAR 2 & 397 & DIVII & 30.00 & 9355.3 & $3.21 \mathrm{e}-03$ \\
\hline GRAND GULF & 416 & DG13 & 42.00 & 13546.6 & $3.10 \mathrm{e}-03$ \\
\hline WASHINGTON NUCLEAR 2 & 397 & DrvIII & 24.00 & 9355.3 & $2.57 \mathrm{e}-03$ \\
\hline BYRON 1 & 454 & $1 \mathrm{~A}$ & 38.10 & 15689.6 & $2.43 \mathrm{e}-03$ \\
\hline DUANE ARNOLD & 331 & B & 28.30 & 11760.5 & $2.41 \mathrm{e}-03$ \\
\hline ARKANSAS 2 & 368 & A & 27.02 & 14344.4 & $1.88 \mathrm{e}-03$ \\
\hline HATCH 2 & 366 & $\mathrm{C}$ & 27.70 & 15276.0 & $1.81 \mathrm{e}-03$ \\
\hline HATCH 1 & 321 & $\mathrm{c}$ & 22.00 & 14537.8 & $1.51 \mathrm{e}-03$ \\
\hline KEWAUNEE & 305 & DGB & 8.68 & 15034.3 & $5.77 \mathrm{e}-04$ \\
\hline BRUNSWICK 2 & 324 & EDG4 & 4.23 & 11332.3 & $3.73 e-04$ \\
\hline & & & & AVERAGE* & $2.00 e-02$ \\
\hline
\end{tabular}

*The average is obtained considering 235 EDGs used in the study. For the study period, only one EDG reported zero 00S hours for both PM and $\mathrm{CM}$. 
Table B.4. EDG Unavailability Due to Preventive and Corrective Maintenance, and Testing $\left(\mathrm{U}_{\mathrm{p}, \mathrm{PM}}, \mathrm{U}_{\mathrm{p}, \mathrm{CM}}\right.$, and $\left.\mathrm{U}_{\mathrm{p}, \mathrm{T}}\right)$ During Power Operation

\begin{tabular}{|c|c|c|c|c|}
\hline Plant Name & EDG ID & $\begin{array}{c}\text { Unavail. due } \\
\text { to } \mathbf{P M}^{\mathbf{1}}\end{array}$ & $\begin{array}{c}\text { Unavail. due } \\
\text { to } \mathrm{CM}^{\mathbf{1}}\end{array}$ & $\begin{array}{c}\text { Unavail. due } \\
\text { to Test }\end{array}$ \\
\hline ARKANSAS 1 & A & & $1.12 \mathrm{e}-02$ & $7.36 \mathrm{e}-04$ \\
\hline ARKANSAS 1 & B & & $1.43 \mathrm{e}-02$ & $1.80 e-03$ \\
\hline ARKANSAS 2 & $\mathbf{A}$ & & $1.88 \mathrm{e}-03$ & \\
\hline ARKANSAS 2 & B & & $4.10 \mathrm{e}-03$ & $3.49 \mathrm{e}-05$ \\
\hline BEAVER VALLEY 1 & EDG1-1 & $3.32 \mathrm{e}-03$ & $3.91 \mathrm{e}-03$ & \\
\hline BEAVER VALLEY 1 & EDG1-2 & $2.05 \mathrm{e}-03$ & $5.77 \mathrm{e}-03$ & \\
\hline BEAVER VALLEY 2 & EDG2-1 & $2.21 \mathrm{e}-03$ & $1.80 \mathrm{e}-02$ & \\
\hline BEAVER VALLEY 2 & EDG2-2 & $1.62 \mathrm{e}-03$ & $5.82 \mathrm{e}-03$ & \\
\hline BIG ROCK POINT & A & $6.79 \mathrm{e}-03$ & $1.73 \mathrm{e}-03$ & \\
\hline BRAIDWOOD 1 & $1 \mathrm{~A}$ & $6.78 \mathrm{e}-03$ & $4.99 \mathrm{e}-03$ & $2.01 \mathrm{e}-03$ \\
\hline BRAIDWOOD 1 & $1 \mathrm{~B}$ & $1.29 \mathrm{e}-02$ & $1.18 \mathrm{e}-03$ & \\
\hline BRAIDWOOD 2 & $2 \mathrm{~A}$ & $8.88 \mathrm{e}-03$ & $9.40 \mathrm{e}-03$ & \\
\hline BRAIDWOOD 2 & $2 \mathrm{~B}$ & $4.90 \mathrm{e}-03$ & & $6.56 \mathrm{e}-04$ \\
\hline BROWNS FERRY 2 & A & $2.70 \mathrm{e}-02$ & $2.08 \mathrm{e}-03$ & $1.70 \mathrm{e}-03$ \\
\hline BROWNS FERRY 2 & $\mathrm{~B}$ & $2.10 \mathrm{e}-02$ & $4.46 \mathrm{e}-03$ & $1.05 e-03$ \\
\hline BROWNS FERRY 2 & $\mathrm{C}$ & $1.68 \mathrm{e}-02$ & $2.91 \mathrm{e}-03$ & $1.67 e-03$ \\
\hline BROWNS FERRY 2 & $\mathrm{D}$ & $1.55 \mathrm{e}-02$ & $7.32 \mathrm{e}-03$ & $1.15 \mathrm{e}-03$ \\
\hline BRUNSWICK 1 & EDG1 & $8.18 \mathrm{e}-03$ & $1.78 \mathrm{e}-02$ & $1.84 \mathrm{e}-04$ \\
\hline BRUNSWICK 1 & EDG2 & $2.76 \mathrm{e}-05$ & $7.25 \mathrm{e}-03$ & $1.84 \mathrm{e}-04$ \\
\hline BRUNSWICK 2 & EDG3 & & $5.03 e-03$ & $4.68 \mathrm{e}-04$ \\
\hline BRUNSWICK 2 & EDG4 & $2.21 \mathrm{e}-05$ & $3.51 \mathrm{e}-04$ & \\
\hline BYRON 1 & $1 \mathrm{~A}$ & $2.37 \mathrm{e}-03$ & $5.74 \mathrm{e}-0.5$ & \\
\hline BYRON 1 & $1 \mathrm{~B}$ & $3.39 \mathrm{e}-03$ & $2.80 \mathrm{e}-04$ & \\
\hline BYRON 2 & $2 \mathrm{~A}$ & $1.45 \mathrm{e}-03$ & $2.47 \mathrm{e}-03$ & \\
\hline BYRON 2 & $2 \mathrm{~B}$ & $1.49 \mathrm{e}-03$ & $2.16 \mathrm{e}-03$ & \\
\hline CALLAWAY & $\mathrm{A}$ & $8.99 \mathrm{e}-03$ & $9.72 \mathrm{e}-03$ & $6.21 \mathrm{e}-03$ \\
\hline CALLAWAY & B & $8.49 \mathrm{e}-03$ & $1.06 \mathrm{e}-02$ & $7.00 \mathrm{e}-03$ \\
\hline CALVERT CLIFFS 1 & $11 \mathrm{EDG}$ & $2.58 \mathrm{e}-02$ & $1.83 \mathrm{e}-02$ & $2.52 \mathrm{e}-03$ \\
\hline CALVERT CLIFFS 1 & 12EDG & $2.73 \mathrm{e}-02$ & $3.12 \mathrm{e}-02$ & $8.07 e-03$ \\
\hline CATAWBA 1 & $1 \mathrm{~A}$ & $5.57 \mathrm{e}-03$ & $1.69 \mathrm{e}-02$ & 0.00 \\
\hline
\end{tabular}


Table B.4. (Cont'd)

\begin{tabular}{|c|c|c|c|c|}
\hline Plant Name & EDG ID & $\begin{array}{c}\text { Unavail. due } \\
\text { to } \mathbf{P M}^{\mathbf{1}}\end{array}$ & $\begin{array}{c}\text { Unavail. due } \\
\text { to } \mathbf{C M}^{1}\end{array}$ & $\begin{array}{c}\text { Unavail. due } \\
\text { to Test }\end{array}$ \\
\hline CATAWBA 1 & $1 \mathrm{~B}$ & $8.29 e-03$ & $6.01 \mathrm{e}-03$ & $3.24 \mathrm{e}-04$ \\
\hline CATAWBA 2 & $2 \mathrm{~A}$ & & $3.66 \mathrm{e}-02$ & $1.78 \mathrm{e}-04$ \\
\hline CATAWBA 2 & 2B & $6.86 \mathrm{e}-03$ & $1.34 \mathrm{e}-02$ & \\
\hline CLINTON 1 & 1DG01KA & $1.29 \mathrm{e}-02$ & $3.80 \mathrm{e}-03$ & $3.48 \mathrm{e}-04$ \\
\hline CLINTON 1 & 1DG01KB & $1.22 \mathrm{e}-02$ & $2.39 \mathrm{e}-03$ & \\
\hline CLINTON 1 & $1 \mathrm{E} 22001$ & $2.00 \mathrm{e}-02$ & $1.04 \dot{\mathrm{e}-03}$ & $2.76 \mathrm{e}-05$ \\
\hline COMANCHE PEAK 1 & $1-01$ & $4.70 \mathrm{e}-03$ & $5.34 \mathrm{e}-03$ & $2.59 \mathrm{e}-03$ \\
\hline COMANCHE PEAK 1 & $1-02$ & $1.31 \mathrm{e}-02$ & $2.96 \mathrm{e}-03$ & $2.17 \mathrm{e}-03$ \\
\hline COOK 1 & $1 \mathrm{AB}$ & & $1.13 \mathrm{e}-02$ & $5.22 \mathrm{e}-04$ \\
\hline COOK 1 & $1 \mathrm{CD}$ & & $7.56 \mathrm{e}-03$ & $5.57 \mathrm{e}-04$ \\
\hline COOK 2 & $2 \mathrm{AB}$ & & $1.20 \mathrm{e}-02$ & $5.73 \mathrm{e}-04$ \\
\hline $\mathrm{COOK} 2$ & $2 \mathrm{CD}$ & & $1.03 \mathrm{e}-02$ & $4.12 \mathrm{e}-04$ \\
\hline COOPER STATION & DG-1 & & $4.30 \mathrm{e}-03$ & \\
\hline COOPER STATION & DG-2 & $1.33 \mathrm{e}-04$ & $3.93 \mathrm{e}-03$ & \\
\hline CRYSTAL RIVER 3 & $1 \mathrm{~A}$ & $8.41 \mathrm{e}-03$ & $7.40 \mathrm{e}-03$ & \\
\hline CRYSTAL RIVER 3 & $1 \mathrm{~B}$ & $6.64 \mathrm{e}-03$ & $6.11 \mathrm{e}-03$ & \\
\hline DAVIS-BESSE & EDG1 & $7.30 \mathrm{e}-03$ & $1.99 \mathrm{e}-03$ & \\
\hline DAVIS-BESSE & EDG2 & $8.41 \mathrm{e}-03$ & $1.95 \mathrm{e}-02$ & \\
\hline DIABLO CANYON 1 & DEG1-1 & $1.26 \mathrm{e}-02$ & & $2.34 \mathrm{e}-04$ \\
\hline DIABLO CANYON 1 & DEG1-2 & $1.21 \mathrm{e}-02$ & $1.03 \mathrm{e}-02$ & $3.28 \mathrm{e}-04$ \\
\hline DIABLO CANYON 1 & DEG1-3 & $1.57 \mathrm{e}-02$ & & $2.00 \mathrm{e}-03$ \\
\hline DLABLO CANYON 2 & DEG1-3 & $1.52 \mathrm{e}-02$ & & $3.09 \mathrm{e}-03$ \\
\hline DIABLO CANYON 2 & DEG2-1 & $5.88 \mathrm{e}-03$ & $4.97 \mathrm{e}-04$ & $1.23 \mathrm{e}-03$ \\
\hline DIABLO CANYON 2 & DEG2-2 & $9.72 \mathrm{e}-03$ & & $4.05 e-04$ \\
\hline DRESDEN 2 & DG2 & $3.66 \mathrm{e}-03$ & $1.25 \mathrm{e}-02$ & $4.03 e-03$ \\
\hline DRESDEN 2 & $\mathrm{DG} 2 / 3$ & $3.41 \mathrm{e}-02$ & $2.91 \mathrm{e}-03$ & $9.93 \mathrm{e}-03$ \\
\hline DRESDEN 3 & $\mathrm{DG} 2 / 3$ & $3.27 \mathrm{e}-02$ & $2.79 \mathrm{e}-03$ & $9.50 \mathrm{e}-03$ \\
\hline DRESDEN 3 & DG3 & $7.04 e-03$ & $2.33 \mathrm{e}-03$ & $4.51 \mathrm{e}-03$ \\
\hline DUANE ARNOLD & $\mathbf{A}$ & $1.31 \mathrm{e}-03$ & $7.33 \mathrm{e}-03$ & \\
\hline DUANE ARNOLD & B & $1.03 \mathrm{e}-03$ & $1.38 \mathrm{e}-03$ & 1 \\
\hline FARLEY 1 & IA & $3.42 \mathrm{e}-02$ & $1.45 \mathrm{e}-02$ & $1.19 \mathrm{e}-04$ \\
\hline
\end{tabular}


Table B.4. (Cont'd)

\begin{tabular}{|c|c|c|c|c|}
\hline Plant Name & EDG ID & $\begin{array}{c}\text { Unavail. due } \\
\text { to } \mathbf{P M}^{\mathbf{1}}\end{array}$ & $\begin{array}{c}\text { Unavail. due } \\
\text { to } \mathbf{C M}^{\mathbf{1}}\end{array}$ & $\begin{array}{c}\text { Unavail. due } \\
\text { to Test }{ }^{2}\end{array}$ \\
\hline FARLEY 1 & $1 \mathrm{~B}$ & $4.10 \mathrm{e}-0.2$ & $6.01 \mathrm{e}-03$ & $1.73 \mathrm{e}-05$ \\
\hline FARLEY 1 & $1 \mathrm{C}$ & $1.83 \mathrm{e}-0.2$ & $3.43 \mathrm{e}-03$ & $9.62 e-03$ \\
\hline FARLEY 1 & $2 \mathrm{C}$ & $7.18 \mathrm{e}-0.3$ & $6.12 \mathrm{e}-03$ & \\
\hline FARLEY 2 & $1 \mathrm{C}$ & $1.78 \mathrm{e}-02$ & $3.96 \mathrm{e}-03$ & $1.12 e-02$ \\
\hline FARLEY 2 & $2 \mathrm{~A}$ & $3.63 \mathrm{e}-02$ & $2.17 \mathrm{e}-02$ & $1.39 \mathrm{e}-04$ \\
\hline FARLEY 2 & 2B & $2.98 \mathrm{e}-02$ & $2.23 \mathrm{e}-02$ & \\
\hline FARLEY 2 & $2 \mathrm{C}$ & $1.31 \mathrm{e}-02$ & $1.11 \mathrm{e}-03$ & \\
\hline FERMI 2 & EDG11 & $8.84 \mathrm{e}-03$ & $2.73 \mathrm{e}-03$ & \\
\hline FERMI 2 & EDG12 & $3.85 \mathrm{e}-03$ & & \\
\hline FERMI 2 & EDG13 & $2.58 \mathrm{e}-03$ & $4.15 \mathrm{e}-03$ & \\
\hline FERMI 2 & EDG14 & $9.34 \mathrm{e}-03$ & $3.64 \mathrm{e}-04$ & \\
\hline FITZPATRICK & 12EDG & $9.87 \mathrm{e}-02$ & $6.50 \mathrm{e}-02$ & $2.18 \mathrm{e}-02$ \\
\hline FITZPATRICK & 21EDG & $2.53 \mathrm{e}-02$ & $7.55 \mathrm{e}-03$ & $3.57 e-03$ \\
\hline FORT CALHOUN & DG-1 & $2.32 \mathrm{e}-02$ & $1.44 \mathrm{e}-02$ & \\
\hline FORT CALHOUN & DG-2 & $2.08 \mathrm{e}-02$ & $6.17 \mathrm{e}-03$ & \\
\hline GINNA & EDGA & $2.59 \mathrm{e}-0.03$ & $1.63 \mathrm{e}-03$ & $1.28 \mathrm{e}-03$ \\
\hline GINNA & EDGB & $2.58 \mathrm{e}-03$ & $1.39 \mathrm{e}-03$ & \\
\hline GRAND GULF & DG11 & $1.13 \mathrm{e}-02$ & $1.33 \mathrm{e}-03$ & \\
\hline GRAND GULF & DG12 & $1.06 \mathrm{e}-012$ & $2.44 \mathrm{e}-03$ & \\
\hline GRAND GULF & DG13 & $3.10 \mathrm{e}-03$ & & \\
\hline HADDAM NECK & EG-2A & $3.41 \mathrm{e}-03$ & $5.04 \mathrm{e}-03$ & $4.46 \mathrm{e}-04$ \\
\hline HADDAM NECK & EG-2B & $5.15 \mathrm{e}-(13$ & $9.94 \mathrm{e}-04$ & $1.51 \mathrm{e}-03$ \\
\hline HARRIS 1 & IA-SA & $1.94 \mathrm{e}-03$ & $1.40 \mathrm{e}-02$ & $1 \quad 2.08 \mathrm{e}-03$ \\
\hline HARRIS 1 & 1B-SB & $6.44 \mathrm{e}-04$ & $3.49 \mathrm{e}-03$ & $2.21 \mathrm{e}-03$ \\
\hline НАТСН 1 & $\mathrm{~A}$ & $1.03 \mathrm{e}-04$ & $4.77 \mathrm{e}-03$ & $5.16 \mathrm{e}-05$ \\
\hline НАТСН 1 & B & $7.26 \mathrm{e}-03$ & $3.60 \mathrm{e}-03$ & \\
\hline HATCH 1 & $\mathrm{c}$ & $2.83 \mathrm{e}-04$ & $1.23 \mathrm{e}-03$ & \\
\hline НATCH 2 & $\mathrm{~A}$ & $3.27 \mathrm{e}-05$ & $3.99 \mathrm{e}-03$ & \\
\hline НATCH 2 & B & $4.64 \mathrm{e}-03$ & $3.58 \mathrm{e}-03$ & $8.51 \mathrm{e}-05$ \\
\hline HATCH 2 & c & & $1.81 \mathrm{e}-03$ & \\
\hline HOPE CREEK 1 & A & $6.94 \mathrm{e}-03$ & $3.93 \mathrm{e}-03$ & $3.22 \mathrm{e}-04$ \\
\hline
\end{tabular}


Table B.4. (Cont'd)

\begin{tabular}{|c|c|c|c|c|}
\hline Plant Name & EDG ID & $\begin{array}{l}\text { Unavail. due } \\
\text { to } \mathbf{P M}^{\mathbf{1}}\end{array}$ & $\begin{array}{l}\text { Unavail. due } \\
\text { to } \mathbf{C M}^{1}\end{array}$ & $\begin{array}{c}\text { Unavail. due } \\
\text { to Test }\end{array}$ \\
\hline HOPE CREEK 1 & B & $1.89 \mathrm{e}-03$ & $4.38 \mathrm{e}-03$ & $1.51 \mathrm{e}-04$ \\
\hline HOPE CREEK 1 & $\mathrm{c}$ & $3.16 \mathrm{e}-03$ & $1.19 \mathrm{e}-03$ & $3.02 e-04$ \\
\hline HOPE CREEK 1 & D & & & $1.31 \mathrm{e}-05$ \\
\hline INDIAN POINT 2 & 21EDG & $2.60 \mathrm{e}-02$ & $2.57 \mathrm{e}-03$ & \\
\hline INDIAN POINT 2 & 22EDG & $3.08 \mathrm{e}-02$ & $5.79 \mathrm{e}-04$ & \\
\hline INDIAN POINT 2 & 23EDG & $1.87 \mathrm{e}-02$ & $2.40 \mathrm{e}-03$ & \\
\hline KEWAUNEE & DGA & $1.03 \mathrm{e}-03$ & $9.17 \mathrm{e}-03$ & $1.06 \mathrm{e}-04$ \\
\hline KEWAUNEE & DGB & $2.50 \mathrm{e}-04$ & $3.27 \mathrm{e}-04$ & $3.88 \mathrm{e}-04$ \\
\hline LASALLE 1 & 0 & $1.69 \mathrm{e}-02$ & $6.31 \mathrm{e}-0.3$ & $1.75 \mathrm{e}-03$ \\
\hline LASALLE 1 & $1 \mathrm{~A}$ & $1.22 \mathrm{e}-02$ & $1.91 \mathrm{e}-03$ & \\
\hline LASALLE 1 & $1 \mathrm{~B}$ & $1.44 \mathrm{e}-02$ & $1.52 \mathrm{e}-03$ & \\
\hline LASALLE 2 & 0 & $2.47 \mathrm{e}-02$ & $6.37 \mathrm{e}-03$ & \\
\hline LASALLE 2 & $2 \mathrm{~A}$ & $8.25 \mathrm{e}-03$ & $2.13 \mathrm{e}-03$ & $7.16 \mathrm{e}-05$ \\
\hline LASALLE 2 & $2 \mathrm{~B}$ & $1.79 \mathrm{e}-02$ & $2.15 \mathrm{e}-04$ & $9.77 e-04$ \\
\hline LIMERICK 1 & D11 & $4.11 \mathrm{e}-02$ & $3.13 \mathrm{e}-03$ & \\
\hline LIMERICK 1 & D12 & $3.72 \mathrm{e}-02$ & $7.47 \mathrm{e}-06$ & \\
\hline LIMERICK 1 & D13 & $1.28 \mathrm{e}-02$ & $4.65 \mathrm{e}-03$ & 1 \\
\hline LIMERICK 1 & D14 & $1.56 \mathrm{e}-02$ & & \\
\hline LIMERICK 2 & D21 & $1.71 \mathrm{e}-02$ & $2.29 \mathrm{e}-03$ & \\
\hline LIMERICK 2 & D22 & $1.49 \mathrm{e}-02$ & $1.30 \mathrm{e}-03$ & \\
\hline LIMERICK 2 & D23 & $1.72 \mathrm{e}-02$ & $2.89 \mathrm{e}-03$ & \\
\hline LIMERICK 2 & D24 & $4.54 \mathrm{e}-02$ & $2.75 \mathrm{e}-05$ & \\
\hline MAINE YANKEE & DG-1A & $1.34 \mathrm{e}-02$ & $1.60 \mathrm{e}-02$ & \\
\hline MAINE YANKEE & DG-1B & $1.26 \mathrm{e}-02$ & $5.90 \mathrm{e}-03$ & \\
\hline MCGUIRE 1 & $1 \mathrm{~A}$ & $1.69 \mathrm{e}-02$ & $5.00 \mathrm{e}-03$ & \\
\hline MCGUIRE 1 & 1B & $1.38 \mathrm{e}-02$ & $2.04 \mathrm{e}-03$ & \\
\hline MCGUIRE 2 & $2 \mathrm{~A}$ & $5.95 \mathrm{e}-03$ & $5.42 \mathrm{e}-03$ & \\
\hline MCGUIRE 2 & $2 \mathrm{~B}$ & $8.30 \mathrm{e}-03$ & $4.36 \mathrm{e}-03$ & \\
\hline MILLSTONE 1 & $1 \mathrm{~A}$ & & $4.29 \mathrm{e}-02$ & \\
\hline MILLSTONE 3 & $3 \mathrm{~A}$ & $2.13 \mathrm{e}-02$ & $3.91 e-03$ & \\
\hline MILLSTONE 3 & $3 \mathrm{~B}$ & $1.76 \mathrm{e}-02$ & $5.03 \mathrm{e}-03$ & \\
\hline
\end{tabular}


Table B.4. (Cont'd)

\begin{tabular}{|c|c|c|c|c|}
\hline Plant Name & EDG ID & $\begin{array}{l}\text { Unavail. due } \\
\text { to } \mathbf{P M}^{\mathbf{1}}\end{array}$ & $\begin{array}{l}\text { Unavail. due } \\
\text { to } \mathbf{C M}^{1}\end{array}$ & $\begin{array}{l}\text { Unavail. due } \\
\text { to Test }^{2}\end{array}$ \\
\hline MONTICELLO & 11 & & $1.30 \mathrm{e}-02$ & $6.75 \mathrm{e}-04$ \\
\hline MONTICELLO & 12 & & $3.37 \mathrm{e}-03$ & $7.13 \mathrm{e}-04$ \\
\hline NORTH ANNA 1 & $1 \mathrm{H}$ & $1.30 \mathrm{e}-02$ & $1.51 \mathrm{e}-03$ & $8.86 \mathrm{e}-04$ \\
\hline NORTH ANNA 1 & $1 \mathrm{~J}$ & $1.22 \mathrm{e}-02$ & $2.36 \mathrm{e}-03$ & $2.39 \mathrm{e}-03$ \\
\hline NORTH ANNA 2 & $2 \mathrm{H}$ & $9.94 \mathrm{e}-0.3$ & & $2.13 \mathrm{e}-03$ \\
\hline NORTH ANNA 2 & $2 J$ & $7.10 \mathrm{e}-03$ & $5.17 \mathrm{e}-04$ & $3.28 \mathrm{e}-03$ \\
\hline OYSTER CREEK & EDG-1 & $5.11 \mathrm{e}-0.3$ & $2.43 \mathrm{e}-03$ & \\
\hline OYSTER CREEK & EDG-2 & $4.86 \mathrm{e}-03$ & $1.02 \mathrm{e}-02$ & \\
\hline PALISADES & DG1-1 & $1.05 \mathrm{e}-0.2$ & $1.09 \mathrm{e}-02$ & $2.98 \mathrm{e}-03$ \\
\hline PALISADES & DG1-2 & $8.67 e-0.3$ & $8.81 \mathrm{e}-03$ & $2.76 \mathrm{e}-03$ \\
\hline PALO VERDE 1 & 1MDGAH01 & $8.16 \mathrm{e}-03$ & $1.19 \mathrm{e}-02$ & $3.39 \mathrm{e}-03$ \\
\hline PALO VERDE 1 & 1MDGBH01 & $7.70 \mathrm{e}-03$ & $1.22 \mathrm{e}-02$ & $4.67 \mathrm{e}-03$ \\
\hline PALO VERDE 2 & 2MDGAHOI & $7.18 \mathrm{e}-0.3$ & $1.35 \mathrm{e}-02$ & $7.47 \mathrm{e}-04$ \\
\hline PALO VERDE 2 & 2MDGBHO1 & $8.97 \mathrm{e}-0.3$ & $6.85 \mathrm{e}-03$ & $2.94 \mathrm{e}-04$ \\
\hline PALO VERDE 3 & 3MDGAH01 & $1.60 \mathrm{e}-0.2$ & $1.78 \mathrm{e}-02$ & $6.77 e-04$ \\
\hline PALO VERDE 3 & 3MDGBH01 & $1.51 \mathrm{e}-0.2$ & $2.04 \mathrm{e}-02$ & $1.56 \mathrm{e}-03$ \\
\hline РЕACH ВOTTOM 2 & E1 & $2.04 \mathrm{e}-0.2$ & & \\
\hline PEACH BOTTOM 2 & E2 & $2.27 \mathrm{e}-0.2$ & $8.69 \mathrm{e}-04$ & \\
\hline PEACH BOTTOM 2 & E3 & $1.76 \mathrm{e}-02$ & $4.71 \mathrm{e}-03$ & \\
\hline PEACH BOTTOM 2 & E4 & $2.81 \mathrm{e}-0.2$ & $1.53 \mathrm{e}-02$ & \\
\hline PEACH ВOTTOM 3 & E1 & $2.11 \mathrm{e}-0.2$ & & \\
\hline PEACH BOTTOM 3 & $\mathrm{E} 2$ & $2.35 \mathrm{e}-0.2$ & $8.98 \mathrm{e}-04$ & \\
\hline РЕACH ВОТTOM 3 & E3 & $1.82 \mathrm{e}-0.2$ & $4.87 \mathrm{e}-03$ & \\
\hline PEACH BOTTOM 3 & E4 & $2.91 \mathrm{e}-0.2$ & $1.58 \mathrm{e}-02$ & \\
\hline PERRY 1 & A & $1.45 \mathrm{e}-0.2$ & $8.66 \mathrm{e}-03$ & \\
\hline PERRY 1 & B & $1.43 \mathrm{e}-02$ & $6.72 \mathrm{e}-02$ & $6.01 \mathrm{e}-05$ \\
\hline PERRY 1 & $\mathrm{C}$ & $8.27 \mathrm{e}-0.3$ & $3.55 \mathrm{e}-03$ & \\
\hline PILGRIM 1 & $\mathrm{~A}$ & $3.78 \mathrm{e}-02$ & & \\
\hline PILGRIM 1 & $\mathrm{~B}$ & $3.11 \mathrm{e}-02$ & $3.32 \mathrm{e}-02$ & \\
\hline POINT BEACH 1 & G-01 & $2.95 \mathrm{e}-02$ & & \\
\hline POINT BEACH 1 & $\mathrm{G}-02$ & $2.39 \mathrm{e}-02$ & & \\
\hline
\end{tabular}


Table B.4. (Cont'd)

\begin{tabular}{|c|c|c|c|c|}
\hline Plant Name & EDG ID & $\begin{array}{l}\text { Unavail. due } \\
\text { to } \mathbf{P M}^{1}\end{array}$ & $\begin{array}{l}\text { Unavail, due } \\
\text { to } \mathbf{C M}^{1}\end{array}$ & $\begin{array}{l}\text { Unavail. due } \\
\text { to Test }\end{array}$ \\
\hline POINT BEACH 2 & G-01 & $2.60 \mathrm{e}-02$ & & \\
\hline POINT BEACH 2 & G-02 & $2.32 \mathrm{e}-02$ & $7.71 \mathrm{e}-04$ & \\
\hline PRARIE ISLAND 1 & DI & $6.26 \mathrm{e}-03$ & $2.35 \mathrm{e}-03$ & \\
\hline PRAIRIE ISLAND 1 & $\mathrm{D} 2$ & $2.20 \mathrm{e}-02$ & $5.99 \mathrm{e}-04$ & 1 \\
\hline PRAIRIE ISLAND 2 & D1 & $6.49 \mathrm{e}-03$ & $2.44 \mathrm{e}-03$ & \\
\hline PRAIRIE ISLAND 2 & D2 & $2.20 \mathrm{e}-02$ & $6.20 \mathrm{e}-04$ & \\
\hline QUAD CITIES 1 & U1 & $1.18 \mathrm{e}-03$ & $6.22 \mathrm{e}-03$ & \\
\hline QUAD CITIES 1 & $\mathrm{U} 1 / 2$ & $3.12 \mathrm{e}-02$ & $1.27 \mathrm{e}-02$ & $1.01 \mathrm{e}-03$ \\
\hline QUAD CITIES 2 & $\mathrm{U} 1 / 2$ & $3.14 \mathrm{e}-04$ & $1.04 \mathrm{e}-02$ & \\
\hline QUAD CITIES 2 & U2 & $1.60 \mathrm{e}-03$ & $4.34 \mathrm{e}-03$ & \\
\hline RIVER BEND & I & $1.69 \mathrm{e}-02$ & $9.06 \mathrm{e}-03$ & \\
\hline RIVER BEND & II & $2.13 e-02$ & $1.51 \mathrm{e}-03$ & \\
\hline RIVER BEND & III & $1.64 \mathrm{e}-02$ & $9.48 \mathrm{e}-03$ & \\
\hline ROBINSON 2 & $\mathrm{~A}$ & $9.57 \mathrm{e}-03$ & $2.59 \mathrm{e}-03$ & $2.21 \mathrm{e}-03$ \\
\hline ROBINSON 2 & B & $9.19 \mathrm{e}-03$ & $2.66 \mathrm{e}-03$ & \\
\hline ROBINSON 2 & $D / S$ & $5.23 \mathrm{e}-03$ & $3.74 \mathrm{e}-02$ & \\
\hline SALEM 1 & $1 \mathrm{~A}$ & $1.56 \mathrm{e}-02$ & $3.54 \mathrm{e}-02$ & $5.12 \mathrm{e}-05$ \\
\hline SALEM 1 & IB & $1.59 \mathrm{e}-02$ & $5.61 \mathrm{e}-03$ & \\
\hline SALEM 1 & $1 \mathrm{C}$ & $3.90 \mathrm{e}-03$ & $3.19 \mathrm{e}-03$ & \\
\hline SALEM 2 & $2 \mathrm{~A}$ & $1.57 \mathrm{e}-02$ & $1.76 \mathrm{e}-02$ & $3.40 \mathrm{e}-04$ \\
\hline SALEM 2 & $2 \mathrm{~B}$ & $1.78 \mathrm{e}-02$ & $2.51 \mathrm{e}-02$ & \\
\hline SALEM 2 & $2 \mathrm{C}$ & $1.21 \mathrm{e}-02$ & $2.15 \mathrm{e}-03$ & \\
\hline SAN ONOFRE 1 & DGI & & $1.19 \mathrm{e}-02$ & \\
\hline SAN ONOFRE 1 & DG2 & & $1.88 \mathrm{e}-02$ & \\
\hline SAN ONOFRE 2 & $\mathrm{DG} 2$ & $5.05 \mathrm{e}-03$ & $5.47 \mathrm{e}-03$ & $1.71 \mathrm{e}-03$ \\
\hline SAN ONOFRE 2 & DG3 & $1.15 \mathrm{e}-02$ & $1.36 \mathrm{e}-02$ & $1.97 e-03$ \\
\hline SAN ONOFRE 3 & DG2 & $7.09 \mathrm{e}-03$ & $7.80 \mathrm{e}-03$ & $2.21 \mathrm{e}-03$ \\
\hline SAN ONOFRE 3 & DG3 & $1.07 \mathrm{e}-02$ & $1.34 \mathrm{e}-04$ & $6.22 \mathrm{e}-04$ \\
\hline SEABROOK 1 & $\mathrm{~A}$ & & $5.70 \mathrm{e}-03$ & $2.68 \mathrm{e}-03$ \\
\hline SEABROOK 1 & B & $1.87 \mathrm{e}-02$ & $3.35 \mathrm{e}-02$ & $1.77 \mathrm{e}-03$ \\
\hline SEQUOYAH 1 & $\mathrm{AA}$ & $1.74 \mathrm{e}-02$ & $2.88 \mathrm{e}-03$ & $2.07 \mathrm{e}-03$ \\
\hline
\end{tabular}


Table B.4. (Cont'd)

\begin{tabular}{|c|c|c|c|c|}
\hline Plant Name & EDG ID & $\begin{array}{c}\text { Unavail. due } \\
\text { to } \mathrm{PM}^{\mathbf{1}}\end{array}$ & $\begin{array}{l}\text { Unavail. due } \\
\text { to } \mathbf{C M}^{\mathbf{1}}\end{array}$ & $\begin{array}{l}\text { Unavail. due } \\
\text { to Test }\end{array}$ \\
\hline SEQUOYAH 1 & BB & $1.65 \mathrm{e}-02$ & $1.05 \mathrm{e}-03$ & $2.49 \mathrm{e}-03$ \\
\hline SEQUOYAH 2 & AA & $2.26 \mathrm{e}-02$ & $6.00 \mathrm{e}-03$ & $2.37 e-03$ \\
\hline SEQUOYAH 2 & BB & $2.04 e-02$ & $9.95 \mathrm{e}-04$ & $2.75 e-03$ \\
\hline SOUTH TEXAS 1 & EDG11 1 & $2.27 \mathrm{e}-02$ & $1.06 \mathrm{e}-02$ & \\
\hline SOUTH TEXAS 1 & EDG12 & $2.27 \mathrm{e}-0.2$ & $1.07 \mathrm{e}-02$ & \\
\hline SOUTH TEXAS 1 & EDG13 & $1.42 \mathrm{e}-0.2$ & $5.91 \mathrm{e}-03$ & \\
\hline SOUTH TEXAS 2 & EDG21 & $2.59 \mathrm{e}-0.2$ & $1.19 \mathrm{e}-02$ & $8.63 e-04$ \\
\hline SOUTH TEXAS 2 & EDG22 & $2.29 \mathrm{e}-0.2$ & $7.55 \mathrm{e}-03$ & $4.71 \mathrm{e}-04$ \\
\hline SOUTH TEXAS 2 & EDG23 & $1.98 \mathrm{e}-0.2$ & $8.43 e-03$ & $3.92 \mathrm{e}-04$ \\
\hline ST LUCIE 1 & $1 \mathrm{~A}$ & $1.18 \mathrm{e}-02$ & & \\
\hline ST LUCIE 1 & $1 \mathrm{~B}$ & $8.35 \mathrm{e}-03$ & $4.57 \mathrm{e}-03$ & \\
\hline ST LUCIE 2 & $2 \mathrm{~A}$ & $1.09 \mathrm{e}-02$ & $6.86 e-06$ & \\
\hline ST LUCIE 2 & 2B & $1.57 \mathrm{e}-02$ & $8.99 \mathrm{e}-04$ & $7.96 \mathrm{e}-04$ \\
\hline SUMMER & $\mathbf{A}$ & $3.18 \mathrm{e}-02$ & $2.76 \mathrm{e}-03$ & \\
\hline SUMMER & B & $1.50 \mathrm{e}-02$ & $3.70 \mathrm{e}-03$ & $3.85 \mathrm{e}-04$ \\
\hline SURRY 1 & EDG1 & $1.99 \mathrm{e}-03$ & $3.13 e-03$ & $2.91 \mathrm{e}-03$ \\
\hline SURRY 1 & EDG3 & $1.30 \mathrm{e}-02$ & $8.29 \mathrm{e}-03$ & $5.48 \mathrm{e}-03$ \\
\hline SURRY 2 & EDG2 & $1.72 \mathrm{e}-03$ & $6.20 \mathrm{e}-03$ & $3.34 \mathrm{e}-03$ \\
\hline SURRY 2 & EDG3 & $2.79 \mathrm{e}-02$ & $3.08 \mathrm{e}-03$ & $5.05 \mathrm{e}-03$ \\
\hline SUSQUEHANNA 1 & A & $7.48 \mathrm{e}-03$ & $5.17 \mathrm{e}-02$ & $1.71 \mathrm{e}-03$ \\
\hline SUSQUEHANNA I & B & $1.99 \mathrm{e}-03$ & $2.42 \mathrm{e}-02$ & $9.24 \mathrm{e}-05$ \\
\hline SUSQUEHANNA 1 & $\mathrm{C}$ & $7.29 \mathrm{e}-03$ & $6.78 \mathrm{e}-0.04$ & $1.22 \mathrm{e}-03$ \\
\hline SUSQUEHANNA 1 & $\mathrm{D}$ & $4.77 \mathrm{e}-03$ & $7.04 e-03$ & $1.74 \mathrm{e}-05$ \\
\hline SUSQUEHANNA 1 & $\mathbf{E}$ & $6.01 \mathrm{e}-03$ & $2.49 \mathrm{e}-03$ & $7.73 \mathrm{e}-04$ \\
\hline SUSQUEHANNA 2 & $\mathbf{A}$ & $6.87 \mathrm{e}-013$ & $4.75 \mathrm{e}-02$ & $1.57 \mathrm{e}-03$ \\
\hline SUSQUEHANNA 2 & B & $1.83 e-(13$ & $2.22 \mathrm{e}-02$ & $8.49 \mathrm{e}-05$ \\
\hline SUSQUEHANNA 2 & $\mathrm{c}$ & $5.25 \mathrm{e}-113$ & $1.68 \mathrm{e}-03$ & $1.12 \mathrm{e}-03$ \\
\hline SUSQUEHANNA 2 & $\mathrm{D}$ & $5.83 \mathrm{e}-013$ & $4.35 \mathrm{e}-03$ & $1.60 \mathrm{e}-05$ \\
\hline SUSQUEHANNA 2 & $\mathbf{E}$ & $5.12 \mathrm{e}-03$ & $2.29 \mathrm{e}-03$ & $7.10 \mathrm{e}-04$ \\
\hline THREE MILE ISLAND 1 & EDG-1A & $1.48 \mathrm{e}-(02$ & $2.50 \mathrm{e}-03$ & $6.46 \mathrm{e}-03$ \\
\hline THREE MILE ISLAND 1 & EDG-1B & $1.44 \mathrm{e}-02$ & $4.62 \mathrm{e}-04$ & $5.10 e-03$ \\
\hline
\end{tabular}


Table B.4. (Cont'd)

\begin{tabular}{|c|c|c|c|c|}
\hline Plaut Name & EDG ID & $\begin{array}{l}\text { Unavail. due } \\
\text { to } \mathbf{P M}^{1}\end{array}$ & $\begin{array}{l}\text { Unavail. due } \\
\text { to } \mathbf{C M}^{1}\end{array}$ & $\begin{array}{c}\text { Unavail. due } \\
\text { to Test }\end{array}$ \\
\hline VERMONT YANKEE & EDGA & $6.66 \mathrm{e}-04$ & $1.00 \mathrm{e}-02$ & $2.26 \mathrm{e}-03$ \\
\hline VERMONT YANKEE & EDGB & $8.77 e-03$ & $2.94 \mathrm{e}-03$ & $8.75 \mathrm{e}-03$ \\
\hline VOGTLE 1 & DG1A & & $3.25 \mathrm{e}-02$ & \\
\hline VOGTLE 1 & DG1B & & $1.92 \mathrm{e}-02$ & \\
\hline VOGTLE 2 & DG2A & 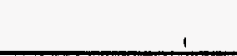 & $2.27 e-02$ & \\
\hline VOGTLE 2 & DG2B & & $1.23 \mathrm{e}-02$ & \\
\hline WASHINGTON NUCLEAR 2 & Drvi & 0.00 & $3.58 \mathrm{e}-03$ & $7.48 \mathrm{e}-04$ \\
\hline WASHINGTON NUCLEAR 2 & DIVII & $7.48 \mathrm{e}-04$ & $2.46 \mathrm{e}-03$ & $6.41 \mathrm{e}-04$ \\
\hline WASHINGTON NUCLEAR 2 & DIVIII & & $2.57 e-03$ & $3.21 \mathrm{e}-04$ \\
\hline WATERFORD 3 & A & $7.87 \mathrm{e}-04$ & $7.40 \mathrm{e}-03$ & \\
\hline WATERFORD 3 & B & $3.84 \mathrm{e}-03$ & $5.76 \mathrm{e}-03$ & \\
\hline WOLF CREEK 1 & $\mathrm{~A}$ & $2.19 \mathrm{e}-02$ & $9.85 \mathrm{e}-03$ & $4.40 \mathrm{e}-04$ \\
\hline WOLF CREEK 1 & B & $2.48 \mathrm{e}-02$ & $4.22 \mathrm{e}-03$ & $7.58 \mathrm{e}-04$ \\
\hline ZION 1 & $1 \mathrm{~A}$ & & $7.00 \mathrm{e}-03$ & \\
\hline ZION 1 & 1B & & $8.60 \mathrm{e}-03$ & \\
\hline ZION 1 & $\mathrm{c}$ & $1.86 \mathrm{e}-03$ & $4.53 \mathrm{e}-02$ & \\
\hline ZION 2 & $2 \mathrm{~A}$ & $6.21 \mathrm{e}-03$ & $1.35 \mathrm{e}-02$ & \\
\hline ZION 2 & $2 \mathrm{~B}$ & $3.93 \mathrm{e}-03$ & $1.52 \mathrm{e}-02$ & \\
\hline ZION 2 & c & $2.47 e-02$ & $5.56 \mathrm{e}-02$ & \\
\hline & AVERAGE $^{3}$ & $1.18 \mathrm{e}-02$ & $8.17 \mathrm{e}-03$ & $2.06 \mathrm{e}-03$ \\
\hline
\end{tabular}

'Empty spaces indicate that no PM or CM was performed during power operation over the period of June 1990 to May 1992 according to the data base.

${ }^{2}$ Empty spaces indicate that test data were not provided for the associated EDGs.

${ }^{3}$ Averages for PM and CM unavailabilities are obtained considering 235 EDGs. Average test unavailability is obtained considering only those EDGs reporting test data, i.e., 117 EDGs. 
Table B.5. EDG Unavailability Due to Preventive Maintenance, $\mathrm{U}_{\mathrm{s}, \mathrm{PM}}$, During Plant Shutdown in Descending Order

\begin{tabular}{|c|c|c|c|c|c|c|}
\hline Plant Name & $\begin{array}{c}\text { Docket } \\
\text { No }\end{array}$ & EDG ID & $\begin{array}{l}\text { Outage } \\
\text { Code }\end{array}$ & $\begin{array}{l}\text { Total EDG } \\
\text { OOS Hours }\end{array}$ & $\begin{array}{l}\text { Plant Off- } \\
\text { Line Hours }\end{array}$ & $\begin{array}{l}\text { Unavail. due } \\
\text { to } P M\end{array}$ \\
\hline DIABLO CANYON 2 & 323 & DEG2-1 & $\mathbf{P}$ & 672.00 & 1471.7 & $4.57 \mathrm{e}-01$ \\
\hline INDIAN POINT 2 & 247 & 21EDG & $\mathbf{P}$ & 2208.00 & 5068.6 & $4.36 \mathrm{e}-01$ \\
\hline QUAD CITIES 2 & 265 & $\mathrm{U} 2$ & $\mathbf{P}$ & 1681.90 & 4490.4 & $3.75 e-01$ \\
\hline ARKANSAS 1 & 313 & A & $\mathbf{P}$ & 1067.65 & 2947.5 & $3.62 \mathrm{e}-01$ \\
\hline DIABLO CANYON 2 & 323 & DEG2-2 & $\mathbf{P}$ & 528.00 & 1471.7 & $3.59 \mathrm{e}-01$ \\
\hline CATAWBA 1 & 413 & IA & $\mathbf{P}$ & 872.40 & 2586.9 & $3.37 e-01$ \\
\hline ZION 1 & 295 & $1 \mathrm{~A}$ & $\mathrm{P}$ & 2432.44 & 7663.9 & $3.17 \mathrm{e}-01$ \\
\hline COOPER STATION & 298 & DG-2 & $\mathbf{P}$ & 641.00 & 2023.1 & $3.17 e-01$ \\
\hline QUAD CITIES 1 & 254 & $\mathrm{U} 1$ & $\mathrm{P}$ & 1678.80 & 5555.5 & $3.02 \mathrm{e}-01$ \\
\hline MCGUIRE 2 & 370 & $2 \mathrm{~A}$ & $\mathrm{P}$ & 1449.00 & 5103.3 & $2.84 \mathrm{e}-01$ \\
\hline GRAND GULF & 416 & DG1 1 & $\mathbf{P}$ & 1124.00 & 3997.4 & $2.81 \mathrm{e}-01$ \\
\hline KEWAUNEE & 305 & DGB & $\mathbf{P}$ & 669.35 & 2509.7 & $2.67 e-01$ \\
\hline PERRY 1 & 440 & $\mathrm{C}$ & $\mathbf{P}$ & 1363.00 & 5395.7 & $2.53 \mathrm{e}-01$ \\
\hline MCGUIRE 2 & 370 & $2 \mathrm{~B}$ & $\mathbf{P}$ & 1236.20 & 5103.3 & $2.42 \mathrm{e}-01$ \\
\hline GRAND GULF & 416 & DG12 & $\mathbf{P}$ & 965.00 & 3997.4 & $2.41 \mathrm{e}-01$ \\
\hline SAN ONOFRE 2 & 361 & DG2 & $\mathrm{P}$ & 864.25 & 3642.3 & $2.37 e-01$ \\
\hline CATAWBA 1 & 413 & IB & $\mathbf{P}$ & 589.50 & 2586.9 & $2.28 \mathrm{e}-01$ \\
\hline BEAVER VALLEY 2 & 412 & EDG2-2 & $\mathrm{P}$ & 790.30 & 3505.6 & $2.25 \mathrm{e}-01$ \\
\hline COOPER STATION & 298 & DG-1 & $\mathbf{P}$ & 538.00 & 2495.8 & $2.16 \mathrm{e}-01$ \\
\hline INDIAN POINT 2 & 247 & 22EDG & $\mathrm{P}$ & 1066.00 & 5068.6 & $2.10 \mathrm{e}-01$ \\
\hline GINNA & 244 & EDGA & $\mathbf{P}$ & 507.72 & 2490.1 & $2.04 \mathrm{e}-01$ \\
\hline HARRIS 1 & 400 & $1 \mathrm{~A}-\mathrm{SA}$ & $\mathbf{P}$ & 502.00 & 2476.6 & $2.03 e-01$ \\
\hline MONTICELLO & 263 & 11 & $\mathbf{P}$ & 476.30 & 2363.1 & $2.02 e-01$ \\
\hline SAN ONOFRE 3 & 362 & $\mathrm{DG} 2$ & $\mathrm{P}$ & 569.77 & 2856.6 & $1.99 \mathrm{e}-01$ \\
\hline CRYSTAL RIVER 3 & 302 & $1 \mathrm{~B}$ & $\mathrm{P}$ & 744.00 & 3762.0 & $1.98 e-01$ \\
\hline DIABLO CANYON 1 & 275 & DEG1-2 & $\mathrm{P}$ & 384.00 & 2049.2 & $1.87 \mathrm{e}-01$ \\
\hline CRYSTAL RIVER 3 & 302 & $1 \mathrm{~A}$ & $\mathbf{P}$ & 696.00 & 3762.0 & $1.85 \mathrm{e}-01$ \\
\hline RIVER BEND & 458 & III & $\mathbf{P}$ & 1033.70 & 5622.7 & $1.84 \mathrm{e}-01$ \\
\hline OYSTER CREEK & 219 & EDG-2 & $\mathbf{P}$ & 721.00 & 3955.8 & $1.82 \mathrm{e}-01$ \\
\hline GINNA & 244 & EDGB & $\mathbf{P}$ & 448.42 & 2490.1 & $1.80 \mathrm{e}-01$ \\
\hline
\end{tabular}


Table B.5. (Cont'd)

\begin{tabular}{|c|c|c|c|c|c|c|}
\hline Plaut Name & $\begin{array}{c}\text { Docket } \\
\text { No }\end{array}$ & EDG ID & $\begin{array}{c}\text { Outage } \\
\text { Code }\end{array}$ & $\begin{array}{l}\text { Total EDG } \\
\text { OOS Hours }\end{array}$ & $\begin{array}{l}\text { Plant Off- } \\
\text { Line Hours } \\
\end{array}$ & $\begin{array}{c}\text { Unavail. due } \\
\text { to } \mathrm{PM}\end{array}$ \\
\hline INDIAN POINT 2 & 247 & 23EDG & $\mathbf{P}$ & 912.00 & 5068.6 & $1.80 \mathrm{e}-01$ \\
\hline OYSTER CREEK & 219 & EDG-1 & $\mathbf{P}$ & 710.00 & 3955.8 & $1.79 \mathrm{e}-01$ \\
\hline RIVER BEND & 458 & II & $\mathbf{P}$ & 969.70 & 5622.7 & $1.72 \mathrm{e}-01$ \\
\hline SUMMER & 395 & B & $\mathbf{P}$ & 320.50 & 1973.0 & $1.62 \mathrm{e}-01$ \\
\hline ROBINSON 2 & 261 & $\mathrm{~A}$ & $\mathbf{P}$ & 977.23 & 6076.5 & $1.61 \mathrm{e}-01$ \\
\hline KEWAUNEE & 305 & DGA & $\mathbf{P}$ & 386.49 & 2509.7 & $1.54 \mathrm{e}-01$ \\
\hline SAN ONOFRE 3 & 362 & DG3 & $\mathrm{P}$ & 436.08 & 2856.6 & $1.53 \mathrm{e}-01$ \\
\hline BEAVER VALLEY 2 & 412 & EDG2-1 & $\mathrm{P}$ & 533.10 & 3505.6 & $1.52 \mathrm{e}-01$ \\
\hline PERRY 1 & 440 & A & $\mathbf{P}$ & 817.00 & 5395.7 & $1.51 \mathrm{e}-01$ \\
\hline WATERFORD 3 & 382 & B & $\mathrm{P}$ & 372.88 & 2477.9 & $1.50 \mathrm{e}-01$ \\
\hline BRAIDWOOD 2 & 457 & $2 \mathrm{~B}$ & $\mathrm{P}$ & 385.40 & 2615.1 & $1.47 \mathrm{e}-01$ \\
\hline SOUTH TEXAS 1 & 498 & EDG13 & $\mathbf{P}$ & 720.00 & 4921.8 & $1.46 \mathrm{e}-01$ \\
\hline HATCH 1 & 321 & A & $\mathbf{P}$ & 439.70 & 3006.2 & $1.46 \mathrm{e}-01$ \\
\hline MONTICELLO & 263 & 12 & $\mathbf{P}$ & 334.95 & 2363.1 & $1.42 \mathrm{e}-01$ \\
\hline HATCH 1 & 321 & $\mathrm{C}$ & $\mathbf{P}$ & 424.50 & 3006.2 & $1.41 \mathrm{e}-01$ \\
\hline WOLF CREEK 1 & 482 & A & $\mathbf{P}$ & 504.40 & 3685.1 & $1.37 \mathrm{e}-01$ \\
\hline PERRY 1 & 440 & B & $\mathbf{P}$ & 734.00 & 5395.7 & $1.36 \mathrm{e}-01$ \\
\hline FORT CALHOUN & 285 & DG-1 & $\mathbf{P}$ & 524.00 & 3944.2 & $1.33 \mathrm{e}-01$ \\
\hline CALLAWAY & 483 & $\mathrm{~A}$ & $\mathbf{P}$ & 402.45 & 3109.8 & $1.29 \mathrm{e}-01$ \\
\hline BRAIDWOOD 2 & 457 & $2 \mathrm{~A}$ & $\mathbf{P}$ & 336.00 & 2615.1 & $1.28 \mathrm{e}-01$ \\
\hline MCGUIRE 1 & 369 & $1 \mathrm{~A}$ & $\mathbf{P}$ & 611.50 & 4826.4 & $1.27 \mathrm{e}-01$ \\
\hline GRAND GULF & 416 & DG13 & P & 465.00 & 3997.4 & $1.16 \mathrm{e}-01$ \\
\hline FERMI 2 & 341 & EDG11 & $\mathrm{P}$ & 434.50 & 3792.6 & $1.15 \mathrm{e}-01$ \\
\hline ROBINSON 2 & 261 & B & $\mathrm{P}$ & 691.86 & 6076.5 & $1.14 \mathrm{e}-01$ \\
\hline DIABLO CANYON 2 & 323 & DEG1-3 & $\mathbf{P}$ & 165.00 & $\$ 471.7$ & $1.12 \mathrm{e}-01$ \\
\hline CALLAWAY & 483 & B & $\mathbf{P}$ & 340.35 & 3109.8 & $1.09 \mathrm{e}-01$ \\
\hline WOLF CREEK 1 & 482 & B & $\mathbf{P}$ & 387.20 & 3685.1 & $1.05 \mathrm{e}-01$ \\
\hline BEAVER VALLEY 1 & 334 & EDG1-1 & $\mathrm{P}$ & 455.53 & 4369.2 & $1.04 \mathrm{e}-01$ \\
\hline SEABROOK 1 & 443 & A & $\mathbf{P}$ & 296.00 & 2904.4 & $1.02 \mathrm{e}-01$ \\
\hline HARRIS 1 & 400 & 1B-SB & $\mathbf{P}$ & 250.00 & 2476.6 & $1.01 \mathrm{e}-01$ \\
\hline MCGUIRE 1 & 369 & 1B & $P$ & 480.00 & 4826.4 & $9.95 e-02$ \\
\hline
\end{tabular}


Table B.5. (Cont'd)

\begin{tabular}{|c|c|c|c|c|c|c|}
\hline Plant Name & $\begin{array}{l}\text { Docket } \\
\text { No }\end{array}$ & EDG ID & $\begin{array}{l}\text { Outage } \\
\text { Code }\end{array}$ & $\begin{array}{l}\text { Total EDG } \\
\text { OOS Hours }\end{array}$ & $\begin{array}{l}\text { Plant Off- } \\
\text { Line Hours }\end{array}$ & $\begin{array}{l}\text { Unavail. due } \\
\text { to } \mathrm{PM}\end{array}$ \\
\hline BRAIDWOOD 1 & 456 & $1 \mathrm{~A}$ & $\mathrm{P}$ & 432.00 & 4586.8 & $9.42 e-02$ \\
\hline SOUTH TEXAS 2 & 499 & EDG21 & $P$ & 442.40 & 4805.0 & $9.21 \mathrm{e}-02$ \\
\hline BRUNSWICK 1 & 325 & EDG2 & $\mathbf{P}$ & 583.16 & 6666.0 & $8.75 e-02$ \\
\hline WATERFORD 3 & 382 & $\mathrm{~A}$ & $\mathbf{P}$ & 214.17 & 2477.9 & $8.64 \mathrm{e}-02$ \\
\hline HATCH 2 & 366 & $\mathrm{c}$ & $\mathbf{P}$ & 193.00 & 2268.0 & $8.51 \mathrm{e}-02$ \\
\hline BRUNSWICK 2 & 324 & EDG4 & $\mathbf{P}$ & 520.44 & 6211.7 & $8.38 \mathrm{e}-02$ \\
\hline QUAD CITIES 2 & 265 & $\mathrm{U} 1 / 2$ & $\mathbf{P}$ & 371.60 & 4490.4 & $8.28 \mathrm{e}-02$ \\
\hline DIABLO CANYON 1 & 275 & DEG1-3 & $\mathbf{P}$ & 165.00 & 2049.2 & $8.05 \mathrm{e}-02$ \\
\hline BIG ROCK POINT & 155 & A & $\mathbf{P}$ & 527.50 & 6644.8 & $7.94 \mathrm{e}-02$ \\
\hline BRUNSWICK 2 & 324 & EDG3 & $\mathbf{P}$ & 469.75 & 6211.7 & $7.56 \mathrm{e}-02$ \\
\hline ZION 1 & 295 & $1 \mathrm{~B}$ & $\mathbf{P}$ & 560.17 & 7663.9 & $7.31 \mathrm{e}-02$ \\
\hline BEAVER VALLEY 1 & 334 & EDG1-2 & $\mathbf{P}$ & 319.20 & 4369.2 & $7.31 \mathrm{e}-02$ \\
\hline VERMONT YANKEE & 271 & EDG B & $\mathbf{P}$ & 191.50 & 2819.0 & $6.79 \mathrm{e}-02$ \\
\hline SOUTH TEXAS 2 & 499 & EDG22 & $\mathbf{P}$ & 319.20 & 4805.0 & $6.64 \mathrm{e}-02$ \\
\hline FERMI 2 & 341 & EDG13 & $\mathbf{P}$ & 243.50 & 3792.6 & $6.42 \mathrm{e}-02$ \\
\hline HADDAM NECK & 213 & EG-2A & $\mathbf{P}$ & 389.88 & 6481.3 & $6.02 \mathrm{e}-02$ \\
\hline SURRY 1 & 280 & EDG3 & $\mathbf{P}$ & 208.57 & 3573.4 & $5.84 \mathrm{e}-02$ \\
\hline ROBINSON 2 & 261 & $\mathrm{D} / \mathrm{S}$ & $\mathbf{P}$ & 333.00 & 6076.5 & $5.48 \mathrm{e}-02$ \\
\hline FORT CALHOUN & 285 & DG-2 & $\mathrm{P}$ & 216.00 & 3944.2 & $5.48 \mathrm{e}-02$ \\
\hline ARKANSAS 2 & 368 & A & $\mathbf{P}$ & 173.17 & 3199.6 & $5.41 \mathrm{e}-02$ \\
\hline НАТСН 2 & 366 & $\mathrm{~A}$ & $\mathbf{P}$ & 122.10 & 2268.0 & $5.38 \mathrm{e}-02$ \\
\hline FERMI 2 & 341 & EDG14 & $\mathbf{P}$ & 188.00 & 3792.6 & $4.96 \mathrm{e}-02$ \\
\hline SOUTH TEXAS 1 & 498 & EDG11 & $\mathbf{P}$ & 237.60 & 4921.8 & $4.83 \mathrm{e}-02$ \\
\hline BRAIDWOOD 1 & 456 & $1 \mathrm{~B}$ & $\mathbf{P}$ & 204.00 & 4586.8 & $4.45 \mathrm{e}-02$ \\
\hline ZION 2 & 304 & $2 \mathrm{~B}$ & $\mathbf{P}$ & 343.03 & 8237.5 & $4.16 \mathrm{e}-02$ \\
\hline LASALLE 1 & 373 & 0 & $\mathbf{P}$ & 122.00 & 3081.9 & $3.96 \mathrm{e}-02$ \\
\hline DRESDEN 3 & 249 & DG3 & $\mathrm{P}$ & 263.40 & 6757.2 & $3.90 \mathrm{e}-02$ \\
\hline BRUNSWICK 1 & 325 & EDG1 & $\mathbf{P}$ & 238.85 & 6666.0 & $3.58 \mathrm{e}-02$ \\
\hline HATCH 2 & 366 & B & $\mathbf{P}$ & 76.60 & 2268.0 & $3.38 \mathrm{e}-02$ \\
\hline FARLEY 1 & 348 & $2 \mathrm{C}$ & $\mathbf{P}$ & 64.50 & 1965.9 & $3.28 \mathrm{e}-02$ \\
\hline ZION 2 & 304 & $2 \mathrm{~A}$ & $\mathbf{P}$ & 230.83 & 8237.5 & $2.80 \mathrm{e}-02$ \\
\hline
\end{tabular}


Table B.5. (Cont'd)

\begin{tabular}{|c|c|c|c|c|c|c|}
\hline Plant Name & $\begin{array}{c}\text { Docket } \\
\text { No } \\
\end{array}$ & EDG ID & $\begin{array}{c}\text { Outage } \\
\text { Code }\end{array}$ & $\begin{array}{l}\text { Total EDG } \\
\text { OOS Hours }\end{array}$ & $\begin{array}{l}\text { Plant Off- } \\
\text { Line Hours }\end{array}$ & $\begin{array}{l}\text { Unavail, due } \\
\text { to } P M\end{array}$ \\
\hline ARKANSAS 2 & 368 & B & $\mathbf{P}$ & 88.80 & 3199.6 & $2.78 \mathrm{e}-02$ \\
\hline ZION 1 & 295 & c & $\mathbf{P}$ & 194.60 & 7663.9 & $2.54 \mathrm{e}-02$ \\
\hline SEABROOK 1 & 443 & B & $\mathbf{P}$ & 65.00 & 2904.4 & $2.24 \mathrm{e}-02$ \\
\hline DRESDEN 2 & 237 & DG2 & $P$ & 155.50 & 7216.9 & $2.15 \mathrm{e}-02$ \\
\hline LIMERICK 2 & 353 & D23 & $\mathrm{P}$ & 62.18 & 3022.7 & $2.06 \mathrm{e}-02$ \\
\hline SOUTH TEXAS 2 & 499 & EDG23 & $\mathbf{P}$ & 96.70 & 4805.0 & $2.01 \mathrm{e}-02$ \\
\hline VERMONT YANKEE & 271 & EDG A & $\mathbf{P}$ & 55.40 & 2819.0 & $1.97 \mathrm{e}-02$ \\
\hline POINT BEACH 2 & 301 & G-01 & $\mathbf{P}$ & 40.95 & 2247.4 & $1.82 \mathrm{e}-02$ \\
\hline SEQUOYAH 1 & 327 & BB & $\mathbf{P}$ & 61.73 & 3399.8 & $1.82 \mathrm{e}-02$ \\
\hline LASALLE 2 & 374 & $2 \mathrm{~A}$ & $\mathbf{P}$ & 64.33 & 3575.8 & $1.80 \mathrm{e}-02$ \\
\hline SEQUOYAH 2 & 328 & BB & $\mathbf{P}$ & 59.54 & 3730.8 & $1.60 \mathrm{e}-02$ \\
\hline SAN ONOFRE 2 & 361 & DG3 & $\mathbf{P}$ & 55.42 & 3642.3 & $1.52 \mathrm{e}-02$ \\
\hline HАTCH 1 & 321 & B & $\mathbf{P}$ & 42.00 & 3006.2 & $1.40 \mathrm{e}-02$ \\
\hline HADDAM NECK & 213 & EG-2B & $\mathbf{P}$ & 90.19 & 6481.3 & $1.39 \mathrm{e}-02$ \\
\hline SEQUOYAH 1 & 327 & $\mathrm{AA}$ & $\mathbf{P}$ & 46.60 & 3399.8 & $1.37 \mathrm{e}-02$ \\
\hline FARLEY 2 & 364 & $1 \mathrm{C}$ & $\mathbf{P}$ & 45.30 & 4057.3 & $1.12 \mathrm{e}-02$ \\
\hline FARLEY 2 & 364 & $2 \mathrm{~A}$ & $\mathrm{P}$ & 44.25 & 4057.3 & $1.09 \mathrm{e}-02$ \\
\hline MAINE YANKEE & 309 & DG-1B & $\mathbf{P}$ & 47.00 & 4497.4 & $1.05 \mathrm{e}-02$ \\
\hline SEQUOYAH 2 & 328 & $\mathrm{AA}$ & $\mathrm{P}$ & 33.64 & 3730.8 & $9.02 \mathrm{e}-03$ \\
\hline PRAIRIE ISLAND 2 & 306 & D2 & $\mathrm{P}$ & 12.40 & 1418.2 & . $\quad 8.74 \mathrm{e}-03$ \\
\hline DRESDEN 3 & 249 & $\mathrm{DG} 2 / 3$ & $\mathrm{P}$ & 58.60 & 6757.2 & $8.67 e-03$ \\
\hline PALO VERDE 3 & 530 & 3MDGAH01 & $\mathbf{P}$ & 23.60 & 2769.9 & $8.52 \mathrm{e}-03$ \\
\hline LASALLE 2 & 374 & $2 \mathrm{~B}$ & $\mathbf{P}$ & 29.50 & 3575.8 & $8.25 \mathrm{e}-03$ \\
\hline DRESDEN 2 & 237 & $\mathrm{DG} 2 / 3$ & $\mathbf{P}$ & 58.60 & 7216.9 & $8.12 \mathrm{e}-03$ \\
\hline ARKANSAS 1 & 313 & B & $\mathbf{P}$ & 19.65 & 2947.5 & $6.67 e-03$ \\
\hline LASALLE 2 & 374 & 0 & $\mathbf{P}$ & 21.25 & 3575.8 & $5.94 \mathrm{e}-03$ \\
\hline PALO VERDE 1 & 528 & 1MDGAH01 & $\mathrm{P}$ & 24.50 & 4560.8 & $5.37 \mathrm{e}-03$ \\
\hline MAINE YANKEE & 309 & DG-1A & $\mathrm{P}$ & 20.00 & 4497.4 & $4.45 \mathrm{e}-03$ \\
\hline RIVER BEND & 458 & I & $\mathbf{P}$ & 22.50 & 5622.7 & $4.00 \mathrm{e}-03$ \\
\hline ZION 2 & 304 & $\mathrm{C}$ & $\mathbf{P}$ & 29.68 & 8237.5 & $3.60 \mathrm{e}-03$ \\
\hline MILLSTONE 3 & 423 & 3B & $\mathbf{P}$ & 18.73 & 6861.0 & $2.73 e-03$ \\
\hline
\end{tabular}


Table B.5. (Cont'd)

\begin{tabular}{|c|c|c|c|c|c|c|}
\hline Plant Name & $\begin{array}{c}\text { Docket } \\
\text { No }\end{array}$ & EDG ID & $\begin{array}{l}\text { Outage } \\
\text { Code }\end{array}$ & $\begin{array}{l}\text { Total EDG } \\
\text { OOS Hours }\end{array}$ & $\begin{array}{l}\text { Plant Off- } \\
\text { Line Hours }\end{array}$ & $\begin{array}{c}\text { Unavail, due } \\
\text { to } \mathrm{PM}\end{array}$ \\
\hline PALISADES & 255 & DG $1-2$ & $\mathbf{P}$ & 16.34 & 6554.4 & $2.49 \mathrm{e}-03$ \\
\hline SUSQUEHANNA 2 & 388 & E & $\mathbf{P}$ & 5.53 & 2301.3 & $2.40 \mathrm{e}-03$ \\
\hline PALISADES & 255 & DG1-1 & $\mathbf{P}$ & 15.22 & 6554.4 & $2.32 \mathrm{e}-03$ \\
\hline DIABLO CANYON 1 & 275 & DEG1-1 & $\mathbf{P}$ & 4.08 & 2049.2 & $1.99 \mathrm{e}-03$ \\
\hline WASHINGTON NUCLEAR 2 & 397 & DIV II & $\mathbf{P}$ & 16.00 & 8188.7 & $1.95 \mathrm{e}-03$ \\
\hline CALVERT CLIFFS 1 & 317 & 11EDG & $\mathrm{P}$ & 1.84 & 3704.4 & $4.97 \mathrm{e}-04$ \\
\hline SURRY 2 & 281 & EDG3 & $\mathbf{P}$ & 1.78 & 3601.9 & $4.94 e-04$ \\
\hline COMANCHE PEAK 1 & 445 & $1-01$ & $\mathbf{p}$ & 1.50 & 4873.8 & $3.08 \mathrm{e}-04$ \\
\hline QUAD CITIES 1 & 254 & $\mathrm{U} 1 / 2$ & $\mathbf{P}$ & 1.30 & 5555.5 & $2.34 \mathrm{e}-04$ \\
\hline FITZPATRICK & 333 & $21 \mathrm{EDG}$ & $\mathbf{P}$ & 1.63 & 7870.3 & $2.07 e-04$ \\
\hline PALO VERDE 1 & 528 & 1MDGBH01 & $\mathrm{P}$ & 0.40 & 4560.8 & $8.77 e-05$ \\
\hline MILLSTONE 3 & 423 & $3 \mathrm{~A}$ & $\mathrm{P}$ & 0.33 & 6861.0 & $4.81 \mathrm{e}-05$ \\
\hline & & & & & AVERAGE* & $8.34 e-02$ \\
\hline
\end{tabular}

*Average is obtained considering 170 EDGs. EDGs reporting zero 00S hours due to PM are not included in this table. 
Table B.6. EDG Unavailability Due to Corrective Maintenance, $\mathrm{U}_{\mathrm{s}, \mathrm{CM}}$, During Plant Shutdown in Descending Order

\begin{tabular}{|c|c|c|c|c|c|c|}
\hline Plaut Name & $\begin{array}{c}\text { Docket } \\
\text { No }\end{array}$ & EDG ID & $\begin{array}{c}\text { Outage } \\
\text { Code }\end{array}$ & $\begin{array}{l}\text { Total EDG } \\
\text { OOS Hours }\end{array}$ & $\begin{array}{l}\text { Plant. Off- } \\
\text { Line Hours }\end{array}$ & $\begin{array}{l}\text { Unavail. due } \\
\text { to } \mathrm{CM}\end{array}$ \\
\hline CATAWBA 2 & 414 & $2 \mathrm{~B}$ & C & 64.30 & 140.0 & $4.59 \mathrm{e}-01$ \\
\hline SAN ONOFRE 2 & 361 & DG3 & $c$ & 1066.42 & 3642.3 & $2.93 \mathrm{e}-01$ \\
\hline BRUNSWICK 2 & 324 & EDG4 & c & 1311.94 & 6211.7 & $2.11 \mathrm{e}-01$ \\
\hline ZION 1 & 295 & c & c & 1345.03 & 7663.9 & $1.76 \mathrm{e}-01$ \\
\hline SAN ONOFRE 1 & 206 & DG1 & C & 1237.35 & 7516.0 & $1.65 \mathrm{e}-01$ \\
\hline SAN ONOFRE 1 & 206 & DG2 & $c$ & 1225.18 & 7516.0 & $1.63 \mathrm{e}-01$ \\
\hline ST. LUCIE 2 & 389 & $2 A$ & $c$ & 480.00 & 2973.0 & $1.61 \mathrm{e}-01$ \\
\hline WATERFORD 3 & 382 & A & $c$ & 390.45 & 2477.9 & $1.58 \mathrm{e}-01$ \\
\hline ARKANSAS 2 & 368 & B & C & 466.14 & 3199.6 & $1.46 \mathrm{e}-01$ \\
\hline ZION 2 & 304 & $\mathrm{C}$ & C & 1178.86 & 8237.5 & $1.43 \mathrm{e}-01$ \\
\hline CALLAWAY & 483 & $\mathrm{~A}$ & $\mathrm{C}$ & 437.45 & $\begin{array}{r}1 \\
\end{array} 3109.8$ & $1.41 \mathrm{e}-01$ \\
\hline ST. LUCIE 2 & 389 & $2 \mathrm{~B}$ & C & 408.00 & 2973.0 & $1.37 \mathrm{e}-01$ \\
\hline BRAIDWOOD 2 & 457 & 2B & $\mathrm{C}$ & 349.60 & 2615.1 & $1.34 \mathrm{e}-01$ \\
\hline BRAIDWOOD 2 & 457 & $2 \mathrm{~A}$ & C & 336.00 & 2615.1 & $1.28 \mathrm{e}-01$ \\
\hline CALLAWAY & 483 & B & $\mathrm{C}$ & 385.85 & 3109.8 & $1.24 \mathrm{e}-01$ \\
\hline BRUNSWICK 1 & 325 & EDG1 & $\mathrm{C}$ & 802.75 & 6666.0 & $1.20 \mathrm{e}-01$ \\
\hline SOUTH TEXAS 1 & 498 & EDG11 & $\mathrm{C}$ & 567.90 & 4921.8 & $1.15 \mathrm{e}-01$ \\
\hline THREE MILE ISLAND 1 & 289 & EDG-1B & C & 120.63 & 1223.4 & $9.86 \mathrm{e}-02$ \\
\hline BEAVER VALLEY 2 & 412 & EDG2-2 & C & 338.70 & 3505.6 & $9.66 \mathrm{e}-02$ \\
\hline BRAIDWOOD 1 & 456 & $1 \mathrm{~A}$ & $\mathrm{C}$ & 432.00 & 4586.8 & $9.42 \mathrm{e}-02$ \\
\hline ST. LUCIE 1 & 335 & $1 \mathrm{~A}$ & C & 240.00 & 2605.3 & $9.21 \mathrm{e}-02$ \\
\hline VOGTLE 1 & 424 & DG1B & C & 31.25 & 340.3 & $9.18 \mathrm{e}-02$ \\
\hline SOUTH TEXAS 1 & 498 & EDG12 & C & 434.00 & 4921.8 & $8.82 \mathrm{e}-02$ \\
\hline BRUNSWICK 1 & 325 & EDG2 & $\mathrm{C}$ & 579.46 & 6666.0 & $8.69 \mathrm{e}-02$ \\
\hline BRUNSWICK 2 & 324 & EDG3 & C & 507.85 & 6211.7 & $8.18 \mathrm{e}-02$ \\
\hline ROBINSON 2 & 261 & $D / S$ & $\mathrm{c}$ & 481.00 & 6076.5 & $7.92 \mathrm{e}-02$ \\
\hline ZION 1 & 295 & $1 \mathrm{~A}$ & C & 597.27 & 7663.9 & $7.79 \mathrm{e}-02$ \\
\hline QUAD CITIES 2 & 265 & $\mathrm{U} 2$ & $\mathrm{C}$ & 348.40 & 4490.4 & $7.76 \mathrm{e}-02$ \\
\hline ZION 2 & 304 & $2 \mathrm{~A}$ & c & 608.60 & 8237.5 & $7.39 \mathrm{e}-02$ \\
\hline BEAVER VALLEY 2 & 412 & EDG2-1 & $\mathrm{C}$ & 228.30 & 3505.6 & $6.51 \mathrm{e}-02$ \\
\hline
\end{tabular}


Table B.6. (Cont'd)

\begin{tabular}{|c|c|c|c|c|c|c|}
\hline Plant Name & $\begin{array}{c}\text { Docket } \\
\text { No }\end{array}$ & EDG ID & $\begin{array}{c}\text { Outage } \\
\text { Code }\end{array}$ & $\begin{array}{l}\text { Total EDG } \\
\text { OOS Hours }\end{array}$ & $\begin{array}{c}\text { Plant Off- } \\
\text { Lime Hours }\end{array}$ & $\begin{array}{l}\text { Unavail. due } \\
\text { to } C M\end{array}$ \\
\hline ST. LUCIE 1 & 335 & 1B & $\mathrm{c}$ & 136.90 & 2605.3 & $5.25 \mathrm{e}-02$ \\
\hline SOUTH TEXAS 2 & 499 & EDG23 & $\mathrm{c}$ & 247.80 & 4805.0 & $5.16 \mathrm{e}-02$ \\
\hline MONTICELLO & 263 & 12 & $\mathrm{c}$ & 120.57 & 2363.1 & $5.10 \mathrm{e}-02$ \\
\hline SOUTH TEXAS 2 & 499 & EDG22 & c & 232.80 & 4805.0 & $4.84 \mathrm{e}-02$ \\
\hline ZION 1 & 295 & $1 \mathrm{~B}$ & $\mathrm{c}$ & 356.57 & 7663.9 & $4.65 e-02$ \\
\hline BEAVER VALLEY 1 & 334 & EDGl-1 & $\mathrm{c}$ & 195.22 & 4369.2 & 4.47e-02 \\
\hline BRAIDWOOD 1 & 456 & $1 \mathrm{~B}$ & $\mathrm{C}$ & 204.00 & 4586.8 & $4.45 \mathrm{e}-02$ \\
\hline SOUTH TEXAS 2 & 499 & EDG21 & $\mathrm{c}$ & 200.10 & 4805.0 & $4.16 \mathrm{e}-02$ \\
\hline SUMMER & 395 & A & C & $\begin{array}{l}1 \quad 76.90 \\
\end{array}$ & 1973.0 & $3.90 \mathrm{e}-02$ \\
\hline VOGTLE 1 & 424 & $\mathrm{DG} 1 \mathrm{~A}$ & $\mathrm{c}$ & 11.95 & 340.3 & $3.51 \mathrm{e}-02$ \\
\hline WASHINGTON NUCLEAR 2 & 397 & DIV III & $\mathrm{c}$ & 286.50 & 8188.7 & $3.50 \mathrm{e}-02$ \\
\hline FARLEY 1 & 348 & $1 \mathrm{~A}$ & $\mathrm{c}$ & 67.17 & 1965.9 & $3.42 \mathrm{e}-02$ \\
\hline MONTICELLO & 263 & 11 & $\mathrm{c}$ & 79.00 & 2363.1 & $3.34 \mathrm{e}-02$ \\
\hline WOLF CREEK 1 & 482 & $\mathrm{~A}$ & $\mathrm{c}$ & 121.20 & 3685.1 & $3.29 e-02$ \\
\hline SAN ONOFRE 3 & 362 & DG3 & $\mathrm{c}$ & 91.77 & 2856.6 & $3.21 \mathrm{e}-02$ \\
\hline WASHINGTON NUCLEAR 2 & 397 & DrV II & $\mathrm{C}$ & 260.50 & 8188.7 & $3.18 \mathrm{e}-02$ \\
\hline QUAD CITIES 2 & 265 & $\mathrm{U} 1 / 2$ & $\mathrm{c}$ & 142.80 & 4490.4 & $3.18 \mathrm{e}-02$ \\
\hline ARKANSAS 2 & 368 & $\mathrm{~A}$ & $\mathrm{C}$ & 101.10 & 3199.6 & $3.16 \mathrm{e}-02$ \\
\hline BEAVER VALLEY 1 & 334 & EDG1-2 & $\mathrm{c}$ & 137.50 & 4369.2 & $3.15 \mathrm{e}-02$ \\
\hline SEQUOYAH 1 & 327 & $\mathrm{BB}$ & c & 105.82 & 3399.8 & $3.11 \mathrm{e}-02$ \\
\hline SOUTH TEXAS 1 & 498 & EDG13 & $\mathrm{c}$ & 145.50 & 4921.8 & $2.96 \mathrm{e}-02$ \\
\hline DIABLO CANYON 2 & 323 & DEG1-3 & c & 42.70 & 1471.7 & $2.90 \mathrm{e}-02$ \\
\hline PILGRIM 1 & 293 & A & c & 96.00 & 3320.6 & $2.89 e-02$ \\
\hline PILGRIM 1 & 293 & B & $\mathrm{c}$ & 96.00 & 3320.6 & $2.89 \mathrm{e}-02$ \\
\hline QUAD CITIES 1 & 254 & $\mathrm{u} 1$ & $\mathrm{c}$ & 142.55 & 5555.5 & $2.57 e-02$ \\
\hline PERRY 1 & 440 & $\mathrm{~A}$ & $\mathrm{c}$ & 130.75 & 5395.7 & $2.42 \mathrm{e}-02$ \\
\hline CATAWBA 1 & 413 & $1 \mathrm{~B}$ & c & 61.30 & 2586.9 & $2.37 \mathrm{e}-02$ \\
\hline QUAD CITIES 1 & 254 & $\mathrm{U} 1 / 2$ & $\mathrm{c}$ & 126.20 & 5555.5 & $2.27 \mathrm{e}-02$ \\
\hline DIABLO CANYON 1 & 275 & DEG1-3 & $\mathrm{c}$ & 42.70 & 2049.2 & $2.08 \mathrm{e}-02$ \\
\hline SURRY 2 & 281 & EDG3 & $\mathrm{c}$ & 72.83 & 3601.9 & $2.02 \mathrm{e}-02$ \\
\hline VOGTLE 2 & 425 & DG2A & C & 39.20 & 1942.9 & $2.02 \mathrm{e}-02$ \\
\hline
\end{tabular}


Table B.6. (Cont'd)

\begin{tabular}{|c|c|c|c|c|c|c|}
\hline Plant Name & $\begin{array}{c}\text { Docket } \\
\text { No }\end{array}$ & EDG ID & $\begin{array}{c}\text { Outage } \\
\text { Code }\end{array}$ & $\begin{array}{l}\text { Total EDG } \\
\text { OOS Hours }\end{array}$ & $\begin{array}{l}\text { Plant Off- } \\
\text { Line Hours }\end{array}$ & $\begin{array}{c}\text { Unavail. due } \\
\text { to } \mathbf{C M} \\
\end{array}$ \\
\hline FARLEY 2 & 364 & $2 \mathrm{C}$ & $\mathrm{c}$ & 80.95 & 4057.3 & $2.00 \mathrm{e}-02$ \\
\hline LIMERICK 1 & 352 & D11 & $\mathrm{C}$ & 108.04 & 5493.3 & $1.97 \mathrm{e}-02$ \\
\hline CRYSTAL RIVER 3 & 302 & $1 \mathrm{~B}$ & c & 73.00 & 3762.0 & $1.94 \mathrm{e}-02$ \\
\hline CATAWBA 1 & 413 & $1 \mathrm{~A}$ & $\mathrm{C}$ & 48.60 & 2586.9 & $1.88 \mathrm{e}-02$ \\
\hline CALVERT CLIFFS 1 & 317 & $11 \mathrm{EDG}$ & $\mathrm{c}$ & 65.23 & 3704.4 & $1.76 \mathrm{e}-02$ \\
\hline WASHINGTON NUCLEAR 2 & 397 & DIV I & $\mathrm{c}$ & 143.30 & 8188.7 & $1.75 e-02$ \\
\hline LASALLE 1 & 373 & 0 & $\mathrm{C}$ & 53.50 & 3081.9 & $1.74 \mathrm{e}-02$ \\
\hline PALO VERDE 2 & 529 & 2MDGBH01 & $\mathrm{c}$ & 58.00 & 3614.4 & $1.60 \mathrm{e}-02$ \\
\hline ROBINSON 2 & 261 & B & $\mathrm{C}$ & 96.64 & 6076.5 & $1.59 \mathrm{e}-02$ \\
\hline LASALLE 2 & 374 & 0 & c & 54.52 & 3575.8 & $1.52 \mathrm{e}-02$ \\
\hline SAN ONOFRE 3 & 362 & DG2 & $\mathrm{c}$ & 37.52 & 2856.6 & $1.31 \mathrm{e}-02$ \\
\hline VERMONT YANKEE & 271 & EDG B & c & 35.90 & 2819.0 & $1.27 \mathrm{e}-02$ \\
\hline HARRIS 1 & 400 & IA-SA & c & 31.20 & 2476.6 & $1.26 \mathrm{e}-02$ \\
\hline ZION 2 & 304 & $2 \mathrm{~B}$ & $\mathrm{C}$ & 103.50 & 8237.5 & $1.26 \mathrm{e}-02$ \\
\hline GINNA & 244 & EDGB & $\mathrm{C}$ & 30.34 & 2490.1 & $1.22 \mathrm{e}-02$ \\
\hline SEQUOYAH 1 & 327 & $\mathrm{AA}$ & $\mathrm{C}$ & 39.93 & 3399.8 & $1.17 \mathrm{e}-02$ \\
\hline SAN ONOFRE 2 & 361 & DG2 & c & 41.68 & 3642.3 & $1.14 \mathrm{e}-02$ \\
\hline OYSTER CREEK & 219 & EDG-2 & $\mathrm{C}$ & 43.00 & 3955.8 & $1.09 \mathrm{e}-02$ \\
\hline DRESDEN 2 & 237 & DG2 & $\mathrm{c}$ & 71.70 & 7216.9 & $9.94 \mathrm{e}-03$ \\
\hline HADDAM NECK & 213 & EG-2A & C & 58.00 & 6481.3 & $8.95 e-03$ \\
\hline WOLF CREEK 1 & 482 & B & $\mathrm{c}$ & 31.30 & 3685.1 & $8.49 \mathrm{e}-03$ \\
\hline SUSQUEHANNA 2 & 388 & $\mathrm{D}$ & $\mathrm{c}$ & 14.53 & 2301.3 & $6.31 \mathrm{e}-03$ \\
\hline COOK 2 & 316 & $2 \mathrm{AB}$ & C & 41.17 & 6566.9 & $6.27 \mathrm{e}-03$ \\
\hline GINNA & 244 & EDGA & $\mathrm{C}$ & 15.19 & 2490.1 & $6.10 \mathrm{e}-03$ \\
\hline MILLSTONE 3 & 423 & $3 \mathrm{~A}$ & c & 39.49 & 6861.0 & $5.76 \mathrm{e}-03$ \\
\hline MILLSTONE 1 & 245 & $1 \mathrm{~A}$ & c & 38.38 & 8439.1 & $4.55 \mathrm{e}-03$ \\
\hline MILLSTONE 3 & 423 & 3B & c & 30.60 & 6861.0 & $4.46 \mathrm{e}-03$ \\
\hline POINT BEACH 1 & 266 & G-02 & $\mathrm{C}$ & 11.80 & 2672.0 & $4.42 \mathrm{e}-03$ \\
\hline COOK 2 & 316 & $2 \mathrm{CD}$ & c & 28.78 & 6566.9 & $4.38 \mathrm{e}-03$ \\
\hline FERMI 2 & 341 & EDG14 & $\mathrm{C}$ & 15.50 & 3792.6 & $4.09 \mathrm{e}-03$ \\
\hline FITZPATRICK & 333 & $21 \mathrm{EDG}$ & c & 22.08 & 7870.3 & $2.81 \mathrm{e}-03$ \\
\hline
\end{tabular}


Table B.6. (Cont'd)

\begin{tabular}{|c|c|c|c|c|c|c|}
\hline Plant Name & $\begin{array}{c}\text { Docket } \\
\text { No }\end{array}$ & EDG ID & $\begin{array}{c}\text { Outage } \\
\text { Code }\end{array}$ & $\begin{array}{l}\text { Total EDG } \\
\text { OOS Hours }\end{array}$ & $\begin{array}{l}\text { Plant Off- } \\
\text { Line Hours }\end{array}$ & $\begin{array}{c}\text { Unavail. due } \\
\text { to } \mathrm{CM}\end{array}$ \\
\hline MCGUIRE 2 & 370 & $2 B$ & C & 13.50 & 5103.3 & $2.65 e-03$ \\
\hline PALISADES & 255 & DG1-1 & $\mathrm{C}$ & 17.30 & 6554.4 & $2.64 e-03$ \\
\hline HADDAM NECK & 213 & EG-2B ' & C & 15.75 & 6481.3 & $2.43 e-03$ \\
\hline KEWAUNEE & 305 & $\mathrm{DGA}$ & $\mathrm{C}$ & 5.02 & 2509.7 & $2.00 e-03$ \\
\hline SEQUOYAH 2 & 328 & AA & C & 5.86 & 3730.8 & $1.57 \mathrm{e}-03$ \\
\hline FORT CALHOUN & 285 & DG-1 & $\mathrm{C}$ & 4.00 & 3944.2 & $1.01 \mathrm{e}-03$ \\
\hline SEQUOYAH 2 & 328 & BB & C & 3.42 & 3730.8 & $9.17 e-04$ \\
\hline HATCH 1 & 321 & B & C & 2.40 & 3006.2 & $7.98 \mathrm{e}-04$ \\
\hline MCGUIRE 1 & 369 & 1B & C & 2.50 & 4826.4 & $5.18 \mathrm{e}-04$ \\
\hline FARLEY 1 & 348 & $2 \mathrm{C}$ & $\mathrm{c}$ & 0.54 & 1965.9 & $2.75 \mathrm{e}-04$ \\
\hline LIMERICK 2 & 353 & $\mathrm{D} 21$ & c & 0.81 & 3022.7 & $2.68 \mathrm{e}-04$ \\
\hline & & & & & AVERAGE* & $3.24 \mathrm{e}-02$ \\
\hline
\end{tabular}

*Average is obtained considering 170 EDGs. EDGs reporting zero 00S hours due to $\mathrm{CM}$ are not included in this table. 
Table B.7. EDG Unavailability Due to Preventive and Corrective Maintenance, $\mathrm{U}_{\mathrm{s}, \mathrm{PM}+\mathrm{CM}}$, During Plant Shutdown in Descending Order

\begin{tabular}{|c|c|c|c|c|c|}
\hline Plant Name & $\begin{array}{c}\text { Docket } \\
\text { No }\end{array}$ & EDG ID & $\begin{array}{l}\text { Total EDG } \\
\text { OOS Hours }\end{array}$ & $\begin{array}{c}\text { Plant Off-line } \\
\text { Hours }\end{array}$ & $\begin{array}{l}\text { Unavail. due to } \\
\mathrm{PM}+\mathrm{CM}\end{array}$ \\
\hline CATAWBA 2 & 414 & 2B & 64.30 & 140.0 & $4.59 \mathrm{e}-01$ \\
\hline DIABLO CANYON 2 & 323 & DEG2-1 & 672.00 & 1471.7 & $4.57 \mathrm{e}-01$ \\
\hline QUAD CITIES 2 & 265 & U2 & 2030.30 & 4490.4 & $4.52 \mathrm{e}-01$ \\
\hline INDIAN POINT 2 & 247 & 21EDG & 2208.00 & 5068.6 & $4.36 \mathrm{e}-01$ \\
\hline ZION 1 & 295 & IA & 3029.71 & 7663.9 & $3.95 \mathrm{e}-01$ \\
\hline ARKANSAS 1 & 313 & A & 1067.65 & 2947.5 & $3.62 \mathrm{e}-01$ \\
\hline DIABLO CANYON 2 & 323 & DEG2-2 & 528.00 & 1471.7 & $3.59 \mathrm{e}-01$ \\
\hline CATAWBA 1 & 413 & $1 \mathrm{~A}$ & 921.00 & 2586.9 & $3.56 \mathrm{e}-01$ \\
\hline QUAD CITIES 1 & 254 & U1 & 1821.35 & 5555.5 & $3.28 \mathrm{e}-01$ \\
\hline BEAVER VALLEY 2 & 412 & EDG2-2 & 1129.00 & 3505.6 & $3.22 \mathrm{e}-01$ \\
\hline COOPER STATION & 298 & DG-2 & 641.00 & 2023.1 & $3.17 \mathrm{e}-01$ \\
\hline SAN ONOFRE 2 & 361 & DG3 & 1121.84 & 3642.3 & $3.08 e-01$ \\
\hline BRUNSWICK 2 & 324 & EDG4 & 1832.38 & 6211.7 & $2.95 \mathrm{e}-01$ \\
\hline MCGUIRE 2 & 370 & $2 \mathrm{~A}$ & 1449.00 & 5103.3 & $2.84 \mathrm{e}-01$ \\
\hline GRAND GULF & 416 & DG11 & 1124.00 & 3997.4 & $2.81 \mathrm{e}-01$ \\
\hline BRAIDWOOD 2 & 457 & $2 B$ & 735.00 & 2615.1 & $2.81 \mathrm{e}-01$ \\
\hline CALLAWAY & 483 & A & 839.90 & 3109.8 & $2.70 e-01$ \\
\hline KEWAUNEE & 305 & DGB & 669.35 & 2509.7 & $2,67 e-01$ \\
\hline BRAIDWOOD 2 & 457 & $2 \mathrm{~A}$ & 672.00 & 2615.1 & $2.57 e-01$ \\
\hline PERRY 1 & 440 & C & 1363.00 & 5395.7 & $2.53 e-01$ \\
\hline CATAWBA 1 & 413 & 1B & 650.80 & 2586.9 & $2.52 \mathrm{e}-01$ \\
\hline SAN ONOFRE 2 & 361 & DG2 & 905.93 & 3642.3 & $2.49 \mathrm{e}-01$ \\
\hline MCGUIRE 2 & 370 & 2B & 1249.70 & 5103.3 & $2.45 \mathrm{e}-01$ \\
\hline WATERFORD 3 & 382 & A & 604.62 & 2477.9 & $2.44 e-01$ \\
\hline GRAND GULF & 416 & DG12 & 965.00 & 3997.4 & $2.41 \mathrm{e}-01$ \\
\hline MONTICELLO & 263 & 11 & 555.30 & 2363.1 & $2.35 \mathrm{e}-01$ \\
\hline CALLAWAY & 483 & B & 726.20 & 3109.8 & $2.34 \mathrm{e}-01$ \\
\hline BEAVER VALLEY 2 & 412 & EDG2-1 & 761.40 & 3505.6 & $2.17 \mathrm{e}-01$ \\
\hline CRYSTAL RIVER 3 & 302 & 1B & 817.00 & 3762.0 & $2.17 \mathrm{e}-01$ \\
\hline COOPER STATION & 298 & DG-1 & 538.00 & 2495.8 & $2.16 \mathrm{e}-01$ \\
\hline
\end{tabular}


Table B.7. (Cont'd)

\begin{tabular}{|c|c|c|c|c|c|}
\hline Plant Name & $\begin{array}{l}\text { Docket } \\
\text { No }\end{array}$ & EDG ID & $\begin{array}{l}\text { Total EDG } \\
\text { OOS Hours }\end{array}$ & $\begin{array}{l}\text { Plant Off-line } \\
\text { Hours }\end{array}$ & $\begin{array}{l}\text { Unavail. due to } \\
\mathbf{P M}+\mathbf{C M}\end{array}$ \\
\hline HARRIS 1 & 400 & IA-SA & 533.20 & 2476.6 & $2.15 \mathrm{e}-01$ \\
\hline SAN ONOFRE 3 & 362 & DG2 & 607.29 & 2856.6 & $2.13 \mathrm{e}-01$ \\
\hline INDLAN POINT 2 & 247 & 22EDG & 1066.00 & 5068.6 & $2.10 \mathrm{e}-01$ \\
\hline GINNA & 244 & EDGA & 522.91 & 2490.1 & $2.10 \mathrm{e}-01$ \\
\hline ZION 1 & 295 & c & 1539.63 & 7663.9 & $2.01 \mathrm{e}-01$ \\
\hline OYSTER CREEK & 219 & EDG-2 & 764.00 & 3955.8 & $1.93 \mathrm{e}-01$ \\
\hline MONTICELLO & 263 & 12 & 455.52 & 2363.1 & $1.93 \mathrm{e}-01$ \\
\hline GINNA & 244 & EDGB & 478.76 & 2490.1 & $1.92 \mathrm{e}-01$ \\
\hline BRAIDWOOD 1 & 456 & $1 \mathrm{~A}$ & 864.00 & 4586.8 & $1.88 \mathrm{e}-01$ \\
\hline DIABLO CANYON 1 & 275 & DEG1-2 & 384.00 & 2049.2 & $1.87 \mathrm{e}-01$ \\
\hline CRYSTAL RIVER 3 & 302 & $1 \mathrm{~A}$ & 696.00 & 3762.0 & $1.85 \mathrm{e}-01$ \\
\hline SAN ONOFRE 3 & 362 & DG3 & 527.85 & 2856.6 & $1.85 \mathrm{e}-01$ \\
\hline RIVER BEND & 458 & III & 1033.70 & 5622.7 & $1.84 \mathrm{e}-01$ \\
\hline INDIAN POINT 2 & 247 & 23EDG & 912.00 & 5068.6 & $1.80 \mathrm{e}-01$ \\
\hline OYSTER CREEK & 219 & EDG-1 & 710.00 & 3955.8 & $1.79 \mathrm{e}-01$ \\
\hline SOUTH TEXAS 1 & 498 & EDG13 & 865.50 & 4921.8 & $1.76 \mathrm{e}-01$ \\
\hline PERRY 1 & 440 & A & 947.75 & 5395.7 & $1.76 \mathrm{e}-01$ \\
\hline BRUNSWICK 1 & 325 & EDG2 & 1162.62 & 6666.0 & $1.74 \mathrm{e}-01$ \\
\hline ARKANSAS 2 & 368 & B & 554.94 & 3199.6 & $1.73 \mathrm{e}-01$ \\
\hline RIVER BEND & 458 & II & 969.70 & 5622.7 & $1.72 e-01$ \\
\hline WOLF CREEK 1 & 482 & $\mathbf{A}$ & 625.60 & 3685.1 & $1.70 \mathrm{e}-01$ \\
\hline SAN ONOFRE 1 & 206 & DG1 & 1237.35 & 7516.0 & $1.65 \mathrm{e}-01$ \\
\hline SOUTH TEXAS 1 & 498 & EDG11 & 805.50 & 4921.8 & $11.64 \mathrm{e}-01$ \\
\hline SAN ONOFRE 1 & 206 & $\mathrm{DG} 2$ & 1225.18 & 7516.0 & $1.63 \mathrm{e}-01$ \\
\hline SUMMER & 395 & B & 320.50 & 1973.0 & $1.62 \mathrm{e}-01$ \\
\hline ST. LUCIE 2 & 389 & $2 \mathrm{~A}$ & 480.00 & 2973.0 & $1.61 \mathrm{e}-01$ \\
\hline ROBINSON 2 & 261 & $\mathrm{~A}$ & 977.23 & 6076.5 & $1.61 \mathrm{e}-01$ \\
\hline BRUNSWICK 2 & 324 & EDG3 & 977.60 & 6211.7 & $1.57 \mathrm{e}-01$ \\
\hline BRUNSWICK 1 & 325 & EDG1 & 1041.60 & 6666.0 & $1.56 \mathrm{e}-01$ \\
\hline KEWAUNEE & 305 & DGA & 391.51 & 2509.7 & $1.56 \mathrm{e}-01$ \\
\hline WATERFORD 3 & 382 & B & 372.88 & 2477.9 & $1.50 \mathrm{e}-01$ \\
\hline
\end{tabular}


Table B.7. (Cont'd)

\begin{tabular}{|c|c|c|c|c|c|}
\hline Plant Name & $\begin{array}{l}\text { Docket } \\
\text { No }\end{array}$ & EDG ID & $\begin{array}{l}\text { Total EDG } \\
\text { OOS Hours }\end{array}$ & $\begin{array}{l}\text { Plant Off-line } \\
\text { Hours }\end{array}$ & $\begin{array}{l}\text { Unavail. due to } \\
\text { PM + CM }\end{array}$ \\
\hline BEAVER VALLEY 1 & 334 & EDG 1-1 & 650.75 & 4369.2 & $1.49 \mathrm{e}-01$ \\
\hline ZION 2 & 304 & C & 1208.54 & 8237.5 & $1.47 \mathrm{e}-01$ \\
\hline HATCH 1 & 321 & $A$ & 439.70 & 3006.2 & $1.46 \mathrm{e}-01$ \\
\hline HATCH 1 & 321 & $\mathrm{c}$ & 424.50 & 3006.2 & $1.41 \mathrm{e}-01$ \\
\hline DIABLO CANYON 2 & 323 & DEG1-3 & 207.70 & 1471.7 & $1.41 \mathrm{e}-01$ \\
\hline ST, LUCIE 2 & 389 & $2 \mathrm{~B}$ & 408.00 & 2973.0 & $1.37 \mathrm{e}-01$ \\
\hline PERRY 1 & 440 & B & 734.00 & 5395.7 & $1.36 \mathrm{e}-01$ \\
\hline ROBINSON 2 & 261 & $\mathrm{D} / \mathrm{s}$ & 814.00 & 6076.5 & $1.34 \mathrm{e}-01$ \\
\hline FORT CALHOUN & 285 & DG-1 & 528.00 & 3944.2 & $1.34 \mathrm{e}-01$ \\
\hline SOUTH TEXAS 2 & 499 & EDG21 & 642.50 & 4805.0 & $1.34 \mathrm{e}-01$ \\
\hline ROBINSON 2 & 261 & B & 788.50 & 6076.5 & $1.30 \mathrm{e}-01$ \\
\hline MCGUIRE 1 & 369 & $1 \mathrm{~A}$ & 611.50 & 4826.4 & $1.27 \mathrm{e}-01$ \\
\hline ZION 1 & 295 & $1 B$ & 916.74 & 7663.9 & $1.20 \mathrm{e}-01$ \\
\hline GRAND GULF & 416 & DG13 & 465.00 & 3997.4 & $1.16 \mathrm{e}-01$ \\
\hline SOUTH TEXAS 2 & 499 & EDG22 & 552.00 & 4805.0 & $1.15 \mathrm{e}-01$ \\
\hline FERMI 2 & 341 & EDG11 & 434.50 & 3792.6 & $1.15 \mathrm{e}-01$ \\
\hline QUAD CITIES 2 & 265 & $\mathrm{U} 1 / 2$ & 514.40 & 4490.4 & $1.15 \mathrm{e}-01$ \\
\hline WOLF CREEK 1 & 482 & B & 418.50 & 3685.1 & $1.14 \mathrm{e}-01$ \\
\hline BEAVER VALLEY 1 & 334 & EDG1-2 & 456.70 & 4369.2 & $1.05 \mathrm{e}-01$ \\
\hline SEABROOK 1 & 443 & $\mathrm{~A}$ & 296.00 & 2904.4 & $1.02 \mathrm{e}-01$ \\
\hline ZION 2 & 304 & $2 \mathrm{~A}$ & 839.43 & 8237.5 & $1.02 \mathrm{e}-01$ \\
\hline DIABLO CANYON 1 & 275 & DEG1-3 & 207.70 & 2049.2 & $1.01 \mathrm{e}-01$ \\
\hline HARRIS 1 & 400 & $1 \mathrm{~B}-\mathrm{SB}$ & 250.00 & 2476.6 & $1.01 \mathrm{e}-01$ \\
\hline MCGUIRE 1 & 369 & $1 \mathrm{~B}$ & 482.50 & 4826.4 & $1.00 \mathrm{e}-01$ \\
\hline THREE MILE ISLAND 1 & 289 & EDG-1B & 120.63 & 1223.4 & $9.86 \mathrm{e}-02$ \\
\hline ST. LUCIE 1 & 335 & $1 \mathrm{~A}$ & 240.00 & 2605.3 & $9.21 \mathrm{e}-02$ \\
\hline VOGTLE 1 & 424 & DG1B & 31.25 & 340.3 & $9.18 \mathrm{e}-02$ \\
\hline BRAIDWOOD 1 & 456 & 1B & 408.00 & 4586.8 & $8.90 \mathrm{e}-02$ \\
\hline SOUTH TEXAS 1 & 498 & EDG12 & 434.00 & 4921.8 & $8.82 \mathrm{e}-02$ \\
\hline ARKANSAS 2 & 368 & $A$ & 274.27 & 3199.6 & $8.57 \mathrm{e}-02$ \\
\hline HATCH 2 & 366 & $\mathrm{c}$ & 193.00 & 2268.0 & $8.51 \mathrm{e}-02$ \\
\hline
\end{tabular}


Table B.7. (Cont'd)

\begin{tabular}{|c|c|c|c|c|c|}
\hline Plant Name & $\begin{array}{c}\text { Docket } \\
\text { No }\end{array}$ & EDG ID & $\begin{array}{l}\text { Total EDG } \\
\text { OOS Hours }\end{array}$ & $\begin{array}{l}\text { Plant Off-line } \\
\text { Hours }\end{array}$ & $\begin{array}{l}\text { Unavail. due to } \\
\mathbf{P M}+\mathbf{C M}\end{array}$ \\
\hline VERMONT YANKEE & 271 & EDG B & 227.40 & 2819.0 & $8.07 \mathrm{e}-02$ \\
\hline BIG ROCK POINT & 155 & $A$ & 527.50 & 6644.8 & $7.94 \mathrm{e}-02$ \\
\hline SOUTH TEXAS 2 & 499 & EDG23 & 344.50 & 4805.0 & $7.17 \mathrm{e}-02$ \\
\hline HADDAM NECK & 213 & EG-2A & 447.88 & 6481.3 & $6.91 \mathrm{e}-02$ \\
\hline FERMI 2 & 341 & EDG13 & 243.50 & 3792.6 & $6.42 \mathrm{e}-02$ \\
\hline SURRY 1 & 280 & EDG3 & 208.57 & 3573.4 & $5.84 \mathrm{e}-02$ \\
\hline LASALLE 1 & 373 & $\mathbf{0}$ & 175.50 & 3081.9 & $5.69 \mathrm{e}-02$ \\
\hline FORT CALHOUN & 285 & DG-2 & 216.00 & 3944.2 & $5.48 \mathrm{e}-02$ \\
\hline ZION 2 & 304 & $2 \mathrm{~B}$ & 446.53 & 8237.5 & $5.42 \mathrm{e}-02$ \\
\hline HATCH 2 & 366 & A & 122.10 & 2268.0 & $5.38 \mathrm{e}-02$ \\
\hline FERMI 2 & 341 & EDG14 & 203.50 & 3792.6 & $5.37 \mathrm{e}-02$ \\
\hline ST. LUCIE 1 & 335 & 1B & 136.90 & 2605.3 & $5.25 \mathrm{e}-02$ \\
\hline SEQUOYAH 1 & 327 & BB & 167.55 & 3399.8 & $4.93 \mathrm{e}-02$ \\
\hline DRESDEN 3 & 249 & DG3 & 263.40 & 6757.2 & $3.90 \mathrm{e}-02$ \\
\hline SUMMER & 395 & $\mathrm{~A}$ & 76.90 & 1973.0 & $3.90 \mathrm{e}-02$ \\
\hline VOGTLE 1 & 424 & DG1A & 11.95 & 340.3 & $3.51 \mathrm{e}-02$ \\
\hline WASHINGTON NUCLEAR 2 & 397 & DIV III & 286.50 & 8188.7 & $3.50 \mathrm{e}-02$ \\
\hline FARLEY 1 & 348 & $1 \mathrm{~A}$ & 67.17 & 1965.9 & $3.42 \mathrm{e}-02$ \\
\hline HATCH 2 & 366 & B & 76.60 & 2268.0 & $3.38 \mathrm{e}-02$ \\
\hline WASHINGTON NUCLEAR 2 & 397 & DIV II & 276.50 & 8188.7 & $3.38 \mathrm{e}-02$ \\
\hline FARLEY 1 & 348 & $2 \mathrm{C}$ & 65.04 & 1965.9 & $3.31 \mathrm{e}-02$ \\
\hline DRESDEN 2 & 237 & DG2 & 227.20 & 7216.9 & $3.15 \mathrm{e}-02$ \\
\hline PILGRIM 1 & 293 & A & 96.00 & 3320.6 & $2.89 \mathrm{e}-02$ \\
\hline PILGRIM 1 & 293 & B & 96.00 & 3320.6 & $2.89 \mathrm{e}-02$ \\
\hline SEQUOYAH 1 & 327 & $\mathrm{AA}$ & 86.53 & 3399.8 & $2.55 \mathrm{e}-02$ \\
\hline QUAD CITIES 1 & 254 & $\mathrm{U} 1 / 2$ & 127.50 & 5555.5 & $2.30 \mathrm{e}-02$ \\
\hline SEABROOK 1 & 443 & B & 65.00 & 2904.4 & $2.24 \mathrm{e}-02$ \\
\hline LASALLE 2 & 374 & 0 & 75.77 & 3575.8 & $2.12 \mathrm{e}-02$ \\
\hline SURRY 2 & 281 & EDG3 & 74.61 & 3601.9 & $2.07 \mathrm{e}-02$ \\
\hline LIMERICK 2 & 353 & D23 & 62.18 & 3022.7 & $2.06 \mathrm{e}-02$ \\
\hline VOGTLE 2 & 425 & $\mathrm{DG} 2 \mathrm{~A}$ & 39.20 & 1942.9 & $2.02 \mathrm{e}-02$ \\
\hline
\end{tabular}


Table B.7. (Cont'd)

\begin{tabular}{|c|c|c|c|c|c|}
\hline Plant Name & $\begin{array}{c}\text { Docket } \\
\text { No }\end{array}$ & EDG ID & $\begin{array}{l}\text { Total EDG } \\
\text { OOS Hours }\end{array}$ & $\begin{array}{c}\begin{array}{c}\text { Plant Off-line } \\
\text { Hours }\end{array} \\
\end{array}$ & $\begin{array}{l}\text { Unavail. due to } \\
\mathbf{P M}+\mathbf{C M}\end{array}$ \\
\hline FARLEY 2 & 364 & $2 \mathrm{C}$ & 80.95 & 4057.3 & $2.00 \mathrm{e}-02$ \\
\hline LIMERICK 1 & 352 & D11 & 108.04 & 5493.3 & $1.97 \mathrm{e}-02$ \\
\hline VERMONT YANKEE & 271 & EDG A & 55.40 & 2819.0 & $1.97 e-02$ \\
\hline POINT BEACH 2 & 301 & G-01 & 40.95 & 2247.4 & $1.82 \mathrm{e}-02$ \\
\hline CALVERT CLIFFS 1 & 317 & 11 EDG & 67.07 & 3704.4 & $1.81 \mathrm{e}-02$ \\
\hline LASALLE 2 & 374 & $2 \mathrm{~A}$ & 64.33 & 3575.8 & $1.80 \mathrm{e}-02$ \\
\hline WASHINGTON NUCLEAR 2 & 397 & DIV I & 143.30 & 8188.7 & $1.75 \mathrm{e}-02$ \\
\hline SEQUOYAH 2 & 328 & BB & 62.96 & 3730.8 & $1.69 \mathrm{e}-02$ \\
\hline HADDAM NECK & 213 & EG-2B & 105.94 & 6481.3 & $1.63 \mathrm{e}-02$ \\
\hline PALO VERDE 2 & 529 & 2MDGBH01 & 58.00 & 3614.4 & $1.60 \mathrm{e}-02$ \\
\hline HATCH 1 & 321 & B & 44.40 & 3006.2 & $1.48 \mathrm{e}-02$ \\
\hline FARLEY 2 & 364 & $1 \mathrm{C}$ & 45.30 & 4057.3 & $1.12 \mathrm{e}-02$ \\
\hline FARLEY 2 & 364 & $2 \mathrm{~A}$ & 44.25 & 4057.3 & $1.09 \mathrm{e}-02$ \\
\hline SEQUOYAH 2 & 328 & $\mathrm{AA}$ & 39.50 & 3730.8 & $1.06 \mathrm{e}-02$ \\
\hline MAINE YANKEE & 309 & DG-1B & 47.00 & 4497.4 & $1.05 \mathrm{e}-02$ \\
\hline PRAIRIE ISLAND 2 & 306 & $\mathrm{D} 2$ & 12.40 & 1418.2 & $8.74 \mathrm{e}-03$ \\
\hline DRESDEN 3 & 249 & DG2/3 & 58.60 & 6757.2 & $8.67 \mathrm{e}-03$ \\
\hline PALO VERDE 3 & 530 & 3MDGAH01 & 23.60 & 2769.9 & $8.52 \mathrm{e}-03$ \\
\hline LASALLE 2 & 374 & $2 \mathrm{~B}$ & 29.50 & 3575.8 & $8.25 \mathrm{e}-03$ \\
\hline DRESDEN 2 & 237 & $\mathrm{DG} 2 / 3$ & 58.60 & 7216.9 & $8.12 \mathrm{e}-03$ \\
\hline MILLSTONE 3 & 423 & 3B & 49.33 & 6861.0 & $7.19 \mathrm{e}-03$ \\
\hline ARKANSAS 1 & 313 & B & 19.65 & 2947.5 & $6.67 e-03$ \\
\hline SUSQUEHANNA 2 & 388 & D & 14.53 & 2301.3 & $6.31 \mathrm{e}-03$ \\
\hline $\mathrm{COOK} 2$ & 316 & $2 \mathrm{AB}$ & 41.17 & 6566.9 & $6.27 e-03$ \\
\hline MILLSTONE 3 & 423 & $3 \mathrm{~A}$ & 39.82 & 6861.0 & $5.80 \mathrm{e}-03$ \\
\hline PALO VERDE 1 & 528 & 1MDGAHO1 & 24.50 & 4560.8 & $5.37 e-03$ \\
\hline PALISADES & 255 & DG1-1 & 32.52 & 6554.4 & $4.96 \mathrm{e}-03$ \\
\hline MILLSTONE 1 & 245 & $1 \mathrm{~A}$ & 38.38 & 8439.1 & $4.55 \mathrm{e}-03$ \\
\hline MAINE YANKEE & 309 & DG-1A & 20.00 & 4497.4 & $4.45 \mathrm{e}-03$ \\
\hline POINT BEACH 1 & 266 & $\mathrm{G}-02$ & 11.80 & 2672.0 & $4.42 \mathrm{e}-03$ \\
\hline $\mathrm{COOK} 2$ & 316 & $2 \mathrm{CD}$ & 28.78 & 6566.9 & $4.38 \mathrm{e}-03$ \\
\hline
\end{tabular}


Table B.7. (Cont'd)

\begin{tabular}{|c|c|c|c|c|c|}
\hline Plant Name & $\begin{array}{l}\text { Docket } \\
\text { No }\end{array}$ & EDG ID & $\begin{array}{l}\text { Total EDG } \\
\text { OOS Hours }\end{array}$ & $\begin{array}{l}\text { Plant Off-line } \\
\text { Hours }\end{array}$ & $\begin{array}{l}\text { Unavail, due to } \\
\mathbf{P M}+\mathbf{C M}\end{array}$ \\
\hline RIVER BEND & 458 & I & 22.50 & 5622.7 & $4.00 \mathrm{e}-03$ \\
\hline FITZPATRICK & 333 & 21 EDG & 23.71 & 7870.3 & $3.01 \mathrm{e}-03$ \\
\hline PALISADES & 255 & DG1-2 & 16.34 & 6554.4 & $2.49 \mathrm{e}-03$ \\
\hline SUSQUEHANNA 2 & 388 & $\mathbf{E}$ & 5.53 & 2301.3 & $2.40 e-03$ \\
\hline DIABLO CANYON 1 & 275 & DEG1-1 & 4.08 & 2049.2 & $1.99 \mathrm{e}-03$ \\
\hline COMANCHE PEAK 1 & 445 & $1-01$ & 1.50 & 4873.8 & $3.08 e-04$ \\
\hline LIMERICK 2 & 353 & $\mathrm{D} 21$ & 0.81 & 3022.7 & $2.68 \mathrm{e}-04$ \\
\hline PALO VERDE 1 & 528 & 1MDGBH01 & 0.40 & 4560.8 & $8.77 e-05$ \\
\hline & & & & AVERAGE* & $1.15 \mathrm{e}-01$ \\
\hline
\end{tabular}

*Average is obtained considering 170 EDGs. EDGs reporting zero 0OS hours due to both PM and CM are not included in this table. 
Table B.8. EDG Unavailability Due to Preventive and Corrective Maintenance, and Testing $\left(\mathrm{U}_{\mathrm{s}, \mathrm{PM}}, \mathrm{U}_{\mathrm{s}, \mathrm{CM}}\right.$, and $\left.\mathrm{U}_{\mathrm{s}, \mathrm{T}}\right)$ During Plant Shutdown

\begin{tabular}{|c|c|c|c|c|}
\hline Plant Name & EDG ID & $\begin{array}{c}\text { Unavail. due to } \\
\text { PM }\end{array}$ & $\begin{array}{c}\text { Unavail.due to } \\
\text { CM }\end{array}$ & $\begin{array}{c}\text { Unavail. due to } \\
\text { Test }\end{array}$ \\
\hline ARKANSAS 1 & A & $3.62 \mathrm{e}-01$ & & \\
\hline ARKANSAS 1 & B & $6.67 \mathrm{e}-03$ & & $8.48 \mathrm{e}-05$ \\
\hline ARKANSAS 2 & A & $5.41 \mathrm{e}-02$ & $3.16 \mathrm{e}-02$ & $4.06 \mathrm{e}-05$ \\
\hline ARKANSAS 2 & B & $2.78 \mathrm{e}-02$ & $1.46 \mathrm{e}-01$ & $3.61 \mathrm{e}-03$ \\
\hline BEAVER VALLEY 1 & EDGI-1 & $1.04 \mathrm{e}-01$ & $4.47 e-02$ & \\
\hline BEAVER VALLEY 1 & EDG1-2 & $7.31 \mathrm{e}-02$ & $3.15 \mathrm{e}-02$ & 1 \\
\hline BEAVER VALLEY 2 & EDG2-1 & $1.52 \mathrm{e}-01$ & $6.51 \mathrm{e}-02$ & \\
\hline BEAVER VALLEY 2 & EDG2-2 & $2.25 \mathrm{e}-01$ & $9.66 \mathrm{e}-02$ & \\
\hline BIG ROCK POINT & A & $7.94 e-02$ & & $2.41 \mathrm{e}-03$ \\
\hline BRAIDWOOD 1 & $1 \mathrm{~A}$ & $9.42 \mathrm{e}-02$ & $9.42 \mathrm{e}-02$ & $5.23 \mathrm{e}-03$ \\
\hline BRAIDWOOD 1 & $1 \mathrm{~B}$ & $4.45 \mathrm{e}-02$ & $4.45 e-02$ & $5.23 \mathrm{e}-03$ \\
\hline BRAIDWOOD 2 & $2 A$ & $1.28 \mathrm{e}-01$ & $1.28 \mathrm{e}-01$ & $1.91 \mathrm{e}-02$ \\
\hline BRAIDWOOD 2 & 2B & $1.47 \mathrm{e}-01$ & $1.34 \mathrm{e}-01$ & $9.18 \mathrm{e}-03$ \\
\hline BRUNSWICK 1 & EDG1 & $3.58 \mathrm{e}-02$ & $1.20 \mathrm{e}-01$ & $1.16 \mathrm{e}-03$ \\
\hline BRUNSWICK 1 & EDG2 & $8.75 e-02$ & $8.69 \mathrm{e}-02$ & \\
\hline BRUNSWICK 2 & EDG3 & $7.56 \mathrm{e}-02$ & $8.18 \mathrm{e}-02$ & $6.44 \mathrm{e}-04$ \\
\hline BRUNSWICK 2 & EDG4 & $8.38 \mathrm{e}-02$ & $2.11 \mathrm{e}-01$ & $1.36 \mathrm{e}-03$ \\
\hline CALLAWAY & $\mathrm{A}$ & $1.29 \mathrm{e}-01$ & $1.41 \mathrm{e}-01$ & $8.04 e-03$ \\
\hline CALLAWAY & $\mathbf{B}$ & $1.09 \mathrm{e}-01$ & $1.24 \mathrm{e}-01$ & $9.00 \mathrm{e}-03$ \\
\hline CALVERT CLIFFS 1 & $11 \mathrm{EDG}$ & $4.97 e-04$ & $1.76 \mathrm{e}-02$ & $6.75 \mathrm{e}-05$ \\
\hline CATAWBA 1 & $1 \mathrm{~A}$ & $3.37 \mathrm{e}-01$ & $1.88 \mathrm{e}-02$ & \\
\hline CATAWBA 1 & $1 \mathrm{~B}$ & $2.28 \mathrm{e}-01$ & $2.37 e-02$ & \\
\hline CATAWBA 2 & 2B & & $4.59 \mathrm{e}-01$ & \\
\hline COMANCHE PEAK 1 & $1-01$ & $3.08 \mathrm{e}-04$ & & $3.41 \mathrm{e}-03$ \\
\hline COMANCHE PEAK 1 & $1-02$ & & & $2.80 \mathrm{e}-03$ \\
\hline COOK 1 & $1 \mathrm{CD}$ & & & $1.41 \mathrm{e}-04$ \\
\hline COOK 2 & $2 \mathrm{AB}$ & & $6.27 \mathrm{e}-03$ & $6.09 \mathrm{e}-05$ \\
\hline COOK 2 & $2 \mathrm{CD}$ & & $4.38 \mathrm{e}-03$ & $2.83 e-03$ \\
\hline COOPER STATION & DG-1 & $2.16 \mathrm{e}-01$ & & \\
\hline COOPER STATION & DG-2 & $3.17 \dot{\mathrm{e}-01}$ & & \\
\hline
\end{tabular}


Table B.8. (Cont'd)

\begin{tabular}{|c|c|c|c|c|}
\hline Plant Name & EDG ID & $\begin{array}{l}\text { Unavail. due to } \\
\text { PM }\end{array}$ & $\begin{array}{l}\text { Unavail.due to } \\
\text { CM }\end{array}$ & $\begin{array}{c}\text { Unavail. due to } \\
\text { Test }\end{array}$ \\
\hline CRYSTAL RIVER 3 & $1 \mathrm{~A}$ & $1.85 \mathrm{e}-01$ & & \\
\hline CRYSTAL RIVER 3 & $1 \mathrm{~B}$ & $1.98 \mathrm{e}-01$ & $1.94 \mathrm{e}-02$ & \\
\hline DIABLO CANYON 1 & DEG1-1 & $1.99 \mathrm{e}-03$ & & 1 \\
\hline DIABLO CANYON 1 & DEG1-2 & $1.87 \mathrm{e}-01$ & & \\
\hline DIABLO CANYON 1 & DEG1-3 & $8.05 \mathrm{e}-02$ & $2.08 \mathrm{e}-02$ & \\
\hline DIABLO CANYON 2 & DEG1-3 & $1.12 \mathrm{e}-01$ & $2.90 \mathrm{e}-02$ & $2.24 \mathrm{e}-04$ \\
\hline DIABLO CANYON 2 & DEG2-1 & $4.57 \mathrm{e}-01$ & & \\
\hline DIABLO CANYON 2 & DEG2-2 & $3.59 \mathrm{e}-01$ & & \\
\hline DRESDEN 2 & DG2 & $2.15 \mathrm{e}-02$ & $9.94 \mathrm{e}-03$ & $4.89 e-03$ \\
\hline DRESDEN 2 & DG2/3 & $8.12 \mathrm{e}-03$ & & $2.77 e-04$ \\
\hline DRESDEN 3 & DG2/3 & $8.67 e-03$ & & $2.96 \mathrm{e}-04$ \\
\hline DRESDEN 3 & DG3 & $3.90 \mathrm{e}-02$ & & $2.07 \mathrm{e}-03$ \\
\hline FARLEY 1 & $1 \mathrm{~A}$ & & $3.42 \mathrm{e}-02$ & $9.51 \mathrm{e}-04$ \\
\hline FARLEY 1 & $1 \mathrm{C}$ & & & 9.51e-04 \\
\hline FARLEY 1 & $2 \mathrm{C}$ & $3.28 \mathrm{e}-02$ & $2.75 \mathrm{e}-04$ & \\
\hline FARLEY 2 & $1 \mathrm{C}$ & $1.12 \mathrm{e}-02$ & & $1.04 \mathrm{e}-04$ \\
\hline FARLEY 2 & $2 \mathrm{~A}$ & $1.09 \mathrm{e}-02$ & & $4.58 \mathrm{e}-04$ \\
\hline FARLEY 2 & $2 \mathrm{~B}$ & & & $8.13 e-05$ \\
\hline FARLEY 2 & $2 \mathrm{C}$ & & $2.00 \mathrm{e}-02$ & \\
\hline FERMI 2 & EDG11 & $1.15 \mathrm{e}-01$ & & \\
\hline FERMI 2 & EDG13 & $6.42 \mathrm{e}-02$ & & \\
\hline FERMI 2 & EDG14 & $4.96 \mathrm{e}-02$ & $4.09 \mathrm{e}-03$ & \\
\hline FITZPATRICK & $21 \mathrm{EDG}$ & $2.07 e-04$ & $2.81 \mathrm{e}-03$ & $5.34 \mathrm{e}-05$ \\
\hline FORT CALHOUN & DG-1 & $1.33 \mathrm{e}-01$ & $1.01 \mathrm{e}-03$ & \\
\hline FORT CALHOUN & DG-2 & $5.48 \mathrm{e}-02$ & & \\
\hline GINNA & EDGA & $2.04 \mathrm{e}-01$ & $6.10 \mathrm{e}-03$ & $2.24 \mathrm{e}-03$ \\
\hline GINNA & EDGB & $1.80 \mathrm{e}-01$ & $1.22 \mathrm{e}-02$ & $4.74 \mathrm{e}-04$ \\
\hline GRAND GULF & DG11 & $2.81 \mathrm{e}-01$ & & \\
\hline GRAND GULF & DG12 & $2.41 \mathrm{e}-01$ & & \\
\hline GRAND GULF & DG13 & $1.16 \mathrm{e}-01$ & & \\
\hline HADDAM NECK & EG-2A & $6.02 \mathrm{e}-02$ & $8.95 \mathrm{e}-03$ & $1.25 \mathrm{e}-03$ \\
\hline
\end{tabular}


Table B.8. (Cont'd)

\begin{tabular}{|c|c|c|c|c|}
\hline Plaut Name & EDG ID & $\begin{array}{c}\text { Unavail. due to } \\
\text { PM }\end{array}$ & $\begin{array}{l}\text { Unavail.due to } \\
\text { CM }\end{array}$ & $\begin{array}{c}\text { Unavail. due to } \\
\text { Test }\end{array}$ \\
\hline HADDAM NECK & EG-2B & $1.39 \mathrm{e}-02$ & $2.43 e-03$ & $2.03 \mathrm{e}-03$ \\
\hline HARRIS I & 1A-SA & $2.03 \mathrm{e}-01$ & $1.26 \mathrm{e}-02$ & $3.15 \mathrm{e}-03$ \\
\hline HARRIS 1 & 1B-SB & $1.01 \mathrm{e}-01$ & & $3.39 \mathrm{e}-03$ \\
\hline НАTCH 1 & $\mathrm{~A}$ & $1.46 \mathrm{e}-01$ & & $2.89 \mathrm{e}-03$ \\
\hline HATCH 1 & B & $1.40 \mathrm{e}-02$ & $7.98 \mathrm{e}-04$ & $4.32 \mathrm{e}-04$ \\
\hline НАТСН 1 & $\mathbf{C}$ & $1.41 \mathrm{e}-01$ & & $1.71 \mathrm{e}-02$ \\
\hline HATCH 2 & $\mathrm{~A}$ & $5.38 \mathrm{e}-02$ & & $8.82 \mathrm{e}-04$ \\
\hline HATCH 2 & B & $3.38 \mathrm{e}-02$ & & \\
\hline HATCH 2 & $\mathrm{c}$ & $8.51 \mathrm{e}-02$ & & $1.06 \mathrm{e}-03$ \\
\hline HOPE CREEK 1 & $\mathrm{~A}$ & & & $8.67 e-05$ \\
\hline HOPE CREEK 1 & c & & & $4.34 \mathrm{e}-05$ \\
\hline HOPE CREEK 1 & D & & & $4.34 \mathrm{e}-05$ \\
\hline INDIAN POINT 2 & 21EDG & $4.36 \mathrm{e}-01$ & & \\
\hline INDIAN POINT 2 & 22EDG & $2.10 \mathrm{e}-01$ & & \\
\hline INDIAN POINT 2 & 23EDG & $1.80 \mathrm{e}-01$ & & \\
\hline KEWAUNEE & DGA & $1.54 \mathrm{e}-01$ & $2.00 \mathrm{e}-03$ & \\
\hline KEWAUNEE & DGB & $2.67 e-01$ & & \\
\hline LASALLE 1 & 0 & $3.96 \mathrm{e}-02$ & $1.74 \mathrm{e}-02$ & \\
\hline LASALLE 2 & 0 & $5.94 \mathrm{e}-03$ & $1.52 \mathrm{e}-02$ & $7.06 \mathrm{e}-03$ \\
\hline LASALLE 2 & $2 \mathrm{~A}$ & $1.80 \mathrm{e}-02$ & & $3.56 \mathrm{e}-03$ \\
\hline LASALLE 2 & 2B & $8.25 \mathrm{e}-03$ & & \\
\hline LIMERICK 1 & D11 & & $1.97 \mathrm{e}-02$ & \\
\hline LIMERICK 2 & D21 & & $2.68 \mathrm{e}-04$ & \\
\hline LIMERICK 2 & D23 & $2.06 \mathrm{e}-02$ & & \\
\hline MAINE YANKEE & DG-1A & $4.45 \mathrm{e}-03$ & & \\
\hline MAINE YANKEE & DG-1B & $1.05 \mathrm{e}-02$ & & \\
\hline MCGUIRE 1 & $1 \mathrm{~A}$ & $1.27 \mathrm{e}-01$ & & \\
\hline MCGULRE 1 & IB & 9.95e-02 & $5.18 \mathrm{e}-04$ & \\
\hline MCGUIRE 2 & $2 \mathrm{~A}$ & $2.84 \mathrm{e}-01$ & & \\
\hline MCGUIRE 2 & $2 \mathrm{~B}$ & $2.42 \mathrm{e}-01$ & $2.65 \mathrm{e}-03$ & \\
\hline MILLSTONE 1 & $1 \mathrm{~A}$ & & $4.55 \mathrm{e}-03$ & \\
\hline
\end{tabular}


Table B.8. (Cont'd)

\begin{tabular}{|c|c|c|c|c|}
\hline Plant Name & EDG ID & $\begin{array}{c}\text { Unavail. due to } \\
\text { PM }\end{array}$ & $\begin{array}{c}\text { Unavail.due to } \\
\text { CM }\end{array}$ & $\begin{array}{c}\text { Unavail. due to } \\
\text { Test }\end{array}$ \\
\hline MILLSTONE 3 & $3 \mathrm{~A}$ & $4.81 \mathrm{e}-05$ & $5.76 \mathrm{e}-03$ & \\
\hline MILLSTONE 3 & 3B & $2.73 \mathrm{e}-03$ & $4.46 \mathrm{e}-03$ & \\
\hline MONTICELLO & 11 & $2.02 \mathrm{e}-01$ & $3.34 \mathrm{e}-02$ & \\
\hline MONTICELLO & 12 & $1.42 \mathrm{e}-01$ & $5.10 \mathrm{e}-02$ & \\
\hline OYSTER CREEK & EDG-1 & $1.79 \mathrm{e}-01$ & & \\
\hline OYSTER CREEK & EDG-2 & $1.82 \mathrm{e}-01$ & $1.09 \mathrm{e}-02$ & \\
\hline PALISADES & DG1-1 & $2.32 \mathrm{e}-03$ & $2.64 \mathrm{e}-03$ & $1.30 \mathrm{e}-03$ \\
\hline PALISADES & DG1-2 & $2.49 \mathrm{e}-03$ & & $2.44 \mathrm{e}-03$ \\
\hline PALO VERDE 1 & 1MDGAH01 & $5.37 \mathrm{e}-03$ & & \\
\hline PALO VERDE 1 & 1MDGBH01 & $8.77 \mathrm{e}-05$ & & \\
\hline PALO VERDE 2 & 2MDGBH01 & & $1.60 \mathrm{e}-02$ & \\
\hline PALO VERDE 3 & 3MDGAHOI & $8.52 \mathrm{e}-03$ & & \\
\hline PERRY 1 & $\mathrm{~A}$ & $1.51 \mathrm{e}-01$ & $2.42 \mathrm{e}-02$ & \\
\hline PERRY 1 & B & $1.36 \mathrm{e}-01$ & & \\
\hline PERRY 1 & $\mathrm{C}$ & $2.53 \mathrm{e}-01$ & & $1.35 \mathrm{e}-04$ \\
\hline PILGRIM 1 & A & & $2.89 \mathrm{e}-02$ & \\
\hline PILGRIM 1 & B & & $2.89 \mathrm{e}-02$ & \\
\hline POINT BEACH 1 & G-02 & & $4.42 \mathrm{e}-03$ & \\
\hline POINT BEACH 2 & G-01 & $1.82 \mathrm{e}-02$ & & \\
\hline PRAIRIE ISLAND 2 & D2 & $8.74 \mathrm{e}-03$ & & \\
\hline QUAD CITIES 1 & u1 & $3.02 \mathrm{e}-01$ & $2.57 \mathrm{e}-02$ & $4.86 \mathrm{e}-04$ \\
\hline QUAD CITIES 1 & $U 1 / 2$ & $2.34 \mathrm{e}-04$ & $2.27 \mathrm{e}-02$ & \\
\hline QUAD CITIES 2 & U1/2 & $8.28 \mathrm{e}-02$ & $3.18 \mathrm{e}-02$ & $2.69 \mathrm{e}-03$ \\
\hline QUAD CITIES 2 & $\mathrm{U} 2$ & $3.75 \mathrm{e}-01$ & $7.76 \mathrm{e}-02$ & $1.79 \mathrm{e}-02$ \\
\hline RIVER BEND & 1 & $4.00 \mathrm{e}-03$ & & \\
\hline RIVER BEND & II & $1.72 \mathrm{e}-01$ & & \\
\hline RIVER BEND & III & $1.84 \mathrm{e}-01$ & & \\
\hline ROBINSON 2 & $\mathrm{~A}$ & $1.61 \mathrm{e}-01$ & & $1.17 \mathrm{e}-01$ \\
\hline ROBINSON 2 & B & $1.14 \mathrm{e}-01$ & $1.59 \mathrm{e}-02$ & $5.63 \mathrm{e}-02$ \\
\hline ROBINSON 2 & $\mathrm{D} / \mathrm{S}$ & $5.48 \mathrm{e}-02$ & $7.92 \mathrm{e}-02$ & \\
\hline SAN ONOFRE 1 & DG1 & & $1.65 \mathrm{e}-01$ & $6.29 \mathrm{e}-03$ \\
\hline
\end{tabular}


Table B.8. (Cont'd)

\begin{tabular}{|c|c|c|c|c|}
\hline Plant Name & EDG ID & $\begin{array}{l}\text { Unavail. due to } \\
\text { PM }\end{array}$ & $\begin{array}{l}\text { Unavail.due to } \\
\text { CM }\end{array}$ & $\begin{array}{c}\text { Unavail. due to } \\
\text { Test }\end{array}$ \\
\hline SAN ONOFRE 1 & DG2 & & $1.63 \mathrm{e}-01$ & $3.21 \mathrm{e}-02$ \\
\hline SAN ONOFRE 2 & DG2 & $2.37 e-01$ & $1.14 \mathrm{e}-02$ & $4.45 e-03$ \\
\hline SAN ONOFRE 2 & DG3 & $1.52 \mathrm{e}-02$ & $2.93 \mathrm{e}-01$ & $1.03 e-03$ \\
\hline SAN ONOFRE 3 & DG2 & $1.99 \mathrm{e}-01$ & $1.31 \mathrm{e}-02$ & $3.68 \mathrm{e}-04$ \\
\hline SAN ONOFRE 3 & DG3 & $1.53 \mathrm{e}-01$ & $3.21 \mathrm{e}-02$ & $2.56 \mathrm{e}-04$ \\
\hline SEABROOK 1 & A & $1.02 \mathrm{e}-01$ & & \\
\hline SEABROOK 1 & B & $2.24 \mathrm{e}-02$ & & \\
\hline SEQUOYAH 1 & AA & $1.37 \mathrm{e}-02$ & $1.17 e-02$ & $3.10 \mathrm{e}-03$ \\
\hline SEQUOYAH 1 & BB & $1.82 \mathrm{e}-02$ & $3.11 e-02$ & $1.94 \mathrm{e}-03$ \\
\hline SEQUOYAH 2 & $\mathrm{AA}$ & $9.02 \mathrm{e}-03$ & $1.57 \mathrm{e}-03$ & $2.55 \mathrm{e}-03$ \\
\hline SEQUOYAH 2 & BB & $1.60 \mathrm{e}-02$ & $9.17 \mathrm{e}-04$ & $4.17 \mathrm{e}-03$ \\
\hline SOUTH TEXAS 1 & EDG11 & $4.83 \mathrm{e}-02$ & $1.15 \mathrm{e}-01$ & \\
\hline SOUTH TEXAS 1 & EDG12 & & $8.82 \mathrm{e}-02$ & \\
\hline SOUTH TEXAS 1 & EDG13 & $1.46 \mathrm{e}-01$ & $2.96 \mathrm{e}-02$ & \\
\hline SOUTH TEXAS 2 & EDG21 & $9.21 \mathrm{e}-02$ & $4.16 \mathrm{e}-02$ & \\
\hline SOUTH TEXAS 2 & EDG22 & $6.64 \mathrm{e}-02$ & $4.84 \mathrm{e}-02$ & $1.10 \mathrm{e}-01$ \\
\hline SOUTH TEXAS 2 & EDG23 & $2.01 \mathrm{e}-02$ & $5.16 \mathrm{e}-02$ & \\
\hline ST. LUCIE 1 & $1 \mathrm{~A}$ & & $9.21 \mathrm{e}-02$ & \\
\hline ST. LUCIE 1 & $1 \mathrm{~B}$ & & $5.25 \mathrm{e}-02$ & \\
\hline ST. LUCIE 2 & $2 \mathrm{~A}$ & & $1.61 \mathrm{e}-01$ & \\
\hline ST. LUCIE 2 & 2B & & $1.37 e-01$ & \\
\hline SUMMER & $A$ & & $3.90 \mathrm{e}-02$ & \\
\hline SUMMER & B & $1.62 \mathrm{e}-01$ & & \\
\hline SURRY 1 & EDG3 & $5.84 \mathrm{e}-02$ & & $2.95 \mathrm{e}-03$ \\
\hline SURRY 2 & EDG3 & $4.94 \mathrm{e}-04$ & $2.02 \mathrm{e}-02$ & $4.64 \mathrm{e}-03$ \\
\hline SUSQUEHANNA 2 & D & & $6.31 \mathrm{e}-03$ & \\
\hline SUSQUEHANNA 2 & E & $2.40 \mathrm{e}-03$ & & \\
\hline THREE MILE ISLAND 1 & EDG-1A & & & $8.56 \mathrm{e}-03$ \\
\hline THREE MILE ISLAND I & EDG-1B & & $9.86 \mathrm{e}-02$ & $1.88 \mathrm{e}-03$ \\
\hline VERMONT YANKEE & EDG A & $1.97 \mathrm{e}-02$ & & $3.19 \mathrm{e}-03$ \\
\hline VERMONT YANKEE & EDG B & $6.79 \mathrm{e}-02$ & $1.27 \mathrm{e}-02$ & $9.54 \mathrm{e}-03$ \\
\hline
\end{tabular}


Table B.8. (Cont'd)

\begin{tabular}{|c|c|c|c|c|}
\hline Plant Name & EDG ID & $\begin{array}{l}\text { Unavail. due to } \\
\text { PM }\end{array}$ & $\begin{array}{l}\text { Unavail.due to } \\
\text { CM }\end{array}$ & $\begin{array}{c}\text { Unavail. due to } \\
\text { Test }\end{array}$ \\
\hline VOGTLE 1 & DGlA & & $3.51 \mathrm{e}-02$ & \\
\hline VOGTLE 1 & DG1B & & $9.18 \mathrm{e}-02$ & \\
\hline VOGTLE 2 & DG2A & & $2.02 e-02$ & \\
\hline WASHINGTON NUCLEAR 2 & DIV I & 0.00 & $1.75 \mathrm{e}-02$ & $1.71 \mathrm{e}-03$ \\
\hline WASHINGTON NUCLEAR 2 & DIV II & $1.95 \mathrm{e}-03$ & $3.18 \mathrm{e}-02$ & $2.93 e-03$ \\
\hline WASHINGTON NUCLEAR 2 & DIV III & 0.00 & $3.50 \mathrm{e}-02$ & $1.47 e-03$ \\
\hline WATERFORD 3 & A & $8.64 e-02$ & $1.58 \mathrm{e}-01$ & \\
\hline WATERFORD 3 & B & $1.50 \mathrm{e}-01$ & & \\
\hline WOLF CREEK 1 & A & $1.37 \mathrm{e}-01$ & $3.29 \mathrm{e}-02$ & $1.90 \mathrm{e}-03$ \\
\hline WOLF CREEK 1 & B & $1.05 \mathrm{e}-01$ & $8.49 \mathrm{e}-03$ & \\
\hline ZION 1 & IA & 3. $17 \mathrm{i}-01$ & $7.79 e-02$ & \\
\hline ZION 1 & 1B & $7.31 \mathrm{e}-02$ & $4.65 e-02$ & \\
\hline ZION 1 & C & $2.54 \mathrm{e}-02$ & $1.76 \mathrm{e}-01$ & \\
\hline ZION 2 & $2 \mathrm{~A}$ & $2.80 \mathrm{e}-02$ & $7.39 \mathrm{e}-02$ & \\
\hline ZION 2 & $2 \mathrm{~B}$ & $4.16 \mathrm{e}-02$ & $1.26 \mathrm{e}-02$ & \\
\hline ZION 2 & $\mathbf{C}$ & $3.60 \mathrm{e}-03$ & $1.43 \mathrm{e}-01$ & \\
\hline Average* & & $8.34 \mathrm{e}-02$ & $3.24 e-02$ & $7.11 \mathrm{e}-03$ \\
\hline
\end{tabular}

*Averages for PM and CM unavailability are obtained considering 170 EDGs. Average test unavailability is estimated considering those EDGs reporting test data, i.e., 75 EDGs. 
APPENDIX C

EDG FAILURE DATA*

"Letter from A. Marion, NUMARC to H. Lewis, ACRS, Industry-Wide Data on Emergency Diesel Generator Performance. 
This appendix presents the Diesel failure data we used; a summary of data for each diesel and all the diesels in each plant site is presented. In the tables, the data for each diesel and diesels in each plant site were summed over four calendar years (1988-1991). Data were available for each year. Table C. 1 presents the data for individual diesels. Table C.2 gives data for each plant site, where the failure data from all the diesels are summed.

Headings in the tables of this appendix are to be interpreted as follows:

Plant Site

$=\quad$ Designation for a given plant site

DG ID

$=\quad$ Diesel identification

Total Start

$=\quad$ Number of starts for an individual diesel or for the diesels in a plant site summed over 1988-1991

Total Loads $\quad=\quad$ Number of loads for an individual diesel or for the diesels in a plant site summed over 1988-1991

Total Start Failure $\quad=\quad$ Number of start failures for an individual diesel or for the diesels in a plant site summed over 1988-1991

Total Load-Run Failure $=$

Number of load-run failures for an individual diesel or for the diesels in a plant site summed over 1988-1991 
Table C. 1. Failure Data of Individual Diesels

(Data Period: 1988-1991)

\begin{tabular}{|c|c|c|c|c|c|}
\hline Plant Site & DG ID & Total Start & $\begin{array}{l}\text { Total } \\
\text { Loads }\end{array}$ & $\begin{array}{l}\text { Total Start } \\
\text { Failure }\end{array}$ & $\begin{array}{c}\text { Total Load-Run } \\
\text { Failure }\end{array}$ \\
\hline 1 & A & 223 & 187 & 1 & 4 \\
\hline 1 & B & 221 & 184 & 0 & 3 \\
\hline 1 & $\mathrm{C}$ & 190 & 160 & 0 & 1 \\
\hline 1 & $\mathrm{D}$ & 208 & 175 & 2 & 3 \\
\hline 1 & $\mathrm{E}$ & $169 \quad$ & 148 & 0 & 0 \\
\hline 2 & $\mathrm{~A}$ & 119 & 81 & 0 & 0 \\
\hline 2 & $\mathrm{~B}$ & 90 & 63 & 1 & 1 \\
\hline 2 & $\mathrm{C}$ & 108 & 104 & 0 & 0 \\
\hline 2 & $\mathrm{D}$ & 131 & 125 & 1 & 1 \\
\hline 3 & A & 125 & 93 & 0 & 0 \\
\hline 3 & $\mathrm{~B}$ & 128 & 101 & 0 & 1 \\
\hline 3 & $\mathrm{C}$ & 151 & 110 & 0 & 0 \\
\hline 3 & $\mathrm{D}$ & 171 & 107 & 0 & 0 \\
\hline 3 & $\mathrm{E}$ & 140 & 104 & 0 & 4 \\
\hline 3 & $\mathrm{~F}$ & 142 & 103 & 0 & 0 \\
\hline 4 & $\mathbf{A}$ & 89 & 81 & 0 & 0 \\
\hline 4 & $\mathrm{~B}$ & 83 & 76 & 1 & 5 \\
\hline 5 & A & 190 & 163 & 0 & 2 \\
\hline 5 & $\mathrm{~B}$ & 307 & 233 & 0 & 0 \\
\hline 5 & $\mathrm{C}$ & 168 & 146 & 1 & 1 \\
\hline 6 & A & 79 & 69 & 0 & 0 \\
\hline 6 & $\mathrm{~B}$ & 72 & 61 & 0 & 1 \\
\hline 6 & $\mathrm{C}$ & 80 & 72 & 0 & 1 \\
\hline 7 & $\mathrm{~A}$ & 239 & 65 & 5 & 0 \\
\hline 8 & A & 152 & 91 & 1 & 2 \\
\hline
\end{tabular}


Table C.1. (Cont'd)

\begin{tabular}{|c|c|c|c|c|c|}
\hline Plant Site & DG ID & Total Start & $\begin{array}{l}\text { Total } \\
\text { Loads } \\
\end{array}$ & $\begin{array}{c}\text { Total Start } \\
\text { Failure }\end{array}$ & $\begin{array}{c}\text { Total Load-Run } \\
\text { Failure } \\
\end{array}$ \\
\hline 8 & B & 131 & 75 & 0 & 0 \\
\hline 9 & A & 170 & 133 & 1 & 0 \\
\hline 9 & B & 195 & 149 & 2 & 2 \\
\hline 9 & $\mathrm{C}$ & 168 & 141 & 1 & 1 \\
\hline 9 & D & 184 &, 151 & 1 & 1 \\
\hline 10 & A & 105 & 97 & 1 & 1 \\
\hline 10 & B & 109 & 104 & 1 & 1 \\
\hline 11 & A & 149 & 113 & 2 & 4 \\
\hline 11 & B & 122 & 98 & 1 & 0 \\
\hline 11 & $\mathrm{C}$ & 122 & 100 & 0 & 4 \\
\hline 11 & D & 110 & 77 & 0 & 0 \\
\hline 12 & A & 92 & 91 & 0 & 1 \\
\hline 12 & B & 110 & 104 & 2 & 1 \\
\hline 12 & $\mathrm{C}$ & 93 & 92 & 0 & 0 \\
\hline 13 & A & 177 & 105 & 0 & 1 \\
\hline 13 & B & 243 & 105 & 0 & 1 \\
\hline 13 & $\mathrm{C}$ & 181 & 104 & 3 & 0 \\
\hline 13 & $\mathrm{D}$ & 183 & 56 & 0 & 0 \\
\hline 13 & $\mathrm{E}$ & 134 & 61 & 0 & 1 \\
\hline 14 & A & 118 & 107 & 3 & 1 \\
\hline 14 & B & 131 & 148 & 3 & 2 \\
\hline 14 & $\mathrm{C}$ & 114 & 103 & 2 & 2 \\
\hline 15 & A & 270 & 236 & 7 & 5 \\
\hline 15 & $\mathrm{~B}$ & 203 & 188 & 2 & 1 \\
\hline 15 & $\mathrm{C}$ & 196 & 183 & 1 & 3 \\
\hline 15 & D & 290 & 260 & 2 & 3 \\
\hline
\end{tabular}


Table C.1. (Cont'd)

\begin{tabular}{|c|c|c|c|c|c|}
\hline Plant Site & DG ID & Total Start & $\begin{array}{l}\text { Total } \\
\text { Loads } \\
\end{array}$ & $\begin{array}{c}\text { Total Start } \\
\text { Failure }\end{array}$ & $\begin{array}{c}\text { Total Load-Run } \\
\text { Failure }\end{array}$ \\
\hline 15 & $\mathbf{E}$ & 284 & .253 & 3 & 2 \\
\hline 16 & $\mathrm{~A}$ & 89 & 80 & 0 & 0 \\
\hline 16 & B & 86 & 82 & 0 & 0 \\
\hline 16 & $\mathrm{C}$ & 92 & 85 & 0 & 0 \\
\hline 16 & $\mathrm{D}$ & 81 & 74 & 1 & 1 \\
\hline 17 & A & 162 & 58 & 0 & 0 \\
\hline 17 & B & 149 & 54 & 0 & 1 \\
\hline 17 & $\mathrm{C}$ & 117 & 61 & 0 & 2 \\
\hline 17 & D & 113 & 52 & 0 & 0 \\
\hline 18 & A & 168 & 136 & 2 & 5 \\
\hline 18 & B & 145 & 107 & 0 & 0 \\
\hline 18 & $\mathrm{C}$ & 137 & 95 & 2 & 2 \\
\hline 18 & $\mathrm{D}$ & 138 & 95 & 2 & 1 \\
\hline 19 & $\mathrm{~A}$ & 166 & 93 & 2 & 1 \\
\hline 19 & $\mathbf{B}$ & 171 & 94 & 1 & 1 \\
\hline 19 & $\mathrm{C}$ & 150 & 101 & 1 & 3 \\
\hline 19 & $\mathrm{D}$ & 230 & 180 & 5 & 2 \\
\hline 20 & A & 122 & 109 & 0 & 1 \\
\hline 20 & B & 130 & 109 & 1 & 0 \\
\hline 21 & A & 174 & 58 & 2 & 3 \\
\hline 21 & $\mathrm{~B}$ & 185 & 63 & 1 & 4 \\
\hline 21 & $\mathrm{C}$ & 198 & 92 & 1 & 1 \\
\hline 21 & $\mathrm{D}$ & 199 & 104 & 2 & 1 \\
\hline 22 & A & 161 & 132 & 1 & 0 \\
\hline 22 & $\mathrm{~B}$ & 131 & 106 & 2 & 0 \\
\hline 23 & A & 68 & 68 & 0 & 0 \\
\hline
\end{tabular}


Table C.1. (Cont'd)

\begin{tabular}{|c|c|c|c|c|c|}
\hline Plant Site & DG ID & Total Start & $\begin{array}{l}\text { Total } \\
\text { Loads }\end{array}$ & $\begin{array}{c}\text { Total Start } \\
\text { Failure }\end{array}$ & $\begin{array}{c}\text { Total Load-Run } \\
\text { Failure }\end{array}$ \\
\hline 23 & B & 113 & 108 & 2 & 1 \\
\hline 23 & $\mathrm{C}$ & 62 & 60 & 1 & 0 \\
\hline 23 & D & 75 & 73 & 1 & 0 \\
\hline 23 & $\mathrm{E}$ & 63 & 61 & 0 & 0 \\
\hline 24 & A & 192 & 150 & 0 & 0 \\
\hline 24 & B & 198 & 152 & 1 & 2 \\
\hline 25 & A & 175 & 78 & 0 & 1 \\
\hline 25 & B & 163 & 74 & 0 & 2 \\
\hline 26 & A & 119 & 103 & 0 & 2 \\
\hline 26 & B & 86 & 73 & 0 & 0 \\
\hline 26 & $\mathrm{C}$ & 135 & 118 & 2 & 0 \\
\hline 27 & A & 54 & 52 & 0 & 0 \\
\hline 27 & B & 52 & 49 & 0 & 0 \\
\hline 28 & A & 89 & 66 & 1 & 0 \\
\hline 28 & B & 94 & 66 & 2 & 0 \\
\hline 28 & $\mathrm{C}$ & 86 & 73 & 2 & 0 \\
\hline 28 & $\mathrm{D}$ & 93 & 78 & 1 & 0 \\
\hline 29 & A & 151 & 63 & 1 & 1 \\
\hline 29 & B & 131 & 54 & 0 & 1 \\
\hline 30 & A & 71 & 57 & 1 & 0 \\
\hline 30 & B & 71 & 58 & 0 & 0 \\
\hline 31 & A & 145 & 118 & 0 & 0 \\
\hline 31 & B & 100 & 78 & 0 & 1 \\
\hline 32 & $\mathrm{~A}$ & 154 & 119 & 1 & 0 \\
\hline 32 & B & 104 & 80 & 0 & 0 \\
\hline 32 & $\mathrm{C}$ & 152 & 111 & 1 & 0 \\
\hline
\end{tabular}


Table C.1. (Cont'd)

\begin{tabular}{|c|c|c|c|c|c|}
\hline Plant Site & DG ID & Total Start & $\begin{array}{l}\text { Total } \\
\text { Loads }\end{array}$ & $\begin{array}{c}\text { Total Start } \\
\text { Failure }\end{array}$ & $\begin{array}{c}\text { Total Load-Run } \\
\text { Failure }\end{array}$ \\
\hline 33 & $\mathrm{~A}$ & 96 & 68 & 0 & 2 \\
\hline 33 & B & 75 & 66 & 0 & 2 \\
\hline 34 & $\mathrm{~A}$ & 73 & 63 & 0 & 2 \\
\hline 34 & B & 75 & 69 & 0 & 0 \\
\hline 35 & A & 124 & 119 & 0 & 0 \\
\hline 35 & B & 128 & 123 & 0 & 0 \\
\hline 36 & A & 157 & 60 & 0 & 2 \\
\hline 36 & B & 157 & 72 & 1 & 2 \\
\hline 37 & A & 82 & 68 & 0 & 1 \\
\hline 37 & B & 104 & 84 & 0 & 0 \\
\hline 37 & $\mathrm{C}$ & 99 & 79 & 1 & 1 \\
\hline 37 & $\mathrm{D}$ & 99 & 89 & 1 & 2 \\
\hline 38 & A & 270 & 260 & 0 & 0 \\
\hline 38 & $\mathrm{~B}$ & 259 & 250 & 0 & 0 \\
\hline 38 & $\mathrm{C}$ & 254 & 249 & 1 & 0 \\
\hline 38 & $\mathrm{D}$ & 245 & 237 & 0 & 0 \\
\hline 39 & A & 67 & 56 & 0 & 0 \\
\hline 39 & $\mathrm{~B}$ & 72 & 65 & 0 & 0 \\
\hline 39 & $\mathrm{C}$ & 72 & 65 & 0 & 1 \\
\hline 39 & $\mathrm{D}$ & 74 & 67 & 1 & 0 \\
\hline 40 & $\mathrm{~A}$ & 270 & 77 & 1 & 1 \\
\hline 40 & B : & 290 & 88 & 1 & 2 \\
\hline 40 & $\mathrm{C}$ & 320 & 89 & 5 & 1 \\
\hline 40 & $\mathrm{D}$ & 383 & 145 & 0 & 4 \\
\hline 40 & $E$ & 365 & 157 & 0 & 5 \\
\hline 40 & $\mathrm{~F}$ & 400 & 148 & 1 & 0 \\
\hline
\end{tabular}


Table C.1. (Cont'd)

\begin{tabular}{|c|c|c|c|c|c|}
\hline Plant Site & DG ID & Total Start & $\begin{array}{l}\text { Total } \\
\text { Loads } \\
\end{array}$ & $\begin{array}{c}\text { Total Start } \\
\text { Failure }\end{array}$ & $\begin{array}{c}\text { Total Load-Run } \\
\text { Failure }\end{array}$ \\
\hline 41 & A & 153 & 80 & 2 & 1 \\
\hline 41 & B & 132 & 71 & 1 & 1 \\
\hline 42 & A & 195 & 83 & 0 & 1 \\
\hline 42 & B & 200 & 81 & 1 & 1 \\
\hline 42 & $\mathrm{C}$ & 238 & 78 & 0 & 0 \\
\hline 42 & $\mathrm{D}$ & 170 & 73 & 0 & 0 \\
\hline 42 & $\mathrm{E}$ & 168 & 70 & 0 & 0 \\
\hline 43 & A & 166 & 70 & 0 & 2 \\
\hline 43 & $\mathrm{~B}$ & 181 & 69 & 1 & 2 \\
\hline 43 & $\mathrm{C}$ & 186 & 77 & 2 & 1 \\
\hline 44 & A & 100 & 62 & 0 & 0 \\
\hline 44 & B & 104 & 64 & 0 & 0 \\
\hline 44 & $\mathrm{C}$ & 100 & 62 & 0 & 0 \\
\hline 44 & D & 104 & 64 & 0 & 0 \\
\hline 45 & A & 85 & 84 & 2 & 0 \\
\hline 45 & $\mathrm{~B}$ & 81 & 79 & 0 & 1 \\
\hline 45 & $\mathrm{C}$ & 80 & 77 & 0 & 0 \\
\hline 45 & $\mathrm{D}$ & 71 & 70 & 0 & 0 \\
\hline 45 & $\underline{E}$ & 112 & 109 & 0 & 0 \\
\hline 46 & A & 81 & 67 & 0 & 0 \\
\hline 46 & $\mathrm{~B}$ & 84 & 69 & 1 & 0 \\
\hline 47 & $\mathrm{~A}$ & 159 & 80 & 0 & 0 \\
\hline 47 & $\mathrm{~B}$ & 171 & 105 & 0 & 3 \\
\hline 48 & A & 151 & 83 & 0 & 0 \\
\hline 48 & $\mathrm{~B}$ & 122 & 70 & 0 & 1 \\
\hline 48 & $\mathrm{C}$ & 100 & 48 & 0 & 0 \\
\hline
\end{tabular}


Table C.1. (Cont'd)

\begin{tabular}{|c|c|c|c|c|c|}
\hline Plant Site & DG ID & Total Start & $\begin{array}{l}\text { Total } \\
\text { Loads }\end{array}$ & $\begin{array}{c}\text { Total Start } \\
\text { Failure }\end{array}$ & $\begin{array}{c}\text { Total Load-Run } \\
\text { Failure }\end{array}$ \\
\hline 48 & D & 113 & 69 & 2 & 3 \\
\hline 48 & $\mathrm{E}$ & 102 & 64 & 1 & 3 \\
\hline 48 & F & 85 & 48 & 0 & 0 \\
\hline 49 & $\mathbf{A}$ & 195 & 139 & 0 & 5 \\
\hline 49 & B & 152 & 82 & 0 & 0 \\
\hline 49 & C & 140 & 83 & 0 & 1 \\
\hline 50 & A & 102 & 60 & 0 & 0 \\
\hline 50 & B & 122 & 70 & 3 & 2 \\
\hline 51 & A & 79 & 65 & 0 & 1 \\
\hline 51 & B & 74 & 56 & 1 & 0 \\
\hline 52 & A & 87 & 76 & 1 & 1 \\
\hline 52 & B & 79 & 70 & 0 & 0 \\
\hline 52 & $\mathrm{C}$ & 84 & 75 & 0 & 1 \\
\hline 52 & $\mathrm{D}$ & 86 & 74 & 0 & 0 \\
\hline 53 & $\mathbf{A}$ & 112 & 100 & 0 & 1 \\
\hline 53 & B & 106 & 86 & 1 & 0 \\
\hline 53 & C & 122 & 103 & 1 & 0 \\
\hline 54 & A & 90 & 86 & 0 & 0 \\
\hline 54 & $\dot{\mathbf{B}}$ & 96 & 95 & 1 & 0 \\
\hline 55 & A & 126 & 72 & 0 & 0 \\
\hline 55 & $\mathrm{~B}$ & 118 & 78 & 0 & 2 \\
\hline 56 & $\mathrm{~A}$ & 179 & 170 & 0 & 0 \\
\hline 56 & $\mathrm{~B}$ & 169 & 164 & 0 & 0 \\
\hline 57 & A & 125 & 85 & 0 & 1 \\
\hline 57 & $\mathrm{~B}$ & 148 & 82 & 0 & 0 \\
\hline 57 & $\mathrm{C}$ & 170 & 96 & 1 & 1 \\
\hline
\end{tabular}


Table C.1. (Cont'd)

\begin{tabular}{|c|c|c|c|c|c|}
\hline Plant Site & DG ID & Total Start & $\begin{array}{l}\text { Total } \\
\text { Loads } \\
\end{array}$ & $\begin{array}{c}\text { Total Start } \\
\text { Failure }\end{array}$ & $\begin{array}{c}\text { Total Load-Run } \\
\text { Failure }\end{array}$ \\
\hline 58 & A & 68 & 47 & 0 & 0 \\
\hline 58 & B & 83 & 45 & 0 & 0 \\
\hline 59 & A & 326 & 158 & 5 & 1 \\
\hline 59 & B & 331 & 154 & 0 & 1 \\
\hline 59 & $\mathrm{C}$ & 324 & 154 & 1 & 0 \\
\hline 60 & A & 157 & 132 & 0 & 1 \\
\hline 60 & $\mathrm{~B}$ & 145 & 119 & 0 & 1 \\
\hline 60 & $\mathrm{C}$ & 148 & 136 & 1 & 0 \\
\hline 61 & A & 85 & 73 & 3 & 0 \\
\hline 61 & B & 120 & 110 & 2 & 1 \\
\hline 62 & $\mathrm{~A}$ & 163 & 139 & 1 & 2 \\
\hline 62 & B & 148 & 139 & 0 & $3^{\prime}$ \\
\hline 63 & A & 177 & 108 & 0 & 0 \\
\hline 63 & B & 138 & 104 & 0 & 0 \\
\hline
\end{tabular}


Table C.2. Diesel Failure Data Aggregated for Plant Sites

\begin{tabular}{|c|c|c|c|c|}
\hline Plant Sites & Total Start & Total Loads & Total Start Failure & $\begin{array}{c}\text { Total Load-Run } \\
\text { Failure }\end{array}$ \\
\hline 1 & 1011 & 854 & 3 & 11 \\
\hline 2 & 448 & 373 & 2 & 2 \\
\hline 3 & 857 & 618 & 0 & 5 \\
\hline 4 & 172 & 157 & 1 & 5 \\
\hline 5 & 665 & 542 & 1 & 3 \\
\hline 6 & 231 & 202 & 0 & 2 \\
\hline 7 & 239 & 65 & 5 & 0 \\
\hline 8 & 283 & 166 & 1 & 2 \\
\hline 9 & 717 & 574 & 5 & 4 \\
\hline 10 & 214 & 201 & 2 & 2 \\
\hline 11 & 503 & 388 & 3 & 8 \\
\hline 12 & 295 & 287 & 2 & 2 \\
\hline 13 & 918 & 431 & 3 & 3 \\
\hline 14 & 363 & 358 & 8 & 5 \\
\hline 15 & 1243 & 1120 & 15 & 14 \\
\hline 16 & 348 & 321 & 1 & 1 \\
\hline 17 & 541 & 225 & 0 & 3 \\
\hline 18 & 588 & 433 & 6 & 8 \\
\hline 19 & 717 & 468 & 9 & 7 \\
\hline 20 & 252 & 218 & 1 & 1 \\
\hline 21 & 756 & 317 & 6 & 9 \\
\hline 22 & 292 & 238 & 3 & 0 \\
\hline 23 & 381 & 370 & 4 & 1 \\
\hline 24 & 390 & 302 & 1 & 2 \\
\hline 25 & 338 & 152 & 0 & 3 \\
\hline 26 & 340 & 294 & 2 & 2 \\
\hline 27 & 106 & 101 & 0 & 0 \\
\hline
\end{tabular}

C-10 
Table C.2. (Cont'd)

\begin{tabular}{|c|c|c|c|c|}
\hline Plant Sites & Total Start & Total Loads & Total Start Failure & $\begin{array}{c}\text { Total Load-Run } \\
\text { Failure } \\
\end{array}$ \\
\hline 28 & 362 & 283 & 6 & 0 \\
\hline 29 & 282 & 117 & 1 & 2 \\
\hline 30 & 142 & 115 & 1 & 0 \\
\hline 31 & 245 & 196 & 0 & 1 \\
\hline 32 & 410 & 310 & 2 & 0 \\
\hline 33 & 171 & 134 & 0 & 4 \\
\hline 34 & 148 & 132 & 0 & 2 \\
\hline 35 & 252 & 242 & 0 & 0 \\
\hline 36 & 314 & 132 & 1 & 4 \\
\hline 37 & 384 & 320 & 2 & 4 \\
\hline 38 & 1028 & 996 & 1 & 0 \\
\hline 39 & 285 & 253 & 1 & 1 \\
\hline 40 & 2028 & 704 & 8 & 13 \\
\hline 41 & 285 & 151 & 3 & 2 \\
\hline 42 & 971 & 385 & 1 & 2 \\
\hline 43 & 533 & 216 & 3 & 5 \\
\hline 44 & 408 & 252 & 0 & 0 \\
\hline 45 & 429 & 419 & 2 & 1 \\
\hline 46 & 165 & 136 & 1 & 0 \\
\hline 47 & 330 & 185 & 0 & 3 \\
\hline 48 & 673 & 382 & 3 & 7 \\
\hline 49 & 487 & 304 & 0 & 6 \\
\hline 50 & 224 & 130 & 3 & 2 \\
\hline 51 & 153 & 121 & 1 & 1 \\
\hline 52 & 336 & 295 & 1 & 2 \\
\hline 53 & 340 & 289 & 2 & 1 \\
\hline 54 & 186 & 181 & 1 & 0 \\
\hline
\end{tabular}


Table C.2. (Cont'd)

\begin{tabular}{|c|c|c|c|c|}
\hline Plant Sites & Total Start & Total Loads & Total Start Failure & $\begin{array}{c}\text { Total Load-Run } \\
\text { Failure }\end{array}$ \\
\hline \hline 55 & 244 & 150 & 0 & 2 \\
\hline 56 & 348 & 334 & 0 & 0 \\
\hline 57 & 443 & 263 & 1 & 2 \\
\hline 58 & 151 & 92 & 0 & 0 \\
\hline 59 & 981 & 466 & 6 & 2 \\
\hline 60 & 450 & 387 & 1 & 2 \\
\hline 61 & 205 & 183 & 5 & 1 \\
\hline 62 & 311 & 278 & 1 & 5 \\
\hline 63 & 315 & 212 & 0 & 0 \\
\hline
\end{tabular}




\section{APPENDIX D}

ESTIMATED EDG FAILURE PROBABILITIES 
This appendix presents the results of empirical Bayes analyses of EDG failure data. For comparison, direct estimations of EDG failure probabilities also are given. The results shown in the tables include the following information for each EDG and for each plant site (comprising of several EDGs):

PLANT SITE $=\quad$ Designation for a given plant

DG.ID $=$ Diesel identification

$\hat{p}$ (ST.FAIL) = Simple estimate of failure probability to start for a diesel or for diesels in a plant site

$\hat{\mathrm{p}}(\mathrm{LD} . \mathrm{FAIL})=\quad$ Simple estimate of failure probability to load-run for a diesel or for diesels in a plant site

$\overline{\mathrm{p}}$ (ST.FAIL) = Empirical Bayes estimate of failure probability to start for a diesel or for diesels in a plant site

$\overline{\mathrm{p}}$ (LD.FAIL) = Empirical Bayes estimate of failure probability to load-run for a diesel or for diesels in a plant site

The simple failure probability estimates both for individual diesels and over plant sites are calculated as amount of failures over amount of trials. Empirical Bayes estimates are calculated with the formula

$$
\bar{p}_{i}=\frac{1}{1+w_{i}} \hat{p}_{i}+\frac{w_{i}}{1+w_{i}} \hat{\mu}
$$

where the values $w_{i}, \hat{p}_{i}, \hat{\mu}$ are obtained from Eqns. 5-7 and 11, Section 3 of the main report.

Table D.1 and D.2, respectively, give the individual diesel failure probabilities and the station failure probabilities for the diesels.

Following the table, histograms of EDG failure probabilities are presented both for individual diesels and over plant sites (Figures D.1 through D.8). The failure probabilities illustrated are the empirical Bayes estimates obtained with Copas estimator (see Section 3). In Figures D.1 through D.8, the 30 bar histogram shows the grosser structure of the distribution and 60 bar histogram shows the finer structure of the distribution. The histograms show clumpings of the failure probability, indicating a subpopulation of the diesels having distinct failure behavior. 
Table D.1. Individual Diesel Failure Probabilities

\begin{tabular}{|c|c|c|c|c|c|}
\hline Plant Sites & DG ID & $\hat{\mathrm{p}}$ (ST.FAIL) & $\hat{\mathbf{p}}$ (LD.FAIL) & $\bar{p}$ (ST.FAIL) & $\overline{\mathbf{p}}$ (LD.FAIL) \\
\hline 1 & $\mathrm{~A}$ & 4.484E-03 & $2.139 \mathrm{E}-02$ & $4.854 \mathrm{E}-03$ & $1.549 \mathrm{E}-02$ \\
\hline 1 & $\mathbf{B}$ & $0.000 \mathrm{E}+00$ & $1.630 \mathrm{E}-02$ & $3.615 \mathrm{E}-03$ & $1.292 \mathrm{E}-02$ \\
\hline 1 & $\mathrm{C}$ & $0.000 \mathrm{E}+00$ & $6.250 \mathrm{E}-03$ & $3.761 \mathrm{E}-03$ & $8.030 \mathrm{E}-03$ \\
\hline 1 & $\mathrm{D}$ & $9.615 \mathrm{E}-03$ & $1.714 \mathrm{E}-0.2$ & $6.218 \mathrm{E}-03$ & $1.324 \mathrm{E}-02$ \\
\hline 1 & $\mathrm{E}$ & $0.000 \mathrm{E}+00$ & $0.000 \mathrm{E}+00$ & $3.867 \mathrm{E}-03$ & 5.324E-03 \\
\hline 2 & A & $0.000 \mathrm{E}+00$ & $0.000 \mathrm{E}+\infty 0$ & 4.144E-03 & $6.660 \mathrm{E}-03$ \\
\hline 2 & $\mathrm{~B}$ & $1.111 \mathrm{E}-02$ & $1.587 \mathrm{E}-02$ & $5.819 \mathrm{E}-03$ & $1.116 \mathrm{E}-02$ \\
\hline 2 & $\mathrm{C}$ & $0.000 \mathrm{E}+00$ & $0.000 \mathrm{E}+00$ & 4.210E-03 & $6.132 \mathrm{E}-03$ \\
\hline 2 & $\mathrm{D}$ & $7.634 \mathrm{E}-03$ & $8.000 \mathrm{E}-03$ & $5.483 \mathrm{E}-03$ & $8.934 \mathrm{E}-03$ \\
\hline 3 & $\mathrm{~A}$ & $0.000 \mathrm{E}+00$ & $0.000 \mathrm{E}+00$ & 4.109E-03 & $6.374 \mathrm{E}-03$ \\
\hline 3 & B & $0.000 \mathrm{E}+00$ & $9.901 \mathrm{E}-03$ & 4.091E-03 & $9.681 \mathrm{E}-03$ \\
\hline 3 & $\mathrm{C}$ & $0.000 \mathrm{E}+00$ & $0.000 \mathrm{E}+00$ & $3.962 \mathrm{E}-03$ & $6.007 \mathrm{E}-03$ \\
\hline 3 & $\mathrm{D}$ & $0.000 \mathrm{E}+00$ & $0.000 \mathrm{E}+00$ & $3.856 \mathrm{E}-03$ & $6.069 \mathrm{E}-03$ \\
\hline 3 & $E$ & $0.000 \mathrm{E}+00$ & $3.846 \mathrm{E}-02$ & $4.023 \mathrm{E}-03$ & $1.993 \mathrm{E}-02$ \\
\hline 3 & $F$ & $0.000 \mathrm{E}+00$ & $0.000 \mathrm{E}+100$ & $4.012 \mathrm{E}-03$ & $6.153 \mathrm{E}-03$ \\
\hline 4 & $\mathbf{A}$ & $0.000 \mathrm{E}+00$ & $0.000 \mathrm{E}+00$ & $4.330 \mathrm{E}-03$ & $6.660 \mathrm{E}-03$ \\
\hline 4 & $\mathrm{~B}$ & $1.205 \mathrm{E}-02$ & $6.579 \mathrm{E}-02$ & $5.881 \mathrm{E}-03$ & $2.588 \mathrm{E}-02$ \\
\hline 5 & $\mathrm{~A}$ & $0.000 \mathrm{E}+00$ & $1.227 \mathrm{E}-02$ & $3.761 \mathrm{E}-03$ & $1.083 \mathrm{E}-02$ \\
\hline 5 & B & $0.000 \mathrm{E}+00$ & $0.000 \mathrm{E}+00$ & 3.264E-03 & 4.244E-03 \\
\hline 5 & $\mathrm{C}$ & $5.952 \mathrm{E}-03$ & $6.849 \mathrm{E}-03$ & $5.211 \mathrm{E}-03$ & 8.369E-03 \\
\hline 6 & A & $0.000 \mathrm{E}+00$ & $0.000 \mathrm{E}+00$ & $4.396 \mathrm{E}-03$ & $6.974 \mathrm{E}-03$ \\
\hline 6 & $\mathrm{~B}$ & $0.000 \mathrm{E}+00$ & $1.639 \mathrm{E}-02$ & $4.443 \mathrm{E}-03$ & $1.125 \mathrm{E}-02$ \\
\hline 6 & $\mathrm{C}$ & $0.000 \mathrm{E}+00$ & $1.389 \mathrm{E}-02$ & $4.389 \mathrm{E}-03$ & $1.077 \mathrm{E}-02$ \\
\hline 7 & $\mathrm{~A}$ & $2.092 \mathrm{E}-02$ & $0.000 \mathrm{E}+00$ & $9.651 \mathrm{E}-03$ & $7.085 \mathrm{E}-03$ \\
\hline 8 & $\mathrm{~A}$ & $6.579 \mathrm{E}-03$ & $2.198 \mathrm{E}-02$ & $5.325 \mathrm{E}-03$ & $1.364 \mathrm{E}-02$ \\
\hline 8 & $\mathrm{~B}$ & $0.000 \mathrm{E}+00$ & $0.000 \mathrm{E}+00$ & $4.074 \mathrm{E}-03$ & $6.813 \mathrm{E}-03$ \\
\hline 9 & $\mathrm{~A}$ & $5.882 \mathrm{E}-03$ & $0.000 \mathrm{E}+00$ & $5.197 \mathrm{E}-03$ & $5.574 \mathrm{E}-03$ \\
\hline
\end{tabular}


Table D.1. (Cont'd)

\begin{tabular}{|c|c|c|c|c|c|}
\hline Plant Sites & DG ID & $\hat{\mathrm{p}}$ (ST.FAIL) & $\hat{\mathrm{p}}$ (LD.FAIL) & $\overline{\mathbf{p}}$ (ST.FAIL) & $\overline{\text { p}(L D . F A I L) ~}$ \\
\hline 9 & $\mathrm{~B}$ & $1.026 \mathrm{E}-02$ & $1.342 \mathrm{E}-02$ & $6.322 \mathrm{E}-03$ & $1.128 \mathrm{E}-02$ \\
\hline 9 & $\mathrm{C}$ & $5.952 \mathrm{E}-03$ & $7.092 \mathrm{E}-03$ & $5.211 \mathrm{E}-03$ & $8.496 \mathrm{E}-03$ \\
\hline 9 & D & $5.435 \mathrm{E}-03$ & $6.623 \mathrm{E}-03$ & $5.102 \mathrm{E}-03$ & $8.244 \mathrm{E}-03$ \\
\hline 10 & $\mathrm{~A}$ & $9.524 \mathrm{E}-03$ & $1.031 \mathrm{E}-02$ & 5.692E-03 & $9.818 \mathrm{E}-03$ \\
\hline 10 & B & $9.174 \mathrm{E}-03$ & 9.615E-03 & $5.659 \mathrm{E}-03$ & $9.581 \mathrm{E}-03$ \\
\hline 11 & $\mathrm{~A}$ & $1.342 \mathrm{E}-02$ & $3.540 \mathrm{E}-02$ & $6.722 \mathrm{E}-03$ & $1.933 \mathrm{E}-02$ \\
\hline 11 & $\mathrm{~B}$ & $8.197 \mathrm{E}-03$ & $0.000 \mathrm{E}+00$ & $5.554 \mathrm{E}-03$ & $6.261 \mathrm{E}-03$ \\
\hline 11 & $\mathrm{C}$ & $0.000 \mathrm{E}+00$ & $4.000 \mathrm{E}-02$ & $4.126 \mathrm{E}-03$ & $2.021 \mathrm{E}-02$ \\
\hline 11 & D & $0.000 \mathrm{E}+00$ & $0.000 \mathrm{E}+00$ & 4.198E-03 & $6.761 \mathrm{E}-03$ \\
\hline 12 & $\mathrm{~A}$ & $0.000 \mathrm{E}+00$ & $1.099 \mathrm{E}-02$ & 4.311E-03 & $1.003 \mathrm{E}-02$ \\
\hline 12 & $\mathrm{~B}$ & $1.818 \mathrm{E}-02$ & $9.615 \mathrm{E}-03$ & $7.102 \mathrm{E}-03$ & $9.581 \mathrm{E}-03$ \\
\hline 12 & $\mathrm{C}$ & $0.000 \mathrm{E}+00$ & $0.000 \mathrm{E}+00$ & 4.304E-03 & $6.396 \mathrm{E}-03$ \\
\hline 13 & $\mathrm{~A}$ & $0.000 \mathrm{E}+00$ & $9.524 \mathrm{E}-03$ & $3.826 \mathrm{E}-03$ & $9.548 \mathrm{E}-03$ \\
\hline 13 & $\mathrm{~B}$ & $0.000 \mathrm{E}+00$ & $9.524 \mathrm{E}-03$ & $3.519 \mathrm{E}-03$ & $9.548 \mathrm{E}-03$ \\
\hline 13 & $\mathrm{C}$ & $1.657 \mathrm{E}-02$ & $0.000 \mathrm{E}+00$ & $7.755 \mathrm{E}-03$ & $6.132 \mathrm{E}-03$ \\
\hline 13 & $\mathrm{D}$ & $0.000 \mathrm{E}+00$ & $0.000 \mathrm{E}+00$ & $3.796 \mathrm{E}-03$ & $7.348 \mathrm{E}-03$ \\
\hline 13 & $\mathrm{E}$ & $0.000 \mathrm{E}+00$ & $1.639 \mathrm{E}-02$ & $4.057 \mathrm{E}-03$ & $1.125 \mathrm{E}-02$ \\
\hline 14 & A & $2.542 \mathrm{E}-02$ & $9.346 \mathrm{E}-03$ & $8.456 \mathrm{E}-03$ & $9.483 \mathrm{E}-03$ \\
\hline 14 & $\mathrm{~B}$ & $2.290 \mathrm{E}-02$ & $1.351 \mathrm{E}-02$ & $8.302 \mathrm{E}-03$ & $1.131 \mathrm{E}-02$ \\
\hline 14 & $\mathrm{C}$ & $1.754 \mathrm{E}-02$ & $1.942 \mathrm{E}-02$ & $7.061 \mathrm{E}-03$ & $1.307 \mathrm{E}-02$ \\
\hline 15 & $\mathrm{~A}$ & $2.593 \mathrm{E}-02$ & $2.119 \mathrm{E}-02$ & $1.166 \mathrm{E}-02$ & $1.606 \mathrm{E}-02$ \\
\hline 15 & $\mathrm{~B}$ & 9.852E-03 & 5.319E-03 & $6.257 \mathrm{E}-03$ & $7.429 \mathrm{E}-03$ \\
\hline 15 & $\mathrm{C}$ & $5.102 \mathrm{E}-03$ & $1.639 \mathrm{E}-02$ & $5.023 \mathrm{E}-03$ & $1.295 \mathrm{E}-02$ \\
\hline 15 & $\mathrm{D}$ & $6.897 \mathrm{E}-03$ & $1.154 \mathrm{E}-02$ & $5.631 \mathrm{E}-03$ & $1.071 \mathrm{E}-02$ \\
\hline 15 & $\mathrm{E}$ & $1.056 \mathrm{E}-02$ & $7.905 \mathrm{E}-03$ & $6.829 \mathrm{E}-03$ & $8.607 \mathrm{E}-03$ \\
\hline 16 & A & $0.000 \mathrm{E}+00$ & $0.000 \mathrm{E}+00$ & $4.330 \mathrm{E}-03$ & $6.685 \mathrm{E}-03$ \\
\hline 16 & $\mathrm{~B}$ & $0.000 \mathrm{E}+00$ & $0.000 \mathrm{E}+00$ & $4.350 \mathrm{E}-03$ & $6.635 \mathrm{E}-03$ \\
\hline
\end{tabular}


Table D.1. (Cont'd)

\begin{tabular}{|c|c|c|c|c|c|}
\hline Plant Sites & DG ID & $\hat{\mathbf{p}}$ (ST.FAIL) & $\hat{\mathrm{p}}$ (LD.FAIL) & $\overline{\text { p(ST.FAIL) }}$ & $\bar{p}$ (LD.FAIL) \\
\hline 16 & $\mathrm{C}$ & $0.000 \mathrm{E}+00$ & $0.000 \mathrm{E}+00$ & $4.311 \mathrm{E}-03$ & $6.562 \mathrm{E}-03$ \\
\hline 16 & $\mathrm{D}$ & $1.235 \mathrm{E}-02$ & $1.351 \mathrm{E}-02$ & $5.899 \mathrm{E}-03$ & $1.069 \mathrm{E}-02$ \\
\hline 17 & A & $0.000 \mathrm{E}+\infty 0$ & $0.000 \mathrm{E}+00$ & $3.903 \mathrm{E}-03$ & $7.288 \mathrm{E}-03$ \\
\hline 17 & B & $0.000 \mathrm{E}+\infty 0$ & $1.852 \mathrm{E}-02$ & $3.973 \mathrm{E}-03$ & $1.158 \mathrm{E}-02$ \\
\hline 17 & $\mathrm{C}$ & $0.000 \mathrm{E}+00$ & $3.279 \mathrm{E}-02$ & $4.156 \mathrm{E}-03$ & $1.530 \mathrm{E}-02$ \\
\hline 17 & $\mathrm{D}$ & $0.000 E+00$ & $0.000 \mathrm{E}+00$ & $4.180 \mathrm{E}-03$ & $7.472 \mathrm{E}-03$ \\
\hline 18 & A & $1.190 \mathrm{E}-02$ & $3.676 \mathrm{E}-02$ & $6.551 \mathrm{E}-03$ & $2.105 \mathrm{E}-02$ \\
\hline 18 & $\mathrm{~B}$ & $0.000 \mathrm{E}+\infty 0$ & $0.000 \mathrm{E}+\infty 0$ & $3.995 \mathrm{E}-03$ & $6.069 \mathrm{E}-03$ \\
\hline 18 & $\mathrm{C}$ & $1.460 \mathrm{E}-02$ & $2.105 \mathrm{E}-02$ & $6.835 \mathrm{E}-03$ & $1.345 \mathrm{E}-02$ \\
\hline 18 & D & $1.449 \mathrm{E}-02$ & $1.053 \mathrm{E}-02$ & $6.825 \mathrm{E}-03$ & $9.888 \mathrm{E}-03$ \\
\hline 19 & $\mathrm{~A}$ & $1.205 \mathrm{E}-02$ & $1.075 \mathrm{E}-0.2$ & $6.568 \mathrm{E}-03$ & $9.959 \mathrm{E}-03$ \\
\hline 19 & $\mathrm{~B}$ & $5.848 \mathrm{E}-03$ & $1.064 \mathrm{E}-0.2$ & $5.191 \mathrm{E}-03$ & $9.923 \mathrm{E}-03$ \\
\hline 19 & $\mathrm{C}$ & $6.667 \mathrm{E}-03$ & $2.970 \mathrm{E}-02$ & $5.340 \mathrm{E}-03$ & $1.665 \mathrm{E}-02$ \\
\hline 19 & $\mathrm{D}$ & $2.174 \mathrm{E}-02$ & $1.111 \mathrm{E}-0.2$ & $9.758 \mathrm{E}-03$ & $1.032 \mathrm{E}-02$ \\
\hline 20 & $\mathrm{~A}$ & $0.000 \mathrm{E}+00$ & $9.174 \mathrm{E}-03$ & $4.126 \mathrm{E}-03$ & $9.418 \mathrm{E}-03$ \\
\hline 20 & B & $7.692 \mathrm{E}-03$ & $0.000 \mathrm{E}+00$ & $5.491 \mathrm{E}-03$ & $6.028 \mathrm{E}-03$ \\
\hline 21 & A & $1.149 \mathrm{E}-02$ & $5.172 \mathrm{E}-02$ & $6.499 \mathrm{E}-03$ & $1.959 \mathrm{E}-02$ \\
\hline 21 & $\mathrm{~B}$ & $5.405 \mathrm{E}-03$ & $6.349 \mathrm{E}-0.2$ & $5.095 \mathrm{E}-03$ & $2.321 \mathrm{E}-02$ \\
\hline 21 & $\mathrm{C}$ & $5.051 \mathrm{E}-03$ & $1.087 \mathrm{E}-02$ & $5.010 \mathrm{E}-03$ & $9.994 \mathrm{E}-03$ \\
\hline 21 & $\mathrm{D}$ & $1.005 \mathrm{E}-02$ & $9.615 \mathrm{E}-0.3$ & $6.290 \mathrm{E}-03$ & $9.581 \mathrm{E}-03$ \\
\hline 22 & $\mathrm{~A}$ & $6.211 \mathrm{E}-03$ & $0.000 \mathrm{E}+\infty 0$ & $5.261 \mathrm{E}-03$ & $5.592 \mathrm{E}-03$ \\
\hline 22 & $\mathrm{~B}$ & 1.527E-02 & $0.000 \mathrm{E}+00$ & $6.892 \mathrm{E}-03$ & $6.090 \mathrm{E}-03$ \\
\hline 23 & $\mathrm{~A}$ & $0.000 \mathrm{E}+00$ & $0.000 \mathrm{E}+\infty 0$ & $4.471 \mathrm{E}-03$ & $7.001 \mathrm{E}-03$ \\
\hline 23 & $\mathrm{~B}$ & $1.770 \mathrm{E}-02$ & $9.259 \mathrm{E}-03$ & $7.072 \mathrm{E}-03$ & $9.450 \mathrm{E}-03$ \\
\hline 23 & $\mathrm{C}$ & $1.613 \mathrm{E}-02$ & $0.000 \mathrm{E}+00$ & $6.074 \mathrm{E}-03$ & $7.229 \mathrm{E}-03$ \\
\hline 23 & $\mathrm{D}$ & $1.333 \mathrm{E}-02$ & $0.000 \mathrm{E}+00$ & $5.953 \mathrm{E}-03$ & $6.866 \mathrm{E}-03$ \\
\hline 23 & $\mathrm{E}$ & $0.000 \mathrm{E}+00$ & $0.000 \mathrm{E}+00$ & $4.506 \mathrm{E}-03$ & $7.199 \mathrm{E}-03$ \\
\hline
\end{tabular}


Table D.1. (Cont'd)

\begin{tabular}{|c|c|c|c|c|c|}
\hline Plant Sites & DG ID & $\hat{\mathbf{p}}$ (ST.FAIL) & $\hat{\mathrm{p}}$ (LD.FAIL) & $\bar{p}($ ST.FAIL $)$ & $\bar{p}($ LD.FAIL) \\
\hline 24 & A & $0.000 \mathrm{E}+00$ & $0.000 \mathrm{E}+00$ & $3.751 \mathrm{E}-03$ & $5.292 \mathrm{E}-03$ \\
\hline 24 & B & $5.051 \mathrm{E}-03$ & $1.316 \mathrm{E}-02$ & $5.010 \mathrm{E}-03$ & $1.118 \mathrm{E}-02$ \\
\hline 25 & A & $0.000 \mathrm{E}+00$ & $1.282 \mathrm{E}-02$ & $3.836 \mathrm{E}-03$ & $1.052 \mathrm{E}-02$ \\
\hline 25 & B & $0.000 \mathrm{E}+00$ & $2.703 \mathrm{E}-02$ & $3.898 \mathrm{E}-03$ & $1.453 \mathrm{E}-02$ \\
\hline 26 & A & $0.000 \mathrm{E}+00$ & $1.942 \mathrm{E}-02$ & 4.144E-03 & $1.307 \mathrm{E}-02$ \\
\hline 26 & B & $0.000 \mathrm{E}+00$ & $0.000 \mathrm{E}+00$ & $4.350 \mathrm{E}-03$ & $6.866 \mathrm{E}-03$ \\
\hline 26 & $\mathrm{C}$ & $1.481 \mathrm{E}-02$ & $0.000 \mathrm{E}+\infty 0$ & $6.854 \mathrm{E}-03$ & $5.849 \mathrm{E}-03$ \\
\hline 27 & A & $0.000 \mathrm{E}+00$ & $0.000 \mathrm{E}+00$ & 4.570E-03 & $7.472 \mathrm{E}-03$ \\
\hline 27 & B & $0.000 \mathrm{E}+00$ & $0.000 \mathrm{E}+00$ & 4.584E-03 & $7.567 \mathrm{E}-03$ \\
\hline 28 & A & $1.124 \mathrm{E}-02$ & $0.000 \mathrm{E}+00$ & $5.828 \mathrm{E}-03$ & $7.057 \mathrm{E}-03$ \\
\hline 28 & $\mathrm{~B}$ & $2.128 \mathrm{E}-02$ & $0.000 \mathrm{E}+00$ & $7.271 \mathrm{E}-03$ & $7.057 \mathrm{E}-03$ \\
\hline 28 & $\mathrm{C}$ & $2.326 \mathrm{E}-02$ & $0.000 \mathrm{E}+00$ & $7.359 \mathrm{E}-03$ & $6.866 \mathrm{E}-03$ \\
\hline 28 & $\mathrm{D}$ & $1.075 \mathrm{E}-02$ & $0.000 \mathrm{E}+00$ & $5.793 \mathrm{E}-03$ & $6.736 \mathrm{E}-03$ \\
\hline 29 & A & $6.623 \mathrm{E}-03$ & $1.587 \mathrm{E}-02$ & $5.333 \mathrm{E}-03$ & $1.116 \mathrm{E}-02$ \\
\hline 29 & B & $0.000 \mathrm{E}+00$ & $1.852 \mathrm{E}-02$ & $4.074 \mathrm{E}-03$ & $1.158 \mathrm{E}-02$ \\
\hline 30 & A & $1.408 \mathrm{E}-02$ & $0.000 \mathrm{E}+00$ & $5.990 \mathrm{E}-03$ & $7.318 \mathrm{E}-03$ \\
\hline 30 & B & $0.000 \mathrm{E}+00$ & $0.000 \mathrm{E}+00$ & $4.450 \mathrm{E}-03$ & $7.288 \mathrm{E}-03$ \\
\hline 31 & A & $0.000 \mathrm{E}+00$ & $0.000 \mathrm{E}+00$ & $3.995 \mathrm{E}-03$ & $5.849 \mathrm{E}-03$ \\
\hline 31 & B & $0.000 \mathrm{E}+00$ & $1.282 \mathrm{E}-02$ & $4.260 \mathrm{E}-03$ & $1.052 \mathrm{E}-02$ \\
\hline 32 & $\mathrm{~A}$ & $6.494 \mathrm{E}-03$ & $0.000 \mathrm{E}+\infty 0$ & $5.311 \mathrm{E}-03$ & $5.830 \mathrm{E}-03$ \\
\hline 32 & B & $0.000 \mathrm{E}+00$ & $0.000 \mathrm{E}+00$ & $4.235 \mathrm{E}-03$ & $6.685 \mathrm{E}-03$ \\
\hline 32 & $\mathrm{C}$ & $6.579 \mathrm{E}-03$ & $0.000 \mathrm{E}+00$ & $5.325 \mathrm{E}-03$ & $5.987 \mathrm{E}-03$ \\
\hline 33 & A & $0.000 \mathrm{E}+00$ & $2.941 \mathrm{E}-02$ & $4.285 E-03$ & $1.488 \mathrm{E}-02$ \\
\hline 33 & B & $0.000 \mathrm{E}+00$ & $3.030 \mathrm{E}-02$ & 4.423E-03 & $1.500 \mathrm{E}-02$ \\
\hline 34 & A & $0.000 \mathrm{E}+00$ & $3.175 \mathrm{E}-02$ & $4.436 \mathrm{E}-03$ & $1.518 \mathrm{E}-02$ \\
\hline 34 & B & $0.00 \mathrm{E}+00$ & $0.000 \mathrm{E}+\infty 0$ & $4.423 E-03$ & $6.974 \mathrm{E}-03$ \\
\hline 35 & A & $0.000 \mathrm{E}+00$ & $0.000 \mathrm{E}+00$ & 4.114E-03 & $5.830 \mathrm{E}-03$ \\
\hline
\end{tabular}


Table D.1. (Cont'd)

\begin{tabular}{|c|c|c|c|c|c|}
\hline Plant Sites & DG ID & $\hat{\mathrm{p}}$ (ST.FAIL) & $\hat{\mathrm{p}}$ (LD.FAIL) & $\bar{p}($ ST.FAIL) & $\overline{\mathrm{p}}$ (LD.FAIL) \\
\hline 35 & $\mathrm{~B}$ & $0.000 \mathrm{E}+\infty 0$ & $0.000 \mathrm{E}+00$ & $4.091 \mathrm{E}-03$ & $5.755 \mathrm{E}-03$ \\
\hline 36 & A & $0.000 \mathrm{E}+00$ & $3.333 \mathrm{E}-02$ & $3.930 \mathrm{E}-03$ & $1.536 \mathrm{E}-02$ \\
\hline 36 & B & $6.369 \mathrm{E}-03$ & $2.778 \mathrm{E}-02$ & $5.289 \mathrm{E}-03$ & $1.465 \mathrm{E}-02$ \\
\hline 37 & A & $0.000 \mathrm{E}+\infty 0$ & $1.471 \mathrm{E}-02$ & $4.376 \mathrm{E}-03$ & $1.094 \mathrm{E}-03$ \\
\hline 37 & B & $0.000 \mathrm{E}+\infty 0$ & $0.000 \mathrm{E}+00$ & $4.235 \mathrm{E}-03$ & $6.586 \mathrm{E}-03$ \\
\hline 37 & $\mathrm{C}$ & $1.010 \mathrm{E}-02$ & $1.266 \mathrm{E}-02$ & $5.742 \mathrm{E}-03$ & $1.048 \mathrm{E}-02$ \\
\hline 37 & $\mathrm{D}$ & $1.010 \mathrm{E}-02$ & $2.247 \mathrm{E}-02$ & $5.742 \mathrm{E}-03$ & $1.374 \mathrm{E}-02$ \\
\hline 38 & A & $0.000 \mathrm{E}+00$ & $0.000 \mathrm{E}+00$ & $3.407 \mathrm{E}-03$ & $3.987 \mathrm{E}-03$ \\
\hline 38 & $\mathrm{~B}$ & $0.000 \mathrm{E}+00$ & $0.000 \mathrm{E}+00$ & $3.451 \mathrm{E}-03$ & $4.078 \mathrm{E}-03$ \\
\hline 38 & $\mathrm{C}$ & $3.937 \mathrm{E}-03$ & $0.000 \mathrm{E}+00$ & $4.673 \mathrm{E}-03$ & $4.087 \mathrm{E}-03$ \\
\hline 38 & $\mathrm{D}$ & $0.000 \mathrm{E}+00$ & $0.000 \mathrm{E}+00$ & $3.510 \mathrm{E}-03$ & $4.203 \mathrm{E}-03$ \\
\hline 39 & A & $0.000 \mathrm{E}+00$ & $0.000 \mathrm{E}+\infty$ & $4.478 \mathrm{E}-03$ & $7.348 \mathrm{E}-03$ \\
\hline 39 & B & $0.000 \mathrm{E}+00$ & $0.000 \mathrm{E}+\infty 0$ & $4.443 E-03$ & $7.085 \mathrm{E}-03$ \\
\hline 39 & $\mathrm{C}$ & $0.000 \mathrm{E}+00$ & $1.538 \mathrm{E}-02$ & $4.443 \mathrm{E}-03$ & $1.107 \mathrm{E}-02$ \\
\hline 39 & $\mathrm{D}$ & $1.351 \mathrm{E}-02$ & $0.000 \mathrm{E}+00$ & $5.962 \mathrm{E}-03$ & $7.029 \mathrm{E}-03$ \\
\hline 40 & $\mathrm{~A}$ & $3.704 \mathrm{E}-03$ & $1.299 \mathrm{E}-02$ & $4.585 \mathrm{E}-03$ & $1.056 \mathrm{E}-02$ \\
\hline 40 & $\mathrm{~B}$ & $3.448 \mathrm{E}-03$ & $2.273 \mathrm{E}-02$ & $4.479 \mathrm{E}-03$ & $1.379 \mathrm{E}-02$ \\
\hline 40 & $\mathrm{C}$ & $1.563 \mathrm{E}-02$ & $1.124 \mathrm{E}-02$ & $8.781 \mathrm{E}-03$ & $1.010 \mathrm{E}-02$ \\
\hline 40 & $\mathrm{D}$ & $0.000 \mathrm{E}+00$ & $2.759 \mathrm{E}-02$ & $3.006 \mathrm{E}-03$ & $1.746 \mathrm{E}-02$ \\
\hline 40 & $\mathrm{E}$ & $0.000 \mathrm{E}+00$ & $3.185 \mathrm{E}-02$ & $3.064 \mathrm{E}-03$ & $1.976 \mathrm{E}-02$ \\
\hline 40 & $\mathrm{~F}$ & $2.500 \mathrm{E}-03$ & $0.000 \mathrm{E}+00$ & $3.976 \mathrm{E}-03$ & $5.324 \mathrm{E}-03$ \\
\hline 41 & A & $1.307 \mathrm{E}-02$ & $1.250 \mathrm{E}-02$ & $6.685 \mathrm{E}-03$ & $1.045 \mathrm{E}-02$ \\
\hline 41 & B & $7.576 \mathrm{E}-03$ & $1.408 \mathrm{E}-02$ & $5.475 \mathrm{E}-03$ & $1.081 \mathrm{E}-02$ \\
\hline 42 & $\mathrm{~A}$ & $0.000 \mathrm{E}+00$ & $1.205 \mathrm{E}-02$ & $3.737 \mathrm{E}-03$ & $1.033 \mathrm{E}-02$ \\
\hline 42 & B & $5.000 \mathrm{E}-03$ & $1.235 \mathrm{E}-02$ & 4.997E-03 & $1.041 \mathrm{E}-02$ \\
\hline 42 & $\mathrm{C}$ & $0.000 \mathrm{E}+00$ & $0.000 \mathrm{E}+00$ & $3.540 \mathrm{E}-03$ & $6.736 \mathrm{E}-03$ \\
\hline 42 & $\mathrm{D}$ & $0.000 \mathrm{E}+00$ & $0.000 \mathrm{E}+00$ & $3.862 \mathrm{E}-03$ & $6.866 \mathrm{E}-03$ \\
\hline
\end{tabular}


Table D.1. (Cont'd)

\begin{tabular}{|c|c|c|c|c|c|}
\hline Plant Sites & DG ID & $\hat{\mathrm{p}}$ (ST.FAIL) & $\hat{p}$ (LD.FAIL) & $\overline{\mathbf{p}}$ (ST.FAIL) & $\overline{\mathrm{p}}($ LD.FAIL) \\
\hline 42 & $\mathrm{E}$ & $0.000 \mathrm{E}+\infty 0$ & $0.000 \mathrm{E}+00$ & $3.872 \mathrm{E}-03$ & $6.946 \mathrm{E}-03$ \\
\hline 43 & A & $0.000 \mathrm{E}+00$ & $2.857 \mathrm{E}-02$ & $3.882 \mathrm{E}-03$ & $1.476 \mathrm{E}-02$ \\
\hline 43 & B & $5.525 \mathrm{E}-03$ & $2.899 \mathrm{E}-02$ & $5.122 \mathrm{E}-03$ & $1.482 \mathrm{E}-02$ \\
\hline 43 & $\mathrm{C}$ & $1.075 \mathrm{E}-02$ & $1.299 \mathrm{E}-02$ & $6.397 \mathrm{E}-03$ & $1.056 \mathrm{E}-02$ \\
\hline 44 & A & $0.000 \mathrm{E}+00$ & $0.000 \mathrm{E}+00$ & $4.260 \mathrm{E}-03$ & $7.170 \mathrm{E}-03$ \\
\hline 44 & B & $0.000 \mathrm{E}+00$ & $0.000 \mathrm{E}+00$ & $4.235 \mathrm{E}-03$ & $7.113 \mathrm{E}-03$ \\
\hline 44 & $\mathrm{C}$ & $0.000 \mathrm{E}+00$ & $0.000 \mathrm{E}+00$ & $4.260 \mathrm{E}-03$ & $7.170 \mathrm{E}-03$ \\
\hline 44 & $\mathrm{D}$ & $0.000 \mathrm{E}+00$ & $0.000 \mathrm{E}+00$ & $4.235 \mathrm{E}-03$ & $7.113 \mathrm{E}-03$ \\
\hline 45 & A & 2.353E-02 & $0.000 \mathrm{E}+00$ & $7.370 \mathrm{E}-03$ & $6.586 \mathrm{E}-03$ \\
\hline 45 & B & $0.000 \mathrm{E}+00$ & $1.266 \mathrm{E}-02$ & 4.383E-03 & $1.048 \mathrm{E}-02$ \\
\hline 45 & $\mathrm{C}$ & $0.000 \mathrm{E}+00$ & $0.000 \mathrm{E}+00$ & $4.389 \mathrm{E}-03$ & $6.761 \mathrm{E}-03$ \\
\hline 45 & $\mathrm{D}$ & $0.090 \mathrm{E}+00$ & $0.000 \mathrm{E}+00$ & $4.450 \mathrm{E}-03$ & $6.946 \mathrm{E}-03$ \\
\hline 45 & $\mathrm{E}$ & $0.000 \mathrm{E}+00$ & $0.000 \mathrm{E}+00$ & $4.186 \mathrm{E}-03$ & $6.028 \mathrm{E}-03$ \\
\hline 46 & A & $0.000 \mathrm{E}+00$ & $0.000 \mathrm{E}+00$ & $4.383 \mathrm{E}-03$ & $7.029 \mathrm{E}-03$ \\
\hline 46 & B & $1.190 \mathrm{E}-02$ & $0.000 \mathrm{E}+00$ & $5.872 \mathrm{E}-03$ & $6.974 \mathrm{E}-03$ \\
\hline 47 & A & $0.000 \mathrm{E}+00$ & $0.000 \mathrm{E}+00$ & $3.919 \mathrm{E}-03$ & $6.685 \mathrm{E}-03$ \\
\hline 47 & B & $0.000 \mathrm{E}+00$ & $2.857 \mathrm{E}-02$ & $3.856 \mathrm{E}-03$ & 1.642E-02 \\
\hline 48 & $\mathrm{~A}$ & $0.000 \mathrm{E}+00$ & $0.000 \mathrm{E}+\infty 0$ & $3.962 \mathrm{E}-03$ & $6.610 \mathrm{E}-03$ \\
\hline 48 & B & $0.000 \mathrm{E}+00$ & $1.429 \mathrm{E}-02$ & $4.126 \mathrm{E}-03$ & $1.085 \mathrm{E}-02$ \\
\hline 48 & $\mathrm{C}$ & $0.000 \mathrm{E}+00$ & $0.000 \mathrm{E}+00$ & $4.260 \mathrm{E}-03$ & $7.600 \mathrm{E}-03$ \\
\hline 48 & $\mathrm{D}$ & $1.770 \mathrm{E}-02$ & $4.348 \mathrm{E}-02$ & $7.072 \mathrm{E}-03$ & $1.874 \mathrm{E}-02$ \\
\hline 48 & $\mathrm{E}$ & $9.804 \mathrm{E}-03$ & $4.688 \mathrm{E}-02$ & $5.717 \mathrm{E}-03$ & $1.912 \mathrm{E}-02$ \\
\hline 48 & $F$ & $0.000 \mathrm{E}+00$ & $0.000 \mathrm{E}+00$ & $4.356 \mathrm{E}-03$ & $7.600 \mathrm{E}-03$ \\
\hline 49 & A & $0.000 \mathrm{E}+\infty 0$ & $3.597 \mathrm{E}-02$ & $3.737 \mathrm{E}-03$ & $2.086 \mathrm{E}-02$ \\
\hline 49 & B & $0.000 \mathrm{E}+00$ & $0.000 \mathrm{E}+00$ & $3.957 \mathrm{E}-03$ & $6.635 \mathrm{E}-03$ \\
\hline 49 & $\mathrm{C}$ & $0.000 \mathrm{E}+00$ & $1.205 \mathrm{E}-02$ & $4.023 \mathrm{E}-03$ & $1.033 \mathrm{E}-02$ \\
\hline 50 & A & $0.000 \mathrm{E}+00$ & $0.000 \mathrm{E}+00$ & $4.247 \mathrm{E}-03$ & $7.229 \mathrm{E}-03$ \\
\hline
\end{tabular}


Table D.1. (Cont'd)

\begin{tabular}{|c|c|c|c|c|c|}
\hline Plant Sites & DG ID & $\hat{\mathrm{p}}$ (ST.FAIL) & $\hat{\mathrm{p}}$ (LD.FAIL) & $\overline{\mathrm{p}}$ (ST.FAIL) & $\overline{\mathrm{p}(\text { LD.FAIL })}$ \\
\hline 50 & B & $2.459 \mathrm{E}-02$ & $2.857 \mathrm{E}-02$ & $8.408 \mathrm{E}-03$ & $1.476 \mathrm{E}-02$ \\
\hline 51 & A & $0.000 \mathrm{E}+00$ & $1.538 \mathrm{E}-02$ & 4.396E-03 & $1.107 \mathrm{E}-02$ \\
\hline 51 & B & $1.351 \mathrm{E}-02$ & $0.000 \mathrm{E}+00$ & $5.962 \mathrm{E}-03$ & $7.348 \mathrm{E}-03$ \\
\hline 52 & A & $1.149 \mathrm{E}-02$ & $1.316 \mathrm{E}-02$ & $5.846 \mathrm{E}-03$ & $1.060 \mathrm{E}-02$ \\
\hline 52 & B & $0.000 \mathrm{E}+00$ & $0.000 \mathrm{E}+00$ & 4.396E-03 & $6.946 \mathrm{E}-03$ \\
\hline 52 & $\mathrm{C}$ & $0.000 \mathrm{E}+00$ & $1.333 \mathrm{E}-02$ & 4.363E-03 & $1.065 \mathrm{E}-02$ \\
\hline 52 & $\mathrm{D}$ & $0.000 \mathrm{E}+00$ & $0.000 \mathrm{E}+00$ & 4.350E-03 & $6.839 \mathrm{E}-03$ \\
\hline 53 & A & $0.000 \mathrm{E}+00$ & $1.000 \mathrm{E}-02$ & $4.186 \mathrm{E}-03$ & $9.715 \mathrm{E}-03$ \\
\hline 53 & $\mathrm{~B}$ & $9.434 \mathrm{E}-03$ & $0.000 \mathrm{E}+00$ & $5.683 \mathrm{E}-03$ & $6.538 \mathrm{E}-03$ \\
\hline 53 & $\mathrm{C}$ & 8.1'97E-03 & $0.000 \mathrm{E}+00$ & $5.554 \mathrm{E}-03$ & $6.153 \mathrm{E}-03$ \\
\hline 54 & A & $0.000 \mathrm{E}+00$ & $0.000 \mathrm{E}+00$ & 4.324E-03 & $6.538 \mathrm{E}-03$ \\
\hline 54 & $\mathrm{~B}$ & $1.042 \mathrm{E}-02$ & $0.000 \mathrm{E}+00$ & $5.768 \mathrm{E}-03$ & $6.328 \mathrm{E}-03$ \\
\hline 55 & A & $0.000 \mathrm{E}+00$ & $0.000 \mathrm{E}+00$ & 4.103E-03 & $6.892 \mathrm{E}-03$ \\
\hline 55 & B & $0.000 \mathrm{E}+00$ & $2.564 \mathrm{E}-02$ & 4.150E-03 & $1.431 \mathrm{E}-02$ \\
\hline 56 & A & $0.000 \mathrm{E}+00$ & $0.000 \mathrm{E}+00$ & $3.816 \mathrm{E}-03$ & 4.995E-03 \\
\hline 56 & $\mathrm{~B}$ & $0.000 \mathrm{E}+00$ & $0.000 \mathrm{E}+00$ & $3.867 \mathrm{E}-03$ & $5.080 \mathrm{E}-03$ \\
\hline 57 & A & $0.000 \mathrm{E}+00$ & $1.176 \mathrm{E}-02$ & 4.109E-03 & $1.025 \mathrm{E}-02$ \\
\hline 57 & B & $0.000 \mathrm{E}+00$ & $0.000 \mathrm{E}+00$ & $3.979 \mathrm{E}-03$ & $6.635 \mathrm{E}-03$ \\
\hline 57 & $\mathrm{C}$ & $5.882 \mathrm{E}-03$ & $1.042 \mathrm{E}-02$ & 5.197E-03 & $9.853 \mathrm{E}-03$ \\
\hline 58 & $\mathrm{~A}$ & $0.000 \mathrm{E}+00$ & $0.000 \mathrm{E}+00$ & $4.471 \mathrm{E}-03$ & $7.632 \mathrm{E}-03$ \\
\hline 58 & $\mathrm{~B}$ & $0.000 \mathrm{E}+00$ & $0.000 \mathrm{E}+00$ & $4.369 \mathrm{E}-03$ & $7.698 \mathrm{E}-03$ \\
\hline 59 & A & $1.534 \mathrm{E}-02$ & $6.329 \mathrm{E}-03$ & 8.723E-03 & 8.077E-03 \\
\hline 59 & B & $0.000 \mathrm{E}+\infty 0$ & $6.494 \mathrm{E}-03$ & $3.178 \mathrm{E}-03$ & 8.172E-03 \\
\hline 59 & $\mathrm{C}$ & $3.086 \mathrm{E}-03$ & $0.000 \mathrm{E}+00$ & $4.311 \mathrm{E}-03$ & $5.230 \mathrm{E}-03$ \\
\hline 60 & A & $0.000 \mathrm{E}+00$ & $7.576 \mathrm{E}-03$ & $3.930 \mathrm{E}-03$ & 8.737E-03 \\
\hline 60 & $\mathrm{~B}$ & $0.000 \mathrm{E}+00$ & $8.403 \mathrm{E}-03$ & $3.995 \mathrm{E}-03$ & 9.109E-03 \\
\hline 60 & $\mathrm{C}$ & $6.757 \mathrm{E}-03$ & $0.000 \mathrm{E}+00$ & $5.355 \mathrm{E}-03$ & $5.522 \mathrm{E}-03$ \\
\hline
\end{tabular}


Table D.1. (Cont'd)

\begin{tabular}{|c|c|c|c|c|c|}
\hline Plant Sites & DG ID & $\hat{\mathbf{p}}$ (ST.FAIL) & $\hat{\mathbf{p}}$ (LD.FAIL) & $\overline{\mathbf{p}}$ (ST.FAIL) & $\overline{\mathbf{p}}$ (LD.FAIL) \\
\hline \hline 61 & A & $3.529 \mathrm{E}-02$ & $0.000 \mathrm{E}+00$ & $8.877 \mathrm{E}-03$ & $6.866 \mathrm{E}-03$ \\
\hline 61 & B & $1.667 \mathrm{E}-02$ & $9.091 \mathrm{E}-03$ & $7.001 \mathrm{E}-03$ & $9.387 \mathrm{E}-03$ \\
\hline 62 & A & $6.135 \mathrm{E}-03$ & $1.439 \mathrm{E}-02$ & $5.246 \mathrm{E}-03$ & $1.163 \mathrm{E}-02$ \\
\hline 62 & B & $0.000 \mathrm{E}+00$ & $2.158 \mathrm{E}-02$ & $3.979 \mathrm{E}-03$ & $1.470 \mathrm{E}-02$ \\
\hline 63 & A & $0.000 \mathrm{E}+00$ & $0.000 \mathrm{E}+00$ & $3.826 \mathrm{E}-03$ & $6.048 \mathrm{E}-03$ \\
\hline 63 & B & $0.000 \mathrm{E}+00$ & $0.000 \mathrm{E}+00$ & $4.034 \mathrm{E}-03$ & $6.132 \mathrm{E}-03$ \\
\hline
\end{tabular}


Table D.2. Station Diesel Failure Probabilities For Plant Sites

\begin{tabular}{|c|c|c|c|c|}
\hline Plant Sites & $\hat{\mathrm{p}}$ (ST.FAIL) & $\hat{\mathbf{p}}$ (LD.FAIL) & $\overline{\mathrm{p}}$ (ST.FAIL) & $\overline{\mathbf{p}}$ (LD.FAIL) \\
\hline 1 & $2.967 \mathrm{E}-03$ & $1.288 \mathrm{E}-02$ & $3.566 \mathrm{E}-03$ & $1.196 \mathrm{E}-02$ \\
\hline 2 & $4.464 \mathrm{E}-03$ & $5.362 \mathrm{E}-03$ & $4.788 \mathrm{E}-03$ & $7.301 \mathrm{E}-03$ \\
\hline 3 & $0.000 \mathrm{E}+\infty 0$ & $8.091 \mathrm{E}-03$ & $1.579 \mathrm{E}-03$ & 8.587E-03 \\
\hline 4 & $5.814 \mathrm{E}-03$ & $3.185 \mathrm{E}-02$ & $5.375 \mathrm{E}-03$ & $1.682 \mathrm{E}-02$ \\
\hline 5 & $1.504 \mathrm{E}-03$ & $5.535 \mathrm{E}-03$ & $2.830 \mathrm{E}-03$ & $7.031 \mathrm{E}-03$ \\
\hline 6 & $0.000 \mathrm{E}+00$ & $9.901 \mathrm{E}-03$ & $3.207 \mathrm{E}-03$ & $9.676 \mathrm{E}-03$ \\
\hline 7 & $2.092 \mathrm{E}-02$ & $0.000 \mathrm{E}+00$ & $1.129 \mathrm{E}-02$ & $7.941 \mathrm{E}-03$ \\
\hline 8 & $3.534 \mathrm{E}-03$ & $1.205 \mathrm{E}-02$ & $4.470 \mathrm{E}-03$ & $1.039 \mathrm{E}-02$ \\
\hline 9 & $6.974 \mathrm{E}-03$ & $6.969 \mathrm{E}-03$ & $6.354 \mathrm{E}-03$ & 7.894E-03 \\
\hline 10 & $9.346 \mathrm{E}-03$ & $9.950 \mathrm{E}-03$ & $6.686 \mathrm{E}-03$ & $9.694 \mathrm{E}-03$ \\
\hline 11 & $5.964 \mathrm{E}-03$ & $2.062 \mathrm{E}-02$ & $5.626 \mathrm{E}-03$ & $1.558 \mathrm{E}-02$ \\
\hline 12 & $6.780 \mathrm{E}-03$ & $6.969 \mathrm{E}-03$ & $5.880 \mathrm{E}-03$ & 8.329E-03 \\
\hline 13 & $3.268 \mathrm{E}-03$ & $6.961 \mathrm{E}-03$ & $3.822 \mathrm{E}-03$ & $8.065 \mathrm{E}-03$ \\
\hline 14 & $2.204 \mathrm{E}-02$ & $1.397 \mathrm{E}-02$ & $1.345 \mathrm{E}-02$ & $1.186 \mathrm{E}-02$ \\
\hline 15 & $1.207 \mathrm{E}-02$ & $1.250 \mathrm{E}-02$ & $1.047 \mathrm{E}-02$ & $1.184 \mathrm{E}-02$ \\
\hline 16 & $2.874 \mathrm{E}-03$ & $3.115 \mathrm{E}-03$ & $4.069 \mathrm{E}-03$ & $6.339 \mathrm{E}-03$ \\
\hline 17 & $0.000 \mathrm{E}+00$ & $1.333 \mathrm{E}-02$ & 2.123E-03 & $1.109 \mathrm{E}-02$ \\
\hline 18 & $1.020 \mathrm{E}-02$ & $1.848 \mathrm{E}-02$ & $8.241 \mathrm{E}-03$ & $1.465 \mathrm{E}-02$ \\
\hline 19 & $1.255 \mathrm{E}-02$ & $1.496 \mathrm{E}-02$ & $1.001 \mathrm{E}-02$ & $1.274 \mathrm{E}-02$ \\
\hline 20 & $3.968 \mathrm{E}-03$ & 4.587E-03 & 4.691E-03 & $7.544 \mathrm{E}-03$ \\
\hline 21 & $7.937 \mathrm{E}-03$ & $2.839 \mathrm{E}-02$ & $7.018 \mathrm{E}-03$ & $1.886 \mathrm{E}-02$ \\
\hline 22 & $1.027 \mathrm{E}-02$ & $0.000 \mathrm{E}+00$ & $7.402 \mathrm{E}-03$ & $5.495 \mathrm{E}-03$ \\
\hline 23 & $1.050 \mathrm{E}-02$ & $2.703 \mathrm{E}-03$ & $7.853 \mathrm{E}-03$ & $5.891 \mathrm{E}-03$ \\
\hline 24 & $2.564 \mathrm{E}-03$ & $6.623 \mathrm{E}-03$ & $3.846 \mathrm{E}-03$ & $8.130 \mathrm{E}-03$ \\
\hline 25 & $0.000 \mathrm{E}+00$ & $1.974 \mathrm{E}-02$ & $2.726 \mathrm{E}-03$ & $1.279 \mathrm{E}-02$ \\
\hline 26 & $5.882 \mathrm{E}-03$ & $6.803 \mathrm{E}-03$ & $5.510 \mathrm{E}-03$ & 8.235E-03 \\
\hline 27 & $0.000 \mathrm{E}+00$ & $0.000 \mathrm{E}+00$ & 4.037E-03 & $7.268 \mathrm{E}-03$ \\
\hline
\end{tabular}

D-10 
Table D.2. (Cont'd)

\begin{tabular}{|c|c|c|c|c|}
\hline Plant Sites & $\hat{\mathbf{p}}$ (ST.FAIL) & $\hat{\mathbf{p}}$ (LD.FAIL) & $\overline{\mathbf{p}}$ (ST.FAIL) & $\overline{\mathbf{p}}($ LD.FAIL $)$ \\
\hline 28 & $1.657 \mathrm{E}-02$ & $0.000 \mathrm{E}+00$ & $1.076 \mathrm{E}-02$ & $5.088 \mathrm{E}-03$ \\
\hline 29 & $3.546 \mathrm{E}-03$ & $1.709 \mathrm{E}-02$ & $4.477 \mathrm{E}-03$ & $1.154 \mathrm{E}-02$ \\
\hline 30 & $7.042 \mathrm{E}-03$ & $0.000 \mathrm{E}+00$ & $5.686 \mathrm{E}-03$ & $7.036 \mathrm{E}-03$ \\
\hline 31 & $0.000 \mathrm{E}+00$ & $5.102 \mathrm{E}-03$ & $3.134 \mathrm{E}-03$ & $7.864 \mathrm{E}-03$ \\
\hline 32 & $4.878 \mathrm{E}-03$ & $0.000 \mathrm{E}+\infty 0$ & $5.020 \mathrm{E}-03$ & $4.871 \mathrm{E}-03$ \\
\hline 33 & $0.000 \mathrm{E}+00$ & $2.985 \mathrm{E}-02$ & $3.558 \mathrm{E}-03$ & $1.548 \mathrm{E}-02$ \\
\hline 34 & $0.000 \mathrm{E}+00$ & $1.515 \mathrm{E}-02$ & $3.714 \mathrm{E}-03$ & $1.116 \mathrm{E}-02$ \\
\hline 35 & $0.000 \mathrm{E}+00$ & $0.000 \mathrm{E}+00$ & $3.099 \mathrm{E}-03$ & $5.457 \mathrm{E}-03$ \\
\hline 36 & $3.185 \mathrm{E}-03$ & $3.030 \mathrm{E}-02$ & $4.269 \mathrm{E}-03$ & $1.555 \mathrm{E}-02$ \\
\hline 37 & $5.208 \mathrm{E}-03$ & $1.250 \mathrm{E}-02$ & $5.192 \mathrm{E}-03$ & $1.101 \mathrm{E}-02$ \\
\hline 38 & $9.728 \mathrm{E}-04$ & $0.000 \mathrm{E}+00$ & $2.099 \mathrm{E}-03$ & $2.339 \mathrm{E}-03$ \\
\hline 39 & $3.509 \mathrm{E}-03$ & $3.953 \mathrm{E}-03$ & $4.457 \mathrm{E}-03$ & $7.086 \mathrm{E}-03$ \\
\hline 40 & $3.945 \mathrm{E}-03$ & $1.847 \mathrm{E}-02$ & $4.137 \mathrm{E}-03$ & $1.565 \mathrm{E}-02$ \\
\hline 41 & $1.053 \mathrm{E}-02$ & $1.325 \mathrm{E}-02$ & $7.480 \mathrm{E}-03$ & $1.072 \mathrm{E}-02$ \\
\hline 42 & $1.030 \mathrm{E}-03$ & $5.195 \mathrm{E}-03$ & $2.188 \mathrm{E}-03$ & $7.178 \mathrm{E}-03$ \\
\hline 43 & $5.629 \mathrm{E}-03$ & $2.315 \mathrm{E}-02$ & $5.441 \mathrm{E}-03$ & $1.498 \mathrm{E}-02$ \\
\hline 44 & $0.000 \mathrm{E}+00$ & $0.000 \mathrm{E}+00$ & $2.483 \mathrm{E}-03$ & $5.362 \mathrm{E}-03$ \\
\hline 45 & $4.662 \mathrm{E}-03$ & $2.387 \mathrm{E}-03$ & $4.901 \mathrm{E}-03$ & $5.503 \mathrm{E}-03$ \\
\hline 46 & $6.061 \mathrm{E}-03$ & $0.000 \mathrm{E}+00$ & $5.444 \mathrm{E}-03$ & $6.715 \mathrm{E}-03$ \\
\hline 47 & $0.000 \mathrm{E}+00$ & $1.622 \mathrm{E}-02$ & $2.757 \mathrm{E}-03$ & $1.196 \mathrm{E}-02$ \\
\hline 48 & $4.458 \mathrm{E}-03$ & $1.832 \mathrm{E}-02$ & $4.715 \mathrm{E}-03$ & $1.429 \mathrm{E}-02$ \\
\hline 49 & $0.000 \mathrm{E}+00$ & $1.974 \mathrm{E}-02$ & $2.256 \mathrm{E}-03$ & $1.448 \mathrm{E}-02$ \\
\hline 50 & $1.339 \mathrm{E}-02$ & $1.538 \mathrm{E}-02$ & $8.240 \mathrm{E}-03$ & $1.121 \mathrm{E}-02$ \\
\hline 51 & $6.536 \mathrm{E}-03$ & $8.264 \mathrm{E}-03$ & $5.568 \mathrm{E}-03$ & $9.190 \mathrm{E}-03$ \\
\hline 52 & $2.976 \mathrm{E}-03$ & $6.780 \mathrm{E}-03$ & $4.138 \mathrm{E}-03$ & $8.222 \mathrm{E}-03$ \\
\hline 53 & $5.882 \mathrm{E}-03$ & $3.460 \mathrm{E}-03$ & $5.510 \mathrm{E}-03$ & $6.670 \mathrm{E}-03$ \\
\hline 54 & $5.376 \mathrm{E}-03$ & $0.000 \mathrm{E}+00$ & $5.241 \mathrm{E}-03$ & $6.116 \mathrm{E}-03$ \\
\hline
\end{tabular}


Table D.2. (Cont'd)

\begin{tabular}{|c|c|c|c|c||}
\hline \hline Plant Sites & $\hat{\mathbf{p}}$ (ST.FAIL) & $\hat{\mathbf{p}}$ (LD.FAIL) & $\hat{\mathbf{p}(S T . F A I L)}$ & $\hat{\mathbf{p}}$ (LD.FAIL) \\
\hline \hline 55 & $0.000 \mathrm{E}+00$ & $1.333 \mathrm{E}-02$ & $3.139 \mathrm{E}-03$ & $1.074 \mathrm{E}-02$ \\
\hline 56 & $0.000 \mathrm{E}+00$ & $0.000 \mathrm{E}+00$ & $2.689 \mathrm{E}-03$ & $4.693 \mathrm{E}-03$ \\
\hline 57 & $2.257 \mathrm{E}-03$ & $7.605 \mathrm{E}-03$ & $3.597 \mathrm{E}-03$ & $8.670 \mathrm{E}-03$ \\
\hline 58 & $0.000 \mathrm{E}+00$ & $0.000 \mathrm{E}+00$ & $3.693 \mathrm{E}-03$ & $7.425 \mathrm{E}-03$ \\
\hline 59 & $6.116 \mathrm{E}-03$ & $4.292 \mathrm{E}-03$ & $5.855 \mathrm{E}-03$ & $6.441 \mathrm{E}-03$ \\
\hline 60 & $2.222 \mathrm{E}-03$ & $5.168 \mathrm{E}-03$ & $3.567 \mathrm{E}-03$ & $7.157 \mathrm{E}-03$ \\
\hline 61 & $2.439 \mathrm{E}-02$ & $5.464 \mathrm{E}-03$ & $1.195 \mathrm{E}-02$ & $8.065 \mathrm{E}-03$ \\
\hline 62 & $3.215 \mathrm{E}-03$ & $1.799 \mathrm{E}-02$ & $4.288 \mathrm{E}-03$ & $1.344 \mathrm{E}-02$ \\
\hline 63 & $0.000 \mathrm{E}+00$ & $0.000 \mathrm{E}+00$ & $2.817 \mathrm{E}-03$ & $5.762 \mathrm{E}-03$ \\
\hline
\end{tabular}




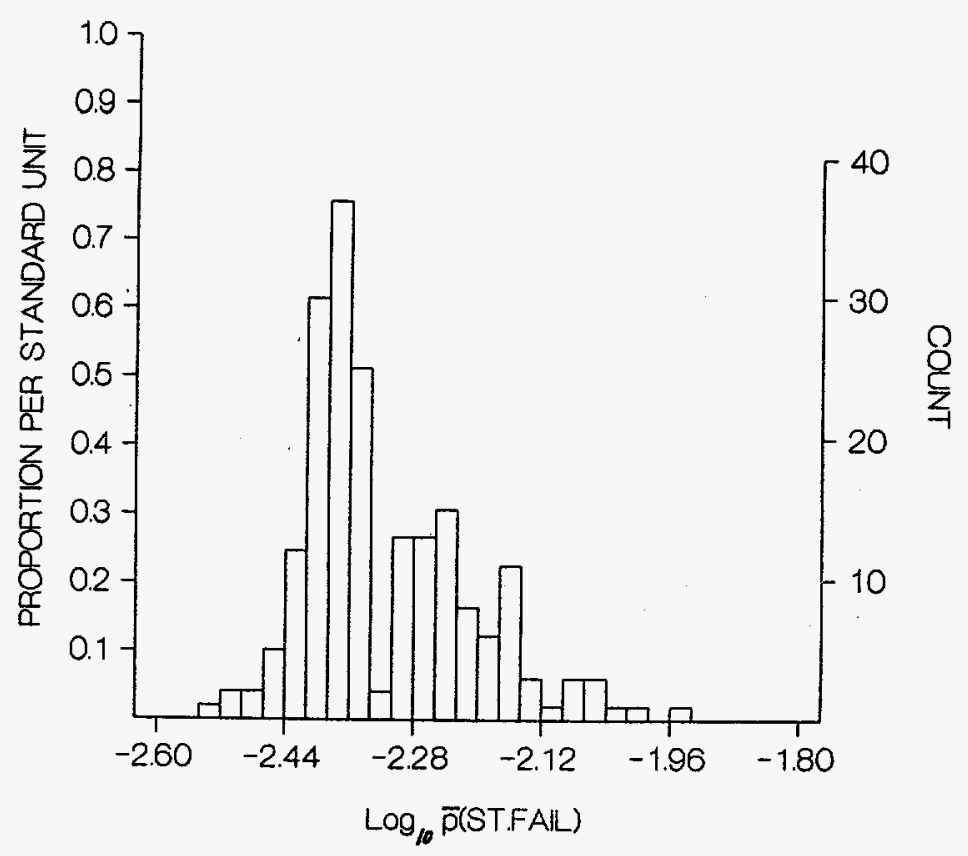

Figure D.1. Failure to start probabilities for individual diesels Number of histogram bars $=30$

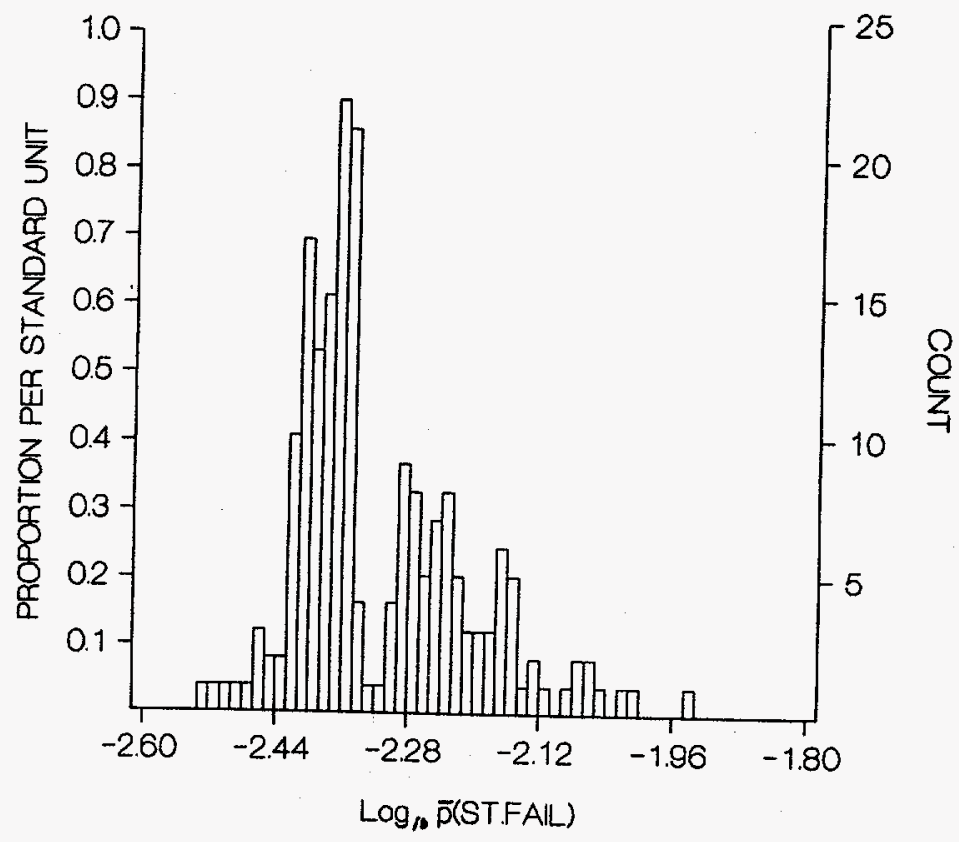

Figure D.2. Failure to start probabilities for individual diesels Number of histogram bars $=60$ 


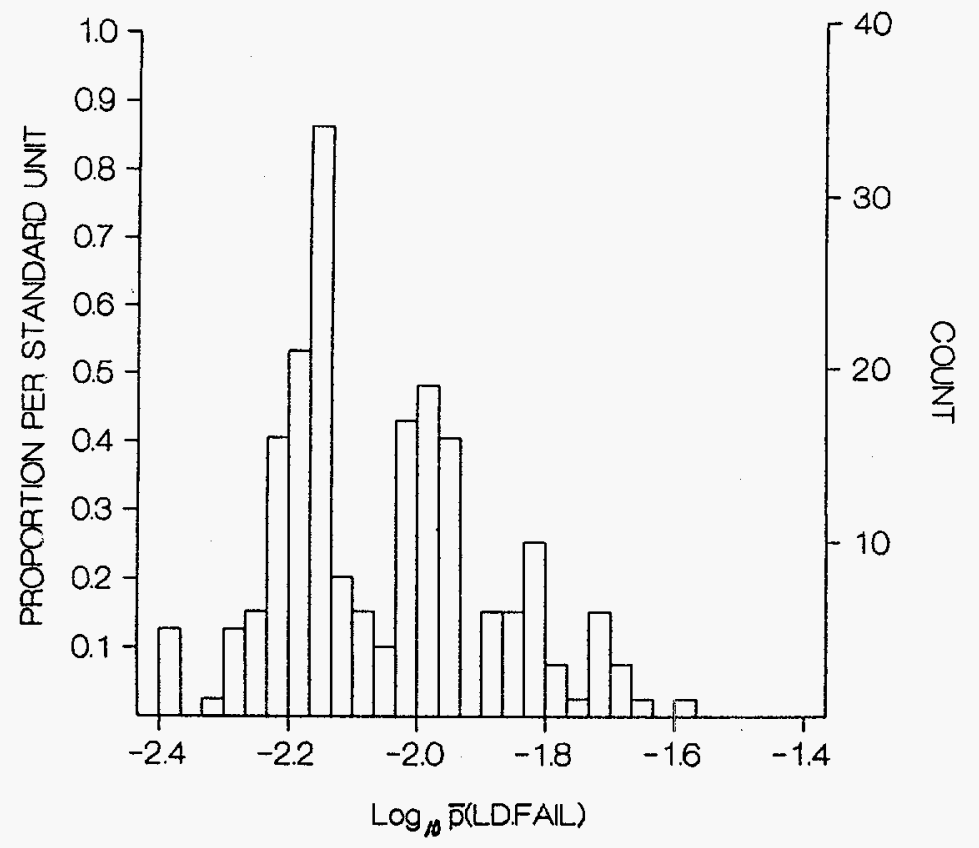

Figure D.3. Failure to load-run probabilities for individual diesels Number of histogram bars $=30$

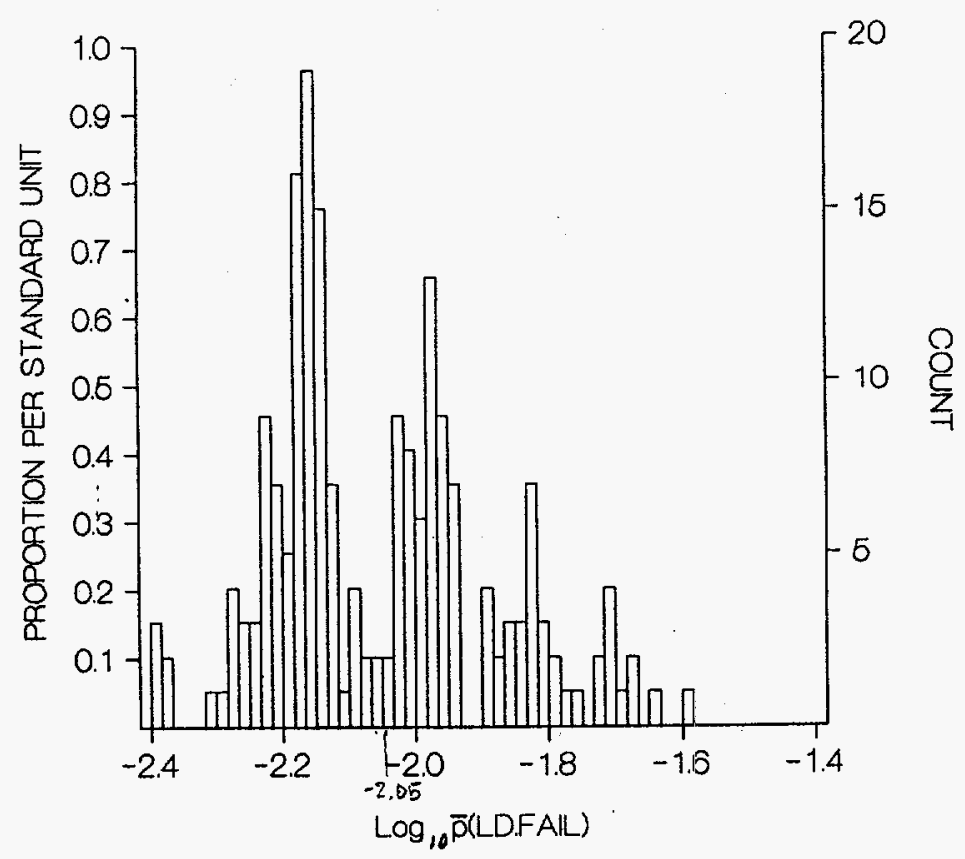

Figure D.4. Failure to load-run probabilities for individual diesels Number of histogram bars $=60$ 


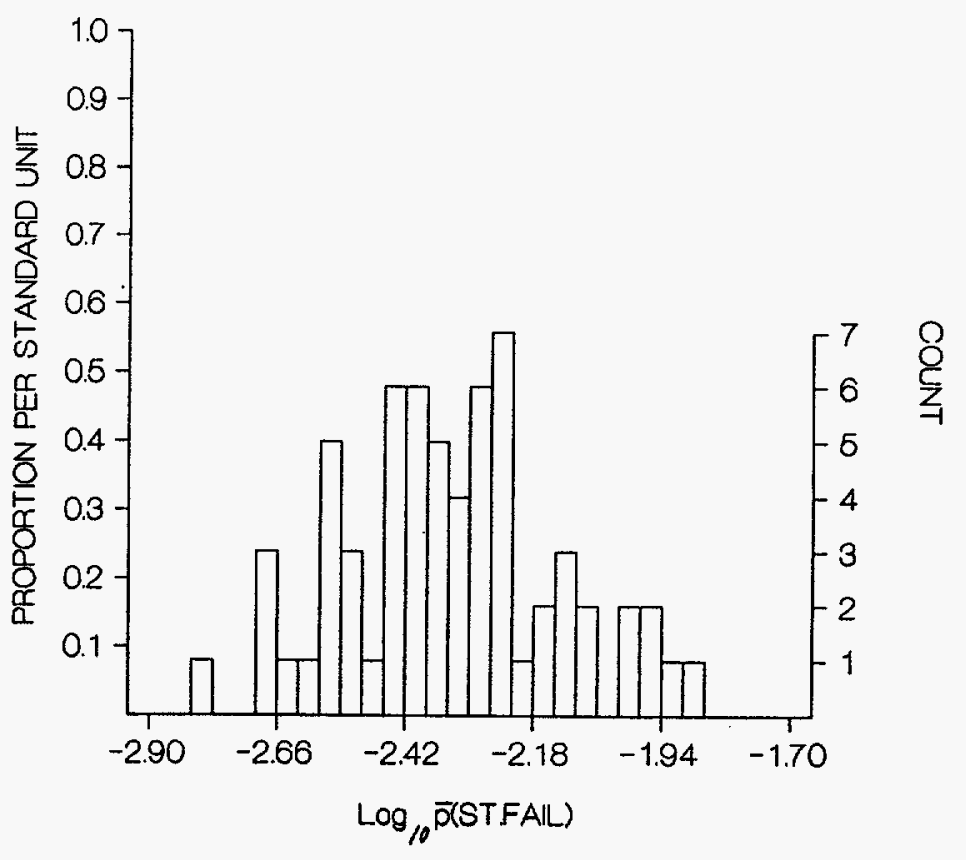

Figure D.5. Failure to start probabilities for stations Number of histogram bars $=30$

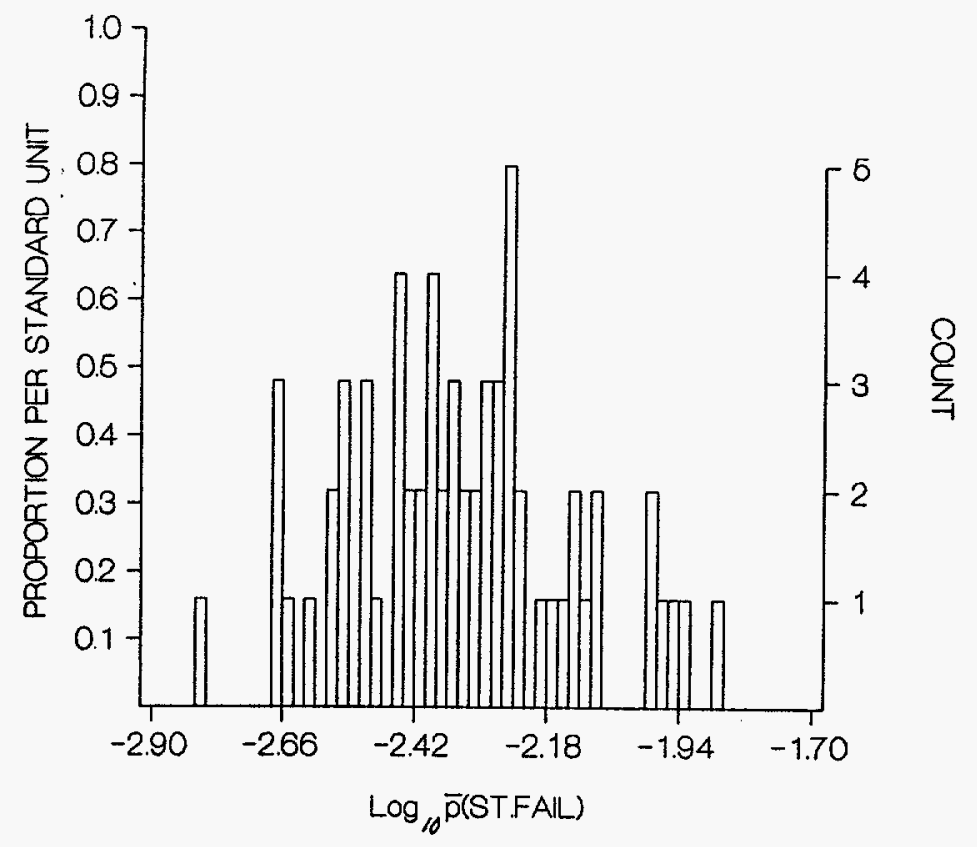

Figure D.6. Failure to start probabilities for stations Number of histogram bars $=60$ 


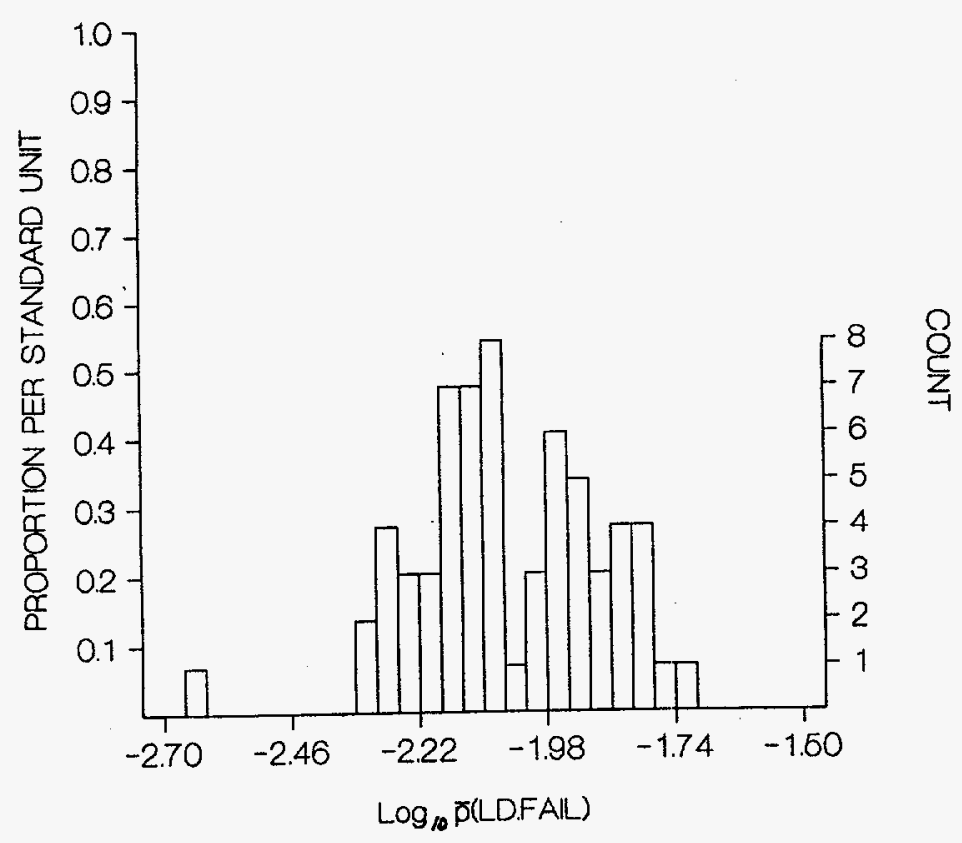

Figure D.7. Failure to load-run probabilities for stations Number of histogram bars $=30$

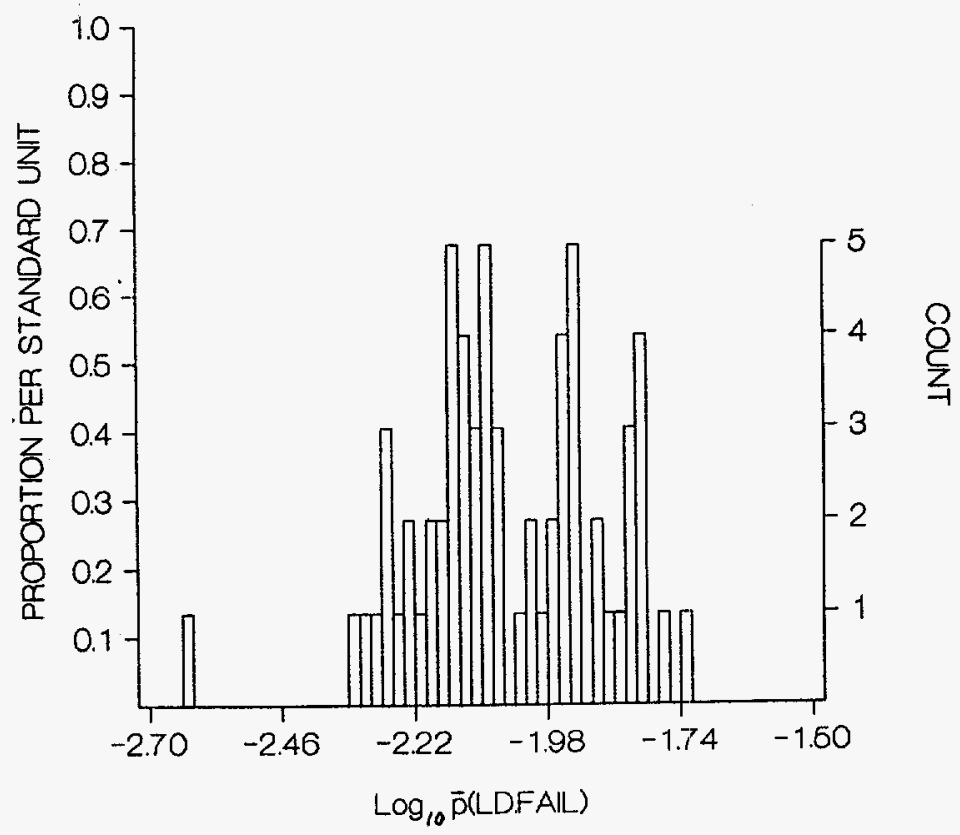

Figure D.8. Failure to load-run probabilities for stations Number of histogram bars $=60$ 
APPENDIX E

BOX AND WHISKER PLOTS OF EMPIRICAL BAYES

PROBABILITIES FOR DIESEL FAILURES 


\section{Box and Whisker Plots of the Empirical Bayes Probabilities}

This appendix presents individual and station diesel failure probabilities in graphical form using Box and Whisker plots. These plots summarize empirical Bayes probabilities and show the spread of the batch of data and outliers. The median of the batch is marked by the center vertical line; the lower and upper hinges comprise the edges of the central box. While the median splits the ordered batch of numbers in half, the hinges split the remaining halves in half again.

"Hspread" is defined as the absolute value of the difference between the values of the hinges. The inner fences are defined as follows:

$$
\begin{aligned}
& \text { inner lower fence }=\text { lower hinge }-(1.5 \text { "Hspread" }) \\
& \text { inner upper fence }=\text { upper hinge }+(1.5 \text { "Hspread" })
\end{aligned}
$$

The lines that extend out of the box indicate the minimum and maximum values within the inner fences.

The outer fences are defined as follows:

$$
\begin{aligned}
& \text { outer lower fence }=\text { lower hinge }-(3 \text { "Hspread" }) \\
& \text { outer upper fence }=\text { upper hinge }+(3 \text { "Hspread" })
\end{aligned}
$$

Values outside the inner fences are plotted with asterisks; those outside the outer fences are plotted with open circles.

For example, Plot E.1 shows individual diesel failure to start probabilities in logarithmic scale:

diesel failure to

start probability

(log scale)

minimum value:

lower hinge:

median:

upper hinge:

maximum value:

amount of outliers outside inner fences:

amount of outliers outside outer fences:
$-2.522$

$-2.357$

$-2.244$

$-1.933$

3

0 diesel failure to start probability
3.0 E-3
4.1 E-3
$4.4 \mathrm{E}-3$
$5.7 \mathrm{E}-3$
$1.2 \mathrm{E}-2$
3
0 
minimum: $\quad-2.522$

lower hinge: -2.389

median:

$-2.357$

upper hinge: -2.244

maximum: $\quad-1.933$

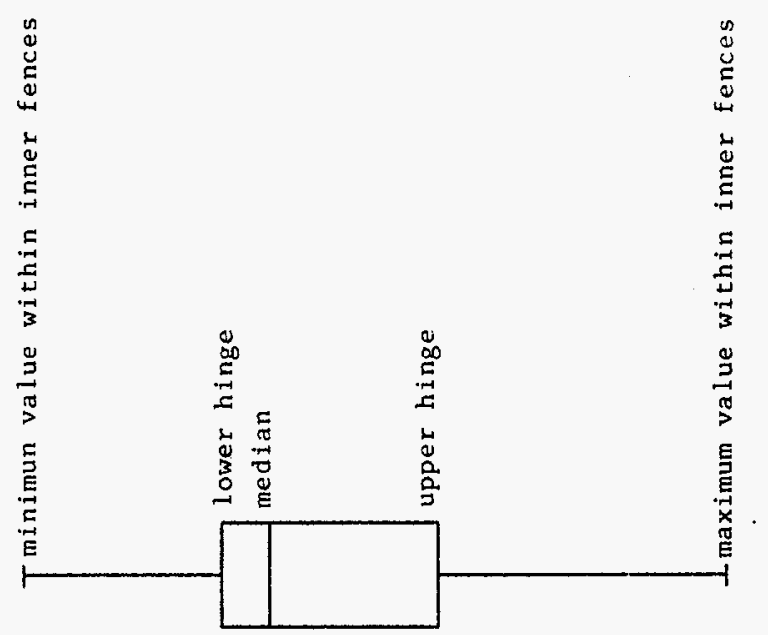

*

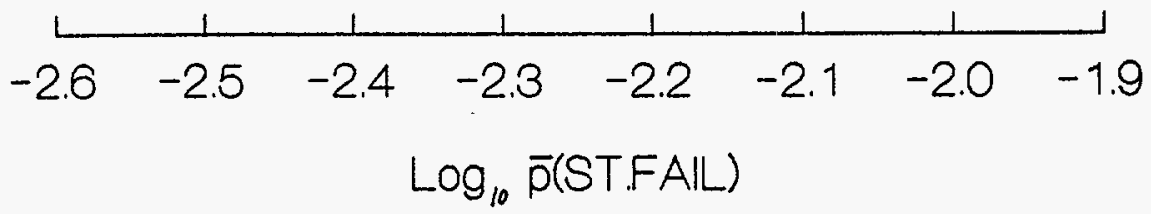

Figure E.1. Box and whisker plot: Diesel failure to start probabilities

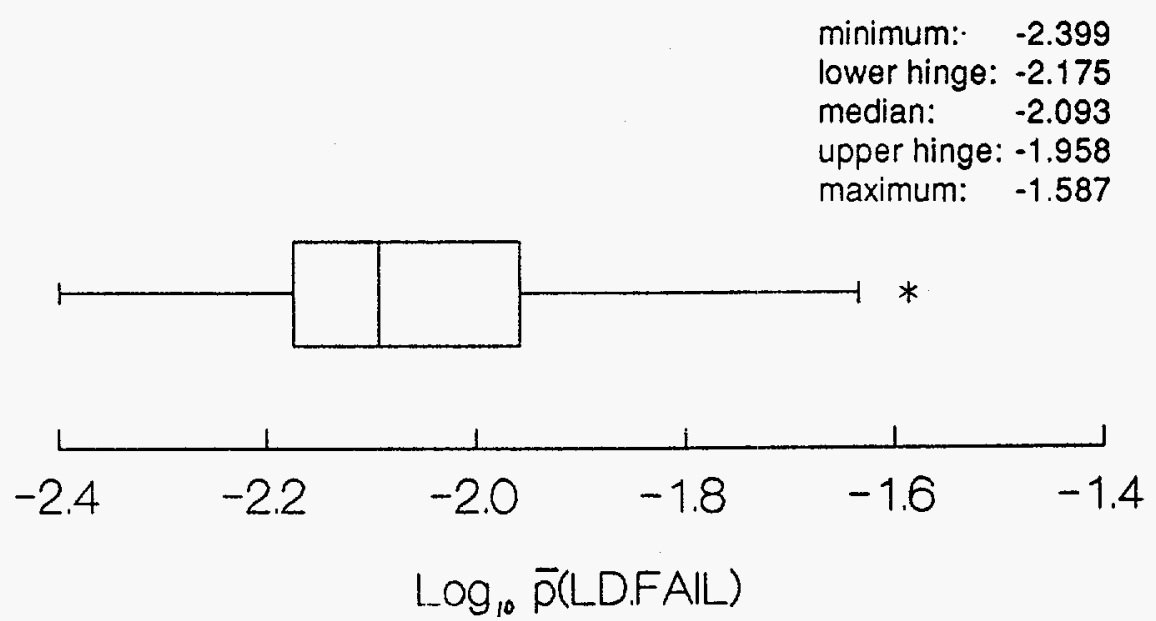

Figure E.2. Box and whisker plot: Diesel failure to load probabilities 
minimum: $\quad-2.802$

lower hinge: -2.448

median: $\quad-2.349$

upper hinge: -2.239

maximum: $\quad-1.871$

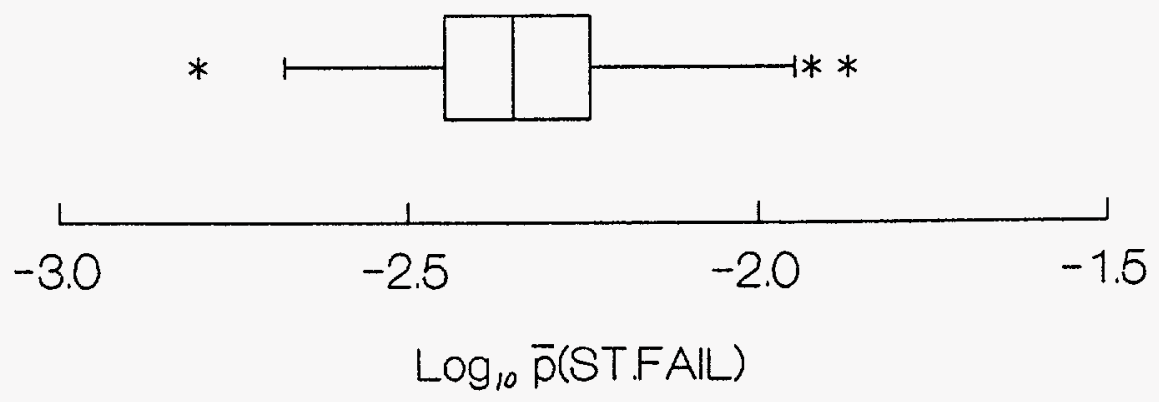

Figure E.3. Box and whisker plot: Station failure to start probabilities

minimum: $\quad-2.631$

lower hinge: -2.153

median: $\quad-2.084$

upper hinge: -1.926

maximum: $\quad-1.724$

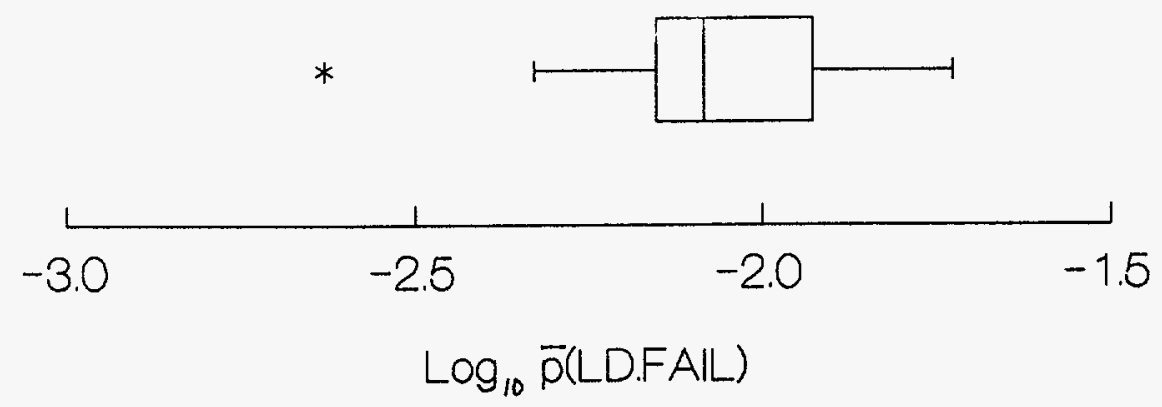

Figure E.4. Box and whisker plot: Station failure to load probabilities 


\begin{abstract}
APPENDIX F
DISTRIBUTIONS FOR DIESEL FAILURE PROBABILITIES

(LOGNORMAL AND BETA)
\end{abstract}


This appendix shows distributions representing population of diesel failure probabilities. As discussed in Chapter 3 (Section 3.2.6 and 3.2.7), diesel failure probabilities were fitted to Beta and Lognormal distributions. The figures in this appendix present beta and lognormal distributions for individual and station diesel failure to start and load-run probabilities. 


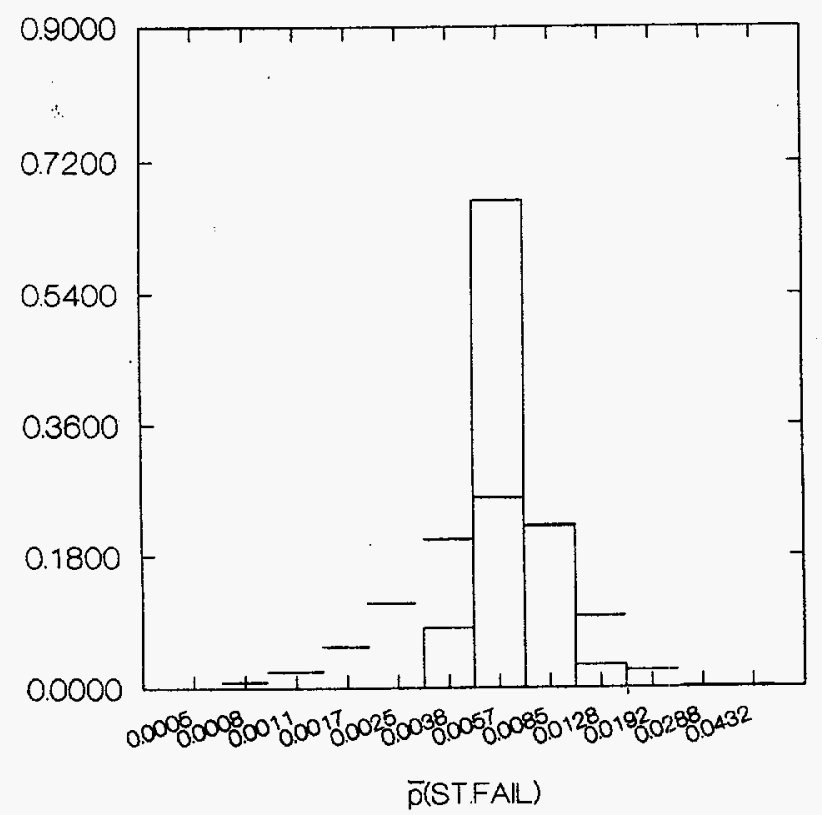

Figure F.1. The fitted beta distribution to the population of individual diesel failure to start probabilities

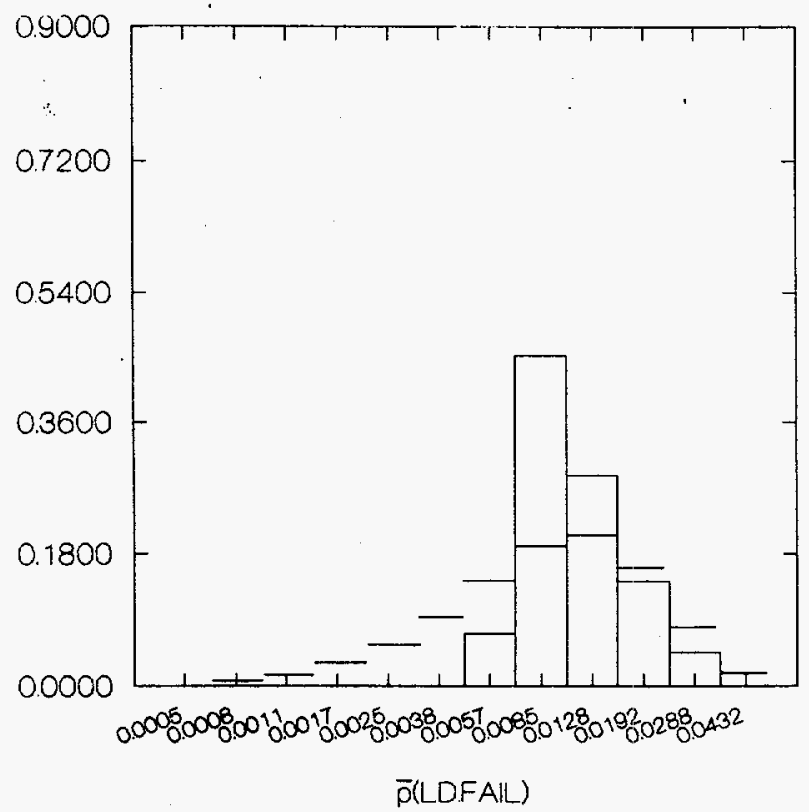

Figure F.2. The fitted beta distribution to the population of individual diesel failure to load probabilities 


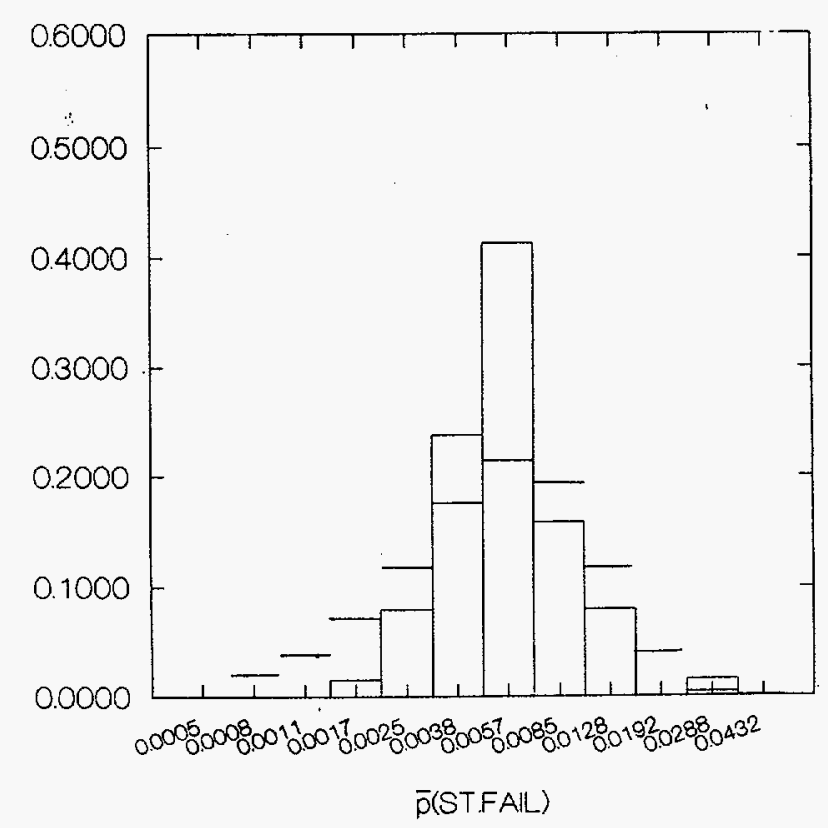

Figure F.3. The fitted beta distribution to the population of station failure to start probabilities

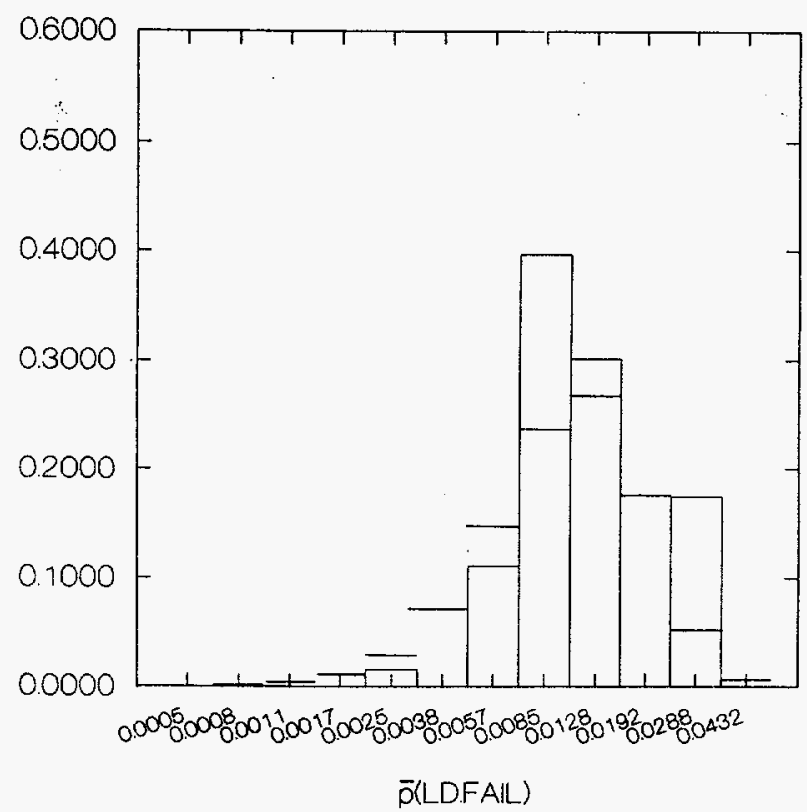

Figure F.4. The fitted beta distribution to the population of station failure to load probabilities 


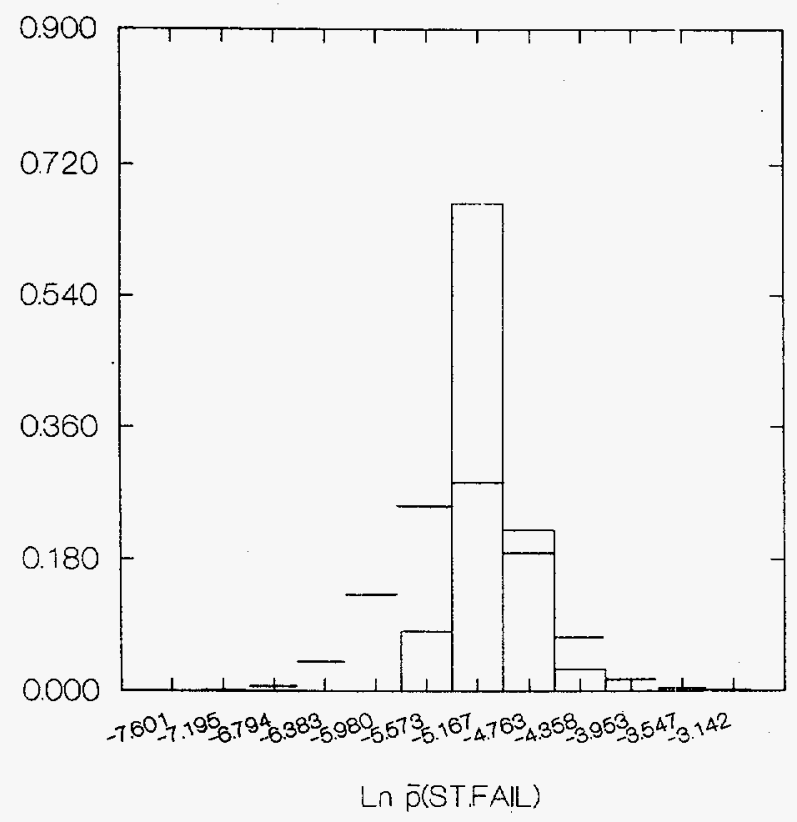

Figure F.5. The fitted $\log$ normal distribution to the population of individual diesel failure to start probabilities

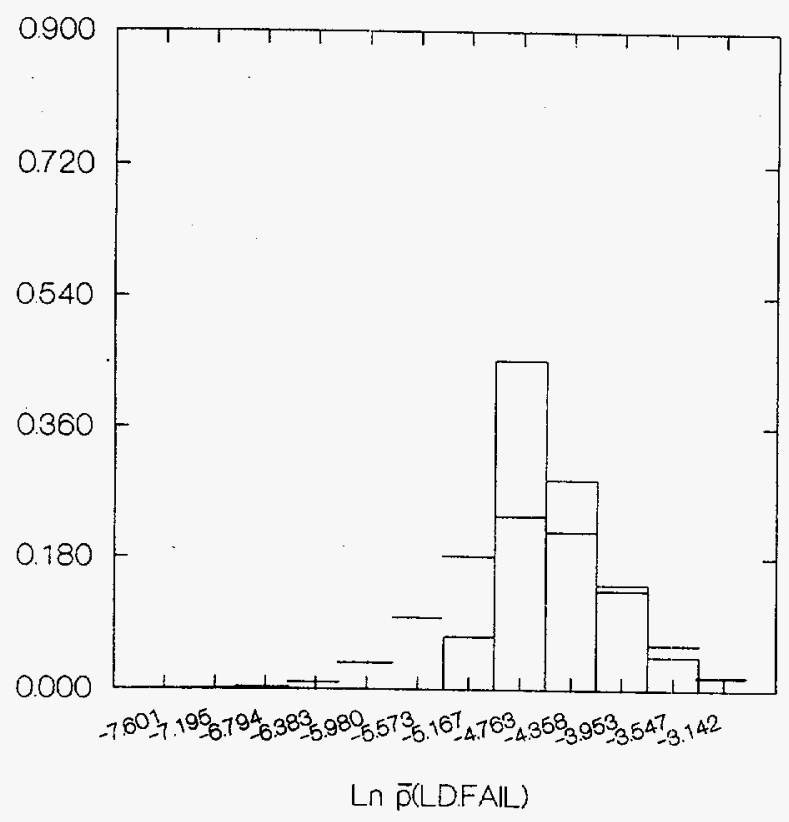

Figure F.6. The fitted $\log$ normal distribution to the population of individual diesel failure to load probabilities 


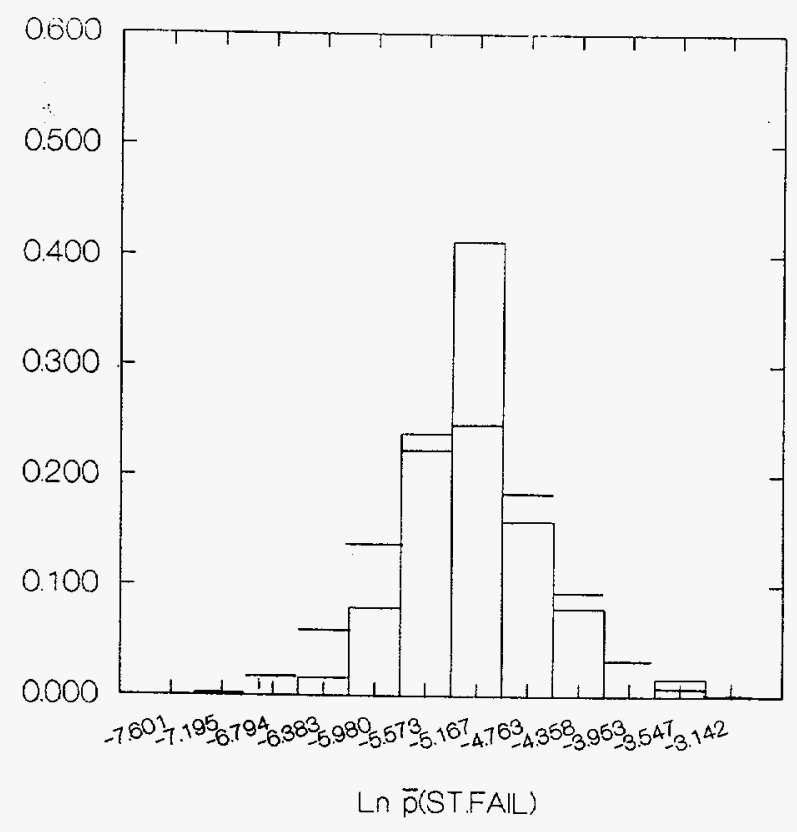

Figure F.7. The fitted log normal distribution to the population of station failure to start probabilities

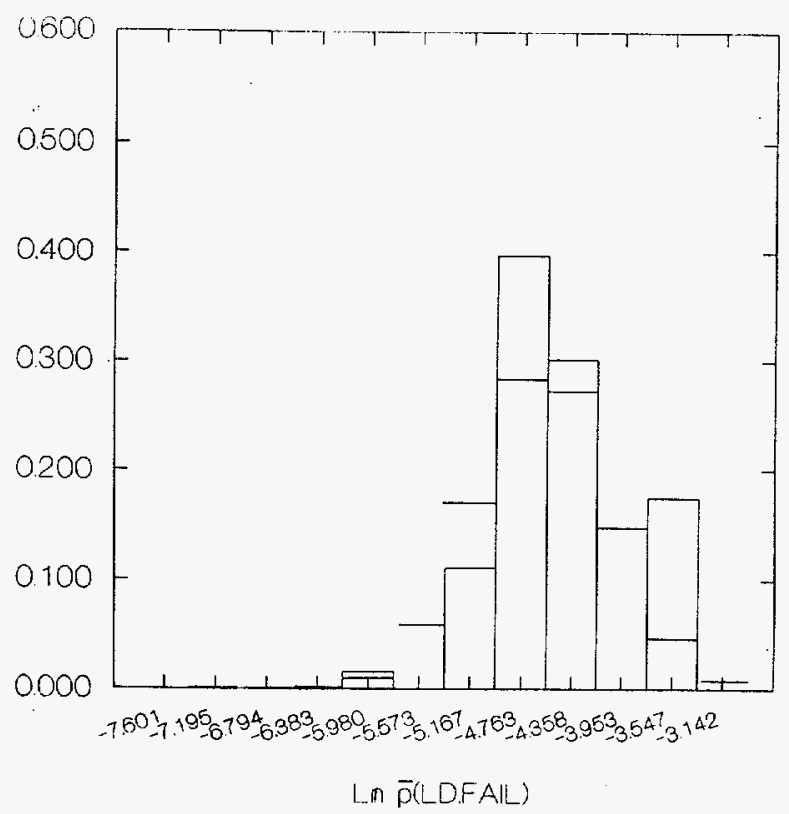

Figure F.8 The fitted log normal distribution to the population of station failure to load probabilities 
APPENDIX G

COMPARISON OF PREDICTED AND ACTUAL EDG FAILURE

STATISTICS, REGRESSION ANALYSES 
Empirical Bayes estimators were used to estimate individual probabilities of diesel failure as well as station failure probabilities in Chapter 3 (see methodological Section 3.3.2, and calculations in Appendix F). With known failure probabilities, it is possible to solve the reverse problem and predict failure statistics. The predicted statistics and actual statistics of failures can be compared. This comparison checks the goodness of fit of estimated failure probabilities. It also can be used to refine estimates and minimize discrepancy between the predicted and actual statistics.

Consider that failures of each diesel $i, i=1, \ldots, I$ follow binomial distribution with parameters $\left(p_{i}, n_{i}\right)$, where

$n_{i}=$ number of starts;

$f_{i}=$ amount of failures;

$p_{i}=$ probability of a failure.

Assuming a binomial distribution with parameters $\left(p_{i}, n_{i}\right)$ for diesel $i$ the probabilities of ratios of failures and trial

$$
\frac{0}{n_{i}}, \frac{1}{n_{i}}, \frac{2}{n_{i}}, \ldots
$$

respectively equal

$$
\left(1-p_{i}\right)^{n_{i}},\left(\begin{array}{c}
n_{i} \\
1
\end{array}\right) p_{i}^{1}\left(1-p_{i}\right)^{n_{i}-1},\left(\begin{array}{c}
n_{i} \\
2
\end{array}\right) p_{i}^{2}\left(1-p_{i}\right)^{n_{i}-2}, \ldots
$$

Thus, probabilities of ratios of amount of failures and amount of trials are known if failure probabilities are available. Statistics of ratios of amount of failures and amount of trials for individual diesels (simple estimates) are shown graphically in Figures 3.1 and 3.2 for failures to start and failures to load-run respectively. In Figures 3.1 and 3.2, interval $[0,1]$ was split on 400 equal subintervals, represented by 20 subintervals in barcharts.

Based on estimates of failure probabilities with binomial distribution, we can construct "theoretical" barchart of ratios of failures and trials. Let us split the interval $[0,1]$ on $M$ subintervals $U_{m}$, with

$$
\mathrm{U}_{\mathrm{m}}=\left(\frac{\mathrm{m}-1}{\mathrm{M}}, \frac{\mathrm{m}}{\mathrm{M}}\right), \mathrm{m}=1, \ldots, \mathrm{M},
$$

where $M=400$ in our calculations. The total (summarized over population of diesels) expected value of the discrete points (ratios of failures and trials) in the interval $U_{m}$ equals 


$$
b_{m}=\frac{1}{I} \sum_{i=1}^{I} \sum_{\frac{\ell}{n_{i}} \in U_{m}}\left(\begin{array}{c}
n_{i} \\
\ell
\end{array}\right) p_{i}^{\ell}\left(1-p_{i}\right)^{n_{i}-\ell}
$$

The sum is weighted with coefficient $\frac{1}{I}$, therefore,

$$
\sum_{m=1}^{M} b_{m}=1
$$

The barchart with values $b_{m}$ can be considered as "predicted" for the ratios of failures and trials. Further we plot only first 20 bars because values of $b_{m}$ are negligibly small for $m>20$.

Figure G.2 presents two barcharts:

gray bars = actual simple failure to start probabilities for individual diesels;

black bars $=$ predicted simple failure to start probabilities for individual diesels.

Analogously, Figure G.3 presents two barcharts:

gray bars = actual simple failure to load-run probabilities for individual diesels;

black bars $=$ predicted simple failure to load-run probabilities for individual diesels.

Visually we can see good correspondence of the predicted and actual values on Figures G.2 and G.3. $\hat{\mu}$ and $\hat{\sigma}^{2}$

The empirical Bayes estimator considered in Chapter 3 depends only upon two parameters

$$
\begin{gathered}
\overline{\mathrm{p}}_{\mathrm{i}}\left(\hat{\mu}, \hat{\sigma}^{2}\right)=\frac{1}{1+\mathrm{w}_{\mathrm{i}}} \hat{\mathrm{p}}_{\mathrm{i}}+\frac{\mathrm{w}_{\mathrm{i}}}{1+\mathrm{w}_{\mathrm{i}}} \hat{\mu}, \\
\mathrm{w}_{\mathrm{i}}=\frac{\hat{\mu}(1-\hat{\mu})-\hat{\sigma}^{2}}{\mathrm{n}_{\mathrm{i}} \hat{\sigma}^{2}} .
\end{gathered}
$$


The estimate $\bar{p}_{i}\left(\hat{\mu}, \hat{\sigma}^{2}\right)$ of individual diesel failure probability is an optimally weighted average of simple estimate of individual diesel failure probability

$$
\hat{p}_{i}=\frac{f_{i}}{n_{i}}
$$

and the average estimate of failure probability for total population. The weighing coefficient $w_{i}$ is obtained through mean $\hat{\mu}$ and variance $\hat{\sigma}^{2}$ estimates. The empirical Bayes estimator (2) shrinks simple estimate $\hat{p}_{i}$ toward the estimate of the average $\hat{\mu}$ (see Figure G.1). This estimator produces nonzero estimate for $\bar{p}_{i}$ even if number of failures for diesel $i$ equals zero, i.e., $\hat{p}_{i}=0$.

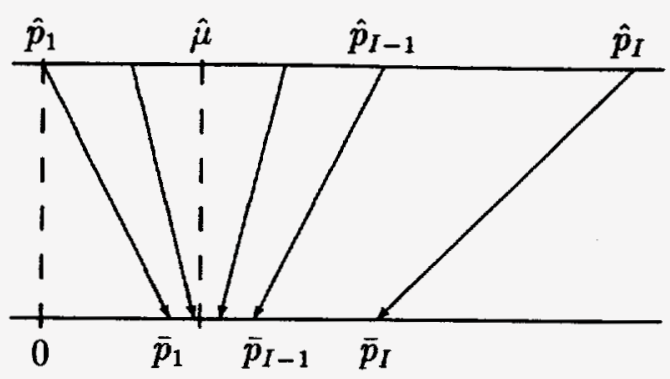

Figure G.1. The empirical Bayes estimator

As discussed, empirical Bayes estimator depends upon mean and variance parameters, therefore $p_{i}$ in the formula (1) can be substituted with $\bar{p}_{i}\left(\hat{\mu}, \hat{\sigma}^{2}\right)$ to obtain

$$
\mathrm{b}_{\mathrm{m}}\left(\hat{\mu}, \hat{\sigma}^{2}\right)=\frac{1}{\mathrm{I}} \sum_{\mathrm{i}=1}^{\mathrm{I}} \sum_{\frac{\ell}{\mathrm{n}_{\mathrm{i}}} \in \mathrm{U}_{\mathrm{m}}}\left(\begin{array}{c}
\mathrm{n}_{\mathrm{i}} \\
\ell
\end{array}\right) \overline{\mathrm{p}}_{\mathrm{i}}^{\ell}\left(\hat{\mu}, \hat{\sigma}^{2}\right)\left(1-\overline{\mathrm{p}}_{\mathrm{i}}\left(\hat{\mu}, \hat{\sigma}^{2}\right)\right)^{\mathrm{n}_{\mathrm{i}}-\ell}
$$

Thus the predicted barchart, actually depends upon two parameters $\hat{\mu}, \hat{\sigma}^{2}$ that can be adjusted to compare predicted and actual values. We fit predicted data into actual data. Let us denote the height of the bars for the actual data barcharts by (see gray bars on Figures G.2 and G.3).

$$
b_{m}^{\text {data }}, m=1, \ldots, 20
$$


The sum of squares between the predicted and actual values is

$$
\mathrm{F}\left(\hat{\mu}, \hat{\sigma}^{2}\right)=\sum_{\mathrm{m}=1}^{20}\left(\mathrm{~b}_{\mathrm{m}}^{\mathrm{data}}-\mathrm{b}_{\mathrm{m}}\left(\hat{\mu}, \hat{\sigma}^{2}\right)\right)^{2}
$$

We can adjust the parameters $\hat{p}, \hat{\sigma}^{2}$ by minimizing $F\left(\hat{\mu}, \hat{\sigma}^{2}\right)$ with respect to these parameters

$$
\mathrm{F}\left(\hat{\mu}, \hat{\sigma}^{2}\right) \rightarrow \min _{\hat{\mu}, \hat{\sigma}^{2}}
$$

This regression analysis can be called a "matching histogram" approach.

To generate the individual diesels failure probabilities, the following estimates were used (see Table 3.1)

$$
\begin{array}{lll}
\text { Start fail: } & \hat{\mu}=5.0 \mathrm{E}-3, & \hat{\sigma}^{2}=8.6 \mathrm{E}-6, \\
\text { Load-run fail: } & \hat{\mu}=9.6 \mathrm{E}-3, & \hat{\sigma}^{2}=5.1 \mathrm{E}-5 .
\end{array}
$$

With regression analysis, we estimated mean and variance:

$$
\begin{array}{lll}
\text { Start fail: } & \hat{\mu}_{f i t}=5.9 \mathrm{E}-3, & \hat{\sigma}_{f i t}^{2}=8.1 \mathrm{E}-5, \\
\text { Load-run fail: } & \hat{\mu}_{f i t}=8.9 \mathrm{E}-3, & \hat{\sigma}_{f i t}^{2}=1.0 \mathrm{E}-4 .
\end{array}
$$

The fitting changes mean values and increase variances both for failures to starts and failures to load-run, and decreases the values of distance function $F\left(\hat{\mu}, \hat{\sigma}^{2}\right)$

$$
\begin{array}{lll}
\text { Start fail: } & F\left(\hat{\mu}, \hat{\sigma}^{2}\right)=158.8, & F\left(\hat{\mu}_{f i t}, \hat{\sigma}_{f i v}^{2}\right)=14.51, \\
\text { Load-run fail: } & F\left(\hat{\mu}, \hat{\sigma}^{2}\right)=154.2, \quad F\left(\hat{\mu}_{f i t}, \hat{\sigma}_{f i v}^{2}\right)=48.98 .
\end{array}
$$

Figures G.4 and G.5 visually present the actual and fitted values for individual diesels failures to start and load-run probabilities.

Figure G.4 presents two barcharts:

gray bars = simple failure to start probabilities for individual diesels;

black bars $=$ fitted failure to start probabilities for individual diesels.

Analogously, Figure G.5 presents two barcharts:

gray bars = simple failure to load-run probabilities for individual diesels; 
black bars $=$ fitted failure to load-run probabilities for individual diesels.

Barcharts on Figures G.4 and G.5 show that fitting increased probabilities of "zero" failures and increased probabilities of "large amount" failures. This is because the shrinking parameter $w_{i}$ monotonically decreases as function of variance $\hat{\sigma}^{2}$ and fitting increased the estimate of variance. 


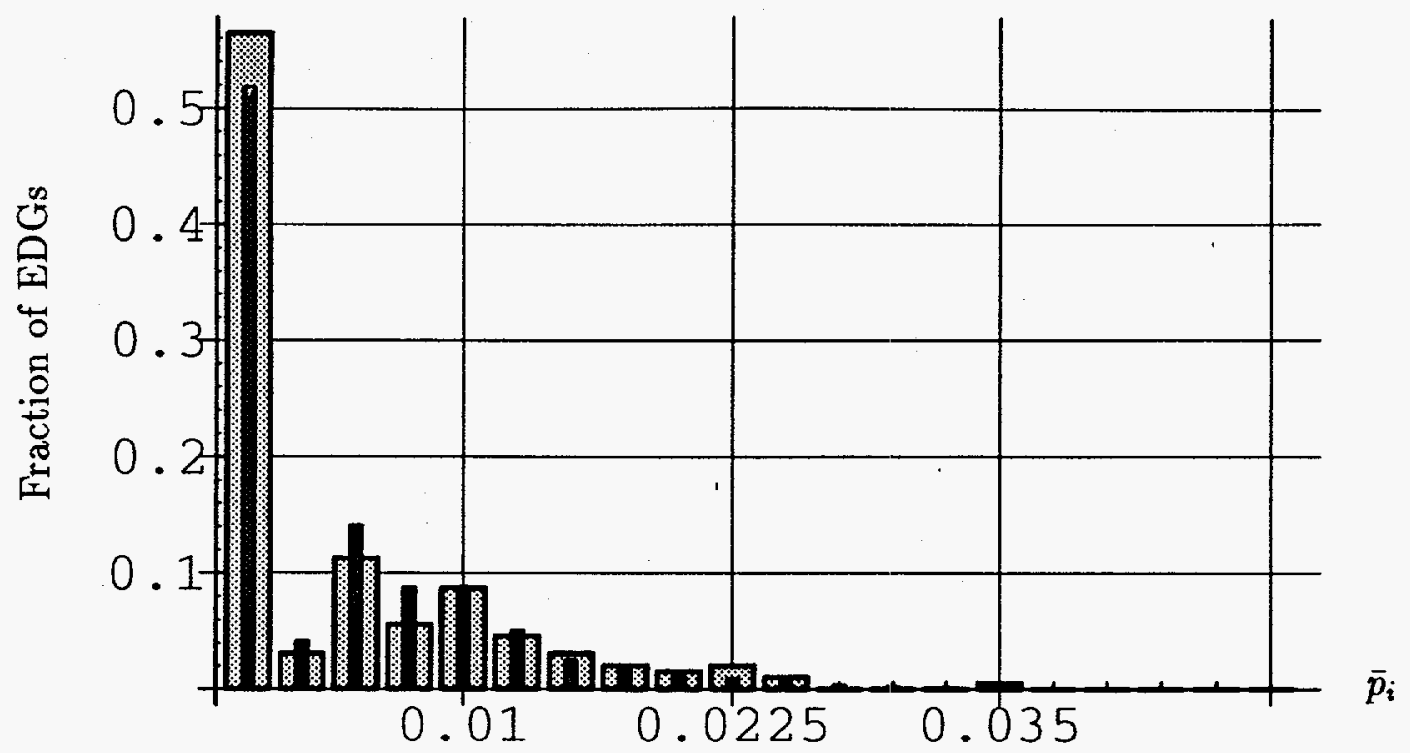

Figure G.2. Histogram of actual data and predicted simple failure to start probabilities for individual diesels (gray bars $=$ actual data, black bars $=$ predicted)

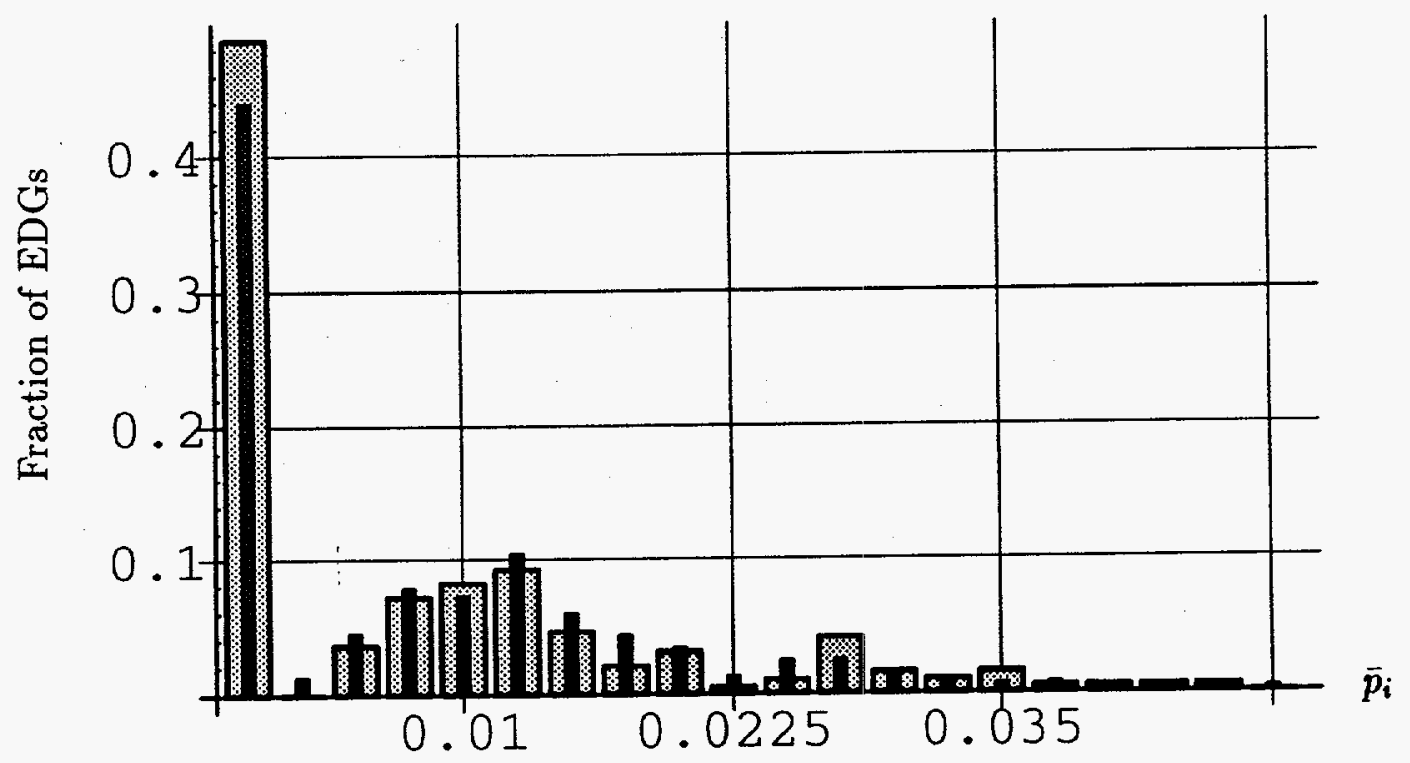

Figure G.3. Histogram of actual data and predicted simple failure to load probabilities for individual diesels (gray bars $=$ actual data, black bars $=$ predicted) 


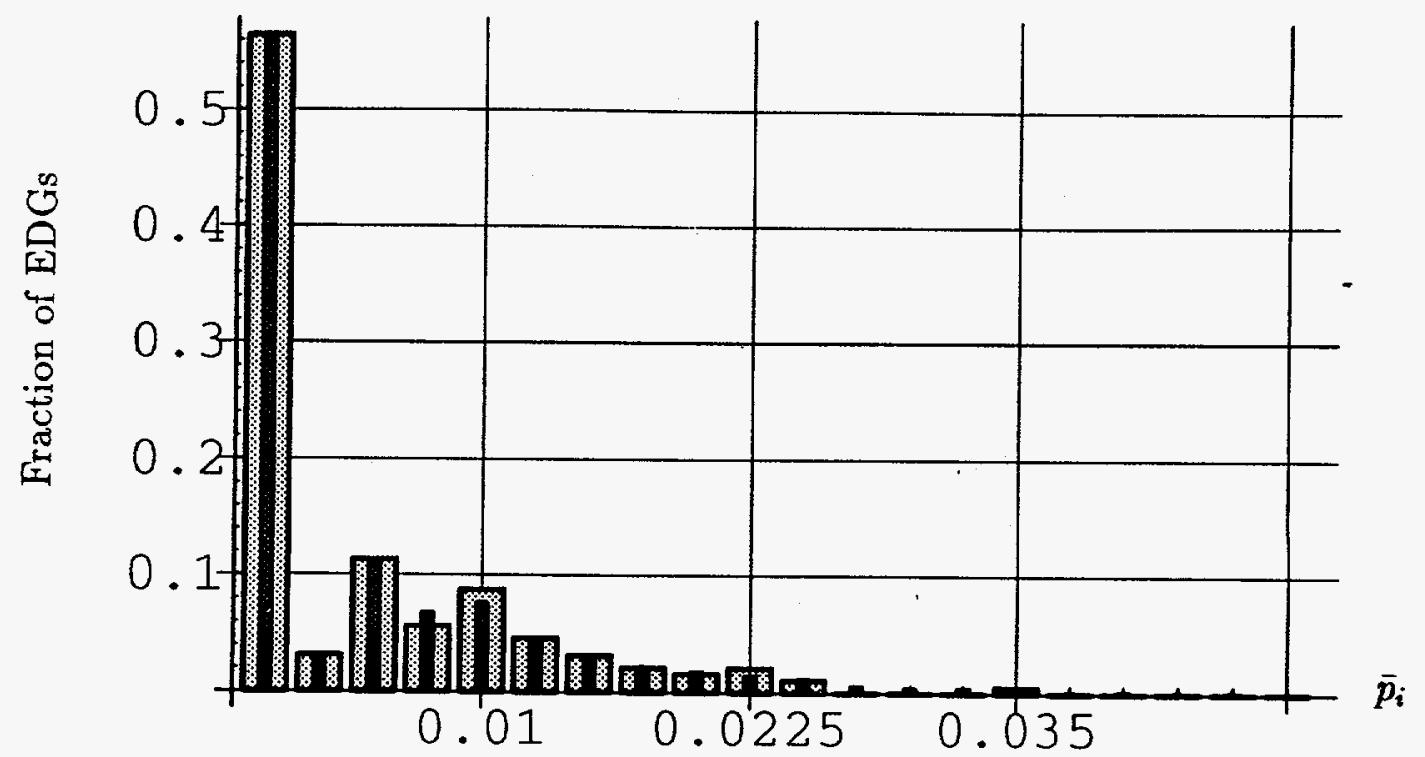

Figure G.4. Histogram of actual data and fitted simple failure to start probabilities for individual diesels (gray bars = actual data, black bars = "matching histogram")

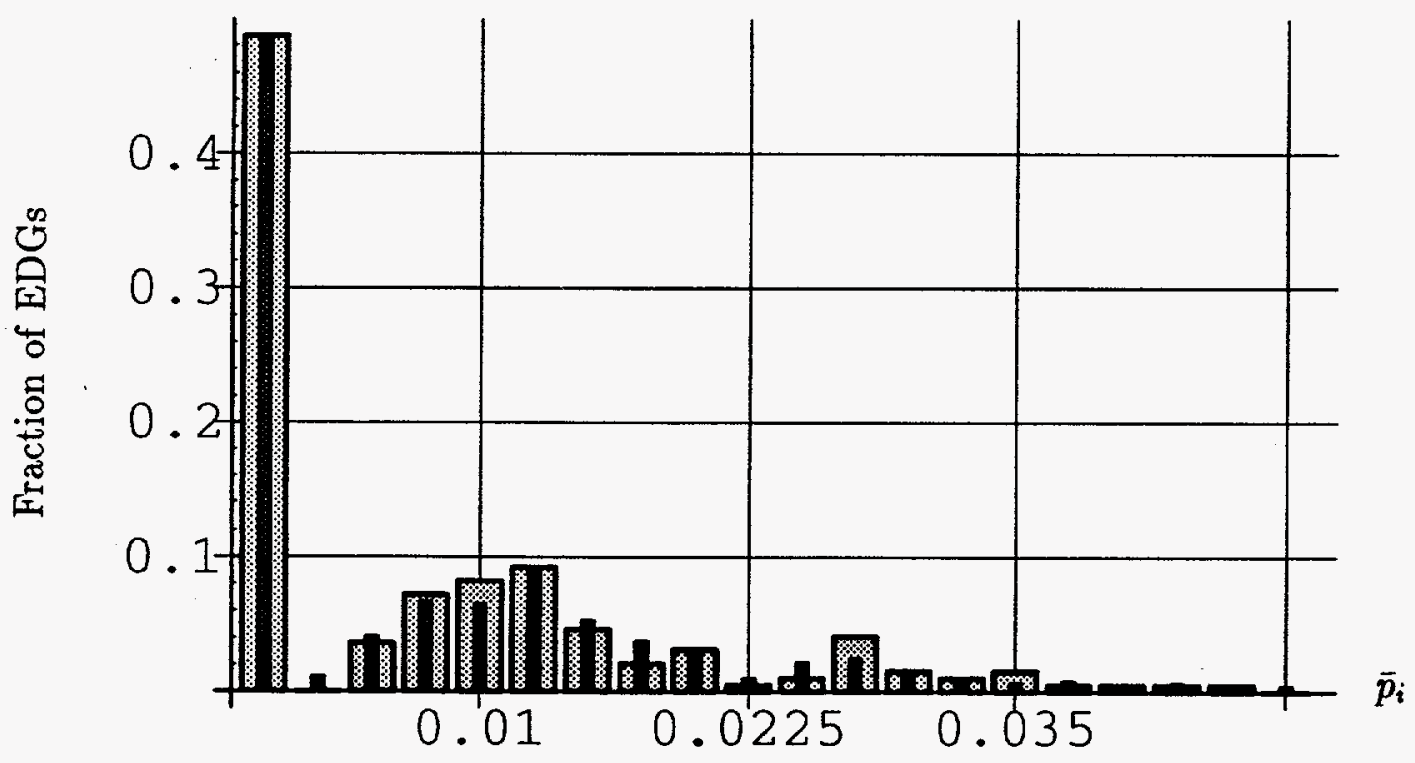

Figure G.5. Histogram of actual data and fitted simple failure to load probabilities for individual diesels (gray bars = actual data, black bars = "matching histogram") 


\section{APPENDIX H}

SENSITIVITY OF PLANT CORE DAMAGE FREQUENCY AND STATION BLACKOUT FREQUENCY TO EDG

MAINTENANCE UNAVAILABILITY 
In this appendix, sensitivity of plant core damage frequency (CDF) and station blackout (SBO) accident sequence frequency to EDG maintenance unavailabilities is presented for six nuclear power plants. In analyzing this effect it was assumed that increased EDG maintenance does not change the EDG failures, i.e., EDG failure to start and run probabilities are assumed to remain the same. Plant-specific PSAs were used to obtain the sensitivity results.

The following figures are presented:

Figure H.1. Sensitivity of plant core damage frequency (CDF) to EDG maintenance unavailability during power operation

Figure H.2. Sensitivity of station blackout (SBO) sequence frequency to EDG maintenance unavailability during power operation

Figure H.3. Sensitivity of plant CDF and SBO frequency to EDG maintenance unavailability for the Surry Nuclear Power plant

Figure H.4. Sensitivity of plant CDF and SBO frequency to EDG maintenance unavailability for the Sequoyah Nuclear Power plant

Figure H.5. Sensitivity of plant CDF and SBO frequency to EDG maintenance unavailability for the Brunswiçk 1 Nuclear Power plant

Figure H.6. Sensitivity of plant CDF and SBO frequency to EDG maintenance unavailability for the Brunswick 2 Nuclear Power plant

Figure H.7. Sensitivity of plant CDF and SBO frequency to EDG maintenance unavailability for the Peach Bottom 2 Nuclear Power plant

Figure H.8. Sensitivity of plant CDF and SBO frequency to EDG maintenance unavailability for the Grand Gulf Nuclear Power plant 


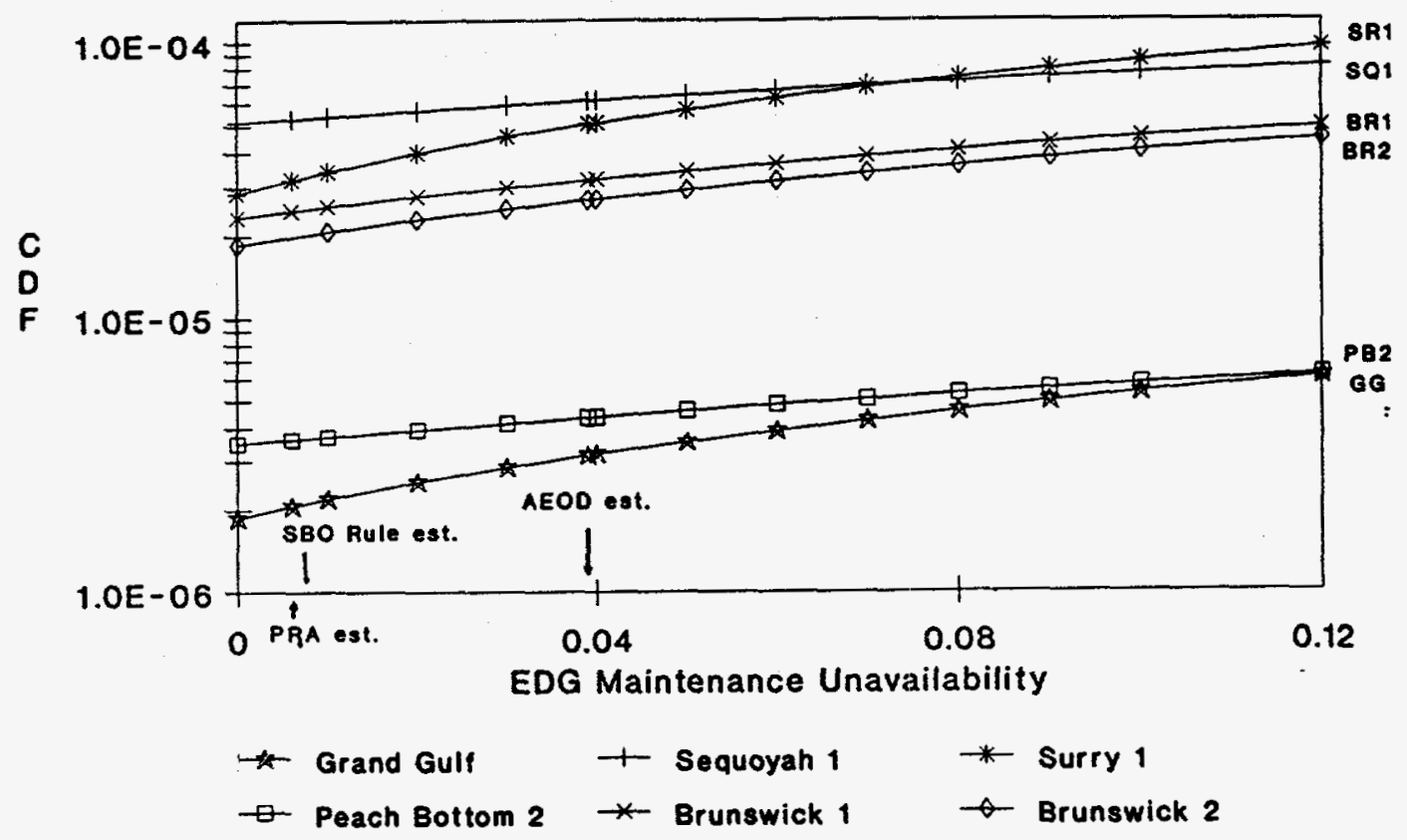

Figure H.1. Sensitivity of plant core damage frequency (CDF) to EDG maintenance unavailability during power operation

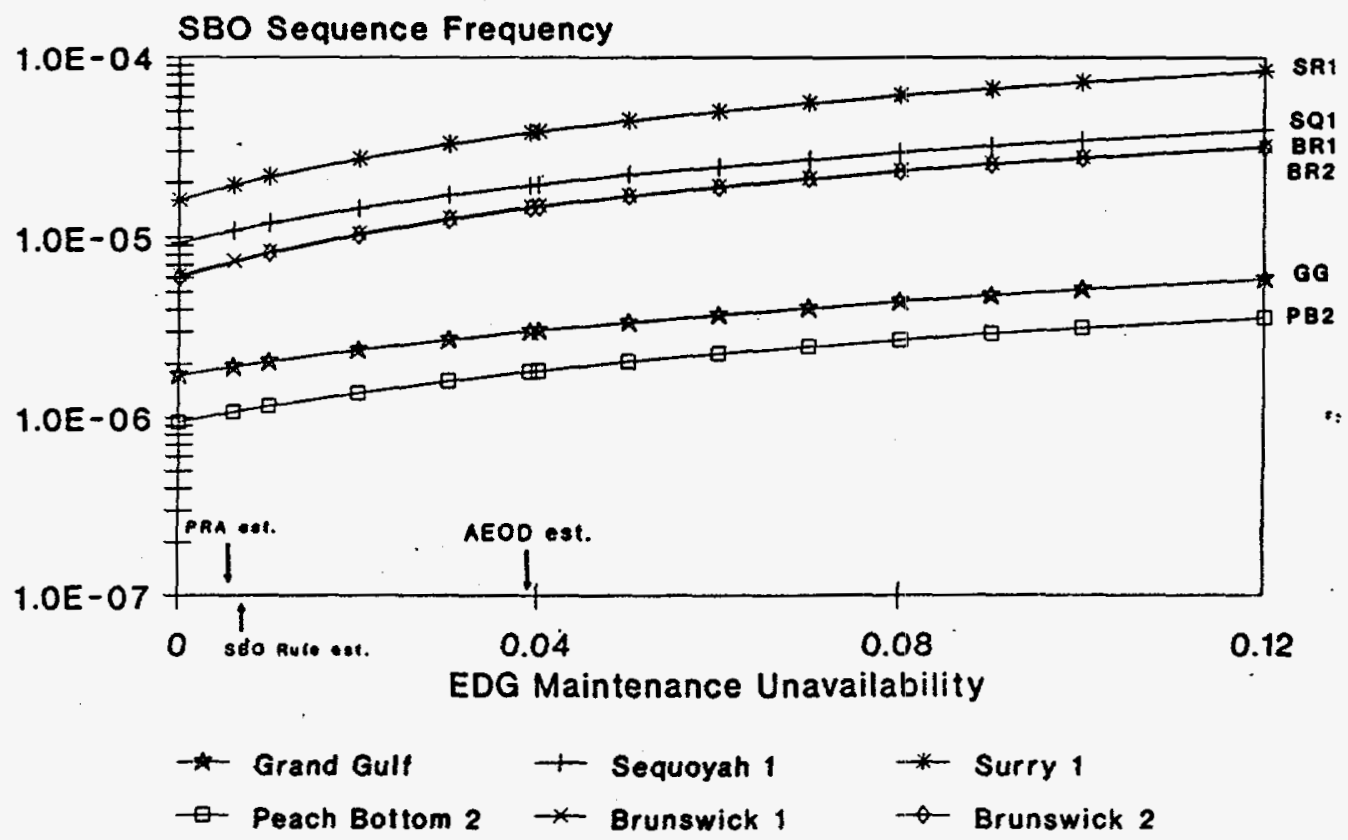

Figure H.2. Sensitivity of station blackout (SBO) sequence frequency to EDG maintenance unavailability during power operation 


\section{PLANT: SURRY 1}

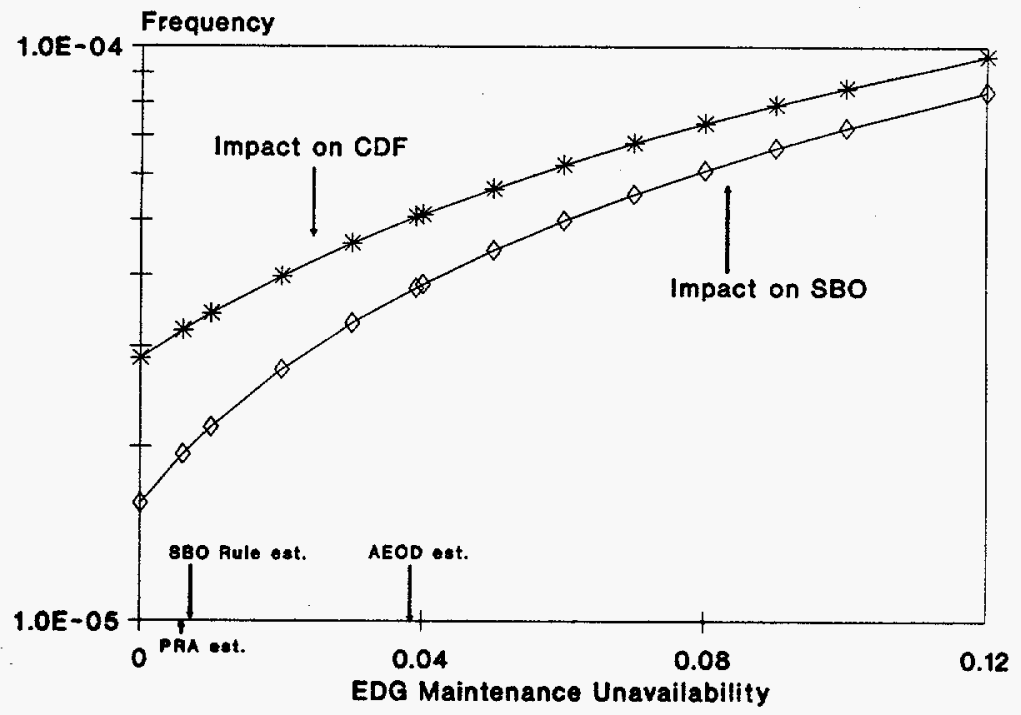

Figure H.3. Sensitivity of plant CDF and SBO frequency to EDG maintenance unavailability for the Surry Nuclear Power plant

PLANT: SEQUOYAH 1

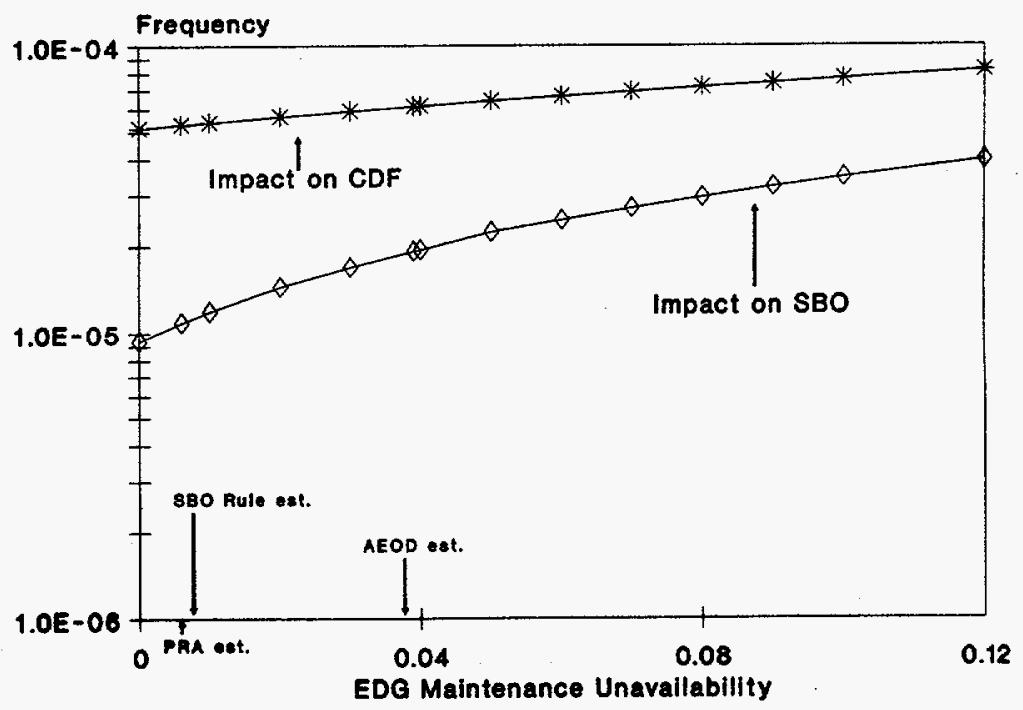

Figure H.4. Sensitivity of plant CDF and SBO frequency to EDG maintenance unavailability for the Sequoyah Nuclear Power plant 
PLANT: BRUNSWICK 1

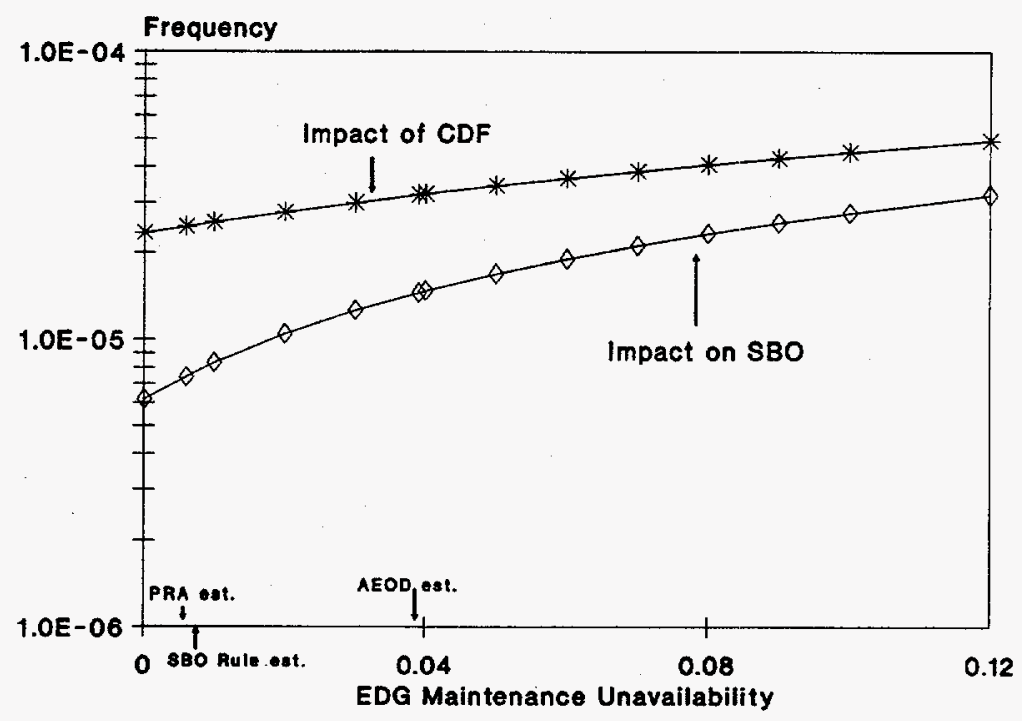

Figure H.5. Sensitivity of plant CDF and SBO frequency to EDG maintenance unavailability for the Brunswick 1 Nuclear Power plant

\section{PLANT: BRUNSWICK 2}

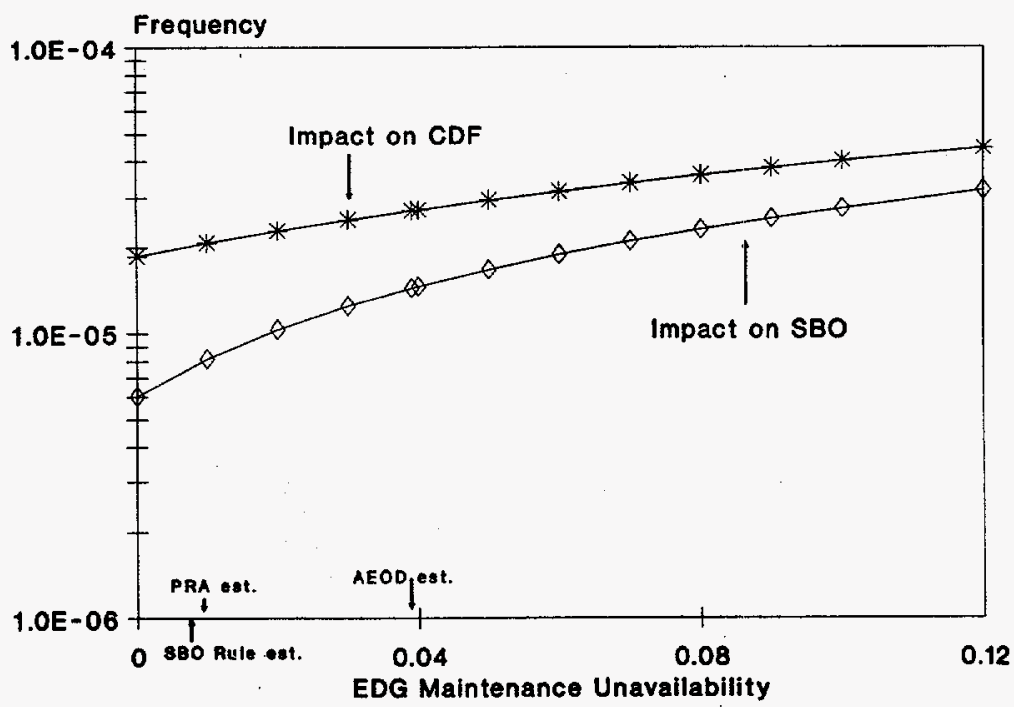

Figure H.6. Sensitivity of plant CDF and SBO frequency to EDG maintenance unavailability for the Brunswick 2 Nuclear Power plant 


\section{PLANT: PEACH BOTTOM 2}

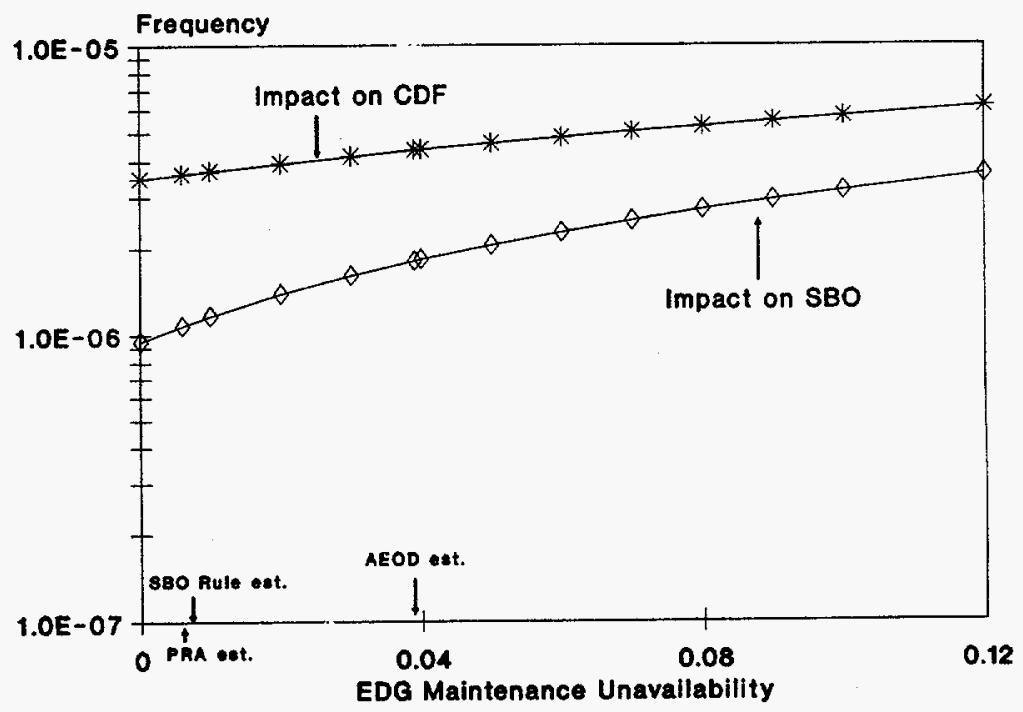

Figure H.7. Sensitivity of plant CDF and SBO frequency to EDG maintenance unavailability for the Peach Bottom 2 Nuclear Power plant

PLANT: GRAND GULF

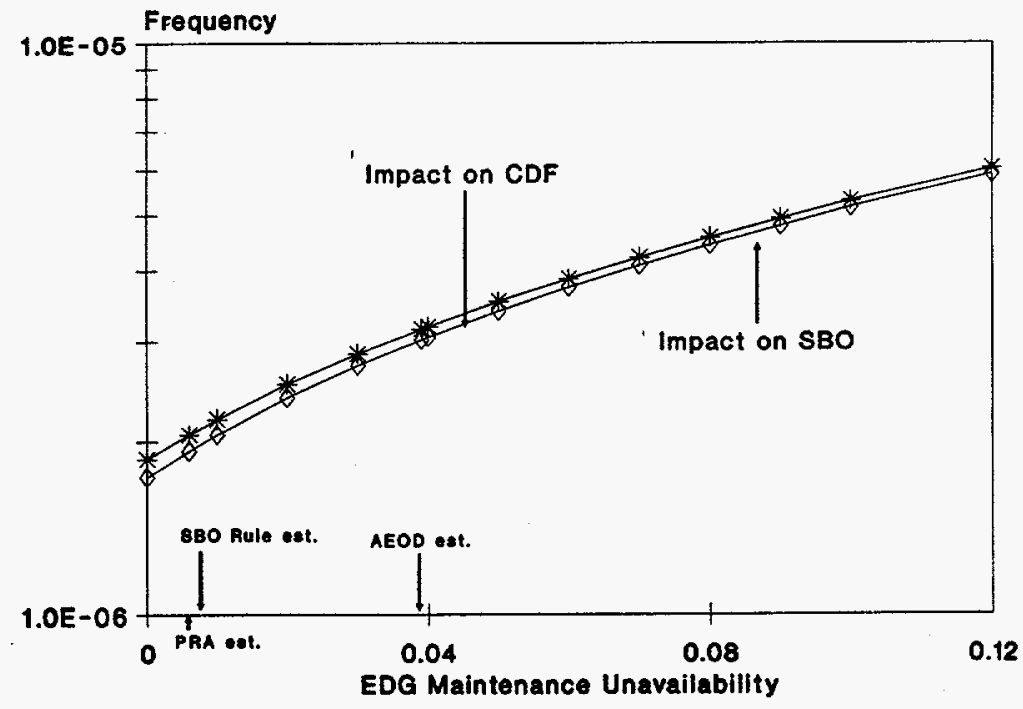

Figure H.8. Sensitivity of plant CDF and SBO frequency to EDG maintenance unavailability for the Grand Gulf Nuclear Power plant 


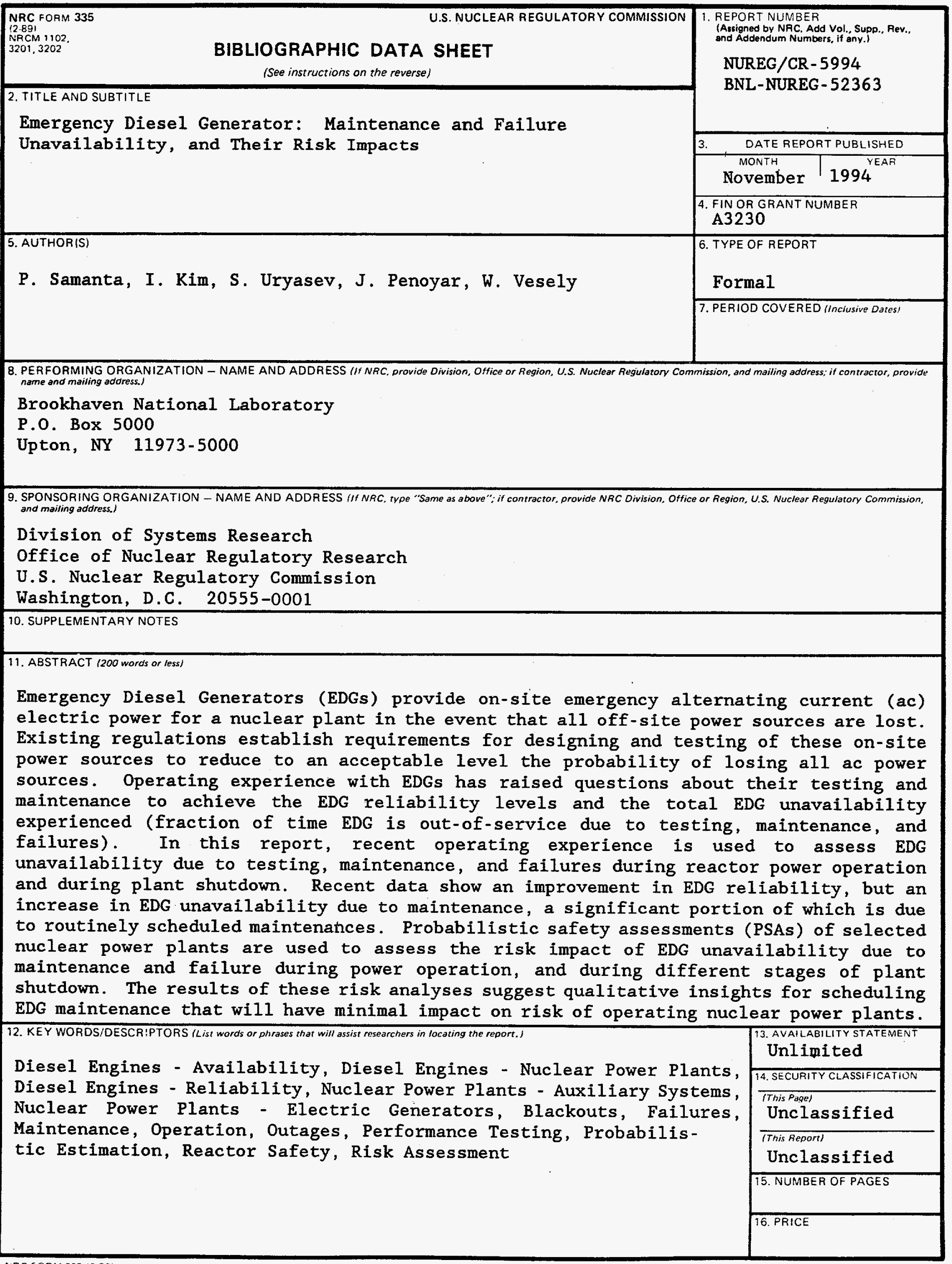

